\title{
Wabash River Coal Gasification Repowering Project
}

\section{Final Technical Report}

August 2000

\author{
Work Performed Under \\ Cooperative Agreement DE-FC21-92MC29310
}

For:

The U.S. Department of Energy

Office of Fossil Energy

National Energy Technology Laboratory

Morgantown, West Virginia

\section{Prepared by:}

The Men and Women of Wabash River Energy Ltd.

For Further Information Contact:

Roy A. Dowd, CHMM

Environmental Supervisor

Wabash River Coal Gasification Repowering Project

444 West Sandford Avenue

West Terre Haute, IN 47885 


\section{LEGAL NOTICE/DISCLAIMER}

This report was prepared by the Wabash River Coal Gasification Repowering Project Joint Venture pursuant to a Cooperative Agreement partially funded by the U.S. Department of Energy, and neither the Wabash River Coal Gasification Repowering Project Joint Venture nor any of its subcontractors nor the U.S. Department of Energy, nor any person acting on behalf of either:

(A). Makes any warranty or representation, express or implied, with respect to the accuracy, completeness, or usefulness of the information contained in this report, or that the use of any information, apparatus, method, or process disclosed in this report may not infringe privately-owned rights; or

(B). Assumes any liabilities with respect to the use of, or for damages resulting from the use of, any information, apparatus, method or process disclosed in this report.

Reference herein to any specific commercial product, process, or service by trade name, trademark, manufacturer, or otherwise, does not necessarily constitute or imply its endorsement, recommendation, or favoring by the U.S. Department of Energy. The views and opinions of authors expressed herein do not necessarily state or reflect those of the U.S. Department of Energy. 


\section{Acknowledgement}

The Wabash River Coal Gasification Repowering Project Joint Venture would like to thank the United States Department of Energy for selecting the Wabash River Project as a participant in its Clean Coal Technology Program. Through this collaborative effort between government and industry, the Wabash River Project has significantly advanced the commercialization of clean coal-based power generation. We would like to particularly acknowledge the contributions of William Langan, whose professional and personal contributions to an idea, an industry, and to the Wabash River Project helped to make the vision a reality. In memory of Bill, the Gasification Control and Administration Building at Wabash was dedicated in his honor on November 7, 1995.

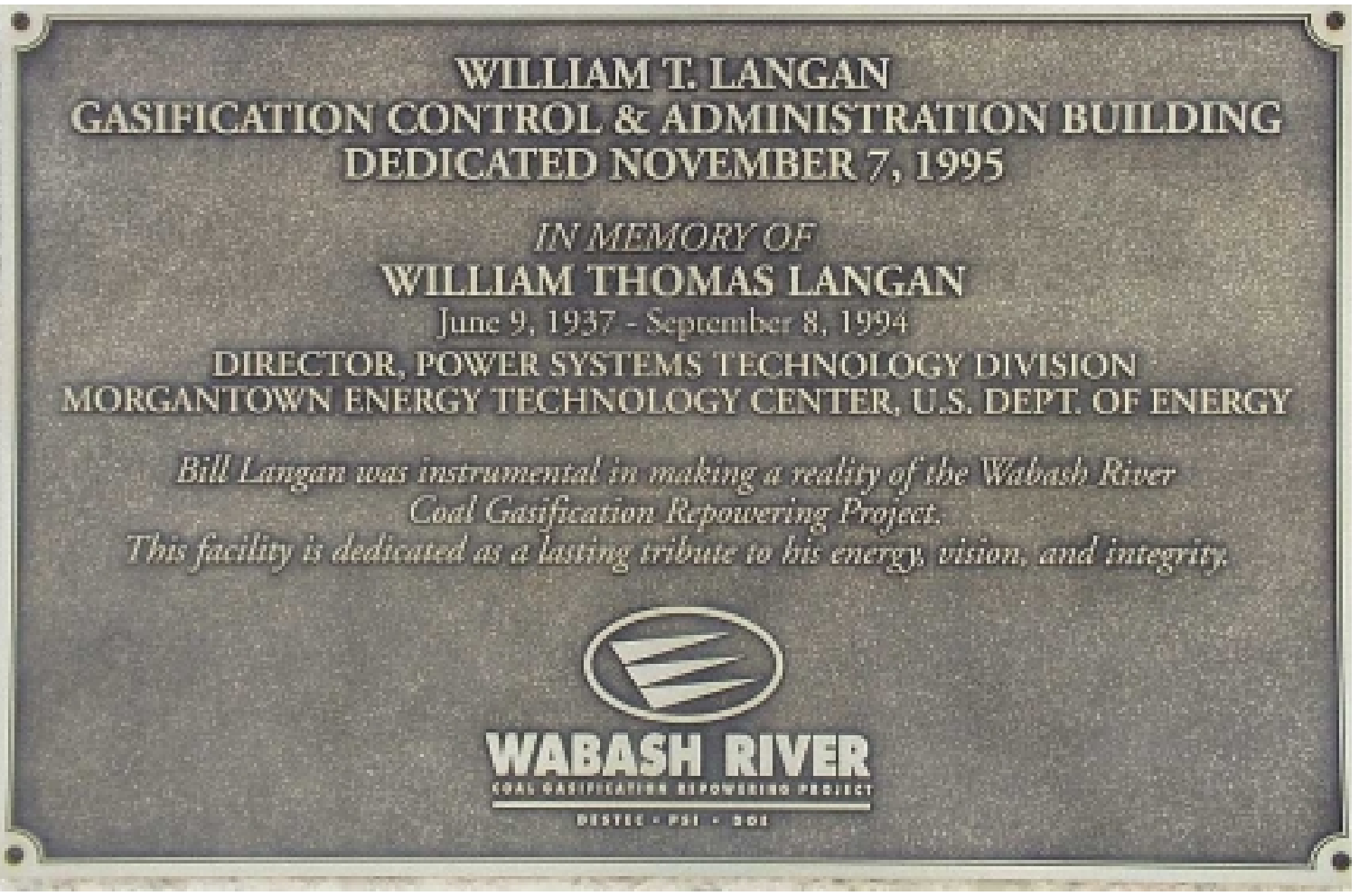




\section{Wabash River Coal Gasification Repowering Project Final Technical Report}

\section{TABLE OF CONTENTS}

\begin{tabular}{|l|l|} 
Contents & Page Number \\
\hline
\end{tabular}

\section{SECTION I - EXECUTIVE SUMMARY AND PROJECT OVERVIEW}

EXECUTIVE SUMMARY ES-1

i. General... ES-1

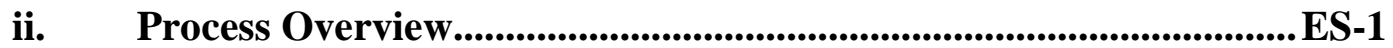

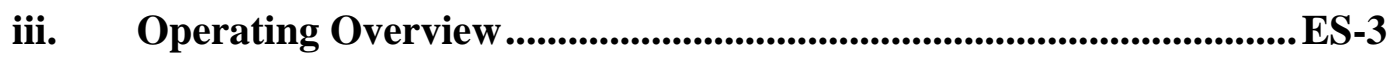

iv. Significant Findings and Modifications ..................................................ES-5

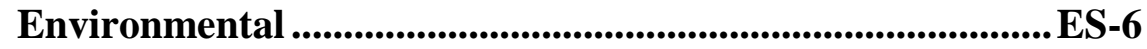

Air Separation Unit...............................................................................

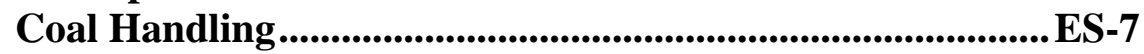

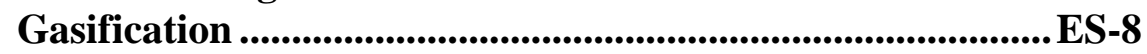

High Temperature Heat Recovery................................................5-9

Particulate Removal .......................................................................5S-9

Low Temperature Heat Recovery ...........................................ES-10

Acid Gas Removal .....................................................................

v. Plant Performance....................................................................ES-11

vi. Economics and Commercialization ............................................................ ES-13

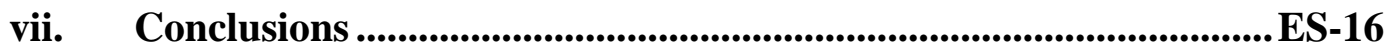

1.0 INTRODUCTION .................................................................................................1-1

1.1 Objectives .........................................................................................................1-3

1.2 General ........................................................................................................................... 1-5

1.3 Project Phase Description...............................................................1-8

1.3.1 Phase I Activities - Engineering and Procurement................... 1-8

1.3.2 Phase II Activities - Construction ................................................. 1-9

1.3.3 Phase III Activities - Demonstration Period ............................. 1-10

1.4 Project Organization......................................................................................1-11

1.5 Project Location and Original Equipment Description ......................1-12

1.6 Permitting and Environmental Activities ...............................................1-14 
3.0 DETAILED PROCESS DESCRIPTION.........................................................3-1

3.1 Air Separation Unit..........................................................................................3-2

3.2 Coal Handling.........................................................................................3-3

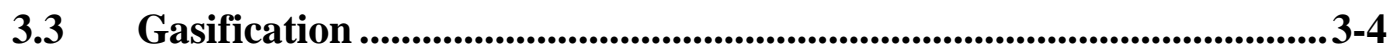

3.3.1 Gasification and Slag Handling .....................................................3-4

3.3.2 Syngas Cooling, Particulate Removal ..........................................3-6

3.3.3 Low Temperature Heat Recovery, Chloride Scrubbing, and Syngas Moisturization ................................................................3-7

3.3.4 Acid Gas Removal ......................................................................3-8

3.3.5 Sulfur Recovery ...........................................................................3-9

3.3.6 Sour Water Treatment........................................................................3-10

3.4 Power Block ..............................................................................................3-11

\section{SECTION II - OPERATIONS AND ECONOMICS}

4.0 DEMONSTRATION PERIOD ........................................................................4-1

4.1 Operation, Maintenance and Technical Impacts ......................................4-2

4.1.1 Air Separation Unit.....................................................................4-7

4.1.2 Coal Handling....................................................................................4-15

4.1.3 Gasification ........................................................................................... 4-20

4.1.3.1 Gasification and Slag Handling ................................4-20

4.1.3.2 Syngas Cooling, Particulate Removal And COS Hydrolysis ............................................................4-32

4.1.3.3 Low Temperature Heat Recovery and Syngas Moisturization........................................................................4-48

4.1.3.4 Acid Gas Removal .....................................................4-53

4.1.3.5 Sulfur Recovery .............................................................4-58

4.1.3.6 Sour Water Treatment..............................................4-65

4.1.4 Power Block ..........................................................................................4-68

4.2 General Information .....................................................................................4-71

4.2.1 Stream Data ..........................................................................4-71

4.2.2 Alternative Fuel Testing ...................................................................4-74

4.3 Critical Component Failure Report .............................................................4-85 
$5.1 \quad$ Air Separation Unit.......................................................................................5-4

5.1.1 Air Compression System ...............................................................5-4

5.1.1.1 System Modifications ..............................................5-5

5.1.1.2 Operating Experience Overview ...............................5-7

5.1.1.3 Summary and Conclusions..........................................5-8

5.1.2 Water Wash System ........................................................5-12

5.1.2.1 System Modifications ................................................5-13

5.1.2.2 Operating Experience Overview ............................5-13

5.1.2.3 Summary and Conclusions....................................5-14

5.1.3 Air Purification System ......................................................5-15

5.1.3.1 System Modifications ................................................5-16

5.1.3.2 Operating Experience Overview ............................5-16

5.1.3.3 Summary and Conclusions....................................5-18

5.1.4 Air Cooling and Liquefaction System ...................................5-21

5.1.4.1 System Modifications .............................................5-22

5.1.4.2 Operating Experience Overview ...............................5-24

5.1.4.3 Summary and Conclusions......................................5-24

5.1.5 Cryogenic Distillation System ....................................................5-27

5.1.5.1 System Modifications ..............................................5-28

5.1.5.2 Operating Experience Overview .............................5-28

5.1.5.3 Summary and Conclusions....................................5-30

5.1.6 Oxygen Mixing System .................................................................5-32

5.1.6.1 System Modifications ................................................5-33

5.1.6.2 Operating Experience Overview ............................5-33

5.1.6.3 Summary and Conclusions.....................................5-35

5.1.7 Nitrogen Handling and Storage System ................................5-36

5.1.7.1 System Modifications ................................................5-38

5.1.7.2 Operating Experience Overview ............................5-38

5.1.7.3 Summary and Conclusions.......................................5-40

5.1.8 Oxygen Compression System ....................................................5-42

5.1.8.1 System Modifications ...........................................5-42

5.1.8.2 Operating Experience Overview .............................5-44

5.1.8.3 Summary and Conclusions.....................................5-46

5.2 Coal Handling .......................................................................................5-48

5.2.1 Coal Hopper System......................................................................5-48

5.2.1.1 System Modifications ............................................5-49

5.2.1.2 Operating Experience Overview ............................5-49

5.1.2.3 Summary and Conclusions.......................................5-50

5.2.2 Rod Mill System ..............................................................................5-51

5.2.2.1 System Modifications .................................................5-52

5.2.2.2 Operating Experience Overview ............................5-53

5.2.2.3 Summary and Conclusions...................................5-54 
5.2.3 Slurry Storage Tank System ........................................................5-56

5.2.3.1 System Modifications ............................................5-57

5.2.3.2 Operating Experience Overview............................5-57

5.2.3.3 Summary and Conclusions........................................5-57

5.2.4 Slurry Feed System ……...................................................................5-58

5.2.4.1 System Modifications .................................................5-58

5.2.4.2 Operating Experience Overview.............................5-59

5.2.4.3 Summary and Conclusions.......................................5-60

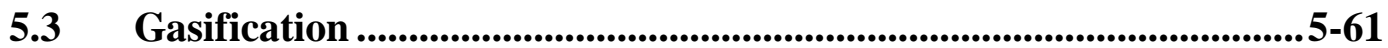

5.3.1 First Stage Gasifier System ..........................................................5-61

5.3.1.1 System Modifications ..................................................5-62

5.3.1.2 Operating Experience Overview..............................5-63

5.3.1.3 Summary and Conclusions.......................................5-65

5.3.2 Second Stage Gasifier System .................................................5-68

5.3.2.1 System Modifications ...................................................5-68

5.3.2.2 Operating Experience Overview..............................5-69

5.3.2.3 Summary and Conclusions.......................................5-70

5.3.3 Raw Syngas Conditioning System ........................................5-71

5.3.3.1 System Modifications ..............................................5-71

5.3.3.2 Operating Experience Overview..............................5-72

5.3.3.3 Summary and Conclusions.......................................5-73

5.3.4 Slag and Solids Handling System...............................................5-74

5.3.4.1 System Modifications ...................................................5-76

5.3.4.2 Operating Experience Overview..............................5-76

5.3.4.3 Summary and Conclusions......................................5-78

5.3.5 Syngas Cooling/Steam Generation System ..............................5-79

5.3.5.1 System Modifications ................................................5-80

5.3.5.2 Operating Experience Overview.............................5-82

5.3.5.3 Summary and Conclusions ........................................5-83

5.3.6 Particulate Removal System.........................................................5-84

5.3.6.1 System Modifications .................................................5-84

5.3.6.2 Operating Experience Overview.............................5-88

5.3.6.3 Summary and Conclusions........................................5-91

5.3.7 Chloride Scrubbing System.............................................................5-93

5.3.7.1 System Modifications ..................................................5-94

5.3.7.2 Operating Experience Overview..............................5-94

5.3.7.3 Summary and Conclusions......................................5-96

5.3.8 COS Hydrolysis System ...................................................................5-97

5.3.8.1 System Modifications .................................................5-97

5.3.8.2 Operating Experience Overview.............................5-99

5.3.8.3 Summary and Conclusions......................................5-99

5.3.9 Low Temperature Heat Recovery System ..............................5-100

5.3.9.1 System Modifications .............................................5-100

5.3.9.2 Operating Experience Overview............................5-102

5.3.9.3 Summary and Conclusions ....................................5-105 
5.3.10 Syngas Moisturization System ..................................................5-106

5.3.10.1 System Modifications .................................................5-106

5.3.10.2 Operating Experience Overview...........................5-106

5.3.10.3 Summary and Conclusions......................................5-107

5.3.11 Acid Gas Removal System ...........................................................5-108

5.3.11.1 System Modifications ................................................5-109

5.3.11.2 Operating Experience Overview............................5-113

5.3.11.3 Summary and Conclusions....................................5-116

5.3.12 Sulfur Recovery System..............................................................5-118

5.3.12.1 System Modifications ................................................5-119

5.3.12.2 Operating Experience Overview............................5-123

5.3.12.3 Summary and Conclusions....................................5-131

5.3.13 Sour Water Treatment System ................................................5-133

5.3.13.1 System Modifications ...............................................5-134

5.3.13.2 Operating Experience Overview............................5-135

5.3.13.3 Summary and Conclusions....................................5-139

5.3.14 Cooling Tower System ................................................................5-141

5.3.14.1 System Modifications ..................................................5-142

5.3.14.2 Operating Experience Overview............................5-142

5.3.14.3 Summary and Conclusions........................................5-143

5.4 Power Block ...........................................................................................5-144

5.4.1 Combustion Turbine ...................................................................5-144

5.4.1.1 System Modifications ...........................................5-145

5.4.1.2 Operating Experience Overview............................5-145

5.4.1.3 Summary and Conclusions....................................5-146

5.4.2 Heat Recovery Steam Generator ............................................5-148

5.4.2.1 System Modifications ..............................................5-148

5.4.2.2 Operating Experience Overview...........................5-148

5.4.2.3 Summary and Conclusions.....................................5-148

5.4.3 Water Treatment/Handling System .......................................5-150

5.4.3.1 System Modifications .................................................5-150

5.4.3.2 Operating Experience Overview...........................5-150

5.4.3.3 Summary and Conclusions......................................5-151

5.4.4 Steam Turbine ................................................................................5-152

5.4.4.1 System Modifications ..................................................5-152

5.4.4.2 Operating Experience ...............................................5-152

5.4.4.3 Summary and Conclusions.....................................5-152

6.0 ENVIRONMENTAL PERFORMANCE ...............................................................6-1

6.1 Non-Proprietary Streams ....................................................................................6-4

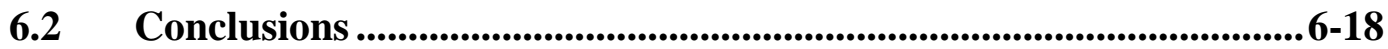

6.2.1 Process Waste and Waste Water ..............................................6-18

6.2.2 Air Emissions ......................................................................................6-19

Wabash River Coal Gasification Repowering Project Final Technical Report 
7.1 Actual Installed Costs for Wabash River........................................... 7-1

7.2 Forecast Costs for Year 2000 Installation.....................................

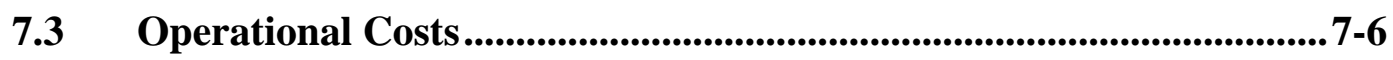

7.3.1 Fuel Cost ............................................................................7-6

7.3.2 Non-Fuel Operation and Maintenance Costs ...........................7-6

7.4 Economic Analysis.......................................................................... 7-7

7.4.1 Historical Perspective .............................................................7.7

7.4.2 Evaluation of Future Power Generation Projects ..................... 7-7

\section{SECTION III - COMMERCIALIZATION AND RECOMMENDATIONS}

8.0 COMMERCIALIZATION POTENTIAL AND PLANS ............................ 8.1

9.0 CONCLUSIONS AND RECOMMENDATIONS ........................................9-1

9.1 Success of the Demonstration Project ....................................................9-1

9.2 Commercialization Barriers and Areas of Recommended Research ...........................................................................................9-5

9.3 Outlook ...............................................................................................9-9

\section{APPENDICES}

Appendix A - Glossary of Acronyms, Abbreviations, and Symbols ........................ A-1

Appendix B - Monthly Plant Performance Data ...................................................... B-1 


\section{Wabash River Coal Gasification Repowering Project Final Technical Report}

\section{LIST OF FIGURES}

\begin{tabular}{|c|c|c||}
\hline Figure & Description & Page Number \\
Number & Dumber \\
\hline
\end{tabular}

Figure ES-1

Figure ES-2

Figure ES-3

Figure $1.5 \mathrm{~A}$

Figure $2.0 \mathrm{~A}$

Figure 4.1A

Figure 4.1B

Figure 4.1.3A

Figure 4.1.3B

Figure 4.1.3C

Figure 4.1.3D

Figure 4.1.3E

Figure 4.1.3F

Figure 4.1.3G

Figure $4.1 .3 \mathrm{H}$

Figure 4.2.1A

Figure 4.2.2A

Figure $4.2 .2 \mathrm{~B}$

Figure 4.2.2C

Figure 4.2.2D

Figure 5.1.1A

Figure 5.1.1B

Figure 5.1.2A

Figure 5.1.3A

Figure 5.1.3B

Figure 5.1.4A

Figure 5.1.4B

Figure 5.1.4C

Figure 5.1.4D

Figure 5.1.5A

Figure 5.1.6A

Figure 5.1.7A

Figure 5.1.7B

Figure 5.1.7C

Figure 5.1.8A

Figure 5.2.1A

Figure 5.2.2A

Figure 5.2.2B
Gasification Process Simplified Block Flow Diagram ES-2

Project Syngas Block and Power Block Availability ES-4

Syngas Production by Year. ES-13

Project Site General Location Map.....

$1-12$

Gasification Process Simplified Block Flow Diagram ....................... 2-1

Project, Syngas Block and Power Block Availability ......................... 4-3

Syngas Production by Year...........................................................4-6

Hours of Operation for Demonstration Period.................................. 4-21

Feed to Gasification Reactor for the Demonstration Period ............... 4-24

1600 psig Steam Produced for Demonstration Period ........................ 4-33

Carbonyl Sulfide in Particulate Free Syngas ......................................4-43

Produced Syngas for Demonstration Period ..................................... 4-49

Hydrogen Sulfide Removal Efficiency for Demonstration Period .....4-54

Sulfur Recovery Efficiency for Demonstration Period......................4-59

Water Outfall for Demonstration Period............................................ 4-66

Monitoring Locations..................................................................... 4-73

Wabash River Plant Performance on Pet Coke................................. 4-77

Petroleum Coke Test Overall Carbon Conversion............................... 4-79

Petroleum Coke Test Flux Content.................................................4-79

Total Sulfur in Product Syngas .................................................... 4-82

Main Air Compressor ........................................................................5-4

Close-up of a Newly Installed Guide Vane Actuator .........................5-9

Water Wash System ..................................................................5-12

Adsorber Beds for the Air Purification System ................................5-15

Regeneration Heater for the Air Purification System ........................5-16

Nitrogen Vaporizer and Enclosure for Main Exchangers.................. 5-21

Compressor/Expander Skid ..........................................................5-22

Damage Inside Enclosure for Main Exchangers...............................5-25

Derime Header Failed Weld ............................................................. 5-25

High-Pressure and Low-Pressure Columns ......................................5-27

Equipment Associated with Oxygen Mixing System .......................5-32

Liquid Nitrogen Pumps ...............................................................5-36

Liquid Nitrogen Pump Skid .......................................................5-37

Liquid Nitrogen Storage Tank and High-pressure Cylinders .............5-37

Oxygen Compressor.................................................................5-42

Weigh Belt Feeder ................................................................... 5-48

Rod Mill ........................................................................... 5-51

Rod Mill Product Tank Pumps ...................................................5-52 


\begin{tabular}{|c|c|c|}
\hline $\begin{array}{c}\text { Figure } \\
\text { Number }\end{array}$ & Description & Page Number \\
\hline
\end{tabular}

Figure 5.2.2C Rod Mill Lube Oil Skid ...........................................................5-53

Figure 5.2.3A Slurry Storage Tank Agitator........................................................5-56

Figure 5.2.3B Slurry Recirculation Pumps ......................................................5-56

Figure 5.2.4A Typical First Stage Reactor Feed Pump............................................. 5-58

Figure 5.3.1A First Stage Gasifier Feed Nozzles.......................................................5-61

Figure 5.3.2B Second Stage Gasifier Slurry Feed Nozzle ..........................................5-70

Figure 5.3.4A Slag Dewatering Tank Building and Slag Water Storage Tank..........5-74

Figure 5.3.4B Slag Fines Settler .......................................................................5-75

Figure 5.3.4C Slag Fines Settler Bottoms Pumps ....................................................5-75

Figure 5.3.4D Slag Quench Feedwater Pumps ………………...............................5-76

Figure 5.3.5A Syngas Cooler \& Steam Drum....................................................5-79

Figure 5.3.6A Wabash River Plant Downtime Summary ……………………..........5-92

Figure 5.3.7A Major Equipment Associated with the Chloride Scrubbing System ..5-93

Figure 5.3.8A Carbonyl Sulfide Reactors .............................................................5-97

Figure 5.3.9A Heat Exchanger Deck for Low Temperature Heat Recovery ............5-100

Figure 5.3.9B Syngas Recycle Compressor and Knockout Drum...........................5-104

Figure 5.3.11A Acid Gas Removal System Major Equipment ..................................5-109

Figure 5.3.12A Sulfur Recovery Unit Major Equipment........................................... 5-119

Figure 5.3.12B Sulfur in No. 4 Sulfur Condenser as a Result of a Plugged

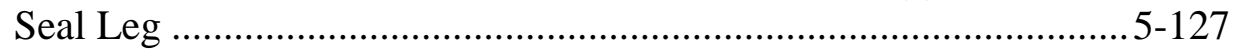

Figure 5.3.12C Tail Gas Recycle Compressors ......................................................5-129

Figure 5.3.13A Sour Water Treatment System Major Equipment..............................5-133

Figure 5.3.14A Cooling Tower Water System.......................................................5-141

Figure 5.4.1A Combustion Turbine ……………............................................ 5-144

Figure 5.4.3A Water Treatment/Handling System................................................ 5-150

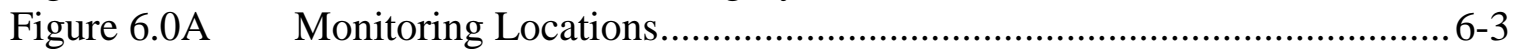

Figure 8.0A $\quad$ World Gasification Facility Capacity .................................................... 8.1

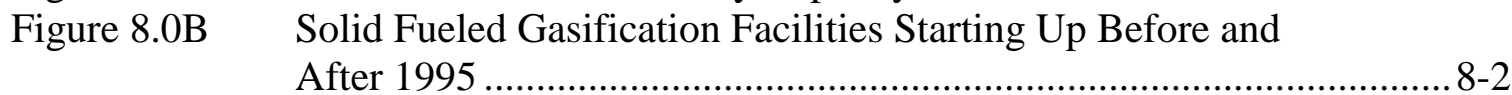




\section{Wabash River Coal Gasification Repowering Project Final Technical Report}

\section{LIST OF TABLES}

\begin{tabular}{|c|c|c|}
\hline $\begin{array}{c}\text { Table } \\
\text { Number }\end{array}$ & Description & Page Number \\
\hline
\end{tabular}

Table ES-1

Table ES-2

Table ES-3

Table ES-4

Table ES-5

Table ES-6

Table 4.1A

Table 4.1B

Table 4.1C

Table 4.1.2A

Table $4.1 .3 \mathrm{~A}$

Table 4.1.4A

Table 4.2.1A

Table 4.2.2A

Table 4.2.2B

Table 4.2.2C

Table 4.3A

Table 4.3B

Table 5.0A

Table 6.0A

Table 6.1A

Table 6.1B

Table 6.1C

Table 6.1D

Table 6.1E

Table 6.1F

Table $6.1 \mathrm{G}$

Table $6.1 \mathrm{H}$

Table 6.1I

Table 6.1J

Table $6.1 \mathrm{~K}$

Table 6.1L

Table $6.1 \mathrm{M}$
Significant Operating Achievements ES-5

Component Emissions in Pounds per MMBtu of Dry Coal Feed...... ES-6

Performance Summary ES-11

Wabash River Coal Gasification Repowering Project Production

Statistics ES-12

Wabash River Coal Gasification Repowering Project Costs ES-14 Results of Economic Analysis for Wabash River Style IGCC ......... ES-15 Significant Operating Achievements ................................................. 4-4 Performance Summary ................................................................... 4-5 Wabash River Coal Gasification Repowering Project Production

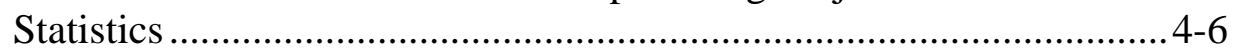

Feedstock Analysis ..................................................................... 4

Product Syngas Quality ............................................................ $4-50$

Power Block Production …………………....................................4-68

Key to Monitoring Locations..........................................................4-72

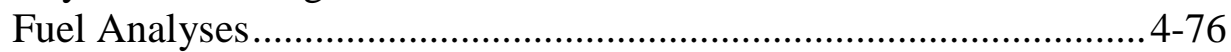

Thermal Performance Summary ................................................... 4-78

Product Syngas Analyses ............................................................. 4.80

Summary of Critical Components by Plant Area …………………..... 4-85

Downtime Consequences of Critical Components by

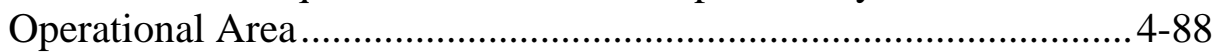

WRCGRP Operating Period Downtime \& Availability ........................5-2

Key to Monitoring Locations............................................................. 6-2

Coal Slurry Analysis ....................................................................... 6-4

Tail Gas Incinerator Permit Limits ..................................................... 6-6

Initial Compliance Stack Testing ......................................................6-6

1997 and 1998 Stack Testing Results ...............................................6-7

Annual Emission Inventory - Tail Gas Incinerator Stack

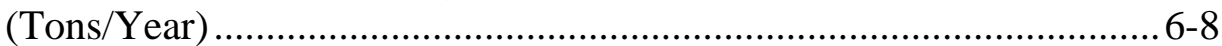

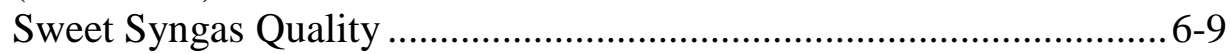

Flare Permit Limits .............................................................................. 6-9

Combustion Turbine Permit Limits ................................................... 6-10

Power Block Emissions (Tons/Year)................................................ 6-11

Slag Analysis .......................................................................

Process Waste Water Permit Limits .................................................. 6-13

Process Waste Water Discharge ....................................................... 6-14

Ash Pond Effluent (Outfall 002) Permit Limits................................... 6-15 


\section{Table} Number

Table 6.1N

Table 6.2.2A

Table 7.1A

Table 7.2A

Table 7.4A

Table B. 1

Table B.2

Table B. 3

Table B.4
Description

Page Number

Fugitive Emission - Tons/Year ................................................... 6-16

Component Emissions in Pounds per MMBtu of Dry Coal Feed....... 6-19

Project Costs ........................................................................... 7-2

Costs of Near Term IGCC Projects, \$/kW ........................................ 7.5

Results of Economic Analysis for Wabash River Style IGCC

Single Train................................................................................ 7-10

1996 Monthly Plant Performance Data ..............................................

1997 Monthly Plant Performance Data ...............................................

1998 Monthly Plant Performance Data .............................................

1999 Monthly Plant Performance Data ............................................B-4 
The following personnel contributed their time, effort, and talent in the compilation of the information contained in this Final Technical Report:

Mr. Phil Amick

Gasification Engineering Corp.

Mr. Newell Carter

Wabash River Energy Ltd

Mr. Roy Dowd

Wabash River Energy Ltd.

Mr. Cliff Keeler

Wabash River Energy Ltd.

Mr. H. Lou Miller

Wabash River Energy Ltd.

Mr. Richard Payonk

Wabash River Energy Ltd.

Mr. Don Sturm

Wabash River Energy Ltd.

Mr. Chancellor Williams

Wabash River Energy Ltd.
Mr. Craig Bittle

Wabash River Energy Ltd.

Mr. Doug Cousins

Wabash River Energy Ltd.

Mr. Mike Hickey

Wabash River Energy Ltd.

Mr. Thomas Lynch

Gasification Engineering Corp.

Mr. David McCleary

Wabash River Energy Ltd.

Mr. Doug Strickland

Gasification Engineering Corp.

Mr. E.J. “Chip" Troxclair

Gasification Engineering Corp.
Mr. David Breton

Gasification Engineering Corp.

Mr. Steven Douglas

Wabash River Energy Ltd.

Mr. Mitch Landess

Wabash River Energy Ltd.

Mr. Mel Mickelson

Wabash River Energy Ltd.

Mr. Dorian Pacheco

Wabash River Energy Ltd.

Mr. Jack Stultz

Cinergy Corp.

Mr. Albert Tsang

Gasification Engineering Corp.

A special thanks from all the personnel listed above goes out to the Office Administrative Assistants: Ms. Melissa Brown, Ms. Brenda Junker, and Ms. Samantha O'Dell.

Gasification Engineering Corp. and Wabash River Energy Ltd. are wholly owned subsidiaries of Global Energy Inc. 


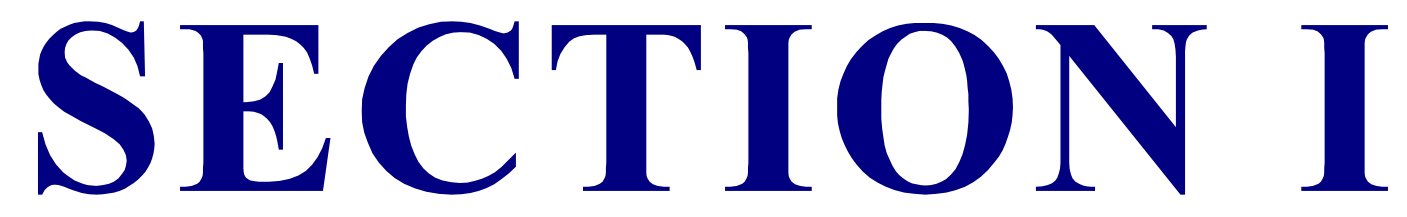

Executive Summary \& Project Overview 


\section{EXECUTIVE SUMMARY}

\section{i. General}

The close of 1999 marked the completion of the Demonstration Period of the Wabash River Coal Gasification Repowering Project. This Final Report summarizes the engineering and construction phases and details the learning experiences from the first four years of commercial operation that made up the Demonstration Period under Department of Energy (DOE) Cooperative Agreement DE-FC21-92MC29310.

This 262 MWe project is a joint venture of Global Energy Inc. (Global acquired Destec Energy's gasification assets from Dynegy in 1999) and PSI Energy, a part of Cinergy Corp. The Joint Venture was formed to participate in the Department of Energy's Clean Coal Technology (CCT) program and to demonstrate coal gasification repowering of an existing generating unit impacted by the Clean Air Act Amendments. The participants jointly developed, separately designed, constructed, own, and are now operating an integrated coal gasification combined-cycle power plant, using Global Energy's E-Gas ${ }^{\mathrm{TM}}$ technology $\left(\mathrm{E}^{-G a s^{\mathrm{TM}}}\right.$ is the name given to the former Destec technology developed by Dow, Destec, and Dynegy). The E-Gas ${ }^{\mathrm{TM}}$ process is integrated with a new General Electric 7FA combustion turbine generator and a heat recovery steam generator in the repowering of a 1950's-vintage Westinghouse steam turbine generator using some pre-existing coal handling facilities, interconnections, and other auxiliaries. The gasification facility utilizes local high sulfur coals (up to $5.9 \%$ sulfur) and produces synthetic gas (syngas), sulfur and slag by-products. The Project has the distinction of being the largest single train coal gasification combined-cycle plant in the Western Hemisphere and is the cleanest coalfired plant of any type in the world. The Project was the first of the CCT integrated gasification combined-cycle (IGCC) projects to achieve commercial operation.

\section{ii. Process Overview}

The E-Gas ${ }^{\mathrm{TM}}$ Process (Figure ES-1) features an oxygen-blown, continuous-slagging, two-stage, entrained-flow gasifier. Coal is slurried in a rod mill and combined with oxygen in slurry mixers and injected into the first stage of the gasifier, which operates at $2,600^{\circ} \mathrm{F}$ and 400 psia. Molten ash falls through a taphole at the bottom of the first stage into a water quench, forming an inert 
vitreous slag. The syngas flows to the second stage, where additional coal slurry is injected. This coal is pyrolyzed by the hot syngas to enhance the syngas heating value and to improve overall efficiency. Syngas leaving the gasifier flows to the high temperature heat recovery unit (HTHRU), also referred to as the boiler, to produce high-pressure saturated steam. After cooling in the HTHRU, particulates in the syngas are removed in a hot/dry filter and recycled to the gasifier where the carbon in the particulates is converted into more syngas.

\section{WRCGRP E-Gas ${ }^{\mathrm{TM}}$ Gasification Process}

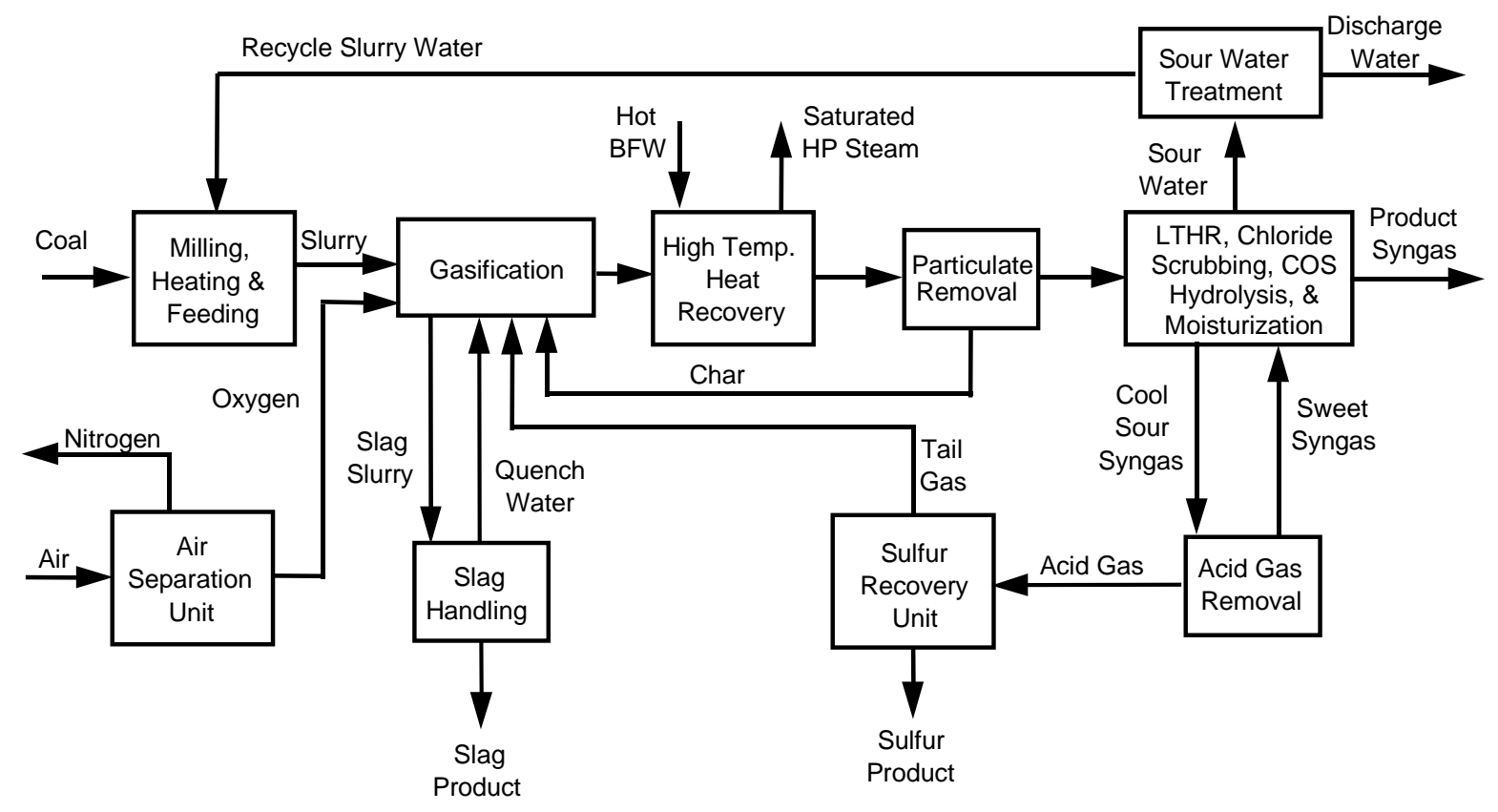

Figure ES-1: Gasification Process Simplified Block Flow Diagram

Following the particulate removal system, the syngas is further cooled in the low temperature heat recovery (LTHR) area, water-scrubbed to remove chloride, and passed through a catalyst that hydrolyzes carbonyl sulfide (COS) to hydrogen sulfide $\left(\mathrm{H}_{2} \mathrm{~S}\right) . \mathrm{H}_{2} \mathrm{~S}$ is removed using methyldiethanolamine (MDEA) based absorber/stripper columns. The "sweet" syngas is then moisturized, preheated, and piped over to the power block, where it is combusted in a General Electric 7FA high-temperature combustion turbine/generator to produce $192 \mathrm{MW}$ electricity. The heat recovery steam generator (HRSG) configuration is optimized to utilize both the gas turbine exhaust energy and the heat energy made available in the gasification process. Steam 
from the HRSG and gasification process drives a Westinghouse turbine that produces $104 \mathrm{MW}$ of electricity. The power from the combustion and steam turbines, less the internally used power, provides a net of $262 \mathrm{MW}$ to the utility grid. An overall thermal efficiency of 8,900 $\mathrm{Btu} / \mathrm{kWh}(\mathrm{HHV})$ has been demonstrated.

The gasification facility also produces two commercial by-products. Sulfur is removed as 99.999 percent pure elemental sulfur and marketed to sulfur users and slag from the process can be used as aggregate in asphalt roads, as structural fill in various types of construction applications, as roofing granules, and as blasting grit.

\section{iii. Operating Overview}

Commercial operation of the facility began late in 1995. Within a short time, both the gasification and combined-cycle plants successfully demonstrated the ability to run at capacity and within environmental compliance parameters. However, numerous operating problems adversely impacted plant reliability and the first year of operation resulted in only a $22 \%$ availability factor. Frequent failure of the ceramic filter elements in the particulate removal system accounted for nearly $40 \%$ of the early facility downtime. Plant reliability was also significantly hindered by high chloride content in the syngas. The high chlorides contributed to exchanger tube failures in the low temperature heat recovery area, COS hydrolysis catalyst degradation and mechanical failures of the syngas recycle compressor. Ash deposits in the post gasifier pipe spool and HTHRU created high system pressure drop, which forced the plant off line and required significant downtime to remove. Slurry mixers experienced several failures and the power block also contributed to appreciable downtime in the early years of operation.

Through a systematic problem-solving approach and a series of appropriate process modifications, all of the foregoing problems were either eliminated or significantly reduced by the end of the second operating year. In 1997, the facility availability factor was $44 \%$ and, by 1998, the availability factor had improved to $60 \%$. As problems were solved and availability improved, new improvement opportunities surfaced. During the third year of commercial operation, the facility demonstrated operation on a second coal feedstock as well as a blend of two different Illinois No. 6 coals. The ability to process and blend new coal feedstocks improved 
the fuel flexibility for the site, but while learning to process varying feedstocks the plant suffered some downtime. On two occasions while processing new coals or fuel blends, the taphole in the gasifier plugged with slag.

In 1998 and 1999 a high percentage of coal interruptions and downtime were caused by the air separation unit (ASU). Ten coal interruptions in 1998 alone were due to the ASU. In 1999, failure of a blade in the compressor section of the combustion turbine required a complete rotor rebuild that idled the Project for 100 days. Run-time in 1999 was also impacted by a syngas leak in the piping system of the particulate removal system, a main exchanger leak in the air separation unit, another plugged taphole, and a failure of a ceramic test filter in the particulate removal system. Consequently, the availability factor for the Project in 1999 dropped to $40 \%$.

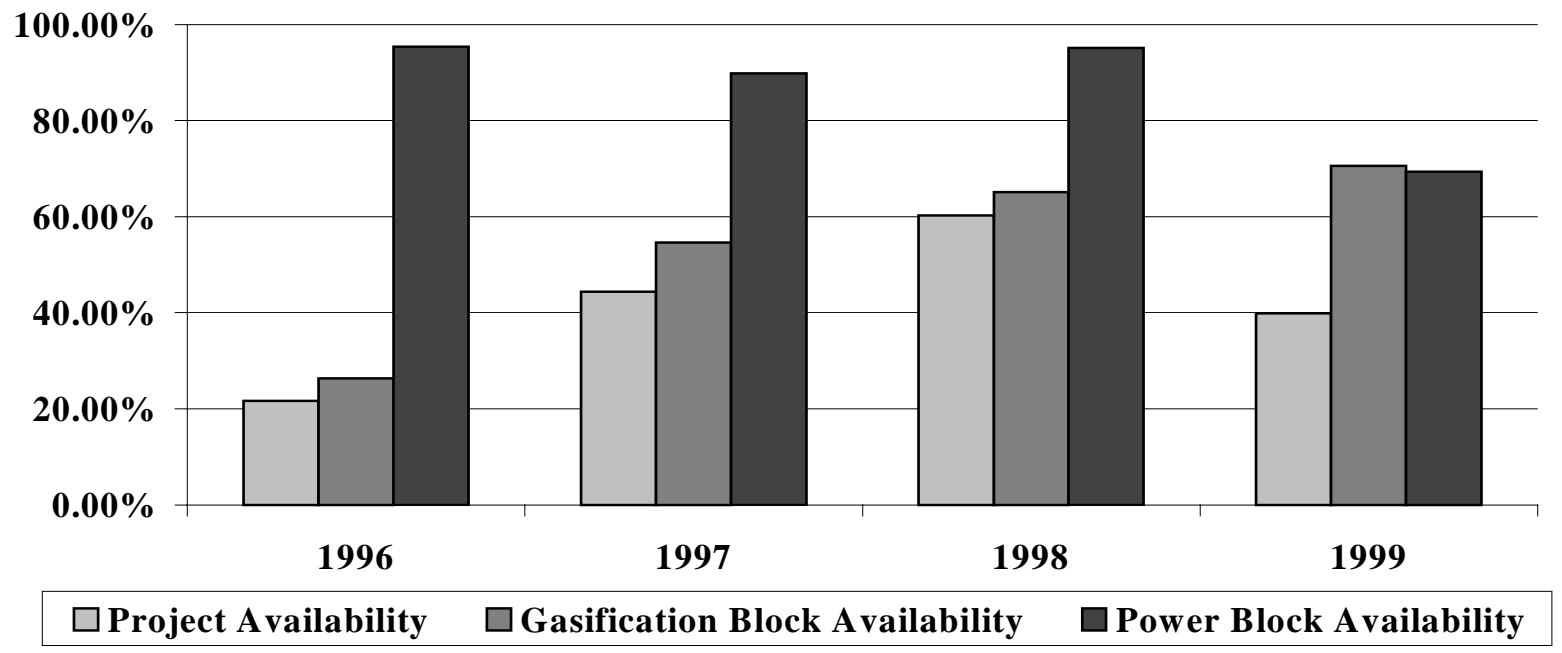

Figure ES-2: Project Syngas Block and Power Block Availability

However, 1999 clearly marked significant advances in the application of commercial IGCC as demonstrated at Wabash River. During the third quarter of 1999, the gasification block produced a record 2.7 trillion Btu of syngas, operated continuously without any interruption for 54 days and finished the year at $70 \%$ availability. Figure ES-2 demonstrates how the reliability of the technology has advanced during the Demonstration Period. The continuous improvement trend for the gasification block, where the majority of the novel technology was demonstrated, is encouraging and is expected to continue. 
Future operating improvements will continue to advance the technology and eliminate cost and availability barriers. Some of the more significant achievements and activities for the demonstration project are highlighted in Table ES-1.

Table ES-1: Significant Operating Achievements

\begin{tabular}{|c|c|}
\hline First coal fire in gasifier & August 17,1995 \\
\hline Commercial operation begins & December 1,1995 \\
\hline Start-up of chloride scrubbing system & October 1996 \\
\hline Initiated use of metal filter elements & December 1996 \\
\hline Conducted 10-day test run of petroleum coke & November 1997 \\
\hline 1998 Governor's Award for Excellence in Recycling & May 1998 \\
\hline Began running new coal feed (Miller Creek) & June 1998 \\
\hline Completed 14-month OSHA recordable-free period & September 1998 \\
\hline Surpassed $1,000,000$ tons of coal processed & September 1998 \\
\hline Surpassed 10,000 hours of coal operation & September 1998 \\
\hline Surpassed $100,000,000$ pounds equivalent of $\mathrm{SO}_{2}$ captured & January 1999 \\
\hline Record quarterly production $(2,712,107 \mathrm{MMBtu})$ & $3^{\text {rd }}$ Quarter 1999 \\
\hline Longest continuous uninterrupted run $(1,305 \mathrm{hrs})$ & August 12 - October 6, 1999 \\
\hline Conducted second successful petroleum coke run & September 1999 \\
\hline Record coal hours between gas path vessel entries $(2,240 \mathrm{hr})$ & June to October 1999 \\
\hline Completed $2^{\text {nd }} 14$-month OSHA recordable-free period & December 1999 \\
\hline
\end{tabular}

\section{iv. Significant Findings and Modifications}

The knowledge gained during the four years of the Demonstration Period has been tremendous and has been used to make hardware and operating changes that improve the reliability and cost effectiveness of the facility. Many of these findings and resulting modifications are discussed in detail in the main body of the Final Report. Some examples of significant learning experiences have been culled from the detailed report and are briefly described by area in this section of the Executive Summary. 


\section{$\underline{\text { Environmental }}$}

Under the requirements of the Cooperative Agreement, a comprehensive Environmental Monitoring Plan (EMP) has been established and followed. The solids, water and gas discharge points as well as internal streams have been sampled and analyzed. Both on-site laboratory personnel and contracted independent laboratories were utilized to fulfill the requirements of the EMP. The EMP has produced a wealth of valuable data and contributed immensely to the understanding of component partitioning throughout the gasification and combustion processes.

The collective data indicate that arsenic, selenium and cyanide (among others) either fully or partially partition into the gas phase. Although portions of these components deposit as solids on equipment surfaces, they typically end up in the condensed vapor stream creating elevated levels in plant process waste water. As a result, process waste water arising from use of the current feedstock, remains out of permit compliance due to elevated levels of arsenic, selenium and cyanide. To rectify these concerns, plant personnel have been working on several potential equipment modifications and treatment alternatives to bring the discharge back into compliance. Wabash River is currently obligated to resolve this issue by September of 2001.

Turning to air emissions, WRCGRP has met or exceeded every expectation outlined in the preconstruction literature. The following table represents total air emissions based on all sources monitored or calculated at the site during the years of 1997 and 1998. These emissions are the lowest from any commercially sized coal-fired power plant.

Table ES-2: Component Emissions in Pounds per MMBtu of Dry Coal Feed

\begin{tabular}{|c|c|c|}
\cline { 2 - 3 } \multicolumn{1}{c|}{} & $\mathbf{1 9 9 7}$ & $\mathbf{1 9 9 8}$ \\
\hline Sulfur Dioxide & 0.13 & 0.13 \\
\hline Nitrogen Oxides & 0.024 & 0.021 \\
\hline Carbon Monoxide & 0.056 & 0.033 \\
\hline Volatile Organics & 0.002 & 0.0021 \\
\hline $\mathrm{PM}_{10}$ & 0.012 & 0.011 \\
\hline
\end{tabular}




\section{$\underline{\text { Air Separation Unit }}$}

Despite the high availability typical of industrial air separation units (ASU), the 2,060 ton per day oxygen plant installed for WRCGRP has not been typical and has suffered more than expected downtime. In 1998 and 1999, the ASU has been responsible for 11 coal interruptions to the gasifier resulting in more than 30 days of downtime. The root causes for the majority of these coal interruptions fall into three categories. First, failures associated with a poorly designed main air compressor inlet guide vane actuator system. Second, poorly designed and incorrectly installed control instrument subsystems. Third, critical components not properly designed for outdoor service such as non-weatherproof motor enclosures for 10,000 and 30,000 horsepower motors. The inlet guide vane system has been replaced with a new design. Many of the questionable instrument subsystems have been modified and improved. Purges and heater systems for the motor enclosures have been added and fixed, respectively, and the enclosures have been made less susceptible to weather. These modifications have improved reliability, but further enhancements are needed.

The initial performance test of the air separation unit did not meet the design nitrogen production or power consumption targets. The original equipment manufacturer added an ancillary nitrogen vaporizer and installed a new high-pressure oxygen recycle line, which improved production. However, the improvements still fell short of the targeted nitrogen production. Both the shortfalls have resulted in higher than expected operating and maintenance cost for imported nitrogen and power.

\section{Coal Handling}

The suction line between the slurry storage tank and the slurry recirculation pumps experienced numerous plugging incidents, which interrupted coal operation six times during the Demonstration Period. Investigation revealed that the agitator in the slurry storage tank was undersized, resulting in coal settling around the perimeter of the tank and in the vicinity of the suction line to the slurry recirculation pumps. Once the solids around the pump suction reached a critical mass, the solids would collapse and plug the suction line. The blade length of the agitator has been optimized to promote thorough mixing without excessive erosion of the tank walls. 


\section{$\underline{\text { Gasification }}$}

Reliable and direct temperature measurement within the first stage gasifier continues to be a challenge, requiring a heavy reliance on indirect observations to control temperature of the gasifier. The gasifier must be hot enough to ensure that molten slag flows from the taphole but not so hot that excessive syngas is consumed, thereby reducing the heating value of the product gas. During the Demonstration Period, five taphole-plugging incidents resulted in significant downtime. These plugging events have occurred as a direct result of learning to process new coal feeds or blends. Investigations after each plugging event have culminated in feed-specific operating guidelines that ensure that proper slag flow from the gasifier is maintained.

Ash deposits formed on the walls of the second stage gasifier and downstream piping systems significantly hampered early plant operation. As the deposit mass increased, either system differential pressure increased or deposits broke free and plugged downstream lines or the HTHRU tubes, forcing the plant off line. Downtime in the first two years from ash-related problems totaled more than 47 days. Study of the ash deposits and formation patterns combined with computational fluid dynamic modeling provided understanding of ash behavior that suggested three solutions: first, the refractory of the second stage reactor was replaced with material that did not form tenacious bonds with the ash. Second, the piping system was replaced to eliminate high velocity impact zones where ash deposits preferentially formed. Third, a screen was installed at the inlet to the boiler to catch any remaining deposits that were too big to pass through the boiler tubes. Since installation of these modifications in 1997, not a single hour of downtime has resulted from ash deposition.

Failures of slurry mixers have interrupted coal operation 8 times resulting in nearly 24 days of downtime. An investigation team has studied the failure mechanisms of slurry mixers, how to properly start-up and shutdown mixers, and how to fabricate mixers for maximum run-time and enhanced mixing performance. Since the initial slurry mixer design, the mixer life has been improved by more than four-fold and the average carbon content in the slag (a measure of carbon conversion and, thus mixer performance) has been reduced more than $50 \%$. 


\section{High Temperature Heat Recovery}

Fouling of the boiler tubes increases the temperature of the downstream filter elements in the particulate removal system. The higher temperature accelerates corrosion and increases the blinding rate of the elements. Operating conditions have been identified that minimize the fouling rate and maintenance personnel have devised cleaning mechanisms that can remove the hard and tenacious deposits during scheduled outages, thus restoring the HTHRU to design heat transfer conditions after outages.

\section{Particulate Removal}

Significant knowledge and experience has been gained in the particulate removal area of the plant because frequent downtime focused plant personnel's efforts on this challenging unit operation from the outset of plant operation. In 1996, the particulate removal system caused more than 100 days of downtime. Through a significant development effort, this system accounted for only 7 days of downtime in 1998 .

During maintenance, over 10,000 pieces of hardware need to be assembled without error to ensure that this system is reliable. Consequently, the quality assurance program over the last four years has grown to encompass filter vendors, hardware suppliers, maintenance contractors, and Operations personnel. The disciplined adherence to this quality assurance program is a major contributor to the improved performance of the system.

Solutions for many of the problems associated with the particulate removal system during the first year of operation were implemented with success, but with each solution a new problem was discovered. After many attempts to improve the filter hardware system, it became evident that many of these design problems were quite complex and as a result, the system was retrofitted with metal filter elements late in 1996. Metal elements immediately improved reliability of the system and improvement efforts were turned to developing a filter with a lower operating and maintenance $(\mathrm{O} \& \mathrm{M})$ cost.

Essentially all applicable commercially available filters for this type service have been tested in the on-site slipstream unit. Off-line cleaning techniques have been developed and improved. 
Filter blinding and corrosion mechanisms remain an intense area of study. Computational fluid dynamic models have been employed to optimize the gas distribution systems within the filter vessels. Hands-on project engineers work directly with metallurgists and vendors to minimize errors and leverage each other's expertise. The ejector system that returns the particulates to the reactor has also been studied and optimized for maximum reliability and lower O\&M cost. Process conditions have been evaluated and modified to minimize element corrosion and provide a balanced flow of syngas to each cluster of elements. The control system has been improved to optimize the operation of the pulse cleaning system. A sophisticated control algorithm and alarm provides operating personnel with advanced warning of potential filter system problems so that immediate corrective actions can be taken before the filters become inoperable. Indeed, Global Energy's filter improvement program is not only wide in its breadth but deep as well.

\section{Low Temperature Heat Recovery}

The low temperature heat recovery system accounted for more than 40 days of downtime in the first year of operation and cost the Project significant dollars to repair or replace failed exchangers and replace spent catalyst. Investigation of the root cause revealed that trace chlorides and metals from the coal remained in the syngas and that these trace components rapidly poisoned the COS hydrolysis catalyst. Investigators also determined that water condensing from the syngas concentrated chlorides in the tubes of the low temperature heat exchangers resulting in chloride stress-corrosion-cracking of the exchanger tubes. Expensive catalyst replacement and frequent repairs to exchanger tubes initiated a fast-track project to install a chloride scrubbing system and replace the failing exchangers with exchangers manufactured from alloys impervious to chloride attack. The scrubber project went from inception to operation in 6 months, and the low temperature heat recovery system has not experienced a single hour of downtime related to chlorides since the scrubber went into operation in October of 1996.

Concurrent with the design and installation of the chloride scrubber, a slipstream unit was installed to test various COS hydrolysis catalysts. The object was to find a catalyst with a probable 5-year life. An appropriate catalyst was found and installed after start-up of the 
chloride scrubber system. Samples taken of the catalyst after two years of operation indicate that the 5-year life is easily obtainable.

\section{Acid Gas Removal}

One problem that beset this system in the first three years of operations was the build-up of heat stable salts in the amine solution. Heat stable salts decrease the removal efficiency of the amine solution, ultimately resulting in higher sulfur emissions from the facility. Although the WRCGRP initially included a process to remove heat stable salts, the initial system was unreliable, costly, and required frequent maintenance. As a result, frequent and costly on-site vacuum distillation or solution replacement was required during the early operation. Numerous process improvements and changes improved reliability of the system and then, in August of 1999, a capacity expansion was installed which satisfied all the remaining system limitations. Since that modification, the system has proved to be very reliable and removes heat stable salts faster than they are formed.

\section{v. Plant Performance}

Despite reliability issues during the first two years of operation, the actual performance of the plant during coal operation compares favorably with design as indicated in Table ES-3.

Table ES-3: Performance Summary

\begin{tabular}{|lcc|}
\hline & $\underline{\text { Design }}$ & $\frac{\text { Actual }}{1,690(1825 \text { max })}$ \\
Syngas Capacity, MMBtu/hr & 1,780 & 192 \\
Steam Turbine Capacity, MW & 192 & 96 \\
Auxiliary Power, MW & 105 & 36 \\
Net Power, MW & 35.4 & 252 \\
Plant Heat Rate, Btu/kWh & 262 & 8,900 \\
Sulfur Removal Efficiency, \% & 9,030 & $>99$ \\
SO 2 Emissions, lbs/MMBtu & $>98$ & $<0.1$ \\
Syngas Heating Value (HHV) & $<0.2$ & $275-280$ \\
Syngas Sulfur Content (ppmv) & 280 & $<100$ \\
\hline
\end{tabular}


The plant has demonstrated a maximum capacity of 1,825 MMBtu/hr but requires only 1,690 MMBtu/hr to satisfy the requirements of the combustion turbine at full load. The noted steam turbine capacity shortage requires a HRSG feedwater heater modification to bring output up to design. With this modification, the overall plant heat rate will drop to 8,650 Btu. The air separation unit was unable to meet the guaranteed power specification, which accounts for the difference in auxiliary power. As indicated previously, the environmental performance of the plant has been superior. Sulfur removal efficiencies all exceed design and total demonstrated sulfur dioxide emissions have been as low as $0.03 \mathrm{lb} / \mathrm{MMBtu}$ of dry coal feed. This quantity is $1 / 40$ that of the $\mathrm{SO}_{2}$ emissions limit of $1.2 \mathrm{lb} / \mathrm{MMBtu}$ with at least a $90 \%$ reduction. Likewise, NOX, CO and particulate emissions average 0.022, 0.044 and $0.012 \mathrm{lb} / \mathrm{MMBtu}$ respectively. Based on these data, the WRCGRP is the cleanest coal-fired power plant in the world.

Operation in 1998 was highlighted by several months where syngas production exceeded one trillion Btu of gas produced. This production milestone was met in March, April, October and November of 1998. As previously indicated, the highest quarterly production of syngas occurred in the third quarter of 1999 in which 2,712,107 MMBtu of gas were produced. Syngas production in September of 1999 was 1,204,573 MMBtu, the highest ever for a month. Furthermore, the combustion turbine operated at maximum capacity for all but 7 hours in September. Key production statistics for the Demonstration Period are presented in Table ES-4.

Table ES-4: Wabash River Coal Gasification Repowering Project Production Statistics

\begin{tabular}{|c|r|r|r|r|r|r|}
\hline Time Period & $\begin{array}{c}\text { On Coal } \\
\text { (Hr) }\end{array}$ & $\begin{array}{c}\text { Coal } \\
\text { Processed } \\
\text { (tons) }\end{array}$ & $\begin{array}{c}\text { On Spec. } \\
\text { Gas } \\
\text { (MMBtu) }\end{array}$ & $\begin{array}{c}\text { Steam } \\
\text { Produced } \\
\text { (Mlb) }\end{array}$ & $\begin{array}{c}\text { Power } \\
\text { Produced } \\
\text { (MWh) }\end{array}$ & $\begin{array}{c}\text { Sulfur } \\
\text { Produced } \\
\text { (tons) }\end{array}$ \\
\hline \hline Start-up ‘95 & 505 & $41,000^{*}$ & 230,784 & 171,613 & $71,000 *$ & 559 \\
1996 & 1,902 & 184,382 & $2,769,685$ & 820,624 & 449,919 & 3,299 \\
1997 & 3,885 & 392,822 & $6,232,545$ & $1,720,229$ & $1,086,877$ & 8,521 \\
1998 & 5,279 & 561,495 & $8,844,902$ & $2,190,393$ & $1,513,629$ & 12,452 \\
$1999 \diamond$ & 3,496 & 369,862 & $5,813,151$ & $1,480,908$ & $1,003,853$ & 8,557 \\
\hline \hline Overall & 15,067 & $1,549,561$ & $23,891,067$ & $6,383,767$ & $4,125,278$ & 33,388 \\
\hline
\end{tabular}

* Estimates. $\diamond N o t e:$ The combustion turbine was unavailable from 3/14/99 through 6/22/99. 
Early identification of availability-limiting process problems led to aggressive implementation of improvement projects which resulted in $224 \%$ more syngas produced during the second year than in year one. The syngas produced during the third year exceeded the second year's production by an additional $42 \%$. Assuming the availability factor during the combustion turbine outage was the same as in 1998, the facility production in 1999 would have favorably matched 1998's output. Figure ES-3 depicts this continuous improvement trend over the last four years as measured by total syngas production.

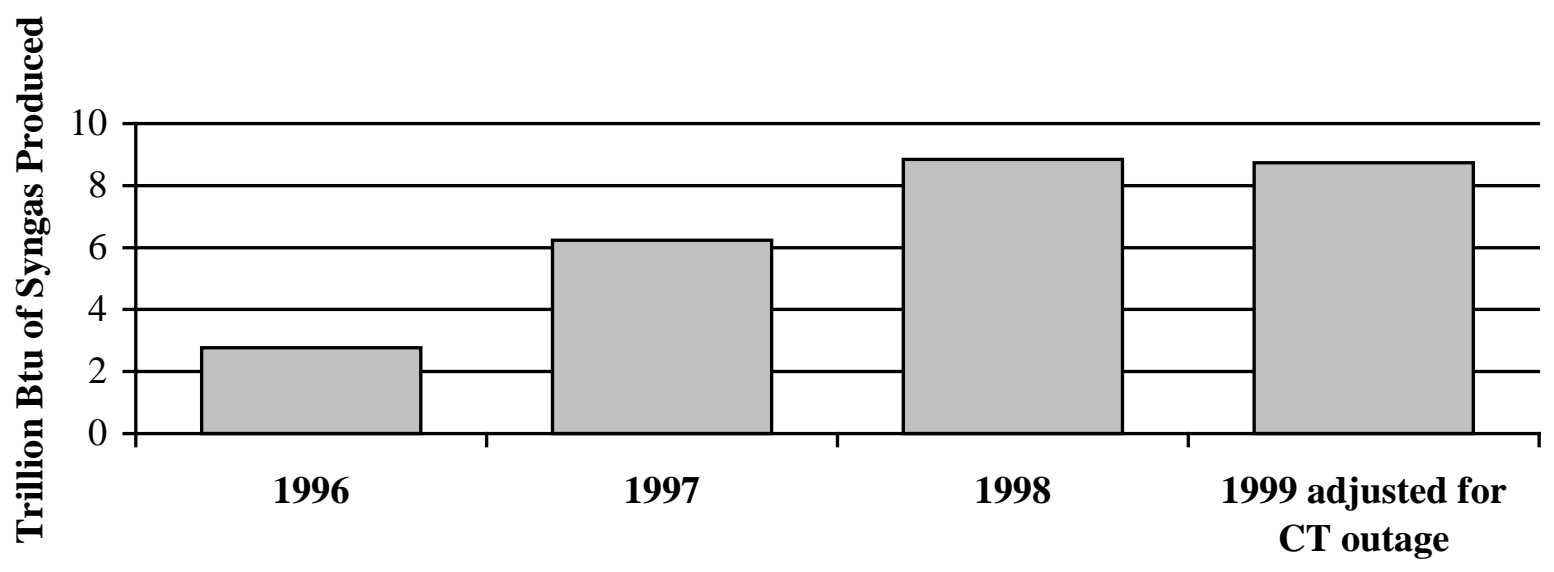

Figure ES-3: Syngas Production by Year

\section{vi. Economics and Commercialization}

The initial budgeted cost for the construction of the Wabash River facility was \$248 million for the syngas facility (Destec scope) and approximately $\$ 122$ million for the new power block and modifications to the existing Wabash River Generating Station (PSI Energy scope). The installed cost of the overall IGCC facility including start-up was about \$1590/kW (1994\$). Allowing for new equipment that would have been required if this had been a greenfield project instead of repowering, the installed cost figure on this demonstration project was $\$ 1700 / \mathrm{kW}$ (1994\$).

As shown in Table ES-5, nearly all cost areas within the syngas facility were completed under budget, with the exception of the construction cost and the pre-operations management cost of the syngas facility. Overruns of the power block budget were in the same areas. The construction cost was nearly double the budgeted amount, due to four factors, many beyond the 
control of the Project participants. Weather delays, equipment shipping problems, mechanical contracting and a prolonged start-up period combined to escalate the construction cost. Despite the construction delays, start-up of the facility occurred on schedule and only three years and four months from the DOE award date, significantly shorter than any other IGCC project. Even with the cost overruns, the Project was by far the least expensive of the first generation coal gasification combined cycle plants built in the 1992-2000 timeframe. The other coal IGCC's, two in the U.S. and two in Europe, all first generation at this scale, have been reported to have cost $\$ 2000 / \mathrm{kW}$ and over.

Table ES-5: Wabash River Coal Gasification Repowering Project Costs

\begin{tabular}{|ccc|}
\hline \multicolumn{1}{c}{ Cost Area } & $\underline{\text { Budget }}$ & $\underline{\text { Actual }}$ \\
SYNGAS FACILITY & & \\
Engineering \& Project Management & 29.6 & 27.3 \\
Equipment Procurement & 98.3 & 84.5 \\
Construction & 55.5 & 106.1 \\
Construction Management & 7.9 & 8.1 \\
ASU & 36.9 & 32.8 \\
Pre-operations Management & 19.8 & 21.7 \\
POWER BLOCK & 121.8 & 136.2 \\
\hline Total \$MM, 1994 average & $\mathbf{3 6 9 . 8}$ & $\mathbf{4 1 6 . 6}$ \\
\hline
\end{tabular}

Future IGCC facilities based on the E-Gas ${ }^{\mathrm{TM}}$ technology will benefit from the lessons learned at Wabash River. A realistic number for a current generation plant is $\$ 1,250-\$ 1,300 / \mathrm{kW}(2000 \$)$ with a heat rate of $8,250 \mathrm{Btu} / \mathrm{kW}(\mathrm{HHV})$ for a greenfield facility. A new, stand-alone greenfield IGCC to produce power, but no other products, and utilizing petroleum coke as fuel has an approximate installed cost of $\$ 1100$ - $\$ 1200 / \mathrm{kW}(2000 \$)$, based on reduced equipment requirements with petroleum coke feeds.

The IGCC model developed by Nexant LLC for the DOE was used to evaluate the rate of return for projects financed IGCC's at today's fuel and power prices. As evidenced in Table ES-6, the strongest driver of overall plant economics is fuel cost. The economic analyses of project returns 
with coal as a feedstock reach a credible economic condition of $12 \%$ IRR at power pricing of $\$ 38$ - \$49/MWh, depending on how capital and O\&M costs are set and on the availability that is assumed. Plant design and operation based on petroleum coke is economically stronger, due not only to the lower fuel cost, but also the incrementally improved capital and operating costs for a plant designed for petroleum coke initially.

Table ES-6: Results of Economic Analysis for Wabash River Style IGCC

\begin{tabular}{|c|c|c|}
\hline & Coal & Petroleum Coke \\
\hline Plant Net Generation, MW & 270 & 271 \\
\hline Plant Heat Rate, Btu/kWh (HHV) & 8910 & 8790 \\
\hline Plant Capital Cost, $\$ / \mathrm{kW}$ & 1275 & 1150 \\
\hline Plant Operating Cost, $\%$ of capital & 5.2 & 4.5 \\
\hline Annual Availability & $75 \%$ & $80 \%$ \\
\hline $\mathrm{NPV}_{10}$, Millions $\$$ & $(128)$ & 45 \\
\hline Internal Rate of Return, at $\$ 35 / \mathrm{MWh}$ power & NA & $14 \%$ \\
\hline Sensitivity Analysis Cases, $12 \%$ IRR & \multicolumn{2}{|c|}{$\underline{\text { Required \$/MWh in first year }}$} \\
\hline $10 \%$ reduction in capital & 46 & 30 \\
\hline $10 \%$ reduction in O\&M & 49 & 32 \\
\hline $10 \%$ increase in availability & 42 & 27 \\
\hline $\begin{array}{l}10 \% \text { reduction in capital, O\&M } \\
10 \% \text { increase in availability }\end{array}$ & 38 & 24 \\
\hline
\end{tabular}

O\&M costs have been relatively high for IGCC plants compared to conventional coal-fired plants. Using 1999 budgeted costs as a basis, the non-fuel O\&M cost for the syngas facility was $7.1 \%$ of installed capital based on a $75 \%$ operating rate. Since Global Energy manages the Wabash River facility as a stand-alone plant, all the infrastructure and support base for labor and maintenance must be provided at the site. This includes contract administration, accounting, inventory, human resources, engineering, environmental and safety, laboratory staff and a base maintenance and operating staff. Since the first year of operation, the syngas facility has reduced 
O\&M spending by $30 \%$ and further areas for reduction have been identified. Projected O\&M for a mature Wabash River syngas facility is $5.2 \%$ of installed capital. O\&M savings for future plants can be realized by sharing infrastructure cost within, for example, a large petrochemical facility.

Market penetration for gasification technologies is rapidly increasing. Gasification-produced megawatts will increase ten-fold from 1992 to 2002, based on plants already in operation or construction. The current opportunities are not primarily in power generation, however. The opportunities are in co-production facilities, especially those able to use opportunity fuels. Exploring low-cost feedstocks and high-value products stretches both ends of the economic equation. These facilities seem to be primarily in the refining sector, and it is expected that most of the next generation of solid fuel gasification plants will be inside the fences of refineries, as opposed to the entire first generation of greenfield and repowering applications for power generation facilities.

\section{vii. Conclusions}

Despite firm technical and operating experience gained at Dow's gasification plant in Louisiana (LGTI), several operating differences set the Wabash River plant apart from its predecessor. In addition, Wabash River incorporated several technical advances never attempted at the LGTI facility.

During the Demonstration Period the operating differences have been resolved and the technical advances have proven successful. Operation of the E-Gas ${ }^{\mathrm{TM}}$ technology on several different high sulfur bituminous coals and blends has been achieved with the lowest environmental emissions of any coal-fired power plant. Even though it had never been previously attempted, the Project repowered a 40 year old utility plant as an IGCC with a high level of integration between the gasification heat recovery unit, the combustion turbine HRSG and the reheat steam turbine. The facility initiated use of one of the first ten General Electric "F" class machines and the first such machine operating on syngas. The Project considerably advanced the technology of particulate filtration and the Wabash River system represents one of the few systems of this size and with much higher particulate loading than other operating systems. Ash deposition, an early downtime cause, has been completely eliminated. Previous gasification operating expertise has 
been magnified and a new generation of engineers and operators has been developed to operate the plant safely and reliably, with ever-increasing availability.

Significant challenges were met and overcome in areas outside of the primary demonstration objectives, including technical, commercial and organizational challenges. The Project also demonstrated success in some areas that were not planned at the outset - operation on petroleum coke, for instance, and operation on a blend and combination of coals that sometimes changes daily. The Project operates today as part of the utility power generation system, competing with Cinergy's alternative market options for on-peak and off-peak power. Competitive market-based pricing allows the syngas facility to run as base load in Cinergy's system

All of these advances demonstrated at the Wabash River Coal Gasification Repowering Project are leading to more confidence in the commercialization of the technology in other settings besides coal and power. These advances in the technology will be leveraged into the next generation of power and chemical production megaplexes as Global Energy participates in the DOE's "Vision 21" program and other viable commercial projects. 


\subsection{INTRODUCTION}

The Wabash River Coal Gasification Repowering Project (WRCGRP or "Project") is currently the largest single-train gasification facility in the United States, as well as the cleanest coal fired plant of any kind in the world. Its design allows for lower emissions than other high sulfur coal fired power plants and a resultant heat rate improvement of approximately $20 \%$ over the previous plant configuration. The Wabash River gasification facility was developed, designed, constructed, started-up and is currently operated by what are now Wabash River Energy Ltd. (WREL) personnel. Wabash River Energy Ltd. is a wholly owned subsidiary of Global Energy Inc. The Project successfully operated through a Demonstration Period from November of 1995 through December of 1999.

The original Project participants, Destec Energy, Inc. (which was later acquired by Dynegy Power Corporation (Dynegy) of Houston, Texas, and PSI Energy, Inc. (PSI), of Plainfield, Indiana, formed a Joint Venture (JV) to participate in the United States Department of Energy's (DOE) Clean Coal Technology (CCT) program to demonstrate coal gasification repowering of an existing generating unit impacted by the Clean Air Act Amendments (CAAA). The participants jointly developed, separately designed, constructed, own, and are now operating an integrated coal gasification combined-cycle power plant, using Destec's coal gasification technology (now known as E-Gas ${ }^{\mathrm{TM}}$ Technology) to repower the oldest of the six units at PSI's Wabash River Generating Station in West Terre Haute, Indiana. In 1999, Global Energy acquired the Project and the gasification technology from Dynegy. The gasification process is integrated with a new General Electric 7FA combustion turbine generator and a heat recovery steam generator in the repowering of a 1950's-vintage Westinghouse steam turbine generator using some pre-existing coal handling facilities, interconnections and other auxiliaries. The Project processes locally-mined Indiana high sulfur coal to produce 262 net megawatts of electricity.

The Project has demonstrated the ability to run at full load capacity while meeting the environmental requirements for sulfur and $\mathrm{NO}_{\mathrm{x}}$ emissions. Cinergy, PSI's parent company, dispatches power from the Project, with a demonstrated heat rate of under 9,000 Btu/kWh 
(HHV), second only to their hydroelectric facilities on the basis of environmental emissions and efficiency.

In late 1998, PSI Energy reached agreement to purchase the gasification services contract from Dynegy subject to regulatory approval. Regulatory approval was granted in September of 1999 and the sale was completed in October of 1999

This agreement allowed PSI to purchase the remaining term of the 25-year contract, which had become "out-of-market" in comparison to today's alternate sources for power. WREL explored alternatives for continued operation of Wabash River in a more "market-based" mode. In June of 2000, Global Energy Inc. announced that WREL had entered into a competitive market contract with PSI for the sale of syngas. Syngas, sold under this market-based three year agreement, is priced to allow the power produced from the syngas to compare favorably yearround to PSI's alternate sources for on-peak and off-peak power.

This recent development, coupled with efforts to improve the commercial viability of the Wabash River Coal Gasification Repowering Project, has sharpened the focus to make the technology competitive in today's market. Building on the lessons learned and the many successes to date, every effort is being made to look past just syngas-to-power and to pursue value-added uses for syngas produced from coal or other feeds such as is envisioned through forward-thinking concepts like the Department of Energy's "Vision 21" initiative. In the face of the current market for gasification, WREL and Global Energy will pursue the application of this technology forward as an economically viable tool for converting carbon feedstocks to higher value products.

Global Energy is an Independent Power Producer (IPP) with gasification technology experience. A founding member of the Gasification Technologies Council (GTC) in Washington D.C., Global Energy is one of the most experienced and innovative companies in the commercial gasification business. Global Energy will market the E-Gas ${ }^{\mathrm{TM}}$ technology through its subsidiary, Gasification Engineering Corp., a company formed by Global Energy after acquiring all the gasification assets of Dynegy, Inc. in late 1999. 
Gasification Engineering Corp. and WREL personnel, have over 1000 years of combined industrial experience. Nearly one third of this experience, about 300 years, is directly related to the design, implementation and operation of gasification plants. This expertise is a complementary addition to Global Energy's existing gasification experience base, which also totals approximately 300 years of combined experience.

This group has a wide-ranging theater of operations, from the daily operation of the Wabash River facility and gasification project development and construction to research and development in several gasification-related fields. Although the group has a vast network of contacts in related industries for ceramic, refractory, metallurgy, instrumentation and other technologies with applications in gasification, most expertise exists in-house in the areas of operations, process modeling, process design, gasification component design (such as slurry mixers), char filtration, and mechanical equipment applications.

\subsection{Objectives}

For CCT Round IV, Public Law 101-121 provided \$600 million to conduct cost-shared CCT projects to demonstrate technologies that are capable of replacing, retrofitting or repowering existing facilities. To that end, a Program Opportunity Notice (PON) was issued by the Department of Energy in January 1991, soliciting proposals to demonstrate innovative energyefficient technologies that were capable of being commercialized in the 1990's. These technologies were to be capable of: (1) achieving significant reductions in the emissions of sulfur dioxide and/or nitrogen oxides from existing facilities to minimize environmental impacts such as transboundary and interstate pollution and/or; (2) providing for future energy needs in an environmentally acceptable manner.

In response to the PON, the DOE received 33 proposals in May 1991. After evaluation, nine projects were selected for award. These projects involved both advanced engineering and pollution control technologies that can be "retrofitted" to existing facilities and "repowering" technologies that not only reduce air pollution but also increase generating plant capacity and extend the operating life of the facility. 
In September 1991, the United States Department of Energy selected the Wabash River Coal Gasification Repowering Project, as one of nine projects, for funding under Round IV of the DOE's Clean Coal Technology Demonstration Program. This was followed by nine months of negotiations and a congressional review period. The DOE executed a Cooperative Agreement on July 28, 1992. The Project's sponsors, PSI Energy, Inc., and Global Energy, are demonstrating, in a fully commercial setting, coal gasification repowering of an existing generating unit affected by the Clean Air Act Amendments (CAAA). The Project also demonstrates important advances in the coal gasification process for high sulfur bituminous coal. After receiving the necessary state, local and federal approvals, this Project began construction in the third quarter of 1993 and started commercial operations in the third quarter of 1995. This facility, originally scheduled for a three-year Demonstration Period and 22-year Operating Period (25 years total), extended the demonstration to span four years and successfully completed this demonstration in December of 1999.

The demonstration confirmed the successful design, construction, and operation of a nominal 2500 ton-per-day, 262 net MWe integrated gasification combined cycle (IGCC) facility using the advanced two-stage, oxygen blown Destec (now E-Gas ${ }^{\mathrm{TM}}$ ) technology. The DOE's share of this Project cost was $\$ 219$ million. 


\subsection{General}

\section{The IGCC system consists of:}

- The E-Gas ${ }^{\mathrm{TM}}$ oxygen-blown, entrained flow, two stage coal gasifier, which is capable of utilizing high sulfur bituminous coal;

- An air separation unit;

- A gas conditioning system for removing sulfur compounds and particulates;

- Systems or mechanical devices for improved coal feed and all necessary coal handling equipment;

- A combined cycle power generation system wherein the gasified coal syngas is combusted in a combustion turbine generator;

- A heat recovery steam generator.

The result of repowering is an IGCC power plant with low environmental emissions $\left(\mathrm{SO}_{2}\right.$ of less than $0.25 \mathrm{lbs} / \mathrm{MMBtu}$ and $\mathrm{NO}_{\mathrm{x}}$ of less than $0.1 \mathrm{lb} / \mathrm{MMBtu}$ ) and high net plant efficiency. The repowering increases unit output, providing a total IGCC capacity of nominal 262 net MWe. The Project demonstrates important technological advancements in processing high sulfur bituminous coal.

In addition to the original Joint Venture members, PSI and Destec, the Phase II project team included Sargent \& Lundy, who provided engineering services to PSI, and Dow Engineering, who provided engineering services to Destec.

The potential market for repowering with the demonstrated technology is large and includes many existing utility boilers currently fueled by coal, oil or natural gas. In addition to greater, more cost-effective reduction of $\mathrm{SO}_{2}$ and $\mathrm{NO}_{\mathrm{x}}$ emissions attainable by using the gasification technology, net plant heat rate is improved. This improvement is a direct result of the combined cycle feature of the technology, which integrates a combustion topping cycle with a steam bottoming cycle. This technology is suitable for repowering applications and can be applied to any existing steam cycle located at plants with enough land area to accommodate coal handling and storage and the gasification and power islands. 
One of the Project objectives is to advance the commercialization of coal gasification technology. The electric utility industry has traditionally been reluctant to accept coal gasification technology and other new technologies as demonstrated in the U.S. and abroad because the industry has no mechanism for differentiating risk/return aspects of new technologies. Utility investments in new technologies may be disallowed from rate-base inclusion if the technologies do not meet performance expectations. Additionally, the rates of return on these are regulated at the same level as established lower risk technologies. Therefore, minimal incentives exist for a utility to invest in, or develop, new technologies. Accordingly, the supplier has traditionally assumed most of the risk in new technologies.

The factors described above are constraints to the development of, and demand for, clean coal technologies. Constraints to development of new technologies also exist on the supply side. Developers of new technologies typically self-finance or obtain financing for projects through lenders or other equity investors. Lenders will generally not assume performance and operational risks associated with new technology. The majority of funds available from lending agencies for energy-producing projects are for technologies with demonstrated histories in reliability, maintenance costs and environmental performance. Equity investors who invest in new energy technologies also seek higher returns to accept risk and often require the developer of the new technology to take performance and operational risks.

Consequently, the overall scenario results in minimum incentives for a commercial size development of new technologies. Yet without the commercial size test facilities, the majority of the risk issues remain unresolved. Addressing these risk issues through utility scale demonstration projects is one of the primary objectives of DOE's Clean Coal Technology Program.

The WRCGRP was developed in order to demonstrate the E-Gas ${ }^{\mathrm{TM}}$ Coal Gasification Technology in an environment, and at such a scale, as to prove the commercial viability of the technology. Those parties affected by the success of this Project include the coal industry, electric utilities, ratepayers and regulators. 
Also, the financial community, which provides the funds for commercialization, is keenly interested in the success of this Project. Without a demonstration satisfying all of these interests, the technology will make little advancement. Factors of relevance to further commercialization are:

- The Project scale (262 net MWe) is compatible with all current, commercially available advanced gas turbines and thus completely resolves the issue of scale-up risks.

- The operational term of the Project is expected to be approximately 25 years including the DOE Demonstration Period of the first 3 years (actually 4 years). This should alleviate any concerns that the demonstration does not define a fully commercial plant from a cost and operational viewpoint.

- The Project dispatches on a utility system and is called upon to operate in a manner similar to other utility generating units.

- The Project operates under a service agreement that defines guarantees of environmental performance, capacity, availability, coal to gas conversion efficiency and maximum auxiliary power consumption. This agreement serves as a model for future commercialization of the E-Gas ${ }^{\mathrm{TM}}$ Coal Gasification Technology and defines the fully commercial nature of the Project.

- The Project is designed to accommodate most coals available in Indiana and typical of those available to midwestern utilities, thereby enabling utilities to judge fuel flexibility. The Project also enables testing of varying coal types and other feedstocks in support of future commercialization of the E-Gas ${ }^{\mathrm{TM}}$ Coal Gasification Technology. 


\subsection{Project Phase Description}

The Project Cooperative Agreement (CA) was signed on July 28, 1992, with an effective date of August 1, 1992. Under the terms of the CA, the Project activities were divided into three phases:

- Phase I Engineering and Procurement

- Phase II Construction and Start-up

- Phase III Demonstration

\subsubsection{Phase I Activities - Engineering and Procurement}

Under the provisions of the CA, the work activity in Phase I (engineering and procurement) focused on detailed engineering of both the syngas and power plant elements of the Project which included design drawings, construction specifications and bid packages, solicitation documents for major hardware and the procurement. Site work was undertaken during this time period to meet the overall construction schedule requirements. The Project team included all necessary management, administrative and technical support.

The activities completed during this period were those necessary to provide the design basis for construction of the plant, including capital cost estimates sufficient for financing, and all necessary permits for construction and subsequent operation of the facility.

The work during Phase I can be broken down into the following main areas:

- Project Definition Activities

- Plant Design

- Permitting and Environmental Activities

Each of these activities is briefly described below. All Phase I activities were complete by 1993. 


\section{Project Definition Activities}

This work included the conceptual engineering to establish the Project size, installation configuration, operating rates and parameters. Definition of required support services, all necessary permits, fuel supply, and waste disposal arrangements were also developed as part of the Project Definitions Activities. From this information, the cost parameters and the Project economics were established (including capital costs, project development costs and operation and maintenance costs). Additionally, all project agreements necessary for construction of the plant were concluded. These include the CA and the Gasification Services Agreement (GSA).

\section{Plant Design}

This activity included preparation of design and major equipment specifications along with plant piping and instrumentation diagrams (P\&ID's), process control releases, process descriptions and performance criteria. These were prepared in order to obtain firm equipment specifications for major plant components, which established the basis for detailed engineering and design.

\section{Permitting and Environmental Activities}

During Phase I, applications were made and received for the permits and environmental activities necessary for the construction and subsequent operation of the Project.

\subsubsection{Phase II Activities - Construction}

Construction activities occurred in Phase II and included the necessary construction planning and integration with the engineering and procurement effort. Planning the construction of the Project began early in Phase I. Separate on-site construction staffs for both Destec and PSI were provided to focus on their respective work for each element of the Project. Construction personnel coordinated the site geo-technical surveys, equipment delivery, storage, and lay down space requirements. The construction activities included scheduling, equipment delivery, erection, contractors, security and control.

The detail design phase of the Project included engineering, drawings, equipment lists, plant layouts, detail equipment specifications, construction specification, bid packages and all activities necessary for construction, installation, and start-up of the Project. 
Performance and progress during this period were monitored in accordance with previously established baseline plans.

\subsubsection{Phase III Activities - Demonstration Period}

Phase III consisted of a three-year (extended to four years) Demonstration Period. The operation effort for the Project began with the development of the operating plan including integration with the early engineering and design work of the Project. Plant operation input to engineering was vital to assure optimum considerations for plant operations and maintenance and to assure high reliability of the facilities. The operating effort continued with the selection and training of operating staff, development of the operating manuals, coordination of start-up with construction, planning and execution of plant commissioning, conduct and documentation of the plant acceptance test, and continued operation and maintenance of the facility throughout the Demonstration Period.

Phase III activities were intended to establish the operational aspects of the Project in order to prove the design, operability and longevity of the plant in a fully commercial utility environment. 


\subsection{Project Organization}

The WRCGRP Joint Venture (JV) established a Project Office for the execution of the Project. The Project Office was originally located at Dynegy's corporate offices in Houston, Texas. All management, reporting and project reviews for the Project are carried out as required by the Cooperative Agreement. The JV partners, through a JV Agreement, are responsible for the performance of all engineering, design, construction, operation, financial, legal, public affairs and other administrative and management functions required to execute the Project. A JV Manager was designated as responsible for the management of the Project. The JV Manager was the official point of interface between the JV and the DOE for the execution of the Cost Sharing Cooperative Agreement. The JV Manager was responsible for assuring that the Project is conducted in accordance with the cost, schedule, and technical baseline established in the Project Management Plan (PMP) and subsequent updates. 


\subsection{Project Location and Original Equipment Description}

The site of the Project is PSI's Wabash River Generating Station, located on approximately 437 acres northwest of Terre Haute, Indiana in Vigo County. Indianapolis, the state capital, is located approximately 65 miles to the east-northeast of Terre Haute. The Illinois border is located approximately 7 miles to the west of Terre Haute. A general location map depicting the location of the Project, in reference to the existing Wabash River Generating Station Station is shown in Figure 1.5A. The region surrounding the property may be described as wooded with gently rolling terrain to the north, west and south and river valley (Wabash River) to the east. The Project is located within Vigo County, but outside the municipal limits of Terre Haute, Indiana.

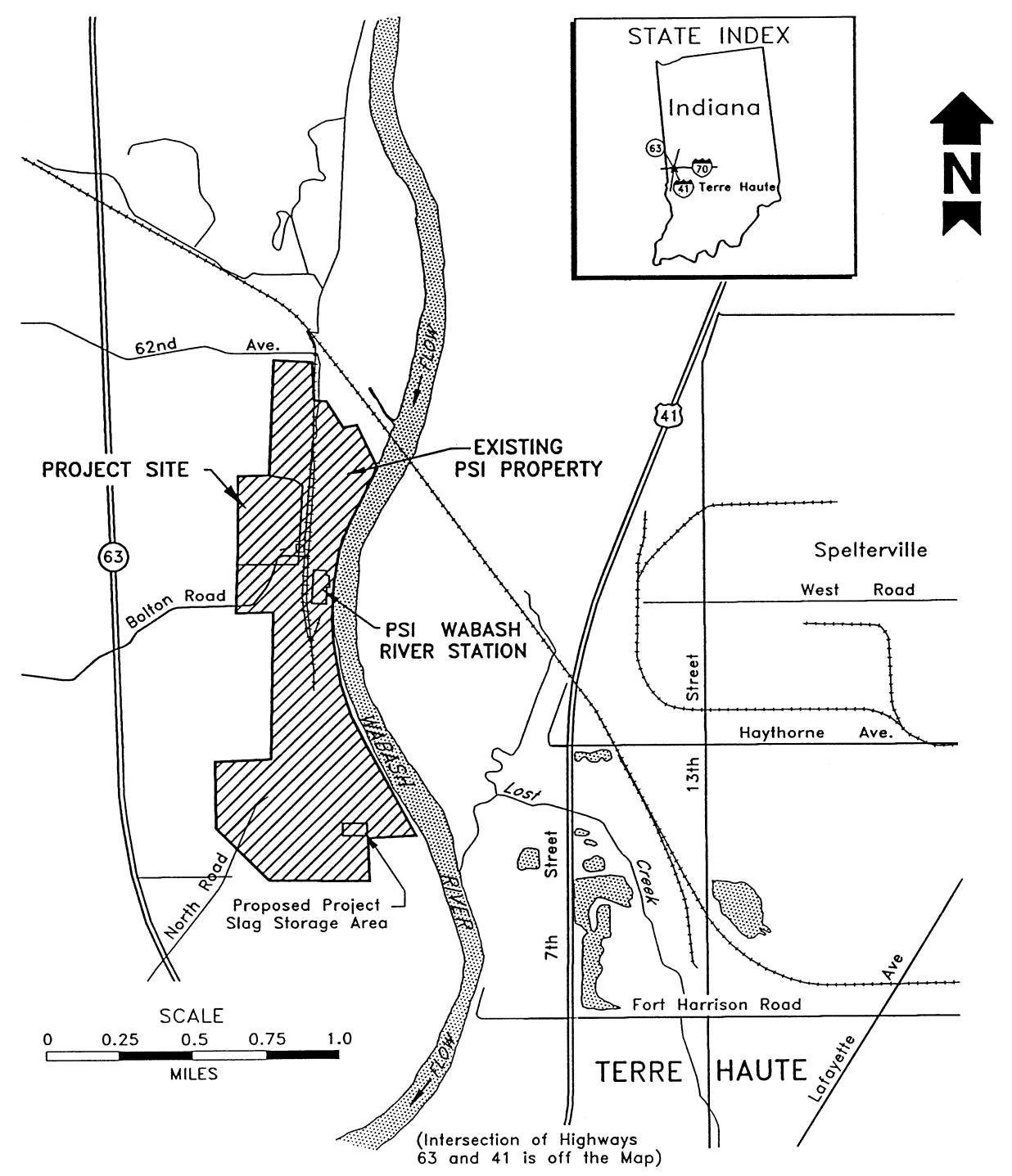

Figure 1.5A: Project Site General Location Map

Wabash River Coal Gasification Repowering Project Final Technical Report 
PSI's existing equipment at the Wabash River Station consisted of six pulverized-coal generating units. Units 1 through 4 boilers were manufactured by Foster-Wheeler, the Unit 5 boiler was manufactured by Riley Stoker, and the Unit 6 boiler was manufactured by Combustion Engineering. At the time of initial Project development each unit featured a Research-Cottrell electrostatic precipitator, shared a common 450-foot tall exhaust stack, and was fueled by pulverized bituminous coal, while fuel oil was used for start-up and flame stabilization. Natural gas was not used at the Station, although a main transmission line of Indiana Gas Company was located approximately 1 mile west of the powerhouse.

The Unit 1 steam turbine, repowered by implementation of the Project, was permitted at 99 MW under the Station's existing air quality permit (limited to $90 \mathrm{MW}$ during routine operations). This unit was put into service in 1953. An electrostatic precipitator (two units in parallel with a 98.5 percent collection efficiency) was used for the control of particulates.

The Wabash River was and is the sole water source for all consumptive and nonconsumptive water systems at the Station. 


\subsection{Permitting and Environmental Activities}

During Phase I, applications were made and received for the permits and environmental activities necessary for the construction and subsequent operation of the Project. The major permits for the Project included:

- Indiana Utility Regulatory Commission - The state authority reviewed the Project (under a petition from PSI for a Certificate of Necessity) to ensure the Project will be beneficial to the state and PSI ratepayers. The technical and commercial terms of the Project were reviewed in this process.

- Air Permit - This permit details the allowable emission levels for air pollutants from the Project. It was issued under standards established by the Indiana Department of Environmental Management (IDEM) and the United States Environmental Protection Agency (EPA) Region V and administered by Vigo County Air Pollution Control. This permit also included within it the authority to commence construction.

- NPDES Permit - This National Pollutant Discharge Elimination System permit details and controls the quality of waste water discharge from the Project. It was reviewed and issued by the Indiana Department of Environmental Management. For this Project, this constituted a modification of the existing permit for PSI's Wabash River Generating Station.

- NEPA Review - The National Environmental Policy Act review was carried out by the DOE based on Project information provided by the participants. The scope of this review was comprehensive in addressing all environmental issues associated with potential Project impacts on air, water, terrestrial, quality, health and safety, and socioeconomic impacts. 
Miscellaneous permits and approvals necessary for construction and subsequent operation of the Project included the following.

- FAA Stack Height/Location Approval

Controlling Authority: Federal Aviation Administration

- Industrial Waste Generator

Controlling Authority: Indiana Department of Environmental Management

- Solid Waste

Controlling Authority: Indiana Department of Environmental Management

- FCC Radio License

Controlling Authority: Federal Communications Commission

- Spill Prevention Plan

- Waste Water Pollution Control Device Permit

Controlling Authority: Indiana Department of Environmental Management 


\subsection{TECHNOLOGY DESCRIPTION}

The E-Gas ${ }^{\mathrm{TM}}$ (Destec) Gasification Process features an oxygen-blown, continuous-slagging, twostage, entrained-flow gasifier (Figure 2.0A). Coal or coke is milled with water in a rod mill to form a slurry. The slurry is combined with oxygen in mixer nozzles and injected into the first stage of the gasifier, which operates at $2600^{\circ} \mathrm{F}$ and $400 \mathrm{psig}$. A turnkey 2,060-ton/day lowpressure cryogenic distillation facility that WREL owns and operates supplies 95\% pure oxygen.

\section{WRCGRP E-Gas ${ }^{\mathrm{TM}}$ Gasification Process}

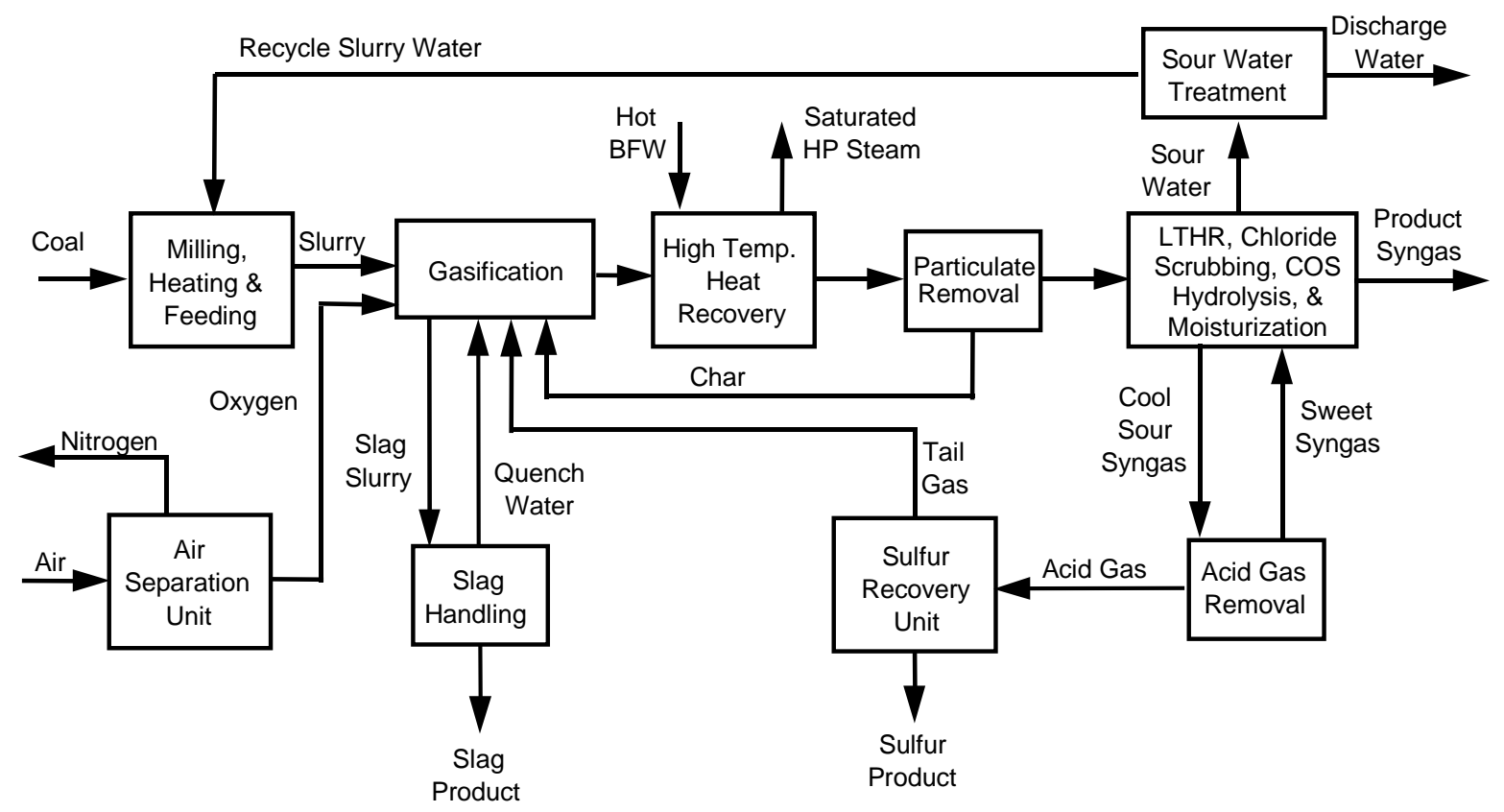

Figure 2.0A: Gasification Process Simplified Block Flow Diagram

In the first stage, slurry undergoes a partial oxidation reaction at temperatures high enough to bring the coal's ash above its melting point. The fluid ash falls through a taphole at the bottom of the first stage into a water quench, forming an inert vitreous slag. The syngas then flows to the second stage, where additional coal slurry is injected. This coal is pyrolyzed in an endothermic reaction with the hot syngas to enhance syngas heating value and to improve overall efficiency. 
The syngas then flows to the high-temperature heat-recovery unit (HTHRU), essentially a firetube steam generator, to produce high-pressure saturated steam. After cooling in the HTHRU, particulates in the syngas are removed in a hot/dry filter and recycled to the gasifier where the carbon in the char is converted to syngas. The syngas is further cooled in a series of heat exchangers, water-scrubbed to remove chlorides, and passed through a catalyst that hydrolyzes carbonyl sulfide to hydrogen sulfide. Hydrogen sulfide is removed using methyldiethanolamine (MDEA) absorber/stripper columns. The "sweet" syngas is then moisturized, preheated and piped over to the power block, where it is burned in a General Electric 7FA high-temperature combustion turbine/generator to produce $192 \mathrm{MW}$ of electricity.

The HRSG configuration was specifically optimized to utilize both the gas-turbine exhaust energy and the heat energy made available in the gasification process. Superheated highpressure steam, when fed to the repowered Westinghouse reheat steam turbine, produces 104 MW, by design, of additional electricity. When combined with the combustion turbine generator's $192 \mathrm{MW}$ and the system's auxiliary load of approximately $34 \mathrm{MW}$, a net of $262 \mathrm{MW}$ is produced to feed the Cinergy grid. An overall thermal efficiency of less than 9,000 Btu/kWh (HHV), which is lower than the design, has been demonstrated. Please note that a lower heat rate indicates greater thermal efficiency.

The gasification facility also produces two commercial by-products. Sulfur is removed as 99.999\% pure elemental sulfur and marketed to sulfur users. Slag is being marketed as an aggregate in asphalt roads, as structural fill in various types of construction applications, as roofing granules, and as blasting grit. 


\subsection{DETAILED PROCESS DESCRIPTION}

The E-Gas ${ }^{\mathrm{TM}}$ gasification process is based on slurry (or liquid) feed utilizing a two-stage gasifier with total solids recycle and coupled with a unique high temperature heat recovery unit. Gasification is accomplished by partial combustion of the feedstock with air or high purity oxygen in the first stage creating hot synthetic gas with the mineral content forming a molten slag. The slag is continuously removed from the gasifier via E-Gas ${ }^{\mathrm{TM}}$ 's proprietary low-profile slag removal system. This avoids expensive, structure-elevating and maintenance-prone lock hoppers. In the second stage, the heat content of the hot syngas from the first stage is used to vaporize and gasify additional coal slurry introduced in the second stage. The syngas exiting the gasifier is cooled and cleaned, and is then moisturized prior to use in an advanced gas turbine for the generation of power (or conditioned further for the production of chemicals such as hydrogen, methanol, urea, Fischer-Tropsch products, etc.). A solid/water slurry approach minimizes feed preparation and storage cost and allows for safe and accurate control of fuel to the gasifier. The two-stage gasifier, coupled with E-Gas's ${ }^{\mathrm{TM}}$ unique application of a firetube syngas cooler design, minimizes the size and temperature level requirements for the high temperature heat recovery system. This is cost effective and yields high conversion efficiencies both for thermal and chemical energy. Raw syngas exiting the gasifier contains entrained solids that are removed and recycled to the first stage of the gasifier. Recycle of these solids also enhances efficiency and consolidates the solid effluent from the process in one stream, the slag leaving the gasifier.

The E-Gas ${ }^{\mathrm{TM}}$ two-stage entrained flow gasification process offers an environmentally superior coal-based power generation source with emissions a fraction of the 1990 Clean Air Act Amendments limits. The process, as demonstrated at Wabash River, can convert coal, petroleum coke, and other solid as well as liquid fuels or wastes into a clean syngas which is used as a fuel gas for power generation in the GE 7FA advanced combustion turbine. The conversion of coal to electric power at Wabash River yields a 38 to $45 \%$ overall efficiency. With these high efficiencies, the emission of carbon dioxide $\left(\mathrm{CO}_{2}\right)$ is significantly lower than for conventional coal-based power generation technology. 
Detailed descriptions are given below for the subsystems based on the E-Gas ${ }^{\mathrm{TM}}$ technology. The subsystems included are oxygen supply, slurry preparation, gasification, slag handling, syngas cooling, particulate removal, syngas scrubbing, low temperature heat recovery, acid gas removal, sulfur recovery, tank vent collection, sour water treatment and combined cycle power block.

\subsection{Air Separation Unit}

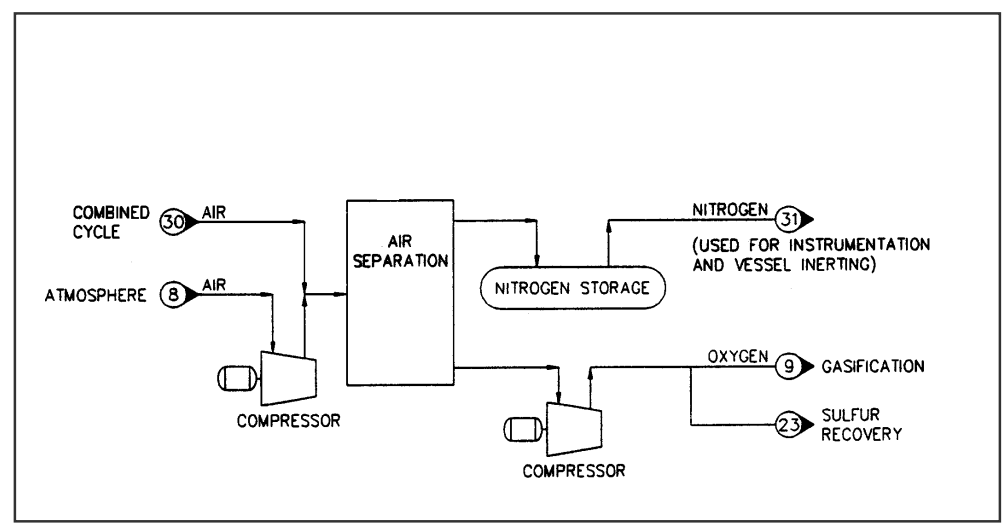

The Air Separation Unit (ASU), or oxygen plant, contains an air compression system, an air separation cold box, an oxygen compression system and a nitrogen compression system.

Atmospheric air compressed by a multi-stage centrifugal compressor is cooled to approximately $40^{\circ} \mathrm{F}\left(5^{\circ} \mathrm{C}\right)$ and directed to the molecular sieve adsorbers where moisture, carbon dioxide and contaminants are removed to prevent them from freezing in the colder sections of the plant. The dry, carbon dioxide-free air is filtered before being separated into oxygen, nitrogen and waste gas in the cryogenic distillation system (cold box). An oxygen stream containing 95\% oxygen is discharged from the cold box and compressed in another multi-stage centrifugal compressor, then fed to the gasifier.

The remaining portion of the air is mainly nitrogen and leaves the separation unit in two nitrogen streams. A small portion of the nitrogen is high-purity, greater than $99.9 \%$, nitrogen, and is used in the gasification plant for purging and inert blanketing. The larger portion of the nitrogen produced, containing $1 \%$ to $2 \%$ oxygen, can be compressed and sent to the combustion turbine for $\mathrm{NO}_{\mathrm{x}}$ control as well as power augmentation. However, at Wabash River, this level of integration was not implemented, so the balance of the nitrogen is discarded. 


\subsection{Coal Handling}

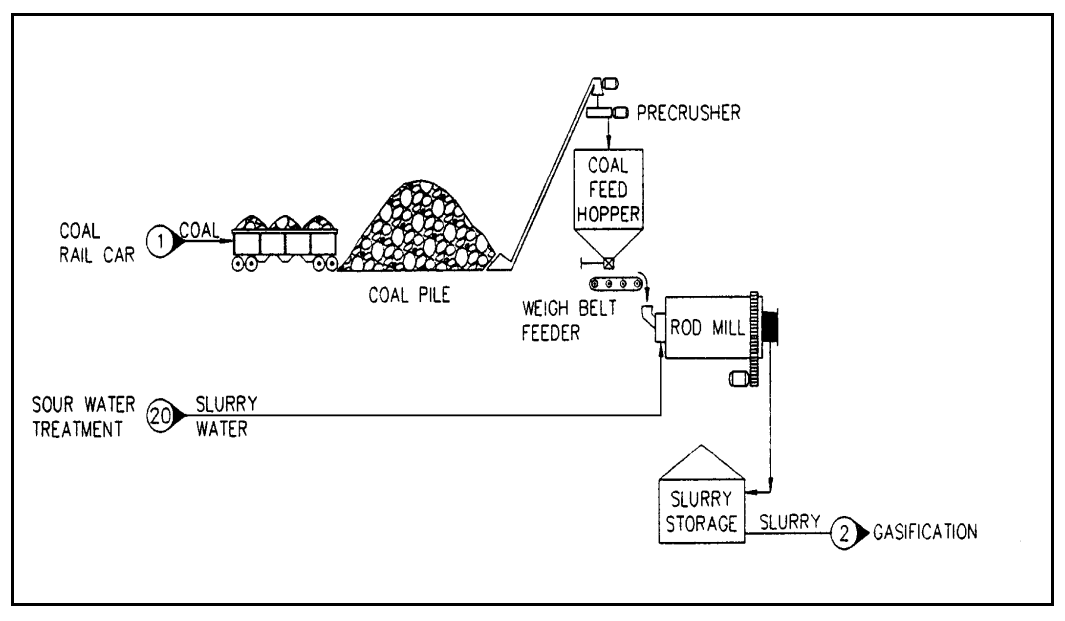

In the slurry preparation area, recycled water and the solid feed are metered to a grinding mill to produce a slurry feedstock. Slurry can be stored in sufficient quantities to accommodate uninterrupted feedstock for the gasifier. Slurry feeding allows for accurate and safe introduction of the solid fuel into the gasifier. The solid fuel comes into the plant with a twoinch maximum top size and enters the feed hopper. To produce slurry, the solid fuel is placed on a weigh belt feeder and directed to the rod mill where it is mixed and ground with treated water and slag fines that are recycled from other areas of the gasification plant. A fluxing agent is sometimes added to the solid feed to adjust the ash fusion temperature of the mineral content of the solid. The use of a wet rod mill reduces potential fugitive particulate emissions from the grinding operations. Collection and reuse of water within the gasification plant minimizes water consumption and discharge.

Prepared slurry is stored in an agitated tank. The capacity of the tank is sufficiently large to supply the gasifier needs without interruption while the rod mill and weigh belt feeder undergo most expected maintenance requirements.

All tanks, drums, and other areas of potential atmospheric exposure of the product slurry or recycle water are covered and vented into the tank vent collection system for vapor emission control. The entire slurry preparation facility is paved and curbed to contain spills, leaks, wash down, and rain water runoff. A trench system carries this water to a sump where it is pumped into the recycled solids storage tank. 


\subsection{Gasification}

\subsubsection{Gasification and Slag Handling}

The E-Gas ${ }^{\mathrm{TM}}$ gasification process accepts solid feed that can contain varying amounts of fixed carbon, volatile matter and mineral matter (ash). During the gasification of the solid fuel, a raw particulate-laden syngas is

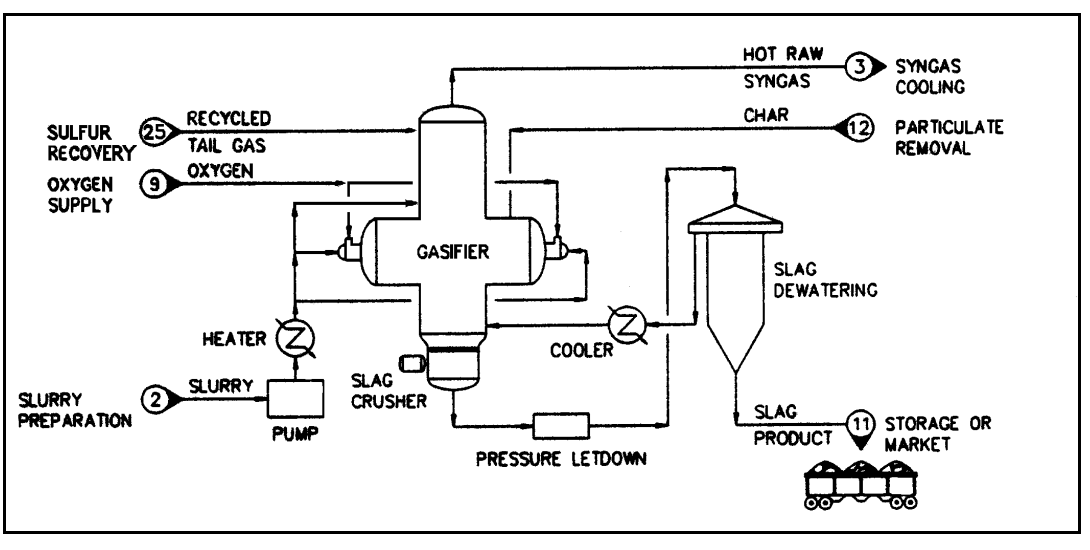
produced as well as a residual solid stream containing the ash content of the feed. The ash of the feedstock exits the bottom of the gasifier as water slurry and is dewatered in the slag handling system.

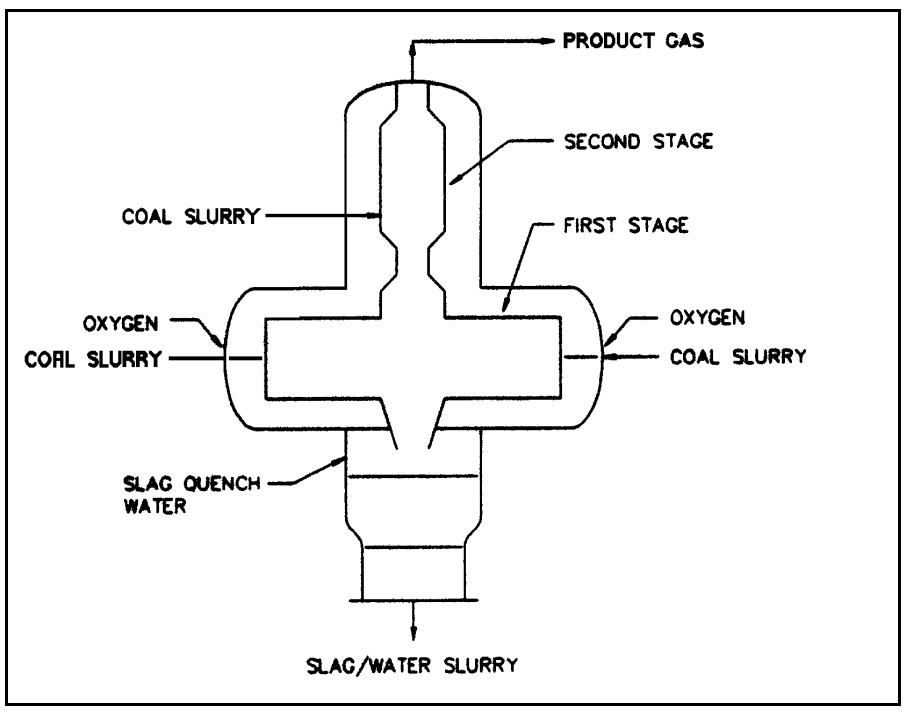

The E-Gas ${ }^{\mathrm{TM}}$ gasifier consists of two stages, a slagging first stage, and an entrained-flow, non-slagging second stage. The first stage is a horizontal, refractory-lined vessel in which carbonaceous fuel is partially combusted with oxygen at elevated temperature and pressure, $2500^{\circ} \mathrm{F} / 420$ psia $\left(1400^{\circ} \mathrm{C} / 29\right.$ bar). Oxygen and preheated slurry are fed to each of two opposing mixing nozzles, one on each end of the horizontal section of the gasifier. E-Gas ${ }^{\mathrm{TM}}$ has developed its own proprietary design for these slurry mixers. Oxygen feed rate to the mixers is carefully controlled to maintain the gasification temperature above the ash fusion point to ensure good slag removal and high carbon conversion. The fuel is almost totally gasified in this environment to form syngas consisting principally of hydrogen, carbon monoxide, carbon dioxide and water. Sulfur in the fuel is converted to primarily hydrogen sulfide $\left(\mathrm{H}_{2} \mathrm{~S}\right)$ with a small portion converted 
to carbonyl sulfide (COS). With appropriate processing downstream, over $98-99 \%$ of the total sulfur can be removed from the feedstock prior to combustion in the combustion turbine.

Mineral matter in the fuel and any added fluxing agent forms a molten slag that flows continuously through a taphole in the floor of the horizontal section into a water quench bath, located below the first stage. The solidified slag exits the bottom of the quench section, is crushed and flows through a continuous slag removal system as a slag/water slurry. This continuous slag removal technique eliminates high maintenance, problem-prone lock hoppers and completely prevents the escape of raw gasification products to the atmosphere during slag removal. The slag/water slurry is then directed to a dewatering and handling area described as follows. The slag/water slurry flows continuously into a dewatering bin. The bulk of the slag settles out in the bin while water overflows into a settler in which the remaining slag fines are settled. The clear water from the settler is passed through heat exchangers where it is cooled as the final step before being returned to the gasifier quench section. Dewatered slag is loaded into a truck or rail car for transport to market or its storage site. The slurry of fine slag particulates from the bottom of the settler is recycled to the slurry preparation area. This final recycle step enhances overall carbon utilization from the incoming solid feedstock.

The raw syngas generated in the first stage flows up from the horizontal section into the second stage of the gasifier. The second stage is a vertical refractory lined vessel in which additional slurry is reacted with the hot syngas stream exiting the first stage. The fuel undergoes devolatilization and pyrolysis thereby generating additional syngas with a higher heating value since no additional oxygen is introduced into the second stage. This additional fuel serves to lower the temperature of the syngas exiting the first stage to $1900^{\circ} \mathrm{F}\left(1030^{\circ} \mathrm{C}\right)$ by the endothermic nature of the devolatilization and pyrolysis reactions. In addition to the above reactions, the water reacts with a portion of the carbon to produce carbon monoxide, carbon dioxide and hydrogen. Unreacted fuel (char) is carried overhead with the syngas. 


\subsubsection{Syngas Cooling, Particulate Removal}

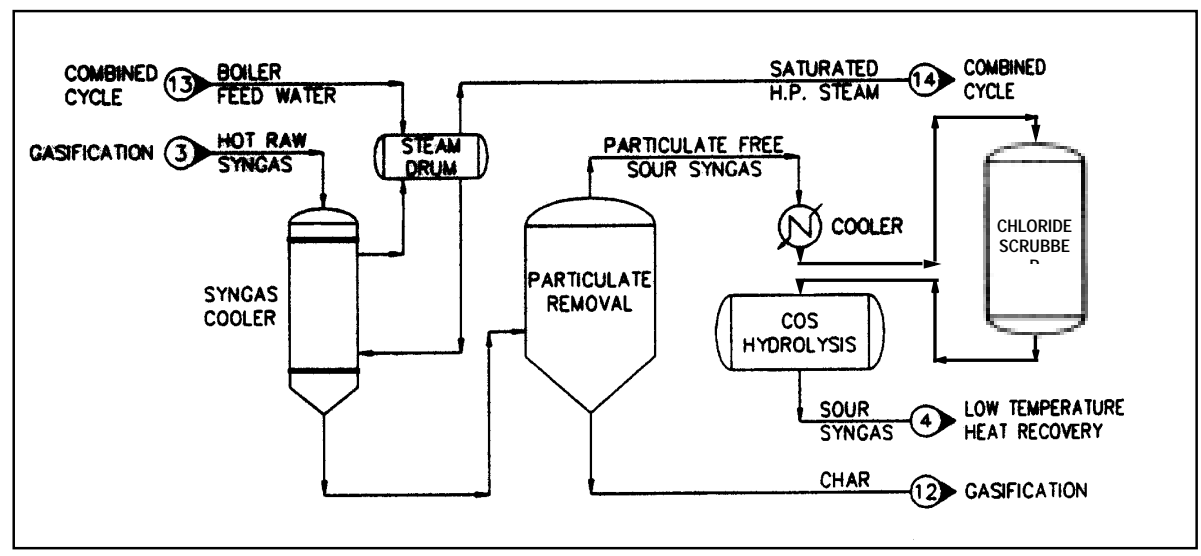

The next two steps in the $\mathrm{E}-\mathrm{Gas}^{\mathrm{TM}}$ process are to cool the syngas and then remove the particulate for recycle to the gasifier. Because of the high temperature of the

syngas exiting the second stage of the gasifier, further cooling is accomplished by producing steam. With cooling preceding the particulate removal step, the filtration of the particulates can be accomplished in a temperature range more forgiving to the particulate removal unit. The hot raw syngas with entrained particulate matter exiting the gasifier system is cooled from 1900 to $700^{\circ} \mathrm{F}\left(1040\right.$ to $370^{\circ} \mathrm{C}$ ) in the syngas cooler. The syngas cooler is a vertical firetube heat recovery boiler system with the hot syngas on the tube side. This unit generates saturated highpressure steam, up to 1600 psia. Steam from the high-temperature heat recovery system is super heated in the gas turbine heat recovery system for use in power generation. Alternatively, syngas can be superheated in the syngas cooler.

After cooling the raw syngas, the gas is directed to the particulate removal system. The filter vessels contain numerous porous filter elements on which the particulate collects and the syngas flows through the elements and exits the unit as a particulate-free syngas. Particulate removal efficiency is better than $99.9 \%$. Periodically the elements are back-pulsed with high-pressure syngas to remove particulate cake formed on the surface of the elements. The particulate cake falls to the bottom of the vessel and is pneumatically transferred to the first stage of the gasifier with high-pressure syngas. With the char recycled to the gasifier, nearly complete gasification of the carbon content of the feedstock is obtained. The particulate-free syngas proceeds to the low temperature heat recovery system. 


\subsubsection{Low Temperature Heat Recovery, Chloride Scrubbing, and Syngas Moisturization}

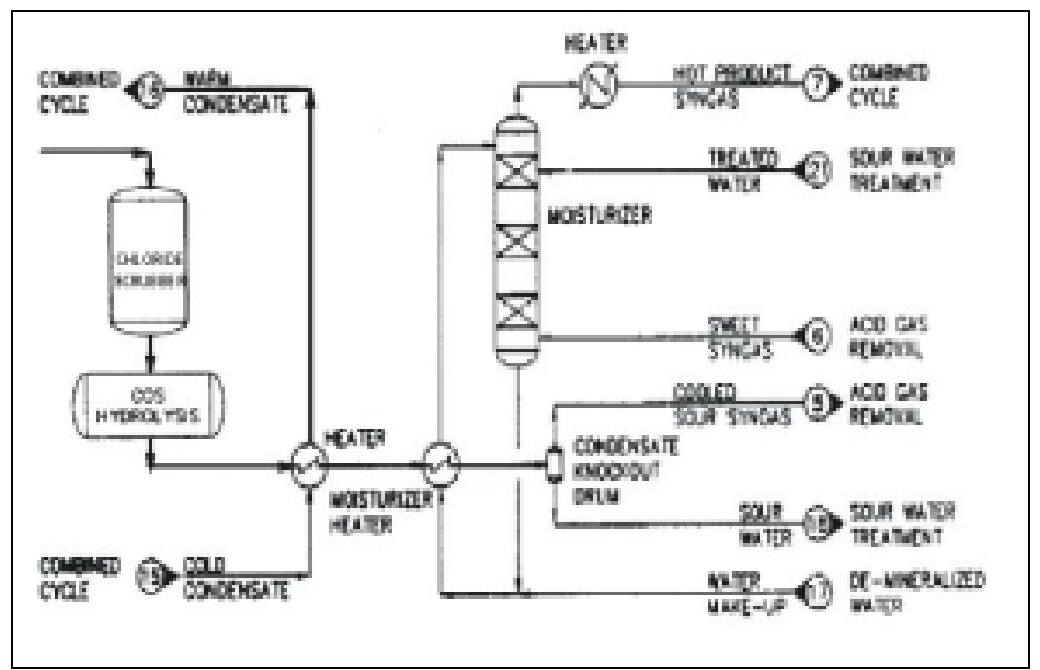

With particulates removed from the syngas, additional gas cleanup and cooling steps can be more easily performed. The syngas is scrubbed to remove troublesome chlorides and trace metals. These components are removed to reduce the potential of corrosion within the piping and vessels as well as reduce the formation of

undesirable products in the acid gas removal (AGR) system. The syngas is cooled further before being directed to the sulfur removal step.

Before being water-scrubbed, the particulate-free sour syngas (i.e., syngas with a significant amount of sulfur compounds present) is further cooled. Scrubbing the syngas removes the chlorides and most of the volatile trace metals released from the feedstock during gasification. The syngas is scrubbed with sour water (i.e., water with dissolved sulfur compounds) condensed from the syngas. After scrubbing and reheating, the syngas enters the COS hydrolysis unit where COS in the gas is converted to $\mathrm{H}_{2} \mathrm{~S}$ for effective removal of sulfur in the AGR system. The syngas is then cooled through a series of shell and tube heat exchangers to less than $100^{\circ} \mathrm{F}$ $\left(35^{\circ} \mathrm{C}\right)$ before entering the acid gas removal system. This cooling condenses water from the syngas. Most of the ammonia $\left(\mathrm{NH}_{3}\right)$ and some of the carbon dioxide $\left(\mathrm{CO}_{2}\right)$ and $\mathrm{H}_{2} \mathrm{~S}$ present in the syngas are absorbed in the water as dissolved gases. The water is collected and sent to the sour water treatment unit. The low temperature heat removed prior to the AGR system is used to heat the product syngas, to heat cold condensate, to provide syngas moisturization heat and to provide process heat in the AGR. The cooled sour syngas is fed to the AGR system where the sulfur compounds are removed to produce a sweet syngas (i.e. syngas with very few sulfur compounds present). The sweet syngas is returned to the low temperature heat recovery area where the syngas is moisturized. The sweet, moisturized syngas is superheated in an exchanger using heat from hot boiler feedwater prior to use in the combustion turbine. 


\subsubsection{Acid Gas Removal}

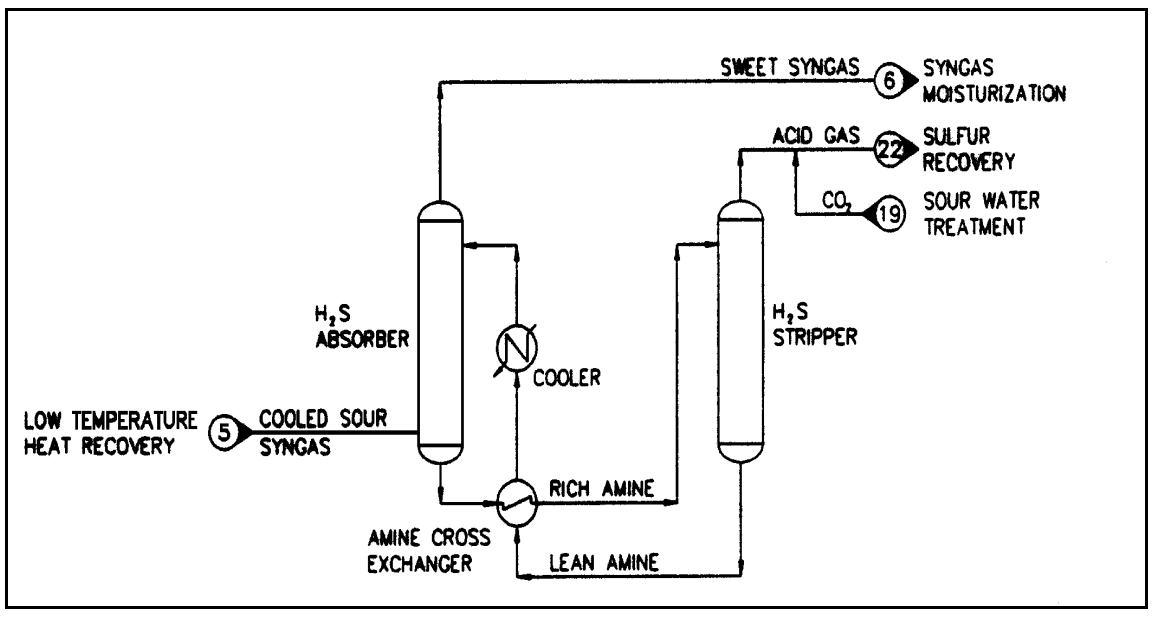

After the syngas has been sufficiently cooled, the sulfur is removed via the acid gas removal system. The principle acid gas removed at this point is hydrogen sulfide. This process contacts the cool sour syngas with a solvent

to remove the $\mathrm{H}_{2} \mathrm{~S}$ and produce a product syngas ready to be used as feed to the combustion turbine. The solvent is continuously regenerated and recycled for reuse. A concentrated acid gas stream containing the removed $\mathrm{H}_{2} \mathrm{~S}$ and $\mathrm{CO}_{2}$ is produced during the regeneration. This acid gas is the feed for a sulfur recovery unit (SRU).

For selective and efficient sulfur removal from the syngas, an AGR system was chosen based on methyldiethanolamine (MDEA), which chemically bonds with $\mathrm{H}_{2} \mathrm{~S}$, yet the bond can be easily broken with low-level heat to effect a regeneration of the absorbent. The $\mathrm{H}_{2} \mathrm{~S}$ is absorbed from the syngas by contacting the gas with MDEA at a system pressure of about 375 psia (25.9 bar) within the $\mathrm{H}_{2} \mathrm{~S}$ absorber column. A portion of the carbon dioxide is absorbed as well. $\mathrm{The}_{2} \mathrm{~S}$ rich MDEA from the bottom of the absorber flows under pressure to a cross exchanger to recover heat from the hot, lean MDEA coming from the stripper. The heated, rich MDEA is then directed to the $\mathrm{H}_{2} \mathrm{~S}$ stripper where the $\mathrm{H}_{2} \mathrm{~S}$ and $\mathrm{CO}_{2}$ are steam-stripped in a reboiled column at near atmospheric pressure. A concentrated stream of $\mathrm{H}_{2} \mathrm{~S}$ in $\mathrm{CO}_{2}$ exits the top of the stripper and flows to the SRU. The lean MDEA is pumped from the bottom of the stripper to the cross exchanger. The lean amine is further cooled to about $100^{\circ} \mathrm{F}\left(35^{\circ} \mathrm{C}\right)$ to remove residual heat before being stored and then circulated back to the absorber. The AGR system does not produce any emissions to the atmosphere. 


\subsubsection{Sulfur Recovery}

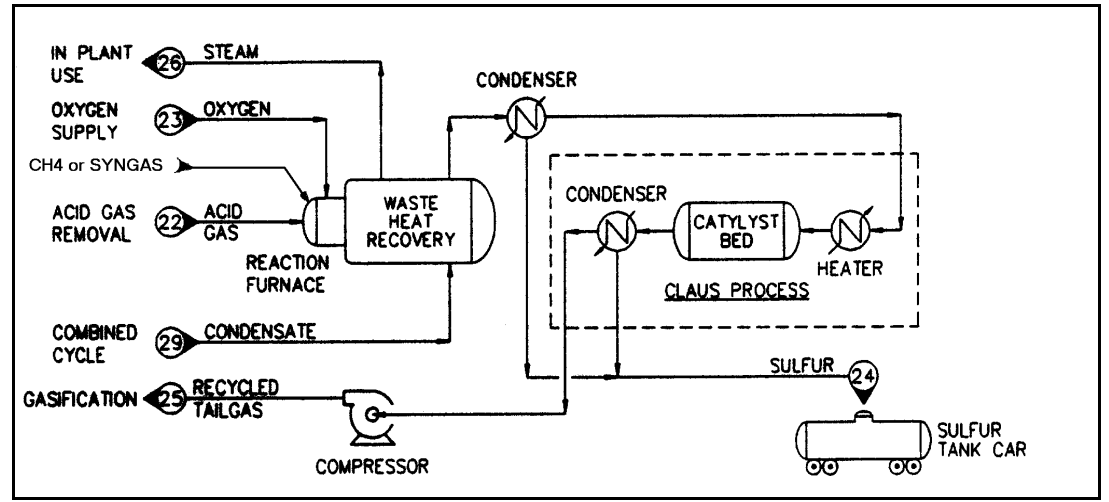

The $\mathrm{H}_{2} \mathrm{~S}$ leaving in the acid gas from the AGR system is converted to elemental sulfur in the sulfur recovery unit (SRU). This technology is based on the Claus process involving the partial oxidation

of the $\mathrm{H}_{2} \mathrm{~S}$ to sulfur gas and steam. The sulfur is selectively condensed and collected. The residual gas, or tail gas, has very little sulfur content; nevertheless, this stream is compressed and recycled to the gasifier, thereby allowing for very high sulfur removal efficiency and, thus, minimal sulfur emissions.

The $\mathrm{H}_{2} \mathrm{~S}$ stream from the AGR stripper and the $\mathrm{CO}_{2} / \mathrm{H}_{2} \mathrm{~S}$ stripped from the sour water are fed to the SRU. First, a third of the $\mathrm{H}_{2} \mathrm{~S}$ is combusted with oxygen to thermally produce sulfur gas in a reaction furnace at about $1950^{\circ} \mathrm{F}$. A waste heat boiler is used to recover heat before the furnace off-gas is cooled to condense the first increment of sulfur. Medium-pressure steam is produced in the waste heat boiler. Gas exiting this first sulfur condenser is fed to a series of heaters, catalytic reaction stages, and sulfur condensers where the $\mathrm{H}_{2} \mathrm{~S}$ is incrementally converted to elemental sulfur. The sulfur is recovered as a molten liquid and sold as a very pure (99.999\%) by-product. The off-gas from the SRU, which is composed mostly of carbon dioxide and nitrogen, with trace amounts of $\mathrm{H}_{2} \mathrm{~S}$, exits the last condenser. The SRU off-gas is catalytically hydrogenated to convert all the remaining sulfur species to $\mathrm{H}_{2} \mathrm{~S}$. This results in a tail gas that is cooled to condense the bulk of the water, compressed and then directed to the gasifier. This allows for a very high overall sulfur removal in the process with minimal recycle requirements. The overall sulfur removal efficiency for the Wabash River process has been greater than $98 \%$.

An incineration system is used to convert trace acid gas components in the tank vents to oxide form $\left(\mathrm{SO}_{2}, \mathrm{NO}_{\mathrm{x}}, \mathrm{H}_{2} \mathrm{O}, \mathrm{CO}_{2}\right)$. The tank vent stream is primarily composed of air purged through various in-process storage tanks, and may contain very small amounts of acid gas. The high temperature produced in the incinerator thermally converts any hydrogen sulfide present in the 
tank vents to $\mathrm{SO}_{2}$ before the gas is vented to the atmosphere. Heat recovery is provided in the hot exhaust gas of the incinerator to produce medium pressure steam before the vent gas is directed to a tall stack for dispersion in the atmosphere

\subsubsection{Sour Water Treatment}

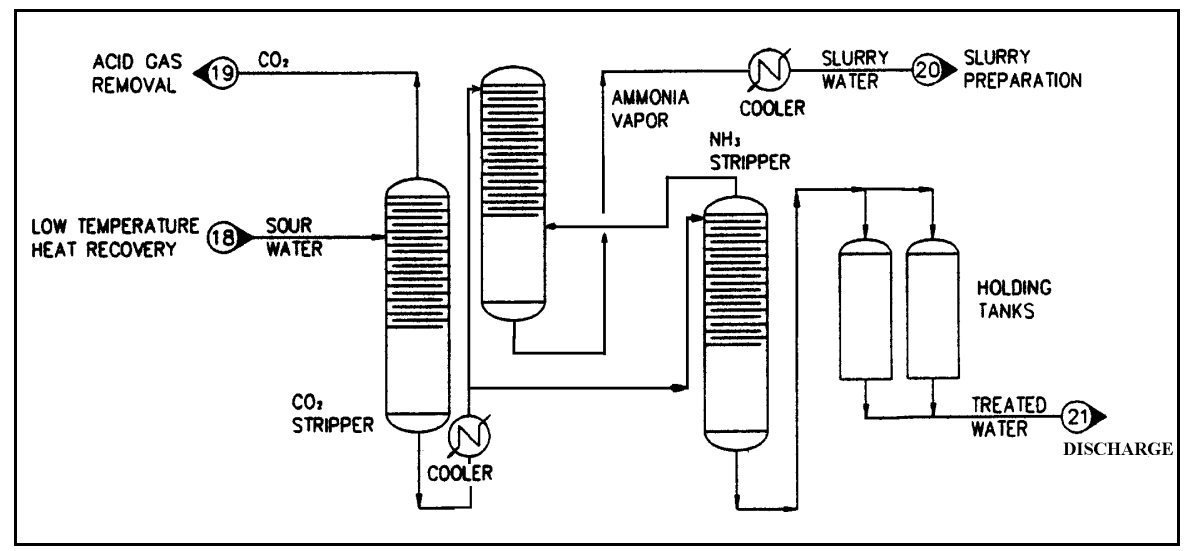

Process water produced within the gasification process must be treated to remove dissolved gases before recycling to the slurry preparation area or being discharged to the water outfall.

Dissolved gases are driven from the water using steam-stripping techniques. The steam provides heat and a sweeping medium to expel the gases from the water, resulting in a degree of purification sufficient for discharge within permissible environmental levels.

Water blown down from the process and condensed during cooling of the sour syngas contains small amounts of dissolved gases. The gases are stripped out of the sour water in a two-step process. First, the $\mathrm{CO}_{2}$ and the bulk of the $\mathrm{H}_{2} \mathrm{~S}$ are removed in the $\mathrm{CO}_{2}$ stripper column by steam stripping. The stripped $\mathrm{CO}_{2}$ is directed to the SRU. The water exits the bottom of this column, is cooled and a major portion is recycled to slurry preparation. Any excess water is treated in an ammonia stripper column to remove the ammonia and remaining trace components. The stripped ammonia is combined with the recycled slurry water.

Reuse of the water within the gasification plant minimizes water consumption and water discharge. Recycle of the ammonia in this manner is the simplest approach. The ammonia could be destroyed via the reaction furnace of the SRU; however, this may require operation of the furnace at less than optimum conditions to insure complete destruction of the ammonia. Alternatively, if desired, the gasification plant could be configured to recover ammonia as a saleable by-product of the process. 
Water from the bottom of the ammonia stripper is purified sufficiently so that it can be discharged through the permitted outfall. If, for any reason the discharge is out of specification, the treated water can be stored in holding tanks for further testing and possible recycle before final disposition.

\subsection{Power Block}

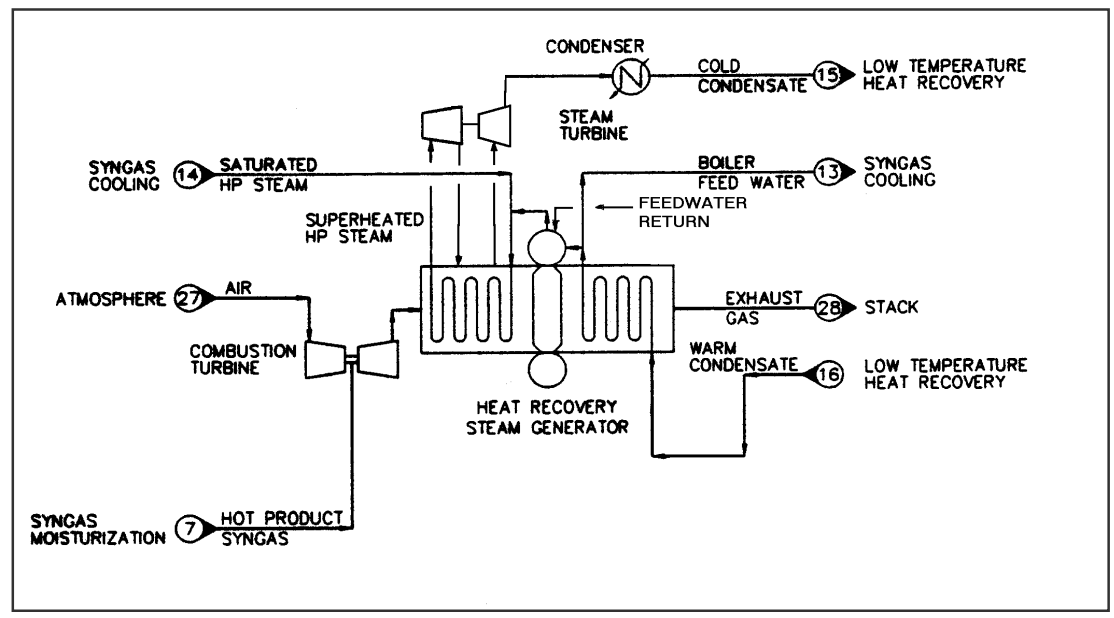

The combined-cycle system consists of a combustion turbine generator, heat recovery steam generator, reheat steam turbine generator, condenser, flash drums, condensate pumps and boiler feedwater pumps.

Preheated, moisturized syngas and compressed air are supplied to the combustor. The hot gas exiting the combustor flows to the turbine, which drives the generator and air compressor section of the combustion turbine. Hot exhaust gas from the expander is ducted to the heat recovery steam generator (HRSG).

The HRSG provides superheat to the 1600 psia high-pressure (HP) steam produced from the gasification process and reheat to the intermediate-pressure (IP) steam. It also generates HP steam and preheats boiler feedwater for the syngas cooler.

The steam turbine generator is comprised of HP, IP and low-pressure (LP) power turbines and a generator. Reheated IP steam is supplied to the IP power turbine. The LP power turbine exhausts to the surface condenser. Process heat from the gasification process is used to preheat the condensate from the steam turbine condenser before it is returned to the HRSG. 


\subsection{DEMONSTRATION PERIOD}

In preparation for the start of the Demonstration Period for the Project, the participants completed the transition from construction to operation through an organized program of equipment commissioning, system turnover and operator training. The months of preparation by Operations personnel to systematically prepare each section of the plant for acceptance testing and operating procedure development led to the plant being turned over from Construction to Operations system by system. "First-fire" of the combustion turbine on fuel oil occurred on June 6, 1995, followed by first coal slurry to the gasifier on August 17, 1995. For the next three months, the plant worked through the start-up phase, which culminated in the Project achieving commercial operations status and entering the Phase III Demonstration Period under the Cooperative Agreement on November 18, 1995. Significant in the start-up phase was the successful demonstration of the thermal integration of the combined operations. Except for minor feedwater control problems, which contributed to early syngas interruptions, there were no substantial problems integrating the steam and water systems. The plant completed demonstration testing to qualify for commercial status on November 18, 1995, and then entered a short outage from November 18 through early December prior to starting operation under the Demonstration Period. In December of 1995, the gasification plant operated for a total of 84 hours on coal, with the combustion turbine operating on syngas feed for 49 hours. The following section details operations and maintenance of the facility for the 1996 through 1999 years considered as the Demonstration Period.

Section 5.0 Technical Performance of this Final Technical Report analyzes a 12-month period within the four-year Demonstration Period and provides greater detail on subsystem equipment reliability, availability and maintainability as defined in Section 5.0. Due to the nature of this more technical analysis and the fact that it encompasses a portion of the Demonstration Period, Section 5.0 Technical Performance includes some information similar to that contained in the following section. This redundancy is intentional, allowing these two sections of the Final Technical Report to be reviewed independently.

Also within Section 4.0 are special sections that review alternate fuel tests conducted during this period and also analyze critical components within the gasification system. 


\subsection{Operation, Maintenance and Technical Impacts}

Commercial operation of the facility began late in 1995. Within a short time, both the gasification and combined-cycle plants successfully demonstrated the ability to run at capacity and within environmental parameters. However, numerous operating problems impacted plant performance and reliability and the first year of operation resulted in only a $22 \%$ availability factor. Frequent failure of the ceramic filter elements in the particulate removal system accounted for nearly $40 \%$ of the early facility downtime. Plant reliability was also significantly hindered by high chloride content in the syngas. The high chlorides contributed to exchanger tube failures in the low temperature heat recovery area, COS hydrolysis catalyst degradation, and mechanical failures of the syngas recycle compressor. Ash deposits in the post gasifier pipe spool and HTHRU created high system pressure drops, which forced the plant off line and required significant downtime to remove. Slurry mixers experienced several failures and the power block also contributed to appreciable downtime in the early years of operation.

Through a systematic problem-solving approach and a series of appropriate process modifications, all of the foregoing problems were either eliminated or significantly reduced by the end of the second operating year. In 1997, the facility availability factor was $44 \%$ and, by 1998, the availability factor had improved to $60 \%$. As problems were solved and availability improved, new improvement opportunities surfaced. During the third year of commercial operation, the facility demonstrated operation on a second coal feedstock as well as a blend of two different Illinois No. 6 coals. The ability to process and blend new coal feedstocks improved the fuel flexibility for the site but, while learning to process varying feedstocks, the plant suffered some downtime. On two occasions while processing new coals or fuel blends, the taphole in the gasifier plugged with slag.

In 1998 and 1999 a high percentage of coal interruptions and downtime were caused by the air separation unit (ASU). Ten coal interruptions in 1998 alone were due to the ASU. In 1999, failure of a blade in the compressor section of the combustion turbine required a complete rotor rebuild that idled the Project for 100 days. Run-time in 1999 was also impacted by a syngas leak in the piping system of the particulate removal system, a main exchanger leak in the air separation unit, another plugged taphole, and a failure of a ceramic test filter in the particulate 
removal system. Consequently, the availability factor for the facility in 1999 dropped to $40 \%$. However, 1999 clearly marked significant advances in the application of commercial IGCC as

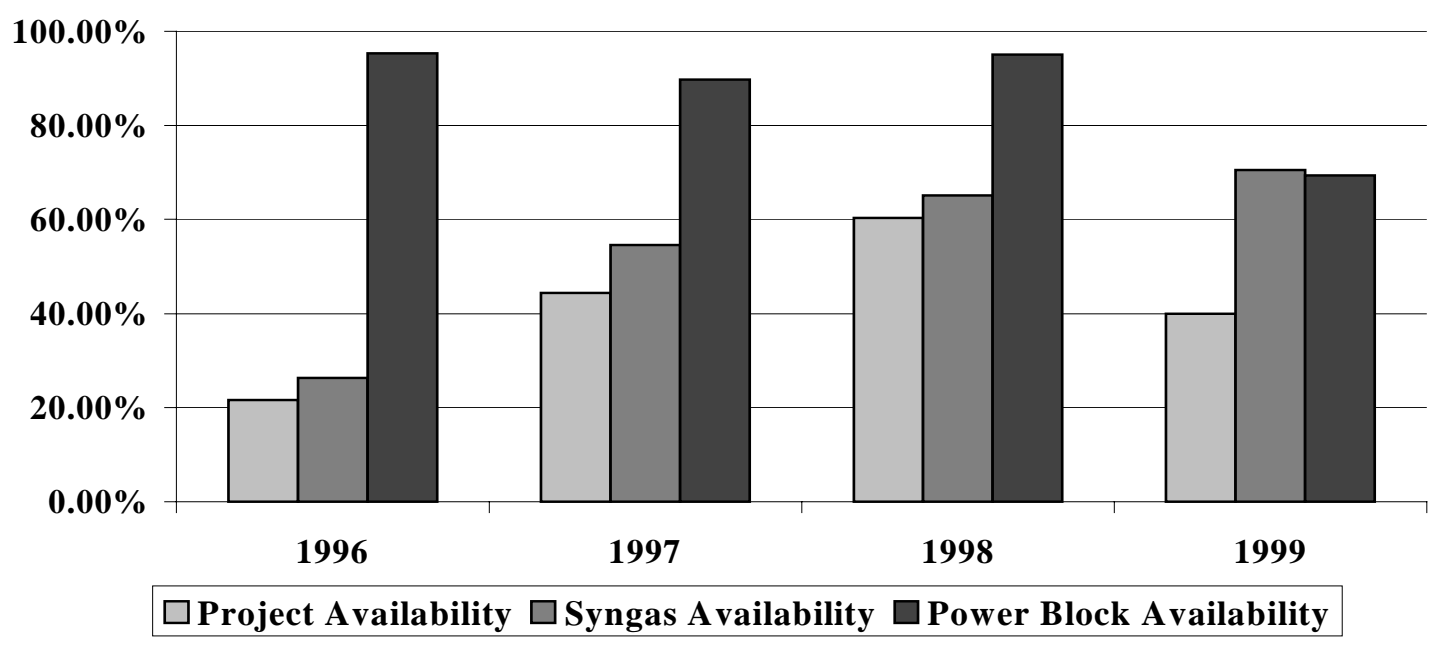

Figure 4.1A: Project, Syngas Block and Power Block Availability

demonstrated at Wabash River. During the third quarter of 1999, the gasification block produced a record 2.7 trillion Btu of syngas, operated continuously without interruption for 54 days and finished the year at $70 \%$ availability. Figure 4.1A demonstrates how the reliability of the technology has advanced during the Demonstration Period. The continuous improvement trend for the gasification block, where the majority of the novel technology was demonstrated, is encouraging and is expected to continue. Future operating improvements will continue to advance the technology and eliminate cost and availability barriers. Some of the more significant achievements and activities for the Demonstration Project are highlighted in Table 4.1A. 
Table 4.1A: Significant Operating Achievements

\begin{tabular}{|c|c|}
\hline First coal fire in gasifier & August 17, 1995 \\
\hline Commercial operation begins & December 1, 1995 \\
\hline Start-up of chloride scrubbing system & October 1996 \\
\hline Initiated use of metal filter elements & December 1996 \\
\hline Conducted 10-day test run of petroleum coke & November 1997 \\
\hline 1998 Governor's Award for Excellence in Recycling & May 1998 \\
\hline Began running new coal feed (Miller Creek) & June 1998 \\
\hline Completed 14-month OSHA recordable-free period & September 1998 \\
\hline Surpassed 1,000,000 tons of coal processed & September 1998 \\
\hline Surpassed 10,000 hours of coal operation & September 1998 \\
\hline Surpassed $100,000,000$ pounds equivalent of $\mathrm{SO}_{2}$ captured & January 1999 \\
\hline Record quarterly production $(2,712,107 \mathrm{MMBtu})$ & $3^{\text {rd }}$ Quarter 1999 \\
\hline Longest continuous uninterrupted run $(1,305 \mathrm{hrs})$ & August 12 - October 6, 1999 \\
\hline Conducted second successful petroleum coke run & September 1999 \\
\hline Completed $2^{\text {nd }} 14$-month OSHA recordable-free period & December 1999 \\
\hline Record coal hours between gas path vessel entries $(2,240 \mathrm{hr})$ & June to October 1999 \\
\hline
\end{tabular}

Despite reliability issues during the first two years of operation, the actual performance of the plant during coal operation compares favorably with design as indicated in Table 4.1B. The plant has demonstrated a maximum capacity of $1825 \mathrm{MMBtu} / \mathrm{hr}$ but requires only 1,690 MMBtu/hr to satisfy the requirements of the combustion turbine at full load. The noted steam turbine capacity shortfall requires a HRSG feedwater heater modification to bring output up to design. With this modification the overall plant heat rate will drop even lower to 8,650 Btu. The air separation unit was unable to meet the guaranteed power specification, which accounts for the difference in auxiliary power.

The environmental performance of the plant has been superior. Sulfur removal efficiencies all exceed design and total demonstrated sulfur dioxide emissions have been as low as $0.03 \mathrm{lb} / \mathrm{MMBtu}$ of dry coal feed. This quantity is 40 times lower than the year 2000 Clean Air Act Amendment standards. Likewise $\mathrm{NO}_{\mathrm{x}}, \mathrm{CO}$ and particulate emissions average 0.022, 0.044 
and $0.012 \mathrm{lb} / \mathrm{MMBtu}$ respectively. The WRCGRP is the cleanest coal-fired power plant in the world.

Table 4.1B: Performance Summary

\begin{tabular}{|lcc|}
\hline & $\underline{\text { Design }}$ & $\frac{\text { Actual }}{1,690(1825 \text { max })}$ \\
Syngas Capacity, MMBtu/hr & 1,780 & 192 \\
Steam Turbine Capacity, MW & 192 & 96 \\
Auxiliary Power, MW & 105 & 36 \\
Net Power, MW & 35.4 & 252 \\
Plant Heat Rate, Btu/kWh & 262 & 8,900 \\
Sulfur Removal Efficiencies, \% & 9,030 & $>99$ \\
SO 2 Emissions, lbs/MMBtu & $>98$ & $<0.1(0.03)$ \\
Syngas Heating Value (HHV) & $<0.2$ & $275-280$ \\
Syngas Sulfur Content (ppmv) & 280 & $<100$ \\
\hline
\end{tabular}

Operation in 1998 was highlighted by several months during which syngas production exceeded one trillion Btu of gas produced. This production milestone was met in March, April, October and November of 1998. As previously indicated, the highest quarterly production of syngas occurred in the third quarter of 1999 in which 2,712,107 MMBtu of gas was produced. Syngas production in September of 1999 was 1,204,573 MMBtu, the highest ever for a month. Furthermore, the combustion turbine was at maximum capacity for all but 7 hours in September. Key production statistics for the Demonstration Period are presented in Table 4.1C. 
Table 4.1C: Wabash River Coal Gasification Repowering Project Production Statistics

\begin{tabular}{|l|l|l|l|l|l|l|}
\hline Time Period & $\begin{array}{c}\text { On Coal } \\
\text { (Hr) }\end{array}$ & $\begin{array}{c}\text { Coal } \\
\text { Processed } \\
\text { (Tons) }\end{array}$ & $\begin{array}{c}\text { On Spec. } \\
\text { Gas } \\
\text { (MMBtu) }\end{array}$ & $\begin{array}{c}\text { Steam } \\
\text { Produced } \\
\text { (Mlb) }\end{array}$ & $\begin{array}{c}\text { Power } \\
\text { Produced } \\
\text { (MWh) }\end{array}$ & $\begin{array}{c}\text { Sulfur } \\
\text { Produced } \\
\text { (Tons) }\end{array}$ \\
\hline \hline Start-up '95 & 505 & $41,000^{*}$ & 230,784 & 171,613 & $71,000 *$ & 559 \\
1996 & 1,902 & 184,382 & $2,769,685$ & 820,624 & 449,919 & 3,299 \\
1997 & 3,885 & 392,822 & $6,232,545$ & $1,720,229$ & $1,086,877$ & 8,521 \\
1998 & 5,279 & 561,495 & $8,844,902$ & $2,190,393$ & $1,513,629$ & 12,452 \\
$1999 \diamond$ & 3,496 & 369,862 & $5,813,151$ & $1,480,908$ & $1,003,853$ & 8,557 \\
\hline \hline Overall & 15,067 & $1,549,561$ & $23,891,067$ & $6,383,767$ & $4,125,278$ & 33,388 \\
\hline
\end{tabular}

* ESTIMATES. $>$ NOTE: THE COMBUSTION TURBINE WAS UNAVAILABLE FROM 3/14/99 THROUGH 6/22/99.

Early identification of availability-limiting process problems led to aggressive implementation of improvement projects which resulted in $224 \%$ more syngas produced during the second year than in year one. The syngas produced during the third year exceeded the second year's production by an additional $42 \%$. Assuming that the availability factor during the combustion turbine outage was the same as in 1998, the facility production in 1999 would have matched 1998's output. Figure 4.1B illustrates this continuous improvement trend over the last four years as measured by total syngas production.

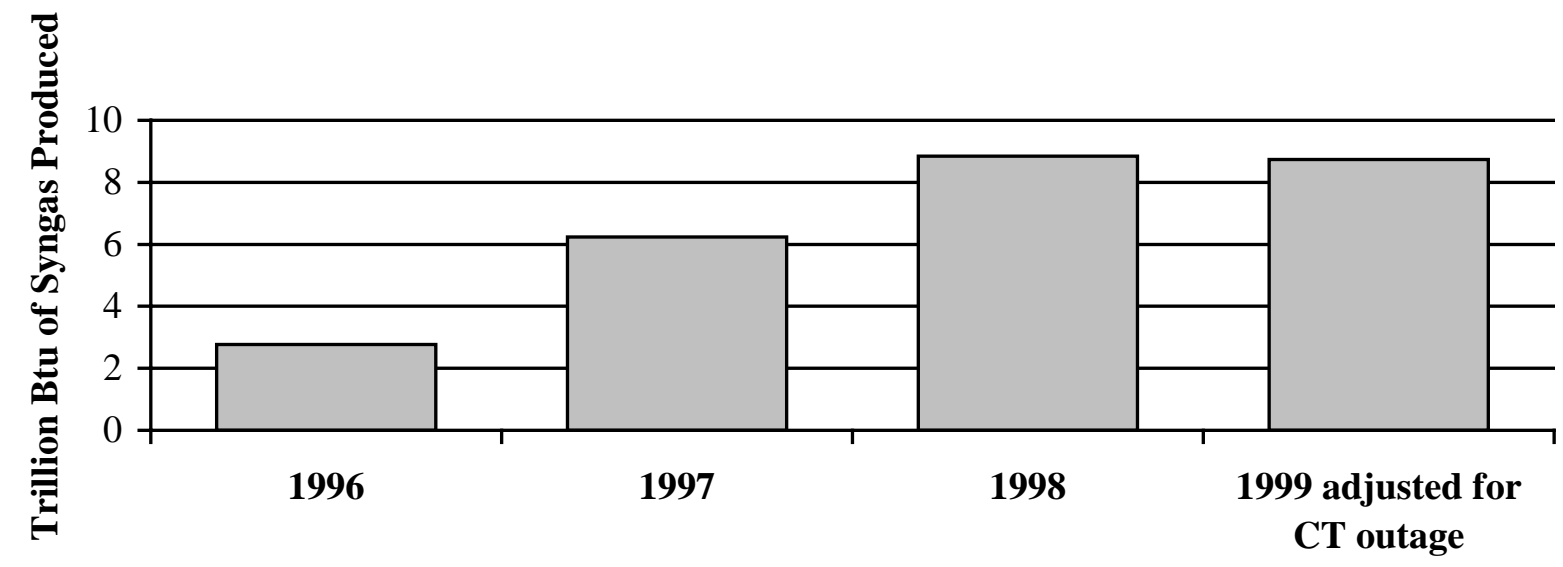

Figure 4.1B: Syngas Production by Year

The remainder of this section of the report will summarize the chronological history of plant operation by area for the four-year Demonstration Period. 


\subsubsection{Air Separation Unit}

\section{Opportunities and Improvements}

During the first quarter of 1996, prior to contractual performance testing of the Air Separation Unit (ASU), a production shortfall of nitrogen was identified. Liquid Air Engineering, the supplier of the ASU, identified a process change to enhance nitrogen production. The change involved the installation of a new heat exchanger to recover the refrigeration lost during the vaporization of nitrogen for high-pressure gaseous nitrogen production. The original design used steam energy to vaporize and heat the liquid nitrogen for continuous delivery to the gasifier systems. The new exchanger allows more cooling of inlet air to the distillation column, resulting in higher production of product nitrogen.

One negative side effect of the new exchanger was that the airflow to the main heat exchanger was reduced, causing liquefaction of the waste nitrogen to occur upstream of the exchanger. A follow-up project was required to correct this side effect. A second project to re-route a highpressure oxygen recycle stream to the main exchanger was implemented, which served to keep the waste nitrogen from liquefying, thus eliminating potential damage which can be caused by two-phase flow. This modification along with the addition of the new exchanger, results in higher nitrogen production. However, the ASU never achieved the full performance guarantees for simultaneous delivery of all product streams.

With the frequent plant interruptions and shorter duration runs characteristic of the early operation, the ASU could not maintain nitrogen production at the rate of consumption in the gasifier island. This required additional liquid nitrogen to be trucked into the facility at additional costs. Efforts to identify potential sources for conservation throughout the year resulted in a decrease in demand. Nitrogen conservation projects, identified during the fourth quarter of 1996, will be discussed later in this section.

Additional minor issues addressed in the ASU in 1996 included: 
- A gradual reduction in flow rate from the liquid oxygen pumps during the second quarter created concern over system reliability. Inspection of the pumps and related equipment revealed that the suction strainers had been improperly installed during construction resulting in excessive particulate build-up within the pumps. Following total pump overhauls within the quarter, performance was restored to design specifications.

- A manufacturer's inspection in September, following numerous valve failures, uncovered a design flaw in the bushings of the adsorber bed sequencing valves. The manufacturer agreed to produce one set of modified valves with a new bushing design, with a plan to use the extra valves to systematically change out valves and upgrade the bushings over an 18-month period.

- In December of 1996, the main air compressor surged and shutdown due to a failure of the third stage guide vane controller. The guide vanes went to the closed position after a rupture of a connector attached to the third stage actuator. This failure caused a four-day interruption in syngas delivery to repair the actuator and restore gasifier operation. No long-term negative effects to the compressor were observed as a result of this compressor surge.

In 1997, nitrogen production shortfall continued as a critical key production issue. Excessive nitrogen usage, especially during start-up periods, required supplemental nitrogen to be brought in via truck to facilitate start-up of the gasification island. Operational procedures were modified to minimize and balance the usage and high volume uses were targeted for improvement opportunities addressed as follows:

The heat-up process utilized by the dry char filtration system and the carbonyl sulfide (COS) catalyst vessels, which require inert heating, were requiring significant time and nitrogen quantities to heat at start-up. Corrective measures included the installation of three new heat exchangers, and the installation of recycle piping, which allows faster heat-up and cool down of these systems using significantly less nitrogen than the previous once through system. Optimization of nitrogen purges on various equipment and instrumentation in the gasifier system. 
By focusing on these critical areas, significant reductions in additional nitrogen purchases were possible as well as reduction in start-up and shutdown timing. By the end of 1997, nitrogen demand had been closely matched to nitrogen production. Deliveries of external nitrogen decreased from a 1997 high of 15 trucks per month (9 million standard cubic feet) down to two trucks per month (1.2 million standard cubic feet).

Oxygen production during 1997 was sufficient to meet the demands of the gasification island. Total annual production was approximately 328,000 tons of $95 \%$ purity oxygen. Several trips of the main air compressor (MAC) caused shutdowns of the gasification process due to the inability to supply oxygen to the slurry mixers (there is no oxygen storage capability at the facility). The first, in the second quarter of 1997, was due to an electrical design flaw in the ancillary systems of the main air compressor. Several of the ancillary systems were not adequately fuse protected. Therefore, when an over-amperage condition occurred on one of the auxiliary pieces of equipment it was sufficient to trip the main circuit breaker for the MAC. Corrective action included inspection and replacement as necessary of all susceptible fuses. During the third quarter, a loose fuse resulted in the failure of an oxygen vent valve, which subsequently tripped the main air compressor and the gasification process. It is suspected that the fuse was not properly seated after the inspection/replacement that occurred during the second quarter. All fuses were rechecked to prevent recurrence of this problem.

A potential preventative maintenance issue was identified when, in December, the alternate oxygen pump suffered a failure of the lower impeller shaft bearing. Wabash River personnel worked with the manufacturer to identify a new lower impeller design for installation at the next available outage.

Additional upgrades to the ASU during 1998 included the following:

- A lube oil system upgrade was made to facilitate oil changes to the main air compressor.

- The main air compressor guide vanes (all stages) were put on a more aggressive preventative maintenance schedule due to a second stage guide vane failure in December. 
In 1998 the ASU contributed 397 hours of gasification plant downtime (approximately 20.4\% of total downtime) compared to 198 hours (or approximately 7.1\%) in 1997. While these hours are elevated for 1998, it is important to note that oxygen production from the ASU increased from approximately 328,000 tons in 1997 to over 442,000 tons in 1998. Nitrogen shortfalls, while still occurring in 1998, were reduced by careful application of operating and start-up procedures incorporated into the system in 1997 and continuing in 1998.

Several key outages occurred in 1998 which led to the increase in ASU contributions to plant downtime. Those occurrences were:

- In January, a control system I/O power supply experienced a blown fuse resulting in loss of power to multiple automatic operated valves. This, in turn, forced a gasification plant trip via an oxygen compressor shutdown in the ASU resulting in five hours of lost production. Evidence suggested the incident was a result of an amperage load imbalance for the control circuit and a relatively simple redistribution of load proved successful in preventing further occurrence.

- A second lost production incident occurred later in January when the anti-surge valve protecting the MAC failed and ultimately caused the pressure safety valves (PSV's) to open. The PSV's which failed to reseat on closing and consequently required repair resulting in 35 lost production hours. The sticking surge valve was related to actuator corrosion due to extended operation with only minor valve movement. A simple preventative maintenance plan was implemented which calls for full-stroke actuator operation and lubrication during all shutdown periods.

- A third event occurred in January, when the MAC tripped due to excessive vibration resulting from malfunction of the inlet guide vane electronic positioning system, which loads the compressor. The net effect was a production loss of 53 hours. Design deficiency was responsible for the guide vane failure resulting in increased system maintenance (short term) and a request for proposal to replace the actuator system. Guide vane actuator replacement is discussed later in this section and in Section 5.0 Technical Performance.

- In February, a high voltage switchgear fuse $(15 \mathrm{kV})$ failed forcing both the MAC and oxygen compressors to shutdown resulting in 33 hours of downtime. No apparent cause was found 
for the blown fuse in the high voltage system, so no modifications or predictive measures could be identified to prevent recurrence of this event.

- On June $8^{\text {th }}$ and $9^{\text {th }}$, production delays occurred resulting from packing fires inside the chiller tower during vessel entry work. A total of 61 hours in start-up delays resulted from this event. Evidence suggested the incident resulted from inadequate fire barriers and failure to use a low energy welding technique such as heli-arc versus stick welding.

- On August $9^{\text {th }}$, a production interruption occurred when the power card for the MAC inlet guide vane, programmable logic controller failed. Difficulties in lining out the ASU after the controller failed prevented gasification operation for 110 hours. A voltage surge consistent with a probable lightning strike was identified as the root cause for the power card failure.

- On August $15^{\text {th }}$, production was lost when a high voltage $(15 \mathrm{kV})$ potential transformer (PT) blew a primary fuse in the motor control center (MCC) switchgear. Both the oxygen compressor and MAC utilize the PT for voltage reference and for under-voltage protection. Although neither machine suffered a failure, the blown fuse shutdown both compressor motors instantaneously via the power factor relay. All testing confirmed no problem with the potential transformer equipment but suggested a problem upstream of the primary side of the PT fuse itself or the $15 \mathrm{kV}$ system. The PT was swapped with an identical type from less critical service, and no repeat failures have occurred.

- On August $4^{\text {th }}$, a nine-hour production loss occurred when the oxygen compressor shutdown from the simultaneous activation of six safety interlocks. The root cause was determined to be a loose wire on the power supply to the fast digital input card for the oxygen compressor.

- On October $8^{\text {th }}$, a five-hour production interruption occurred due to a power disruption to the vibration monitoring cabinet. A technician accidentally tripped the power toggle while working inside the cabinet for installation of a new data collection system. This resulted in all vibration interlocks "failing safe", shutting down both MAC and oxygen compressors. Work within the vibration cabinet was postponed until the next scheduled outage to prevent further production interruptions. Additionally, a sign was posted on the cabinet door warning of plant shutdown potential due to unprotected power switching inside the cabinet.

- A ten-hour interruption occurred on October $27^{\text {th }}$ and followed actuator problems associated with the adsorption process valves. The actuator worked itself loose from the valve resulting in a limit switch failure, which prevented the regeneration sequence from completing. This 
halted operation until a full regeneration cycle could be completed for the adsorption bed. Training was initiated for all ASU operators regarding the maintenance work request policy and all related aspects of adsorption process control troubleshooting. New and modified alarms were placed in the distributed control system (DCS) control logic to facilitate problem identification.

Several projects were implemented in the ASU in 1998 to enhance industrial hygiene and plant performance. Those projects were:

- In the second quarter, an ancillary silencer was placed onto the adsorber tower exhaust vents reducing peak noise levels in the area from $105 \mathrm{~dB}$ to below $87 \mathrm{~dB}$.

- The nitrogen vaporizer bellows trap and condensate pump systems were eliminated in favor of a float and thermostatic steam trap. Enhanced performance and energy and maintenance savings have resulted.

- The adsorber regeneration heater gas distribution system was overhauled with enhanced stiffening supports. Once installed, the regeneration heat peaks improved approximately $25^{\circ} \mathrm{F}$, increasing efficiency and reducing cycle time.

- The failed water distribution system within the chiller tower was reinforced with stiffening elements to prevent liquid channeling and inherent performance problems. A temperature improvement of $5^{\circ} \mathrm{F}$ is attributed to the better water distribution.

- In the fourth quarter, both liquid oxygen pumps were fitted with a solids purge system. This new system will improve oxygen pump bearing life by eliminating the primary source of bearing wear, namely particulate.

In 1999 the ASU contributed 340 hours of gasification plant downtime (approximately 10.5\% of total downtime) compared to 397 hours (or approximately 20.4\%) in 1998. The key occurrences that contributed to plant downtime were:

- In January, there was a 15-hour delay of plant start-up when the nitrogen storage tank ran short of liquid. Emergency road conditions consisting of ice and snow prevented the requested nitrogen delivery, which delayed gasifier start-up. In response to this shortfall, two 
new contracts have been negotiated with spot market nitrogen suppliers as a hedge against delivery and production problems.

- A second short production delay of 11 hours occurred in February, due to the performance of a safety test on the ASU's distillation exchanger to look for evidence of hydrocarbon accumulation in the cryogenic system. The supplier recommended the test after having two ASU plant explosions worldwide on similarly designed units. The test results indicated that the ASU at Wabash River was at very low risk.

- The failure of an automatic valve to properly seat prevented depressurization of an adsorber bed that interrupted oxygen supply and resulted in 15 hours of gasifier downtime. A temporary fix involving manual operation was implemented until the valve was repaired during the next scheduled outage.

- Failure of the derime header inside the main exchanger cold box resulted in 14 days of downtime in August. The root cause was determined to be insufficient weld penetration at the socket welds in the header during plant construction. The weld repairs required only two days but entry into the cold box required the removal of 10,000 cubic feet of insulation and a subsequent process derime to remove moisture and organics from the system. The repaired header was dye tested to insure full weld penetration and supports were added to further enhance reliability. This repair is covered in more detail in Section 5.0 Technical Performance.

Several projects were implemented in the ASU in 1999 to enhance plant performance. Those projects were:

- The adsorber sequencer valve solenoids, which were not rated for outdoor service, were upgraded to prevent the actuator from working itself loose from the valve. This problem was identified in the fourth quarter of 1998 when the actuator separated from the valve and resulted in a limit switch failure that prevented the regeneration sequence from completing. Additionally, a new bushing design was implemented on the adsorber system valve to correct previously identified problems.

- The inlet guide vane system on the MAC was replaced with upgraded actuators and several other modifications were made to insure reliability. These improvements are expected to 
eliminate the ASU's major cause of downtime since 1997 and are discussed further in Section 5.0 Technical Performance.

- Modifications to the water distribution trays in the water chiller tower were performed to address nitrogen production limitations experienced during the summer of 1999.

In addition to these projects, the ASU underwent a complete "derime" during an extended outage in the second quarter. A derime involves evacuation of all cryogenic liquids and warming the plant to drive all moisture and impurities from the system. This process is recommended at the frequency of every two years to ensure safe, reliable operation, free of ice and hydrocarbons. 


\subsubsection{Coal Handling}

$\underline{\text { Production Information }}$

Throughout the Demonstration Period, the gasifier operated on two different base coals, both individually and in a blended mode, as well as petroleum coke on a test basis. The gasifier is capable of handling feedstocks with a relatively wide range of characteristics; however, variations too far from the design basis coal could result in syngas and steam production limitations. Also, sudden changes in feedstocks, and thus their constituents, can be problematic if undetected; therefore, attempts were made to stay on top of feedstock analysis and blending activities.

Table 4.1.2A illustrates the average analysis by year for each feedstock during the Demonstration Period:

Table 4.1.2A: Feedstock Analysis

\begin{tabular}{|c|l|c|c|c|c|c|c|c|c|}
\cline { 3 - 10 } \multicolumn{2}{c|}{} & \multicolumn{9}{|c|}{ Dry Analysis } & \multicolumn{2}{c|}{ Heating Value } \\
\hline Year & Feedstock & $\begin{array}{c}\% \\
\text { Carbon }\end{array}$ & $\begin{array}{c}\% \\
\text { Hydrogen }\end{array}$ & $\begin{array}{c}\% \\
\text { Nitrogen }\end{array}$ & $\begin{array}{c}\% \\
\text { Oxygen }\end{array}$ & $\begin{array}{c}\% \\
\text { Sulfur }\end{array}$ & $\begin{array}{c}\% \\
\text { Ash }\end{array}$ & $\begin{array}{c}\text { Btu/lb - } \\
\text { as } \\
\text { received }\end{array}$ & $\begin{array}{c}\text { Btu/lb - } \\
\text { dry } \\
\text { basis }\end{array}$ \\
\hline 1996 & Hawthorne Coal & 70.2 & 4.56 & 1.45 & 7.91 & 2.42 & 13.46 & 10,733 & 12,483 \\
\hline 1997 & Hawthorne Coal & 70.15 & 4.84 & 1.32 & 8.13 & 2.57 & 12.93 & 10,812 & 12,652 \\
\hline 1997 & Pet coke & 87.49 & 2.74 & 0.99 & 3.08 & 5.17 & 0.52 & 14,282 & 15,353 \\
\hline 1998 & Hawthorne Coal & 69.58 & 4.55 & 1.08 & 8.48 & 2.85 & 13.5 & 10,645 & 12,566 \\
\hline 1998 & $\begin{array}{l}\text { Miller Creek } \\
\text { Coal }\end{array}$ & 65.89 & 4.0 & 1.38 & 7.06 & 3.45 & 12.07 & 10,765 & 12,890 \\
\hline \multirow{2}{*}{1999} & $\begin{array}{l}\text { Hawthorne / } \\
\text { Miller Creek } \\
\text { Blended Coal }\end{array}$ & 69.66 & 4.85 & 1.44 & 8.48 & 2.95 & 11.23 & 10,645 & 12,566 \\
\hline
\end{tabular}

In 1996, a total of approximately 184,382 tons (as received) of coal was processed through the rod mill with an equivalent heat rating of approximately 4,341,382 MMBtu.

In 1997, a total of approximately 374,822 tons (moisture free) of coal was processed through the rod mill. An additional 18,000 tons of petroleum coke (pet coke) were also processed during a 
trial run late in the fourth quarter. This accounted for an equivalent heat rating of approximately 8,910,111 MMBtu processed through the rodmill. Petroleum coke, while having a higher Btu value and lower ash content than Hawthorne coal, was blended with coal-generated slag to enhance slag flow characteristics (coal generated slag was used as a fluxing agent). Its effect on gasifier operation will be discussed later in this report.

In 1998, a total of approximately 561,495 tons (moisture free) of coal was processed through the rod mill with an equivalent heat rating of approximately 12,071,728 MMBtu.

Hawthorne and Miller Creek coals were fed at various ratios during 1998. Blends ratios were adjusted as necessary to ensure consistent gasifier performance.

In 1999, a total of approximately 369,589 tons (moisture free) of coal was processed through the rod mill. Slurry fed to the gasifier totaled approximately 7,772,568 MMBtu.

\section{Opportunities and Improvements}

Incoming coal fed to the rod mill is sampled via an automated sampling system. During 1996, extreme weather conditions contributed to two major mechanical failures of this automated sampling system. First, heavy snowfall resulted in a wet, sticky coal supply, which caused plugging problems with the sampler. To solve this problem, mechanical scrapers and vibrators were installed during the first quarter. With the additional installation of a non-stick coating to the inlet crusher chute in the second quarter, overall system reliability improved. The second problem resulted from coal dust during dry periods. Coal dust, dispersed by air movement generated by the system components, tended to collect around the pulleys of the belt conveyor and interfere with conveyor movement. To correct this problem, additional seals were installed in the system to limit air movement thereby limiting the amount of dust accumulation in this system. During periods when the mechanical samplers were out of service, Operations personnel hand sampled the coal to ensure feedstock consistency.

The rod mill is designed to crush the coal to a desired particle size distribution to ensure stable "slurryability" and optimum carbon conversion in the gasifier. In the third quarter of 1996, it 
was determined that the rod mill rod charge was insufficient to generate the optimum grind. Problems with coal slurry flow variations resulted from large coal particles in the check valves of the positive displacement gasifier feed pumps. Subsequent analysis of particle size distribution indicated that there was a significant increase in the distribution of larger particles, which warranted the addition of rods to the rod mill. Wear rate of the rod mill rods was within the manufacturer specifications for the number of hours of operation. Operation of the gasifier feed pumps returned to normal after adding the rods. A program was established to monitor the rod charge and rod mill performance more frequently for the need to adjust the rod charge. Areas of localized erosion and corrosion were identified throughout the slurry handling system during the year. Erosive and corrosive wear affected centrifugal slurry recirculation pumps, stainless steel pipe fittings, the inlet chute to the rod mill and piping in the slurry handling system. Where possible, hardened metal internal coatings were placed in the system while, in some cases, metallurgy had to be changed to improve equipment life.

The primary problems encountered in this area in 1997 centered around foreign material in the coal which caused rod mill wear and damage, especially on the trommel screen, which is designed to prevent oversized particles and debris from entering the coal slurry feed tank. During the second quarter of the year an excessive quantity of oversized limestone and other foreign material (e.g., metal objects) entered the mill causing an excess of large particles in the slurry (objects that lodge themselves between the rods during milling prevent effective crushing of the coal). This foreign material punched holes in the trommel screen allowing the oversized foreign material to pass to the slurry storage tank. This material eventually ended up partially plugging the check valves to the slurry feed pumps resulting in a plant shutdown due to fluctuations in slurry feed to the gasifier.

Fluctuations in slurry feed also caused slag flow problems in the gasifier, which eventually led to plugging of the taphole. Foreign material in the coal continued to be a problem in the third quarter, which prompted discussions of this problem with the mine operators. Diligence in the mining/blending operations and coal handling upgrades (magnetic separators on the belt feeder) resolved the problems. 
Due to problems encountered in 1997 with foreign material from the coal pile, rod mill rod charge and discharge trommel screen damage was monitored throughout the year. To reduce the occurrences of holes in the screen, a steel band was added to the end of the screen. Preventative maintenance (PM) inspections have been increased on the screen and the incidences of failure were minimized. Optimum slurry concentration (62-63\%) was monitored and rods replaced as necessary to ensure adequate system performance. In the fourth quarter, a slight increase in routine rod charge was implemented which led to finer slurry grind than normal. This resulted in increased reactivity of the slurry in the gasifier, and had a slight positive impact on the cold gas efficiency for the quarter. Overall, the coal preparation and slurry area was responsible for only $0.3 \%$ of the total plant downtime in 1998 .

During the first quarter of 1999, the trommel screen was replaced during an outage. The screen replacement provided the opportunity for some metallurgical improvements and the addition of erosion-resistant materials in the mill outlet chute. As a result of this project no further rod mill trommel screen failures were encountered during the Demonstration Period.

The ventilation system from the rod mill trommel screen shroud was upgraded as well. The ventilation upgrade increased the efficiency of the vent collection system thus lowering the ammonia (from recycled water) concentration in and around the rod mill building. Data from air monitoring collected during the second quarter, indicates more than an $80 \%$ reduction in ammonia concentration has been realized since implementation of this improvement.

In 1999, the coal handling area accounted for 61 hours of overall plant downtime (approximately $1.9 \%$ of total gasification plant downtime). In comparison, approximately 10 hours of total downtime was experienced in 1998 in this area. The following is a brief description of the causation factors and corrective measures that occurred in 1999:

- During a start-up in early February, the slurry feed system logged 23 hours of downtime due to problems with pumps and instrumentation. During two transfers to coal operation, a slurry pressure transmitter failed low, resulting in a slurry mixer trip. The associated shutdown 
alarm code was re-written in the second quarter to require low signals from both of the redundant pressure transmitters before initiating a slurry mixer trip.

- Additionally, during the same start-up period, a piston failure occurred on one of the positive displacement gasifier feed pumps. This resulted in contamination of the piston flush water with coal slurry, which necessitated shutting down of the remaining positive displacement pumps on this common flush system, interrupting coal operation for 5 hours. The root cause of the failure was prolonged use of a hard water supply for the piston flush system. Piston flush water is now supplied only from soft water sources.

- In June, July, September and December, failures in the slurry feed system resulted in trips off of coal operations resulting in a total of 16 hours of plant downtime. In each event, the suction of the slurry recirculation pump plugged, causing an interruption of slurry to the positive displacement gasifier feed pumps. The root cause of the problem was identified as excessive agitator blade wear in the slurry storage tank. The loss of effective agitation resulted in the accumulation of solids near the pump suction in the tank. When the accumulation became significant, the corresponding solids would dislodge and plug the suction of the recirculation pumps. To correct the problem, the blades on the agitator will be lengthened and coated with wear-resistant material during the spring outage in 2000 . This issue is discussed in more detail in Section 5.0 Technical Performance.

- Erosion of slurry piping components was responsible for stopping coal feed three times in October, which resulted in 22 hours of downtime. Two of the failures were attributed to inadequate material selection for valves in the coal slurry piping system. During the November outage, the failed valves, as well as some others, were upgraded to a more erosion/corrosion-resistant metallurgy. 


\subsubsection{Gasification}

\subsubsection{Gasification And Slag Handling}

\section{Production Information}

Figure 4.1.3A indicates the hours of operation, by quarter, for the gasifier during the Demonstration Period. The gasifier and downstream equipment is heated up from a cold start via the use of natural gas burners, which are referred to throughout the report as methane burners along with the period of heat-up as methane operations. At Wabash River, the natural gas used for this heat-up process is primarily composed of methane, hence the term methane operations. It must be reiterated that syngas generated during heat-up operations is not suitable for use as fuel for the combustion turbine and that coal/methane mix is simply a measure of transition from methane heat-up to coal operation. Methane operations presented in each graph indicate the total methane and coal/methane mix hours for heating of the gasifier and associated equipment and the transition into full coal operations.

During the operational campaigns in 1996, the gasifier operated on coal for 1,902 hours. During heat-up operations, the gasifier operated on methane and a blend of coal/methane for 1,990 hours. In 1997, gasifier operation improved over 1996. Coal operating hours increased approximately $200 \%$ over the previous year as the gasifier operated on coal for over 3,885 hours. A 215 hour run on pet coke in November of 1997 is included in the coal hours for 1997. During heat-up operations, the gasifier operated on methane and a blend of coal/methane for 1,490 hours. During the 1998 operational period the gasifier operated on coal 5,278 hours, which represented an increase over 1997 operations of 144\%. During heat-up operations in 1998, the gasifier operated on methane and a blend of coal/methane for 976 hours. The 1998 methane operation hours were substantially reduced from the 1997 total, illustrating increased operator experience, newly established procedures to limit start-up time, and fewer unscheduled outages. Finally, in 1999, the gasifier operated on coal 3,496 hours. Included in the coal hours for 1999 is a 77-hour run on pet coke. During heat-up operations in 1999, the gasifier operated on methane and a blend of coal/methane for 933 hours. 

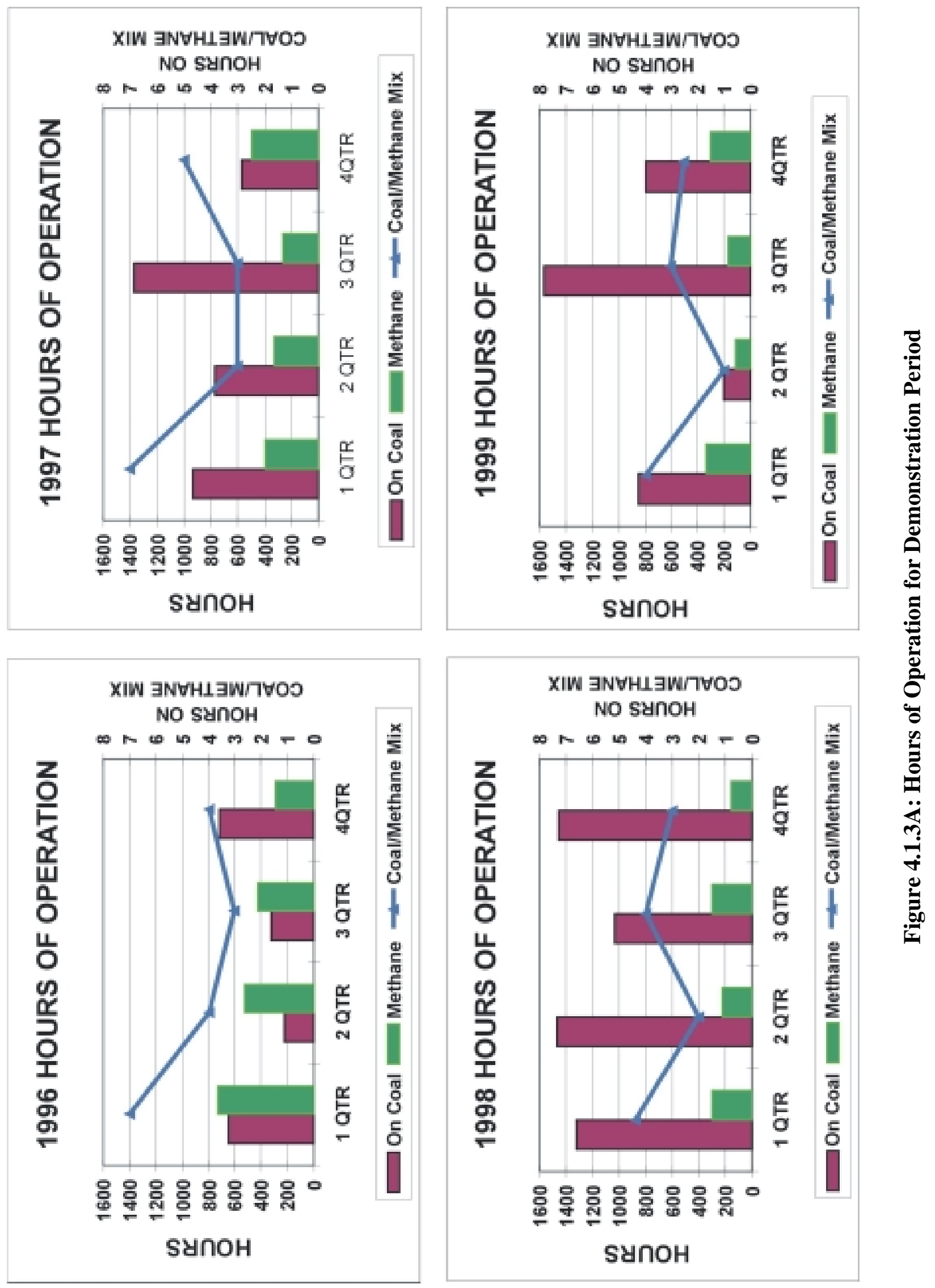

Wabash River Coal Gasification Repowering Project Final Technical Report 
Table 4.1.3B indicates the tons of coal fed to the gasifier by month for the duration of the Demonstration Period. In 1996, coal to the gasifier totaled over 180,000 tons and oxygen from the ASU to the gasifier totaled in excess of 160,000 tons. This combined feed was utilized in the production of over 2,769,600 MMBtu of syngas. By-product slag from the process totaled approximately 23,288 tons. With the increase of coal operation hours in 1997, coal to the gasifier also increased, totaling over 374,822 tons for 1997. Additionally, 18,000 tons of pet coke were processed in the gasifier. Oxygen from the ASU to the gasifier totaled 328,600 tons. Syngas production topped 6,200,000 MMBtu while 51,417 tons of by-product slag was produced. The production increase in 1998 was also significant. Coal feed to the gasifier totaled 561,494 tons for 1998 and oxygen feed from the ASU to the gasifier totaled 442,000 tons. The production of 8,884,902 MMBtu of on-spec syngas represents a significant increase over 1997 production. The amount of by-product slag produced from the process totaled approximately 70,228 tons. Finally, coal and pet coke feed to the gasifier totaled 315,951 tons for 1999 and oxygen feed from the ASU to the gasifier was 289,930 tons. This combined feed was utilized in the production of 5,813,151 MMBtu of on-spec syngas. Production was significantly impacted by a combustion turbine failure in mid-March lasting into June and by failure of a recycle line in the particulate removal system in November. More detail on these outages is contained in the following sections. The amount of by-product slag produced from the process in 1999 was 45,216 tons.

\section{Opportunities and Improvements}

Three areas of concern in the gasifier system were identified in 1996 that were run limiters or represented potential reductions of equipment service life. Those three areas were:

- Burner Longevity

- Refractory Life

- System Ash Deposition

In the first quarter of 1996, the plant experienced three failures of slurry mixers on the gasifier. Investigation revealed that all three failures were similar in nature and were attributed to coal slurry backing into the oxygen space in the burner during the transition to coal operations. Valve 
sequence timing modifications were completed to prevent recurrence. No similar failures occurred during the remainder of 1996.

In an effort to reduce ash deposition and increase gasifier efficiency, new offset mixers were installed in the fourth quarter of 1996. The offset mixer operation seemed to result in a reduction in ash deposition downstream of the gasifier; however, the carbon content in the slag was elevated, indicating possible lower gasification efficiency. Further testing of offset mixers was discontinued in lieu of alternate initiatives to address ash deposition and mixer efficiency. Later in the third quarter, a new refractory was tested in the gasifier outlet piping where ash deposition was a problem. The results showed promising reductions in ash deposition from the previous refractory, all of the entire outlet pipe refractory was replaced on the next outage. Deposition occurring in the second stage gasifier and continuing through the high temperature heat recovery unit (high pressure steam boiler) created difficulty in maintaining operation and extended scheduled shutdowns due to the necessity to remove the deposits. Plugging of the boiler tubes by material spalled from ash deposits increased equipment downtime due to the time required to remove the deposits. Minor changes have occurred through 1996, from varying operational temperatures in the gasifier and associated equipment, to changes in the type of brick in the system. The rate of ash deposition is also proportional to the number of thermal cycles (full or partial load trips) experienced in the system.

In 1996, there were 51 separate trips of the gasifier off of coal operation that contributed to ash deposition and subsequent spalling of these deposits. With increased run-time on the gasifier, increased operational experience was gained and more reliable equipment operation was achieved, thereby reducing the number of thermal cycles on the gasification system and subsequently reducing the potential for system deposition and associated problems downstream.

During a routine inspection of the first stage gasifier refractory lining, the wear rate was found to be significantly greater than anticipated. Core sampling of the lining indicated a failure associated with the bond matrix of the refractory brick. An alternate refractory brick test panel was placed in service to evaluate it for future use. 

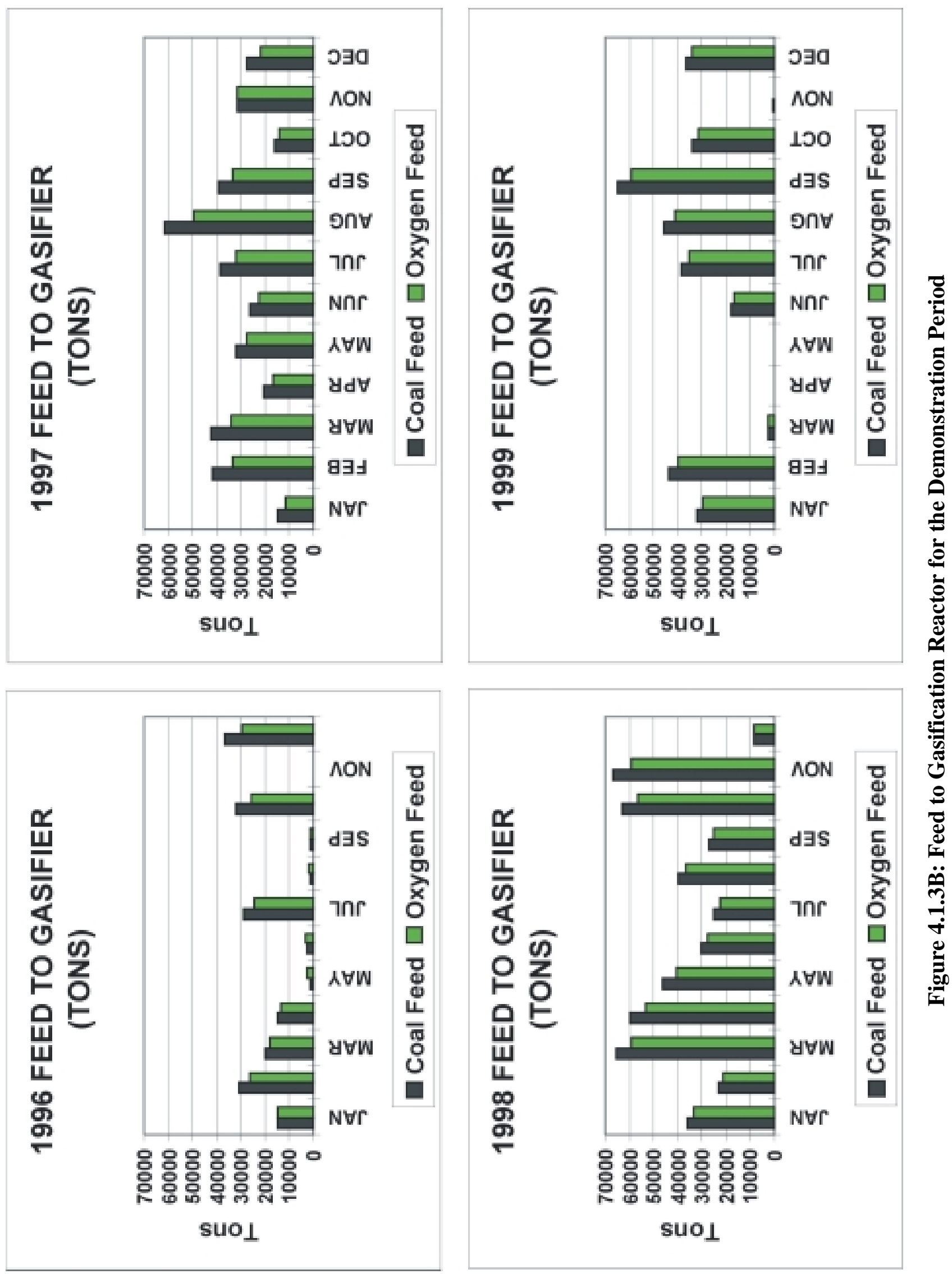

Wabash River Coal Gasification Repowering Project Final Technical Report 
In October of 1996, a failure in the gasifier water-cooled nozzle system caused a plant outage. Several devices on the gasifier are cooled by water contained in a closed-loop system. In the event of a leak in a device or in the piping, this closed-loop system receives make-up water from a high-pressure (1,800 psig) boiler feedwater source. Flashing of the 1,800 psig water stream as it flows into the lower pressure (450 psig) cooling loop caused a piping failure and subsequent failure of the cooling system. The make-up piping was re-designed to eliminate these problems. The following modifications took place in 1997 to improve overall performance:

- As a follow-up to the gasifier nozzle water-cooling system failure in 1996, the source of the make-up water to this system was changed from high-pressure boiler feedwater to medium pressure cold condensate. The new make-up source has eliminated the vibration experienced from the flashing flow of the boiler feedwater.

In addition to the problems associated with the cooling water loop above, failure of tubes in the cooling water loop heat exchanger also occurred. Shell-side boiling of the cooling water along with induced vibration, eventually caused damage to the exchanger tubes. Corrective measures included increasing cooling water flow to the exchanger and installation of a new cold condensate makeup line.

During a third quarter inspection of the first stage gasifier in 1997, it was noted that there was substantial refractory wear in certain areas. While the gasifier could have been repaired in the worn areas and put back into service for the next operational run, the decision was made to swap to the spare gasifier. The spare gasifier had been equipped with new brick material based on the information gained from the wear rate data experienced in the "running" gasifier. Re-bricking of the gasifier that was taken out of service with upgraded materials could now be accomplished while running on the spare gasifier.

One project, identified to extend run-time by reducing deposition, was implemented in the third quarter. It involved a redesigned piping arrangement between the gasifier and the post gasifier residence vessel. The new post-gasifier pipe spool was designed to reduce deposition and help eliminate stress between the two vessels. By design, the new transition piece created a smoother 
gas flow path between the two vessels for the particulate-laden raw syngas. The old design utilized a straight piece of transitional piping that connected to the gasifier second stage and the post gasifier residence vessel just below the tops of both vessels. The abrupt change in the gas flow direction caused solids impingement resulting in ash deposition. This resulted in problems related to vessel hot spots and spalling of deposits. The new transition pipe was very successful in resolving the problems encountered.

Several minor problems were identified in 1997, which led to a decrease in gasifier efficiency or the shutdown of the operation. Those specific problems and corrective actions are identified below:

- During the first quarter of 1997, slag flow was lost due to insufficient flow of extraction gas (raw syngas utilized during normal operation to enhance slag flow) through the taphole. Loss of extraction gas flow caused a taphole plug, which eventually led to a shutdown of the gasifier. An investigation into the problem indicated that there was no mechanical process that needed evaluation or correction, but the problem existed in the computer control code for the gasifier. The control code was revised to ensure the presence of adequate extraction gas flow and to give operators a more accurate means of monitoring flow measurement. Once the control code was modified, no further problems with gasifier operation were noted due to extraction gas flow control.

- In the second quarter, following an inspection of the slag handling system, a significant amount of scaling was identified in the piping and equipment downstream of the slag crushers. Following laboratory testing, a scale inhibitor was added to the flow stream to reduce scale formation and the potential for slag flow reduction due to restriction of the lines.

- A raw syngas analyzer failed in the third quarter due to erosion from a high velocity of particulate-laden gas passing through the flow meter and associated piping. The situation was temporarily corrected by increasing the piping diameter for the flow meter to reduce velocity. Following a recurrence of the problem in September, it was decided that the analyzer would have to be isolated from the main gas path if the problem was going to be corrected. The analyzer inlet configuration was subsequently rearranged, utilizing a side stream path with less velocity. No further problems were directly associated with this unit. 
During the first operational run in September, the redundant slurry flow meters (measuring flow to the gasifier) began deviating (from set point) significantly, which reduced the stability of the slurry flow to the gasifier (which is a primary control point for gasifier operation). The deviations became so severe that they eventually caused a shutdown of the gasifier due to the inability of the control system to properly adjust oxygen-to-coal ratios to the flow deviations. To correct this problem, a more aggressive preventative maintenance schedule for the flow meters was implemented.

- In the fourth quarter, an area of the gasifier steel shell developed a "hot spot" that required the application of cooling water to prevent thermal damage to the shell. When applying the cooling water spray, the water ran down one side of the gasifier creating unequal thermal growth between sides of the vessel and subsequent vessel movement. This, in turn, caused a misalignment of the slag crushers that ultimately caused a failure of one of the crusher couplings. The cooling water flow was drastically reduced to a "mist" which alleviated the problem of unequal thermal growth and no further failures were encountered. The hot spot was repaired internally during the next scheduled outage.

During November of 1997, a successful test run on an alternate feedstock (pet coke) was completed. From November 17-26, approximately 18,000 tons of petroleum coke were successfully gasified and used for power generation. Due to the higher Btu value of the pet coke, full syngas capacity was achieved at substantially lower slurry feed rates than are necessary with coal. Slag production decreased due to the much lower ash content of the feedstock. Additionally, the sulfur recovery unit operated at peak efficiencies during the trial run due to the higher sulfur content of the pet coke.

In 1998 the gasification and slag handling area contributed approximately 14.7\%, or 286 hours, of downtime due to associated equipment failures or operational difficulties encountered with the alternate coal feedstock. Ash deposition from the gasifier to the inlet of the high temperature heat recovery unit did not contribute to downtime in 1998, an indication that prior actions have alleviated this problem. 


\section{Slurry Mixers}

Slurry mixers continued to be a source of downtime due to the corrosive/erosive nature of the slurry (and slurry/oxygen mix) and efforts continued throughout 1998 to improve the design and operation of these units. The following is an overall summary of downtime contributors and the corrective actions taken, or in progress, for 1998:

- Two coal runs in early January ended due to slurry mixer failures. A third, similar mixer failure occurred during the first run of February. Investigation of these incidents revealed that the slurry flow rate at the time oxygen was introduced to the mixers was $40 \%$ higher than in previous coal start-ups. The oxygen flow controller exceeded the set point at the higher slurry flow resulting in a high transient temperature during the start-up, which damaged the mixer. Following these failures, the slurry flow set point for start-up was lowered and emphasized in operator run plans.

- Despite the above operating improvements, a fourth slurry mixer failure occurred in early March. However, unlike the previous three failures, which exhibited excessive cooling media loss, this failure was traced to a failure in the oxygen feed section of the mixer. The other mixer was shutdown in a controlled fashion to take the gasifier off line and allow change out of the failed mixer, which was eroded by the coal/water slurry. Inspections of these parts are now carried out with greater scrutiny during mixer rebuilds to accurately identify necessary repairs or component replacements.

- In early August, following an oxygen compressor trip, some difficulty was experienced returning to coal operations. As oxygen feed was initiated to the mixer, the gasifier tripped on high temperature. The root cause was traced to a slag mound in front of the mixer, which prevented proper mixing of the oxygen and slurry and resulted in high temperatures. Characteristic of sudden losses of oxygen (as is the case with an oxygen plant trip) slag quickly freezes in the gasifier and must be heated above melting points on re-start to allow de-slagging prior to reintroduction of slurry. To remove slag mounds after oxygen plant trips, a procedural change was implemented, requiring the reactor to be de-slagged longer before returning to coal operations.

- Newly designed mixers, intended to enhance slurry/oxygen mixing, were installed in the gasifier late in the third quarter of 1998. While they were in service, the gasification plant 
was able to make syngas capacity at slurry rates $4-6 \%$ lower than normal, indicating improved conversion efficiency.

- In early October, an internal cooling media leak was detected on one of the new mixers, previously mentioned, so both were replaced at the next opportunity. Internal inspection of the mixers revealed that swirling flow characteristic of the new design, accelerated the erosion of the mixer, which significantly shortened the mixer life. Standard mixers were reinstalled and coal operations resumed.

\section{Taphole Plugging}

The "taphole" refers to the transition opening located in the center of the horizontal section of the gasifier that allows slag to flow into the slag quenching section. Plugging becomes a problem when characteristics of the slag change, which decrease its ability to flow as a liquid. The following events contributed to downtime in 1998 as a direct result of taphole plugging:

- An extended outage of 20 days occurred when a gasifier taphole plug forced the unit off of coal operations in late June. Subsequent de-slagging attempts on methane operations were unsuccessful so the gasifier was shutdown for manual removal of the plug. Investigation revealed that slag had not only plugged the taphole but bridged over the grinders as well, which prevented slag from exiting the gasifier. The root cause of the incident appears to have been a combination of events. Higher slag viscosity in the Miller Creek coal was the primary factor, but this was exacerbated by the fact that the gasifier was run slightly cooler due to fouling problems in the high temperature heat recovery boiler and high-level excursions in the dry char recovery vessel. Improved knowledge of Miller Creek slag behavior and new operating guidelines allowed successful gasifier operation on various blends of Miller Creek and Hawthorn coal for the remainder of the year. Since establishing new guidelines, no unusual slag flow or ash deposition problems have been noted as a result of using Miller Creek coal.

- A taphole plug during methane operation shutdown coal operations in late December. Preliminary investigation indicates that an ash deposit fell from the second stage gasifier and blocked the taphole. Maintenance personnel were able to clear the plug within four days and heat-up operations were reinitiated. 
In 1999, the gasification and slag handling area contributed 806 hours of downtime due to associated equipment failures or operational difficulties encountered with the alternate coal feedstock. The following represents some specific equipment and operational issues encountered and resolved in 1999 .

Operations were terminated in January of 1999 due to plugging of the gasifier slag taphole. The cause of the taphole plug was related to a batch of coal with abnormally high ash fusion temperature. Increased number of lab analyses of the slurry fed to the gasifier have been implemented in an effort to catch feed abnormalities and respond more quickly in the future. Improved guidelines relative to the gasifier operating temperature have also been established.

Testing conducted in the first quarter on scale model mixers resulted in a new mixer design that was installed in the gasifier during the second quarter. The new mixers demonstrated good performance from the outset as evidenced by increased cold gas efficiency and lower carbon content in the slag. By the end of the third quarter, the new mixers had exceeded expectations by accumulating over 1,800 coal hours with no evidence of degraded performance. In October, after approximately 1,980 hours of operation, one of the mixers failed due to thermal stress in the metallic mixer face. At the time of this failure, inspection of the other slurry mixer revealed minimal wear; however, the mixer was not placed back in service but, was disassembled and inspected further for learning value. The geometry of future mixer faces was modified to relieve some of the stress and the metallurgy of the mixer face will be upgraded to better resist stress cracking.

During 1999 some mechanical difficulties that led to plant downtime were identified in the slag system and are described below:

- During the first quarter, a slag precrusher motor trip resulted in transfer off of coal. The root cause of the problem was identified as reversed wiring of the slag pre-crusher motor causing it to run backwards. The motor was rewired and no further problems were noted. 
- Slag crusher packing leaks resulted in 2.5 days of downtime in August. A manufacturer applied (owner specified) coating on the grinder shafts was found to be incompatible with the shaft metal, which caused the coating to break loose from the shaft and begin cutting into the packing. A packing injection pump was installed in early August to enable packing additions; but the situation deteriorated until it became impossible to maintain an adequate seal. Subsequently, an additional packing ring follower and packing was installed over the existing stuffing box, which minimized leakage so that operations could continue safely without excessive packing addition. Due to the time required to facilitate a shaft replacement, a suitable coating will be applied to the grinder shaft when the on-line gasifier is taken out of service for re-bricking in 2000. The crusher shafts for the off-line gasifier have been re-coated with the proper material to ensure that this problem does not recur when the off-line gasifier is placed back in service.

- In late December of 1999 , the slag crusher began experiencing packing leaks similar to those encountered on the slag pre-crusher. The addition of an auxiliary packing ring installed over the stuffing box was not successful in stopping the leak. To properly repair the leak, the plant was down for 42 hours to add larger packing to the stuffing box. The root cause of this failure was identified as inappropriate coating on the grinder shaft, as was the case with the slag pre-crusher. 


\subsubsection{Syngas Cooling, Particulate Removal And COS Hydrolysis}

\section{Syngas Cooling}

Figure 4.1.3A indicates total high-pressure steam production from the High Temperature Heat Recovery Unit (HTHRU) by month for the Demonstration Period. Steam production, as shown in each graph, tracks the operational run history of the gasifier but is also impacted by deposition problems in the heat recovery boiler.

Total 1,600 psig steam production for 1996 was approximately 820 million pounds. Total steam production for 1997 increased over 200\% from 1996, as did most other operational parameters. While the HTHRU continued to experience fouling problems, new methods of cleaning the tubes were incorporated into the maintenance program allowing operations to come back on line with an outlet temperature close to design. Steam production for 1998 was approximately 2,190 million pounds. This figure represents a production increase of approximately 129\% over 1997 and a production in excess of 269\% over 1996 steam production figures. In 1999, total 1600 psig steam production was approximately 1,481 million pounds. This decrease from 1998 was primarily due to the loss of the availability of the combustion turbine late in the first quarter. Additionally, production figures were low in November due to a planned outage and the failure of a recycle line in the particulate removal system and subsequent fire, which caused significant damage to the electrical circuitry of the main gasifier structure.

\section{Opportunities and Improvements}

Ash deposition in the HTHRU and associated equipment was of great concern during the early operation. As discussed in the gasification section, thermal cycles of the hot gas path were a leading contributor to HTHRU plugging due to spalling of ash deposits in upstream equipment and piping. Solids accumulation at the tubesheet causes tube plugging and high differential pressures. At some point, the solids-laden gas through the open tubes reaches a velocity high enough to cause erosion. To help control ash deposition in the tubes of the HTHRU, a boiler inlet screen was installed in the third quarter of 1996 to prevent large particles from reaching the tubesheet. 

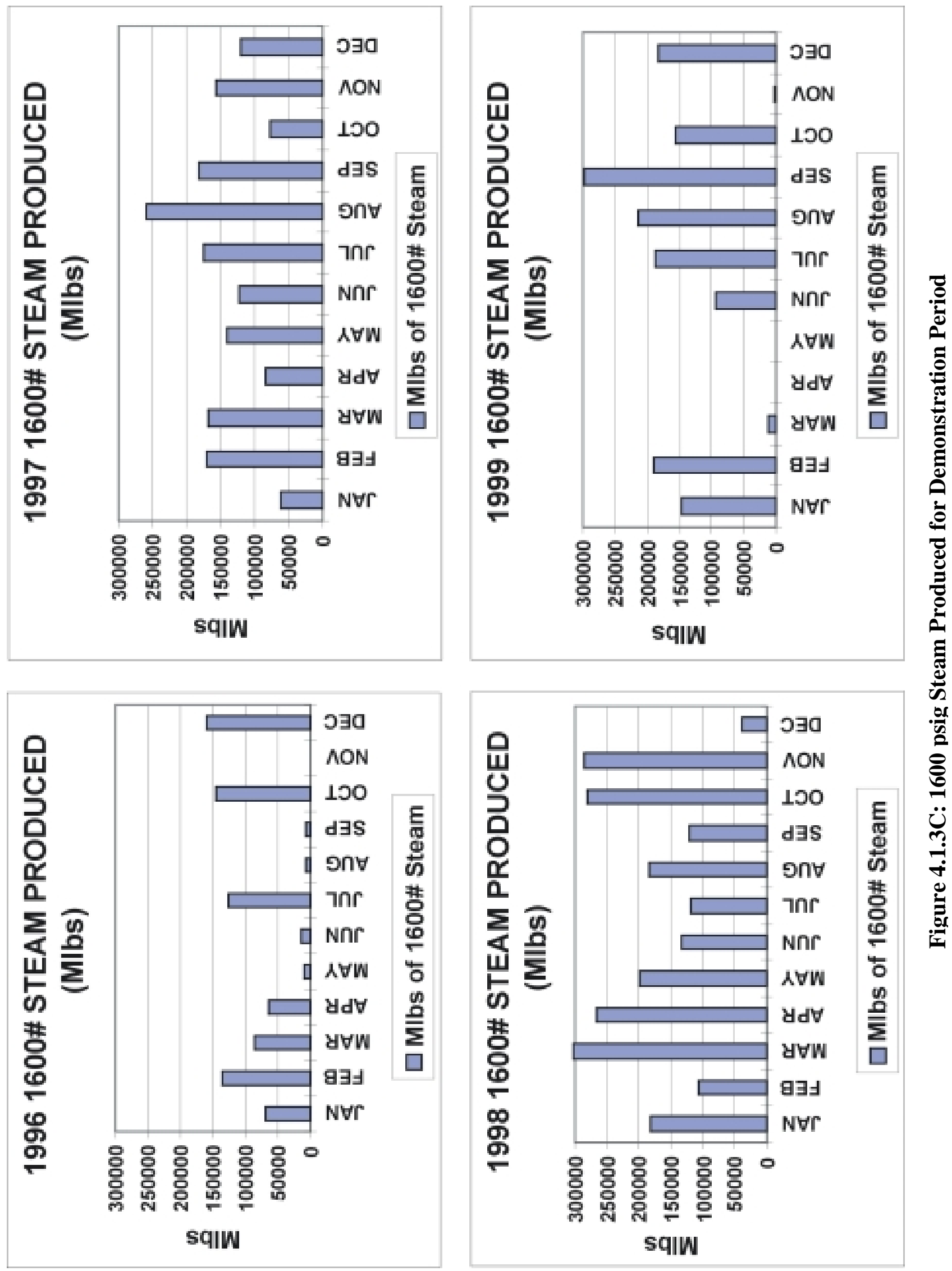

Wabash River Coal Gasification Repowering Project Final Technical Report 
Deposition and corrosion within the HTHRU continued to be addressed in 1997. Several major projects and improvements occurred during the year to enhance system performance and improve reliability. Those include:

- The post gasifier pipe spool was replaced with a long, sweeping, 180 degree ell that provides significantly lower velocities between the second stage gasifier and the post gasifier residence vessel. This modification dramatically reduced ash deposition near the exit of the gasifier, meaning less ash deposits to break loose and plug the HTHRU.

- Thermal cycles (shutdown and start-up) not only affected deposition in the system but also served to accentuate installation flaws within the piping scheme. In March of 1997, due to misalignment of a piping spool during construction/installation, a syngas leak developed in a spool piece on the outlet of the HTHRU. The released gas combusted as it leaked from the process causing a small fire and subsequent shutdown of the gasification process. In the process of purging the system with nitrogen, the flare pilot was extinguished resulting in an odor noticeable in the surrounding area (due to minor concentrations of hydrogen sulfide in the purge gas). After this release, the spool flanges were re-machined and the pipe reconnected with a new gasket. Later in the Demonstration Period, the flanged pipe spool was permanently removed and replaced with a welded-in piping section to eliminate this potential source of leakage.

Into the third year of the Demonstration Period (1998), an upgraded boiler inlet screen was installed. Due to the corrosive/erosive service, upgraded materials of construction and design changes were implemented to extend the life of the screen. Following the installation of the new screen early in the second quarter of 1998, the screen remained in place for the remainder of the year, experiencing only normal wear while limiting deposition on the boiler inlet.

The post gasifier pipe spool installed in 1997 dramatically reduced ash deposition in the gas path. However, inlet screen corrosion and the maintenance required to remove boiler tube fouling resulted in 160 hours of downtime in 1998. 
- Although not directly responsible for downtime, heavy fouling of the HTHRU tubes during 1998 caused the unit to operate at elevated syngas outlet temperatures. While this does not pose an imminent problem with the HTHRU, itself, elevated syngas temperatures (in combination with the acid gas environment) cause accelerated corrosion rates downstream. Attempts to remove the deposits off line with high-pressure hydro-blast rigs, mechanical scrapers and knockers were only marginally successful.

- In the third quarter, chemical cleaning of the boiler tubes was completed with excellent results. Upon returning to operation, an approximate $100^{\circ} \mathrm{F}$ decrease in heat recovery boiler syngas outlet temperature was noted, which essentially restored the heat transfer area to near new conditions. Although the chemical cleaning was very successful, it was also very costly and presented an increased risk of chemical exposure to plant personnel. Therefore, an effort to develop acceptable mechanical cleaning methods is ongoing.

- Boiler fouling accelerated in June of 1998 while operating with Miller Creek coal as a primary feedstock. A significant increase in boiler syngas outlet temperature was observed as the unit continued to operate on this Miller Creek coal feedstock. By the end of June, when the boiler was opened during an outage, an increased degree of deposition was found on the tubesheet screen and boiler tubes. The boiler fouling experienced while processing Miller Creek coal was caused by the higher iron content in the ash. Iron reduces the viscosity of molten ash entrained in the gas, which increases its tendency to adhere to surfaces such as the boiler screen and tube walls. It was found that by running the boiler inlet temperature cooler, the ash viscosity increases, thus minimizing its fouling characteristics.

- In August of 1998, utilizing modified operating parameters, the plant successfully processed a 25\% Miller Creek/Hawthorne blend with acceptable boiler fouling when compared to the initial run in June. However, boiler fouling continued to be a run-limiting concern during the fourth quarter campaign. During a scheduled December outage, cleaning of the boiler deposits continued to result in higher-than-desired maintenance cost. Various mechanical cleaning methods were utilized to clean the boiler tubes. Although improvements to cleaning methods were noted, continual investigation into improved cleaning methods was necessary during the fourth year of the Demonstration Period. 
The boiler fouling "opportunity" became a strong focus for plant personnel in 1999. During the extended outage following the combustion turbine compressor failure in March 1999, a new process to mechanically clean the boiler tubes was developed. The new process utilizes coredrilling bits and apparatus developed on-site. The new method restored the boiler tubes to "likenew" condition during a planned 3-week outage. The outlet temperature of the boiler, when returned to operation, was approximately $20-40^{\circ} \mathrm{F}$ lower than it had been in the previous two years, which is an indication of significantly improved heat transfer. The lower temperature should reduce the corrosion rate of the downstream metallic particulate removal system filter elements and appears to have decreased the filter-blinding rate as well. Modified HTHRU operating parameters have reduced the fouling rate, such that current projections indicate that six months of run-time can be achieved before process-side boiler cleaning is required.

During the October 1999 outage, the HTHRU tubes were again successfully cleaned to "likenew" condition, although approximately 8 days of the downtime was required for the cleaning. Continued optimization of operating and cleaning methods will remain a focus after the Demonstration Period.

\section{$\underline{\text { Particulate Removal }}$}

During the first quarter of 1996, 5 different interruptions in coal operation occurred due to the particulate removal system filters. One interruption was caused by erosion in the char recycle line that transports the filtered char back to the first stage gasifier. Erosion-resistant linings were used to address this problem. The other four interruptions were due to high blinding rates of the filter elements. As the filter element pores are permanently blinded, the differential pressure across the filters increases until the system design constraints are exceeded and the unit must be shutdown.

During this first year of the Demonstration Period, localized erosion in several areas of the char filtration system was encountered, including the filter elements, gas distribution piping, char conveying ejectors, and the char recycle piping. These problems were systematically addressed as they occurred and began an ongoing improvement effort that would extend well into the balance of the Demonstration Period. 
The primary cause of char filtration related downtime during this first year of operation stemmed from repeated problems with leakage of char through the tie-rod candle filter elements. Three outages were caused directly from either breakage of ceramic candle elements or leakage of gasketing used in the primary filter system. Although the plant utilized a secondary filter system, this backup system was not adequate to sustain operation with appreciable leakage of char through the primary system. Improvements to the particulate removal system in 1996 included the previously mentioned upgrades to manage localized erosion. Other improvements were: increasing the effectiveness of the primary and secondary pulse gas systems, modifying the gas distribution system to provide more even flow distribution in the vessels to prevent filter system erosion and char bridging, and a replacement of the ceramic tie-rod type filter elements with more robust metal filter elements.

The installation of metal elements in late 1996 immediately improved the reliability of the particulate removal system and started a learning curve on metal filter elements that would last for the remainder of the Demonstration Period. In conjunction with the installation of metal filters, a heat exchanger was installed to increase the temperature of filter pulse gas above the syngas dew point, thereby reducing the tendency for fouling and corrosion of the elements due to syngas condensation.

Although the dry char filtering system continued to demonstrate improved performance throughout 1997, the system was still on a steep improvement curve in the operational area and in the area of design and metallurgy. Significant events during the year include:

- During the first quarter 1997, and after installation of first generation metal filter candles in the fourth quarter of 1996, a single gasifier trip in January was caused by primary filter failure. The failure was due to a combination of corrosion-weakened metal filters and flow surges through the vessels caused by backpulse valve failures. The failure of the backpulse valves prevented the cleaning of certain element clusters, causing them to blind off the flow through the filters. During that time, flow imbalances caused a significantly increased flow of gas through the clean filters, damaging the already weakened filter elements. Some of the 
experimental metallurgy utilized for filter construction during this run showed evidence of corrosion after only 523 hours of service and one type was corroded to the extent that the filters lost strength and ductility. During the ensuing plant outage, all of the filters of this type were replaced with filters of alternate metallurgies that demonstrated superior resistance to corrosion. All of the pulse valves were disassembled and many were found to have extensive seat damage. The valves were rebuilt and the pulse gas heat exchanger was taken out of service for the next run, since the hotter pulse gas was believed to be contributing to the valve failures. Leakage of the valve seats effectively stopped after this correction. Overall, the particulate removal system continued to operate acceptably until additional problems occurred in the fourth quarter of 1997, when it caused the plant to be brought off line four times. Three of the four occurrences were caused by flow imbalances between the two vessels and poor char recycle ejector performance, preventing the flow of char from the vessels. A dimensional discrepancy in one of the recently-fabricated ejector internal parts was determined to be the cause of this failure.

- High primary filter blinding rates continued in the fourth quarter of 1997 and, as a result, the filters were removed and externally cleaned during an extended plant outage in October. The high blinding rate was partially caused by a HTHRU tube leak. Filter blinding rates were again high during the period preceding the pet coke test in September 1997. Upon completing this test, the filters were again cleaned in early December, utilizing a new cleaning procedure that proved more effective. As a result, the primary char filter vessel differential pressures in December were much lower compared to the October start-up.

Other enhancements to the system in 1997, including a modification to the internal inlet gas distribution system in the dry char vessels and installation of a new test unit, continued to provide longer operational time frames. Specifically, those items were:

- A design change was made to provide more uniform flow distribution throughout the vessel, thereby reducing both the gas velocity in the high-wear areas of the inlet distributor piping and the particle impingement velocity on the filters.

- Initial construction began on a new Dry Char Slipstream unit (DOE Cooperative Agreement No. DE-FC26-97FT34158), which will provide the opportunity to test filter elements and 
materials of construction outside of the primary filtration vessels. The project was completed and put into service during the fourth quarter of 1997.

In 1997 the particulate removal system accounted for approximately 25\% (706 hours) of total plant downtime. In 1998, through an increased understanding of system operation and continuing research into filter element composition and design, plant downtime due to the particulate removal system was reduced to 180 hours or only $9.3 \%$ of total downtime for the plant.

The following key areas of operation and mechanical malfunction were responsible for the majority of the downtime for 1998:

- The particulate removal system continued to experience high primary filter blinding rates, initially experienced in the fourth quarter of 1997, until the February 1998 outage. In this outage, new filter elements with increased resistance to blinding were installed. The particulate removal system operated with minimal primary filter blinding until early in the third quarter when, during an outage, the filter system required cleaning and some replacements of filter elements. Due to supply constraints of the newer filter elements, older elements more susceptible to blinding were reinstalled in July. The high blinding rate limited the length of the subsequent run to 846 hours, forcing a plant outage in early September. A combination of old and new style elements was installed in September to maximize run-time and minimize cost.

- In April 1998, one of the char ejectors was replaced with a modified ejector, designed for improved erosion-resistance. Later in the run, the ejector failed due to a manufacturing error during the unit's previous rebuild. The failure resulted in a high level in the dry char vessel that resulted in fluctuations in the gasifier temperature when char was emptied from the vessel. These thermal excursions, combined with the high slag viscosity associated with Miller Creek coal, resulted in gasifier taphole plugging problems that caused a plant outage. Failed dry char ejectors again contributed to downtime in July and August, however the downtime was limited to only 3-4 hours in each instance. Further improvements were made to the dry char ejectors and new ejectors were in service for the remainder of 1998 . While 
changing the failed ejector in August, a backpulse valve was also changed due to leak-by when in the closed position. Upon return to coal operations, a second backpulse valve was discovered to be leaking. The run was terminated to allow replacement of the valve. The root cause of the failures was high pulse gas temperatures that resulted when the pulse gas heater, used during start-up operations, was left in service after coal operation was established. Operations personnel were re-instructed on the proper use of this heater to prevent future pulse valve failures.

- The first run following the third quarter 1998 scheduled outage was terminated due to a leak, and subsequent fire, on the primary char filter vessel inlet flange. The leak is suspected to have resulted from pipe movement encountered when new primary char filter vessel inlet isolation block valves were installed in this system (discussed below). Installation of the new valves did not include inspection of downstream piping so it is possible that a shift in the flanges would lead to a breach in the gasket-sealing surface. The leak was wire wrapped and clamped to allow safe return to operation with a permanent repair made at the next planned outage. Inspection during a fourth quarter outage confirmed that misalignment of the sealing surfaces was indeed the root cause of this incident. This was an isolated case that can be associated with project implementation in a very specific area.

Several projects/equipment enhancements were made to the particulate removal system to enhance performance and/or to improve operability. The following were accomplished in 1998:

- A test cluster of ceramic filters, previously tested in the slipstream unit, was installed in one of the primary vessels for evaluation. To avoid jeopardizing plant availability, fail-safe devices were installed to prevent char breakthrough if a filter element failed. The fail-safe devices were installed after extensive testing and evaluation and are used as a back up to the primary dry char filters. The fail-safe device is a highly porous filter used to capture solids that might breakthrough the primary filter elements. These devices were installed on all alloy filter elements that were most susceptible to corrosion-related failures.

- Additionally, testing continued on several corrosion-resistant filter alloys, which yielded some promising results. Corrosion rate data suggested that one of these alloys could more than double the life of the filters currently in service. 
- The butterfly valves at the inlet to the particulate removal system were replaced with ball valves during the September outage. Positive shutoff with the previous valves was impossible, resulting in extended cooling and heating times for shutdowns and start-ups, respectively.

- Initial testing of an improved seat design for primary char filter system backpulse valves was conducted. The evaluation proved the new design to be much more reliable than the original style valve seats. Consequently, all backpulse valves were converted to the improved seat design. This eliminated all of the valve failure problems previously associated with seat failures.

In 1999, the particulate removal system accounted for approximately $12.9 \%$ of total facility downtime (772 hours) primarily due to the failure of the inlet line and char breakthrough in the system due to a ceramic element failure. Comparatively, 1999 downtime hours are significantly higher than the 1998 total of 180 hours and slightly higher than the total 1997 hours of 706.

The following key areas of operation and mechanical malfunction were responsible for the majority of the downtime for 1999:

- During the first quarter, a failure of a ceramic filter element in the particulate removal system resulted in a transfer off of coal and nearly two weeks of downtime. During the December 1998 outage, a test cluster of ceramic filters (previously tested successfully in the slipstream unit) was installed in one of the primary char filter vessels. A defect in the element support hardware resulted in a premature failure of one of the filter elements.

- During the October outage, high-wear areas of the dry char recycle piping were replaced with erosion-resistant material. Shortly after returning the unit to coal operations in November, a failure occurred in one of the new segments of erosion-resistant pipe, which resulted in a syngas leak. The leak ignited and the subsequent fire caused damage to an adjacent cable tray. The cause of the piping failure was traced to pieces of polyvinyl chloride left in the piping by the manufacturer during installation of the lining. The material decomposed at process temperatures and resulted in excessive and rapid chloride stress-corrosion-cracking of the piping. Subsequently, all of the recently installed piping was replaced with new piping 
in which tighter quality control of the manufacturing process was exercised, including having

a company representative personally witness the assembly of the piping. Approximately 18 days of downtime resulted from the failure and the associated replacement of piping, burned instrument wiring, and cable tray repairs.

Key positive indicators of particulate removal system performance during 1999 include:

- The dry char ejectors have shown no evidence of degraded performance since their installation in 1998.

- The dry char filter-blinding rate during the initial campaign after the combustion turbine outage was exceptionally positive. Projections based on third quarter 1999 data indicate that filter life (limited by blinding) could exceed one year. The blinding rate of the char filters increased in late September. This increase was attributed to the pet coke test. During the pet coke test, the char filters were subjected to approximately $100 \%$ more char loading which may have resulted in some element bridging. This bridging can be avoided during future pet coke operation by increasing the backpulse frequency of the filter elements.

\section{Carbonyl Sulfide Hydrolysis}

Figure 4.1.3D depicts ppm levels of COS on a comparative basis between 1996, 1997, 1998 and 1999. As illustrated by this graph, significant progress has been made in the control of COS from the hydrolysis unit and in operating the system on a more consistent basis. In 1996 the average ppm level of COS leaving the hydrolysis unit was 102.9 ppm. The 1997 average increased to $139.4 \mathrm{ppm}$. This increase was due to catalyst contamination by trace metals and chlorides in 1996, and to partial degradation in 1997 resulting from a deflagration incident that reduced the total surface area of the catalyst and promoted channeling through the reactor bed. The first year of optimum operation occurred in 1998, as is indicated by an average value of 26.8 ppm of COS in the product syngas. This was achieved following catalyst bed replacement in the fourth quarter of 1997, and illustrates the capabilities of this unit when it is properly operated and maintained. This trend continued in 1999 with an overall average COS concentration in the product syngas of $26.2 \mathrm{ppm}$. 
Figure 4.1.3D: Carbonyl Sulfide in Particulate Free Syngas

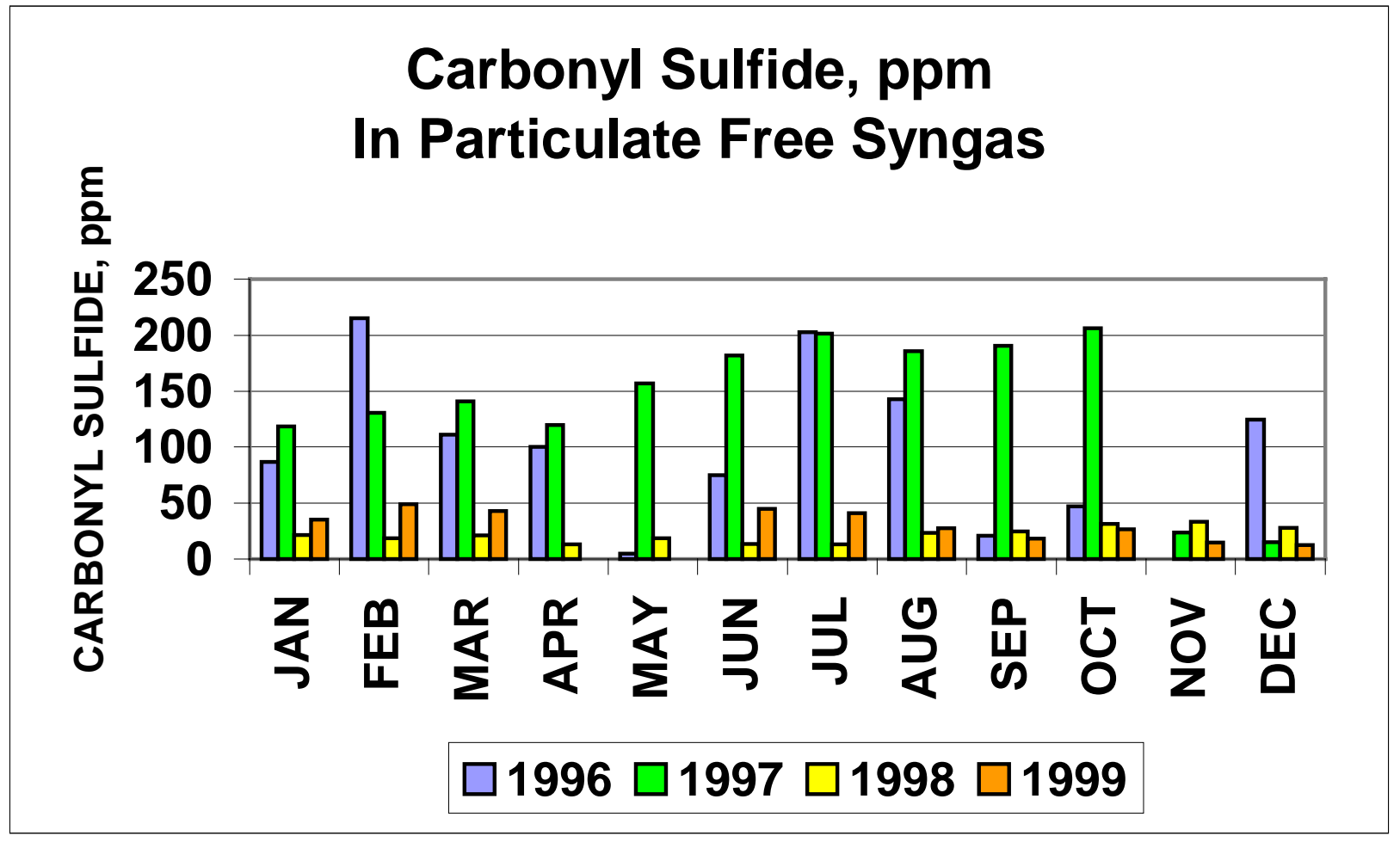

During runs early in the first quarter of 1996, COS removal efficiency in the catalyst beds began to decline. It was determined through sampling and analysis that the catalyst was being poisoned and blinded by trace metals and chlorides present in the syngas system. Catalyst degradation required the catalyst to be replaced during a February 1996 outage. Slipstream testing was initiated at this time to determine alternate catalyst selection. Catalyst efficiencies during the second quarter of 1996 continued to decline indicating the need for an alternate catalyst or a means of eliminating the contaminating agents. Through the use of the slipstream unit, an alternate catalyst was selected which showed a greater resistance to poisoning. Additionally, an improvement project was identified which required the installation of a system to remove chlorides from the syngas stream. The project would be beneficial, not only in the COS hydrolysis system, but also in equipment downstream from the installation (see section 4.1.3.3).

In the third quarter 1996, a new chloride scrubbing system (CSS) was installed along with a new catalyst for COS hydrolysis. The new catalyst was not only lower in cost, but testing indicated 
that it would be more efficient and less vulnerable to poisoning. While initial start-up and subsequent operation of this system went smoothly, a later system start-up in November led to a deflagration event in the system that partially reduced the surface area of the catalyst and damaged the CSS. The cause of this event was found to be the use of ambient air for pressure testing which created a spontaneous combustion event within the still-hot core of the COS catalyst bed.

The investigation and repair of the system was completed and the plant returned to operation in December 1996. Damage to the catalyst was not enough to warrant replacement; however, some degradation of activity was seen in an elevation in the amount of COS in the product syngas for the month of December. COS levels between 50 to $100 \mathrm{ppm}$ were normal during operation, up from less than $50 \mathrm{ppm}$ previously. However, overall sulfur in the product gas was still well within environmental and contractual requirements in the product syngas.

The COS catalyst system ran well within limits during the entire year for 1997, although the damage done in 1996 would require a premature replacement of the catalyst. The catalyst was replaced in the fourth quarter of 1997 and the system performance was restored to very low levels of COS in the product syngas.

The CSS, installed in 1996 after chlorides were identified as a contaminant to the COS catalyst, plays an essential role in syngas preparation prior to COS hydrolysis. By removing a substantial portion of the chlorides entrained in the syngas, it not only protects the COS catalyst but also reduces the potential of chloride stress-corrosion-cracking in the low temperature heat recovery unit (LTHRU). The CSS operated within design specification during 1998 with only minor problems associated with fouling of the demister pads and associated vessel packing.

The COS hydrolysis unit continued to provide stable operation throughout the Demonstration Period, and has proven to be a very reliable process operation within the Wabash River gasification facility. 


\section{Syngas Recycle Compressor}

The syngas recycle compressor recycles particulate-free raw syngas back to the dry char filtration system for use in filter backpulse cleaning, and to the gasifier for use in the second stage gasifier for syngas quenching. Recycled syngas is also used to atomize coal slurry in the second stage gasifier slurry nozzle and to prevent nozzle plugging in the methane burners. Additionally, recycled syngas purges are used to prevent obstruction of gasifier instrumentation.

Syngas production was limited due to difficulties with the recycle syngas compressor in both January and March of 1996. At the end of January, a steady decline in the machine's second stage performance necessitated a compressor overhaul. The source of the problem was ammonium chloride deposition due to condensate carryover into the compressor during methane operation. In lieu of re-opening the machine, the deposits were successfully removed using a water-wash process. Because condensate carryover also occurs at a slower rate during coal operations, two improvement projects were instituted to minimize the long-term effects of this problem.

During the third quarter 1996 the compressor tripped on two separate occasions, preventing the plant from going to coal operations. In early August, a discharge-end labyrinth shaft seal failed. The cause of the failure was identified as chemical attack of the seal material. The seal was replaced with a material similar to that used in the inter-stage seals. The shaft sleeve was also damaged when the seal failed, which required a rotor assembly replacement. Shortly after restart, the new seal failed and was replaced with an upgraded material, which has operated since then without failure.

An interruption of coal operation in late August 1996 was caused by the failure of one of the compressor impellers, which was found to have cracked and moved on the shaft. The cause of the crack was determined to be mechanical in nature, although it propagated due to chemical attack. The rotor assembly was replaced and the compressor operated for the rest of the quarter with no mechanical problems. 
The recycle syngas compressor was disassembled, cleaned and re-assembled during the October/November 1996 outage. Although the compressor had not affected plant performance prior to the outage, operational data indicated that it was slightly fouled. After the initial problems encountered during the first year of the Demonstration Period, the syngas recycle compressor has not required any major maintenance and has been a very reliable piece of equipment.

\section{Chloride Scrubbing System}

As mentioned earlier, the chloride scrubbing system was installed in the third quarter of 1996 to remove chlorides and other impurities from the syngas.

Some problems were observed with the chloride scrubber system upon initial operation due to ammonia accumulation. Due to the scrubbing of hot syngas with sour water, the chloride scrubber was also functioning as an ammonia stripper. This resulted in ammonia water being recycled to the sour water receiver, which in turn, was sent back to the CSS. Within two days of operation, ammonia levels had exceeded 4\% (40,000 ppm) in the scrubber water. This reduced efficiency and created some pluggage problems in the low temperature heat recovery unit due to the formation of carbonate and bicarbonate salt-based scales. To abate further operational problems with the system, a blowdown was taken from the sour water tank directly into the sour water system to provide a purge of ammonia from the system. During the November shutdown, control of the blow down was automated to provide consistent control of ammonia levels.

The chloride scrubbing system exhibited effective scrubbing from the outset of operation. However, the demister packing in the top of the vessel began to plug due to coal tar in the raw syngas. During the second quarter of 1997, the plugging began to cause liquid carry over into the gas path requiring a shutdown.

The root cause of the incident was determined to be tar deposits on the packing, which impeded gas and liquid flow through the column. Mitigation of tar accumulation was achieved by modifying the second stage gasifier operations to maximize tar destruction. The column packing was cleaned and put back into service prior to the third quarter 1997 run. Towards the end of the 
run the column began exhibiting a high differential pressure, again, as a result of tar plugging. This time, however, the tar deposition was related to reduced rate gasifier operations.

To correct the problem, manual flushes were periodically implemented during reduced rate operations. Additionally, operating guidelines were revised to limit the time spent at low operating rates during which heat loss from the system is too great to maintain temperatures sufficient to destroy tars. 


\subsubsection{Low Temperature Heat Recovery And Syngas Moisturization}

\section{Production Information}

Figure 4.1.3E illustrates syngas production by month throughout the Demonstration Period. Syngas production for 1996 totaled 2,769,685 MMBtu and increased considerably in 1997 to approximately 6,232,545 MMBtu. Production in 1998 further increased to 8,844,902 MMBtu, or $143 \%$ of the production record set in 1997. Fourth quarter of 1998 production also set a new quarterly production record of 2,503,587 MMBtu. This quarter included a scheduled December outage for maintenance and repair. Product syngas in 1999 totaled 5,813,151 MMBtu. Severely impacting production for 1999 was the unplanned combustion turbine outage between March and June. Additionally, failure of the newly installed dry char recycle line in November negatively impacted production in the fourth quarter. On a more positive note, however, third quarter syngas production exceeded all previous quarterly results by producing 2,712,107 MMBtu, and by more than doubling the previous continuous hours-on-coal record by operating 1,304 continuous hours.

Sweet syngas moisturization operated efficiently and provided consistent product gas moisture content of approximately 20\%-23\% throughout the Demonstration Period. Product syngas quality remained high and can be reviewed for all time periods in the Demonstration Period in Table 4.1.3A.

Product syngas quality remained relatively consistent throughout 1996. One of the primary reasons for this was the use of a single coal source for the year. Minor variations during 1996 in hydrogen sulfide and carbonyl sulfide concentrations (in ppm) were primarily due to equipment problems in the COS catalyst reactor and acid gas recovery systems. Variations in hydrogen content, carbon dioxide and carbon monoxide concentrations and methane content were directly related to operational characteristics of the system (and more specifically to variations in the oxygen-to-coal ratios of the gasifier feed) and cannot be attributed to variations in coal feedstock. 

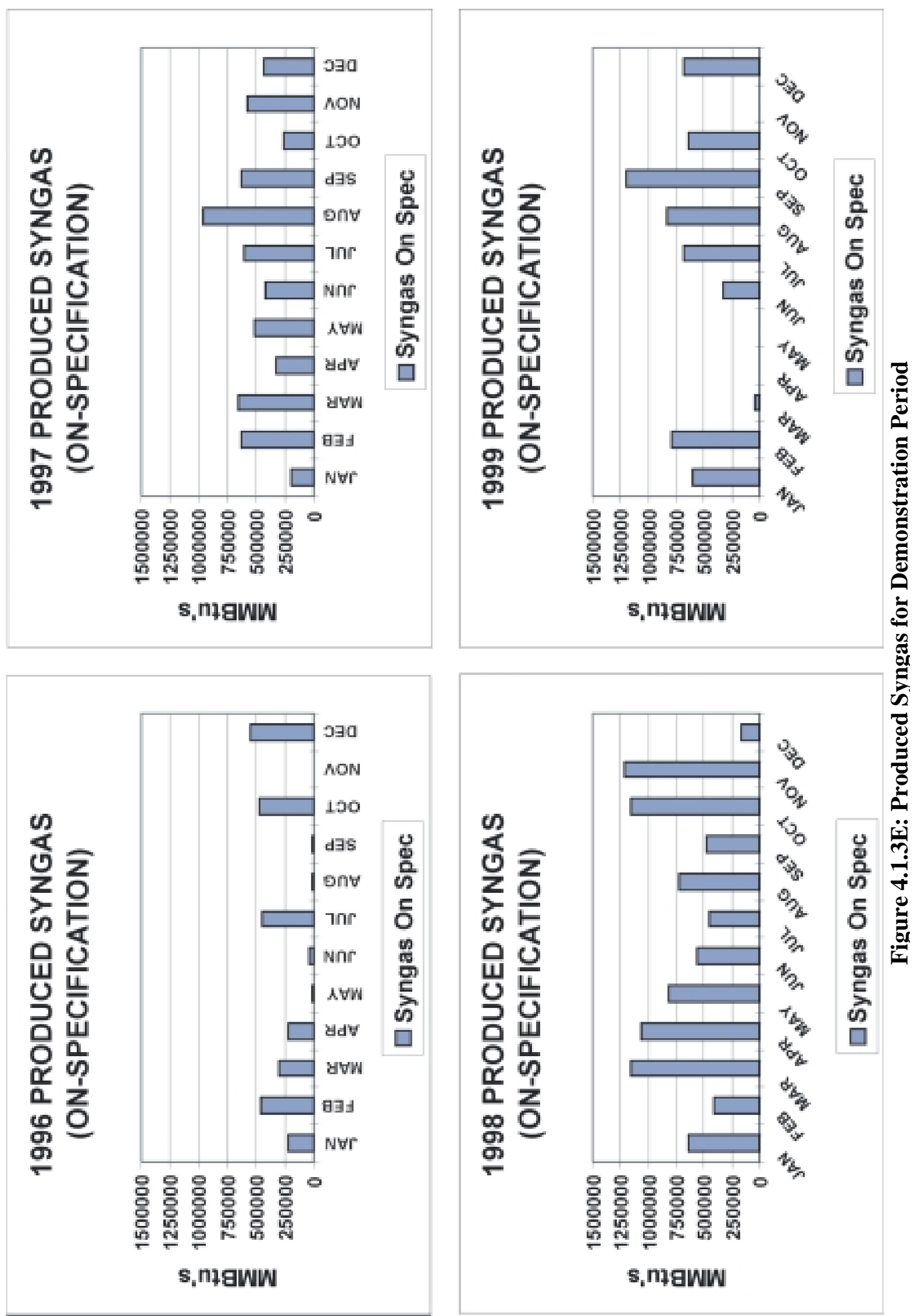

Wabash River Coal Gasification Repowering Project Final Technical Report 
Table 4.1.3A: Product Syngas Quality

\begin{tabular}{|l|c|c|c|c|c|c|c|c|}
\hline \multicolumn{7}{|c|}{ Product Syngas Quality } \\
\cline { 2 - 9 } & \multicolumn{2}{|c|}{1996} & \multicolumn{2}{|c|}{1997} & \multicolumn{2}{|c|}{1998} & \multicolumn{2}{|c|}{1999} \\
\cline { 2 - 9 } & Low & High & Low & High & Low & High & Low & High \\
\hline $\begin{array}{l}\text { Hydrogen } \\
\text { Concentration (\%) }\end{array}$ & 32.87 & 34.21 & 32.9 & 34.4 & 32.71 & 33.82 & 32.31 & 33.44 \\
\hline $\begin{array}{l}\text { Carbon Dioxide } \\
\text { Concentration (\%) }\end{array}$ & 14.89 & 17.13 & 16.6 & 16.9 & 14.92 & 16.06 & 15.25 & 16.22 \\
\hline $\begin{array}{l}\text { Carbon Monoxide } \\
\text { Concentration (\%) }\end{array}$ & 42.34 & 46.03 & 42.2 & 46.7 & 44.25 & 46.73 & 44.44 & 46.31 \\
\hline $\begin{array}{l}\text { Methane } \\
\text { Concentration (\%) }\end{array}$ & 1.26 & 1.99 & 1.04 & 2.02 & 1.91 & 2.29 & 1.88 & 2.17 \\
\hline $\begin{array}{l}\text { Hydrogen Sulfide } \\
\text { Concentration (ppmv) }\end{array}$ & 17.28 & 83.36 & 43.08 & 106.5 & 23.48 & 107.24 & 86.32 & 106.03 \\
\hline $\begin{array}{l}\text { Carbonyl Sulfide } \\
\text { Concentration (ppmv) }\end{array}$ & 36.26 & 162.13 & 22.59 & 111.78 & 9.03 & 36.63 & 11.36 & 24.22 \\
\hline
\end{tabular}

Syngas quality during 1997 was comparable to 1999; however, some assumptions can be made for variations in syngas composition due to the petroleum coke trial in the month of November. Despite the introduction of a new coal feedstock (Miller Creek coal), syngas quality in 1998 remained consistent. The same can be said for quality during 1999 when the gasifier operated on various blends of Miller Creek and Hawthorne feedstocks.

\section{Opportunities and Improvements}

While operations within the low temperature heat recovery unit (LTHRU) were within design parameters, three of the exchangers suffered tube failures in 1996 due to chloride stresscorrosion-cracking of the stainless steel tubes. Two of these exchangers serve to transfer heat between sour syngas and water from the syngas moisturizing system. A third exchanger crossexchanges sour syngas with amine from the acid gas removal system.

The plant had to be taken off of coal operation in early April 1996 due to excessive tube leaks from the syngas/amine exchanger. Leaking tubes were plugged in this exchanger as well as additional tubes in one of the sour syngas/water exchangers. Replacement exchangers for the 
syngas/amine exchanger and one of the syngas/water exchangers were built on an expedited basis and were installed during the June 1996 outage. The replacements were constructed of an upgraded material that is not vulnerable to chloride stress-corrosion-cracking. Tests were performed on tubes within the remaining syngas/water exchanger during the outage, and, an additional $10 \%$ of the tubes in this exchanger were deemed suspect to cracking and were plugged to prevent future tube failures. Later in 1996, with the installation of the chloride scrubbing system, the potential for chloride stress-corrosion-cracking in the remaining stainless steel components was effectively minimized.

The syngas flare system is considered part of the overall low temperature heat recovery and moisturization process. During a syngas leak and subsequent flange fire event in the first quarter of 1997 (previously mentioned), the flare system malfunctioned by losing flame and causing a release of purge gas containing a trace quantity of hydrogen sulfide. The malfunction was attributable to a marginally combustible purge stream being routed to the flare and "snuffing" the flame on the flare pilot, allowing the purge gas to escape unburned. To correct the problem, three new "windproof" pilots were installed on the flare tip during the second quarter 1997 outage. The process control program for the flare purge initiation was also upgraded to ensure that a sufficient volume of natural gas is added to the flare gas to ensure combustion during system purge.

Another flare modification was implemented during the third quarter of 1997 to reduce noise levels during flare operation. Noticeable noise levels were a concern in the surrounding neighborhood, so a project was implemented to install a larger diameter flare tip, which effectively reduced the noise to acceptable levels due to reduced exit gas velocity.

The LTHRU contributed a total of 7 hours of plant downtime in 1998. While this is not significant enough to warrant concern, several key opportunities for operation and maintenance improvements were identified. The following areas of concern were noted during the 1998 operational period: 
- Following an off-line cleaning during a maintenance outage, one of the LTHRU exchangers was hydro-tested for leaking tubes due to suspected failure. Approximately twenty tubes were found leaking and were subsequently plugged on both ends. One tube was extracted for failure analysis. The root cause was attributed to vibration, which is suspected to have occurred during use of a tubesheet spray intended for on-line cleaning. This spray creates thermal shock on the inlet tubesheet. The tubesheet spray had been used quite frequently in an attempt to lower the exchanger differential pressure. This activity has been discontinued due to its limited efficacy and its contribution to tube failures.

- The plant had to be taken off line during the third quarter of 1998 due to problems associated with the LTHRU. A temperature transmitter on the outlet of a condensate/syngas cross exchanger began reading erratically causing syngas flow through the exchanger to be automatically bypassed. When the reading returned to normal, the bypass valve closed before the main exchanger inlet valve opened, causing the gasifier system to overpressure and trip the plant off coal operations. Control program changes were made to prevent this from recurring.

During 1999, the LTHRU contributed a total of 10 hours of plant downtime when an unused tubesheet spray nozzle on an exchanger in that section of the plant failed causing a brief release of syngas. The piping failure was due to chloride stress-corrosion-cracking that developed prior to installation of the chloride scrubber in 1996. Other than this event, the LTHRU operated extremely well for the remainder of the Demonstration Period. 


\subsubsection{Acid Gas Removal}

\section{Production Information}

Figure 4.1.3F illustrates the hydrogen sulfide $\left(\mathrm{H}_{2} \mathrm{~S}\right)$ removal efficiencies for the acid gas removal (AGR) system, by month, during the Demonstration Period. The efficiency calculation uses total combustion turbine stack and flare stack syngas emissions (as sulfur) compared to the total sulfur feed to the gasification plant (sulfur, dry-weight percent) for the most conservative estimate of performance.

Hydrogen sulfide removal efficiencies remained fairly consistent throughout 1996. A drop in efficiency can be noted in August of 1996 due to problems with the methyldiethanolamine (MDEA) reclaim unit, which keeps the amine solvent low in heat stable salts (HSS). High HSS concentration in the amine causes lower absorption efficiencies. Despite continued high solvent HSS loading, the AGR system performance increased in the final quarter of 1996 due to cooler ambient temperatures, which allows cooler amine process temperatures. November had no unit operating days and contributed nothing to quarterly performance.

Hydrogen sulfide removal efficiencies for 1997 also were consistent. During the fourth quarter, efficiencies were slightly higher, when compared to the first nine months of 1997, due to a decrease in activity in the COS reactor catalyst beds and in their ability to convert carbonyl sulfide to hydrogen sulfide.

Hydrogen sulfide removal efficiencies remained fairly consistent throughout 1998 and 1999 due to improvements in the system and more consistent operation of the acid gas removal system and sulfur recovery unit. Removal efficiency for the first quarter of 1998 decreased slightly compared to the fourth quarter of 1997 even though the plant processed an impressive $65 \%$ increase in syngas production. A vacuum distillation was performed on the MDEA to remove HSS in the fourth quarter of 1997 . The distillation effectively restored the $\mathrm{H}_{2} \mathrm{~S}$ removal efficiency of the amine solution. 

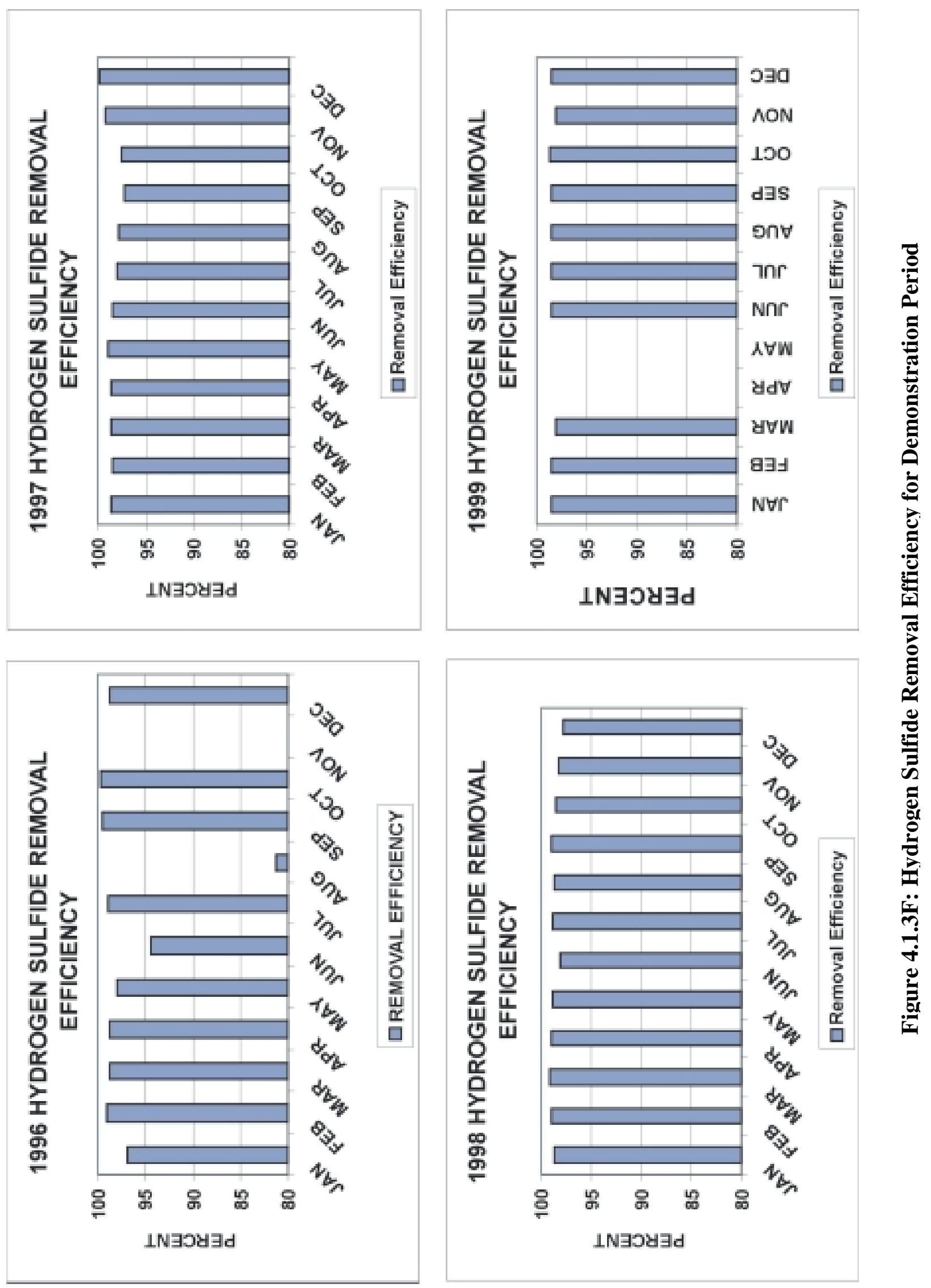

Wabash River Coal Gasification Repowering Project Final Technical Report 
In June of 1998, $\mathrm{H}_{2} \mathrm{~S}$ removal efficiency dropped to $98.1 \%$. This small decrease can be attributed to a combination of factors. First, upon start-up in June, there was a change in the gasifier coal feedstock to Miller Creek coal. This coal contains higher weight-percent sulfur. This created a greater load on the AGR system, leading to a slightly higher level of $\mathrm{H}_{2} \mathrm{~S}$ slippage from the removal system. Second, rising ambient air temperatures during the summer months increased the average amine solution temperature, which, in turn, decreased its stripping efficiency.

\section{Opportunities and Improvements}

The following small-scale project improvements were completed within the AGR area in 1996:

- Design oversights for the internals of the acid gas stripper were identified in the first quarter of 1996. As a result of the deficiency, operation and maintenance costs increased due to solvent attrition, higher start-up quench water requirements, increased ammonia breakthrough to the sulfur recovery unit, reduced solvent strength and a slight efficiency penalty due to reduced solvent inventory. Redesign of the internals incorporated to the system in May rectified the problem.

- The lean amine pumps were modified during the second quarter by the addition of automatic recirculation valves incorporated at each pump discharge in place of a minimum flow orifice. These valves ensure that each pump has minimum safe flow during all periods of operation. The minimum flow orifice system was causing pipe erosion at low flow conditions due to flashing in the piping downstream of the orifice.

- In the third quarter, a pressure drop reduction project was installed for the lean amine return piping. An increase in pipe size in one section of the line allowed for a reduction in system head pressure and corresponding increase in pump flow. The added flow is helpful when higher amine circulation rates are required, such as during warmer weather.

- The MDEA reclaim unit, designed to remove HSS from the MDEA, experienced operational problems throughout the year. Early in 1996, efforts were undertaken to increase salt removal capacity through regenerant feed system modifications. By the second quarter, HSS loading on the MDEA increased to the point where it was necessary to call in an outside vendor to remove the salts via a transportable vacuum distillation process. This process 
reduced the salts to a satisfactory level and restored the amine absorption capability to an acceptable level. Feed system modifications completed late in the second quarter were designed to boost capacity and utilize downtime for solvent reclaim process operation. A condensate cooler was installed to prevent thermal shock to the resin, resulting from elevated chemical feed dilution temperatures.

- During the third quarter, a project was implemented to install chemical feed pulsation dampeners in the MDEA reclaim unit to improve feed consistency and reduce chemical attack of the resin by better controlling the added chemicals concentration.

In early January 1997, the acid gas absorber internals sustained damage resulting from excess loading of the trays. To compensate for the reduced effective contact area, the amine was fed at a higher level on the column. The tray damage to the column was repaired during the late April outage and the feed point and the column performance returned to normal.

Reduced efficiencies encountered in the third quarter of 1997, can be directly attributed to the increase in solvent temperature occurring in the summer months and continued degradation of the COS catalyst, causing higher levels of COS in the absorber column inlet. A single event also occurred in the third quarter directly effecting absorber efficiency when column performance was compromised due to a collapse of a gas-liquid contact tray. Solvent anti-foaming compound was exhausted, and went unnoticed, ten days prior to this event and consequential solution foaming created a high differential pressure across the tray causing it to collapse. This event eventually led to a sulfur dioxide air permit exceedance at the flare when product syngas had to be flared because the product syngas sulfur limit was exceeded.

In the fourth quarter of 1997, because of an ever-increasing HSS loading of the amine, a vacuum distillation was performed on the entire absorbent inventory to remove the salts. The distillation recovered $82 \%$ of the solvent while removing the HSS. Efficiency increases can be attributed to the fresh solvent application. 
The primary system modifications required in the acid gas removal system during 1998 centered on the MDEA reclaim unit. The following represent key improvement projects developed for the unit in 1998:

- In the second quarter of 1998, the canisters containing the ion exchange resin started experiencing reliability problems. It appeared that the resin canisters were being chemically attacked by the combination of chemicals used within the unit. A test canister, constructed of an alternate material, was placed in service for an evaluation period. Also, test coupons were installed to determine the chemical resistance of other potential alternative materials.

- In the fourth quarter of 1998, plans for an expansion of the unit were developed. The expansion included increasing the canister capacity and changing the material of construction from fiberglass to a metal alloy for increased mechanical integrity. These modifications were completed in 1999 and enabled the unit to remove HSS at the rate of formation, thus eliminating the HSS accumulation problem.

The most significant impact on AGR system performance in 1999 was continued project improvements associated with the MDEA reclaim unit. These improvements will reduce the operation and maintenance cost of the facility in two ways. First, the amount of amine purchased annually can be reduced. In the past, HSS accumulation deteriorated the performance of the amine plant, necessitating the purchase of new amine solution. This additional amine solution effectively reduced the concentration of HSS allowing the plant to continue operation. Now, amine should only need to be purchased to replace solution lost due to thermal degradation, blowdown of the regeneration column, and rinsing of the MDEA reclaim unit. The second cost reduction will come from the reduced need for third-party amine reclamation, such as the vacuum distillation process used in the earlier years. The need for these reviews should now be eliminated. 


\subsubsection{Sulfur Recovery}

\section{$\underline{\text { Production Information }}$}

Figure 4.1.3G indicates the recovery efficiencies for the sulfur recovery unit (SRU), by month, for the duration of the Demonstration Period. Sulfur recovery efficiencies indicated are split into two specific areas. The left columns indicate the efficiency of the SRU by comparing total stack emissions with total sulfur feed to the SRU. Overall plant removal efficiencies (right columns) compare total Joint Venture emissions (as sulfur) versus total sulfur feed to the gasifier.

Overall, the 1996 graph follows directly with the reduction in reactivity of the COS catalyst and is representative of degradation and replacement over the course of 1996. Fourth quarter, following the installation of the chloride scrubbing system and improvements in the AGR system, shows a significant increase in the removal efficiency of the SRU. A total of 3,289 tons of sulfur was recovered during 1996.

Again in 1997, sulfur recovery compares directly with the reduction in reactivity of the COS catalyst and illustrates a clear degradation over the course of the year. Fourth quarter replacement of the catalyst resulted in a significant increase in the overall Joint Venture removal efficiency. A total of 8,568 tons of sulfur was recovered during 1997.

In 1998, there were no major changes to the AGR system that would have a direct effect on the sulfur recovery efficiencies. Efficiencies remained very consistent throughout the year, thus sulfur recovery averaged between 97.5 to $98.5 \%$. 

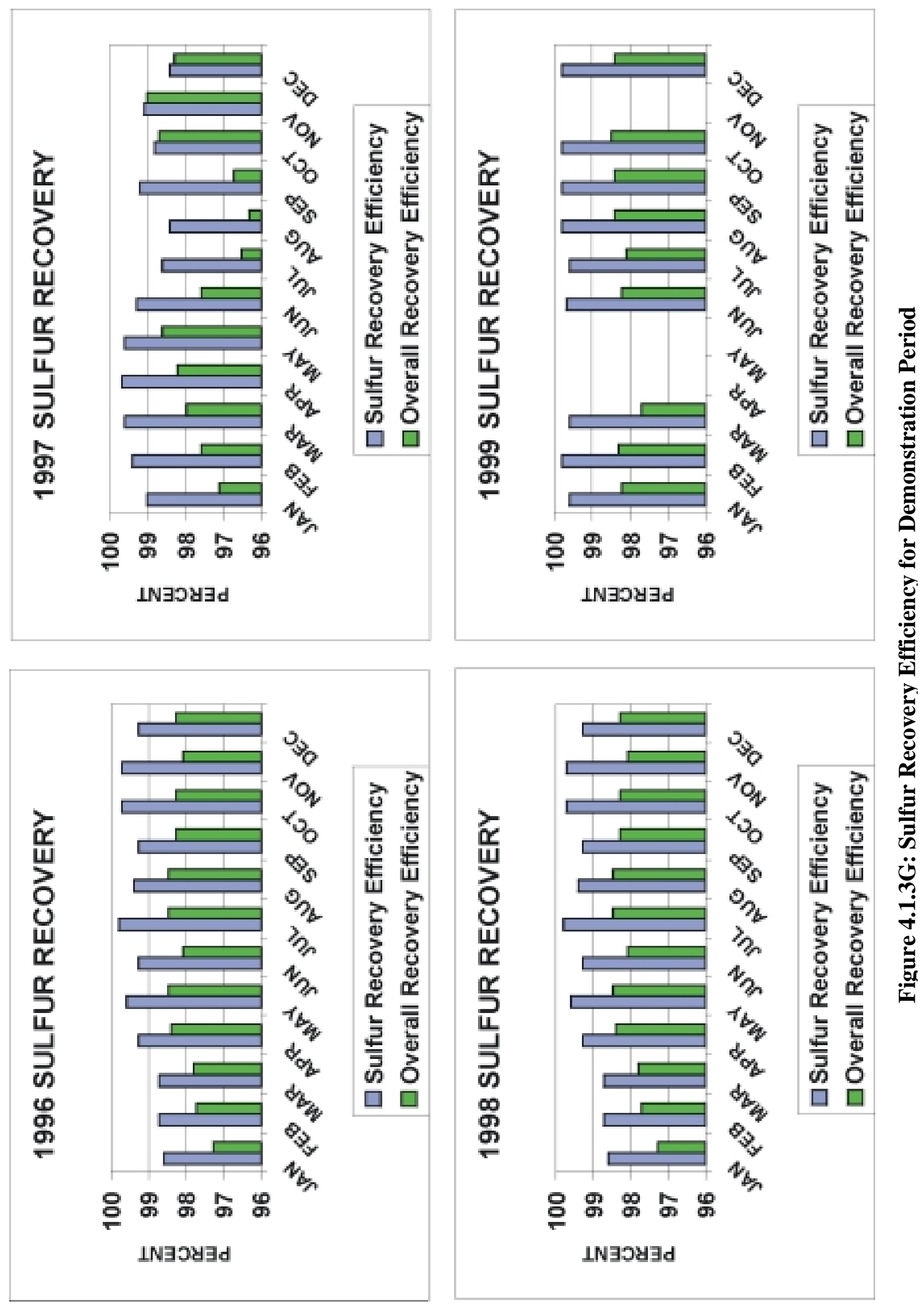

Wabash River Coal Gasification Repowering Project Final Technical Report 
In 1999, continuous operation from June to October contributed to consistent sulfur recovery. Both the SRU sulfur recovery efficiency and the overall sulfur recovery efficiency for the third quarter increased slightly from the second quarter averages. Much credit for this increase can be given to continuous operation of the plant. However, the SRU received the highest average acid gas concentration of any previous quarter. Because the Modified-Claus process is a series of equilibrium driven reactions, higher acid gas concentrations increase the driving force for the formation of elemental sulfur, thereby increasing the single pass recovery efficiency. The increase in acid gas concentration is a result of lower amine circulation rates and higher sulfur feedstock to the gasifier such as Miller Creek coal and petroleum coke.

\section{Opportunities and Improvements}

As with operation of most new systems, the early operation of the sulfur recovery unit was characterized by a learning curve, which identified some unit shortcomings and improvement opportunities. The improvements in 1996 include:

- A bypass line was installed around the hydrogenation reactor, which allowed re-sulfiding of the catalyst to take place on line. This alleviated early problems with sulfur formation and pluggage of the tail gas handling system.

- Modifications to strainers on the tail gas recycle compressor suction lines allowed discretionary filtering, permitting small particle passage while retaining machine protection and reducing the rate of strainer pluggage and compressor downtime. As the tail gas recycle rate increased, sulfur plant recovery efficiency and production increased.

- A project to enhance sulfur area safety and storage tank capacity was implemented in the second quarter 1996. The project consisted of a new vent line to the tail gas incinerator allowing the sulfur tank to operate at lower pressure. The sulfur storage tank usable capacity was increased from $40 \%$ to $100 \%$ in the second quarter with implementation of the new steam-jacketed vent line. The new line isolates the tank from SRU process pressures, resulting in maximum safe capacity.

- In September, a new project was implemented allowing acid gas feed to the SRU prior to coal feed to the gasifier. This increases total recovery by allowing high recovery during start-ups as is reflected in the increase in efficiency for the last month in the third quarter. In 
October, new process-control implementation allowed acid gas feed to the SRU after coal operations cease, thereby reducing emissions at the acid gas flare.

- Some projects designed to enhance safety and reduce O\&M costs were implemented for the SRU in the fourth quarter. A rail car level transmitter replaced the originally installed detection systems, which allows more consistent sulfur rail car loading and reduced the potential for overfilling. Several lines in the SRU were modified to include double block and bleed (DBB) isolation in strategic locations. This eliminates significant line blinding efforts for vessel entry and allows SRU steam and condensate outages without forcing plant-wide steam outages. Finally, the SRU area steam trap system was reconfigured to eliminate ice hazards as well as providing a net reduction of 28 obsolete traps.

- SRU support systems also received project improvements. The tail gas quench cooler required installation of upgraded tie rods to minimize tube vibration. The suction vent gas blower knockout pot level monitoring system was redesigned for earlier high-level warning. One of the two lower explosive limit (LEL) metering systems within the tank vent system was relocated to a position where positive blower pressures would not affect accuracy, reducing nuisance alarming and excessive re-calibration. These improvements will positively impact operability and reduce maintenance needs.

During 1996 several incidents in the SRU led to either production turndowns, or complete shutdowns of the gasification process.

- In the first quarter, several minor problems associated with a plugged condenser and a plugged tank vent on the sulfur storage unit caused several hours of reduced production. Both of these problems were quickly resolved and full production rates restored without further incident. Corrective measures were written into the operating procedure and maintenance guide and no further problems of this nature occurred during the year.

- In November, the pressure safety valve protecting the acid gas stripping column failed, relieving at a pressure less than set point. Acid gas from the column was relieved into the flare header, resulting in an exceedance of permitted limits for sulfur dioxide at the flare. Investigation into the mechanism of failure revealed that debris in the pilot valve prevented proper seating. This allowed the main valve to remain open at pressures below the relief set 
point. The pressure safety valve was subsequently removed and an alternate overpressure protection device has been employed.

Several projects were implemented in 1997 and 1998 in the SRU to improve overall reliability and maintainability. Those projects were:

- The steam generator for the tail gas incinerator was improved to lower incidences of leaks in the low-pressure steam drum safety valves. Rupture disks now isolate the safety selector valve from the safety valves themselves. This has significantly reduced maintenance costs associated with repair of the valves.

- In the second quarter of 1999 , a project designed to enhance safety, reduce emissions, increase availability and lower O\&M costs was instituted. A sulfur seal leg was installed at the hydrogenation pre-heater along with an ancillary heating system. The project was designed to ensure liquid flow at the look box and prevent overpressure by not allowing a solid plug of sulfur to form in that area. Personnel exposure and disposal costs have been reduced as a direct result of this project.

- One project in the first quarter of 1998 was intended to lower O\&M costs and reduce the risk of exposing operators to molten sulfur. The seal leg for the first sulfur condenser was modified to facilitate removal of material causing flow restrictions. The new design allows for removal of the material collecting in the bottom of the seal leg without cutting apart the seal leg. Seal leg drain modifications have also been made which will reduce the potential to expose operators to liquid sulfur.

- Another project, implemented in the second quarter of 1998, is intended to improve safety and increase tail gas recycle compressor reliability. The seal legs of the first stage suction drums on the tail gas recycle compressors continuously over-pressured, allowing tail gas to escape into a sump where it was recovered by the tank vent system. To prevent the seal legs from over-pressuring, they were routinely blocked-in, requiring Operations personnel to manually drain the condensed liquid from the suction drum. Occasionally, the unit would go unchecked until a high liquid level would trip the compressor. During the June outage, the seal legs were extended to prevent over-pressuring, thus reducing operator exposure to tail gas and increasing compressor reliability. 
- Another project was implemented during the outage in early September. Because of a hydrogenation bypass valve leak, sulfur dioxide reacted with the $\mathrm{H}_{2} \mathrm{~S}$ in the tail gas quench column, forming elemental sulfur. This sulfur plugged the column, heat exchanger and filters within the quench loop. Once the bypass valve was repaired, the entire quench loop was flushed with a heated $25 \%$ caustic solution. The flush was successful and there has been no more evidence of sulfur formation within the column.

Downtime attributed to the SRU during 1999 is summarized as follows:

- During the first quarter of 1999,8 hours of outage time were attributed to the SRU. During a plant start-up in March, prior to acid gas addition to the SRU, combustion products from the Claus reaction furnace were released from a sulfur seal leg. The subsequent investigation concluded that the combination of a vacuum downstream and normal controlled pressure upstream was sufficient to de-inventory the seal leg. The vacuum was created while pumping down the liquid sulfur storage tank. The normal pressure control set point for the SRU during outages has been reduced to avoid any recurrence of this incident.

- In July, the gasifier tripped due to slurry feed problems. Shortly after transferring back to coal operation, the SRU air demand analyzer, the instrument responsible for determining fine adjustments to the Claus furnace oxygen supply, experienced an undetected plug in the sample line. Hours later, the accumulating error in the air demand analyzer caused an elevated $\mathrm{SO}_{2}$ concentration in the catalyst beds, necessitating the addition of supplemental hydrogen in the tail gas hydrogenation reactor. When the hydrogen was added, the SRU pressure controller misinterpreted the signal from a pressure transmitter. The controller opened the SRU pressure control valve, bypassing the tail gas recycle compressors and allowing tail gas to flow to the tail gas incinerator. As a result, the $\mathrm{SO}_{2}$ flow from the permitted tail gas incinerator stack reached a reportable level and coal operation was immediately suspended. Since this incident, the pressure controller has been modified to prevent a recurrence. Additionally, there is a project currently being implemented that will give Operations an indication when the air demand analyzer signal is not reliable.

- In early December of 1999, 69 hours of downtime were attributed to the sulfur recovery unit. It was determined that the hydrogenation unit bypass valve was damaged and failing to open 
completely. Upon inspection, it was found that a mass of material had accumulated against the valve, preventing it from opening. The valve then sustained damage when the actuator attempted to open the valve. The material was a mixture of ammonium sulfate, iron sulfide and elemental sulfur. The sulfur can be melted with current heat tracing but the other materials have higher melting points. The reasons that these other materials are present in this location are still being investigated. 


\subsubsection{Sour Water Treatment}

\section{Production Information}

Figure 4.1.3H illustrates the sour water outfall from the sour water treatment system by month for the duration of the Demonstration Period.

Sour water to the outfall remained fairly consistent in volume from 1996 to 1998, but varied in 1999 from a high in September of 7.2 million gallons to a low in April and May of zero. During the third quarter of 1998 there was a short period of atypical operation. The lower slurry rates combined with the lower moisture content of the petroleum coke feed at the end of September caused the sour condensate conditioning unit to see approximately $40 \%$ less flow. Typically, this reduction in feed causes unfavorable hydraulics within the conditioning columns, resulting in the production of off-spec water. However, during this period, a process of false loading was employed. Using existing piping, conditioned water was transferred to the tail gas quench column and then back to the front of the sour condensate conditioning unit. In doing so, proper column hydraulics and in-spec water were maintained without upset or addition of supplemental water.

\section{Opportunities and Improvements}

In the third quarter of 1996, operating data revealed the acid degassing and ammonia stripping columns were exhibiting signs of tray damage. Inspections confirmed the diagnosis and revealed significant damage, which was likely due to liquid flooding of the columns. In addition, damage patterns suggested flashing liquid feed flow to the stripping column was responsible for the loss of about $20 \%$ of the column trays. A new liquid feed distributor was installed to control hammering of the trays. Operating parameters were revised with the inclusion of new control system alarms to warn of impending flooding. 

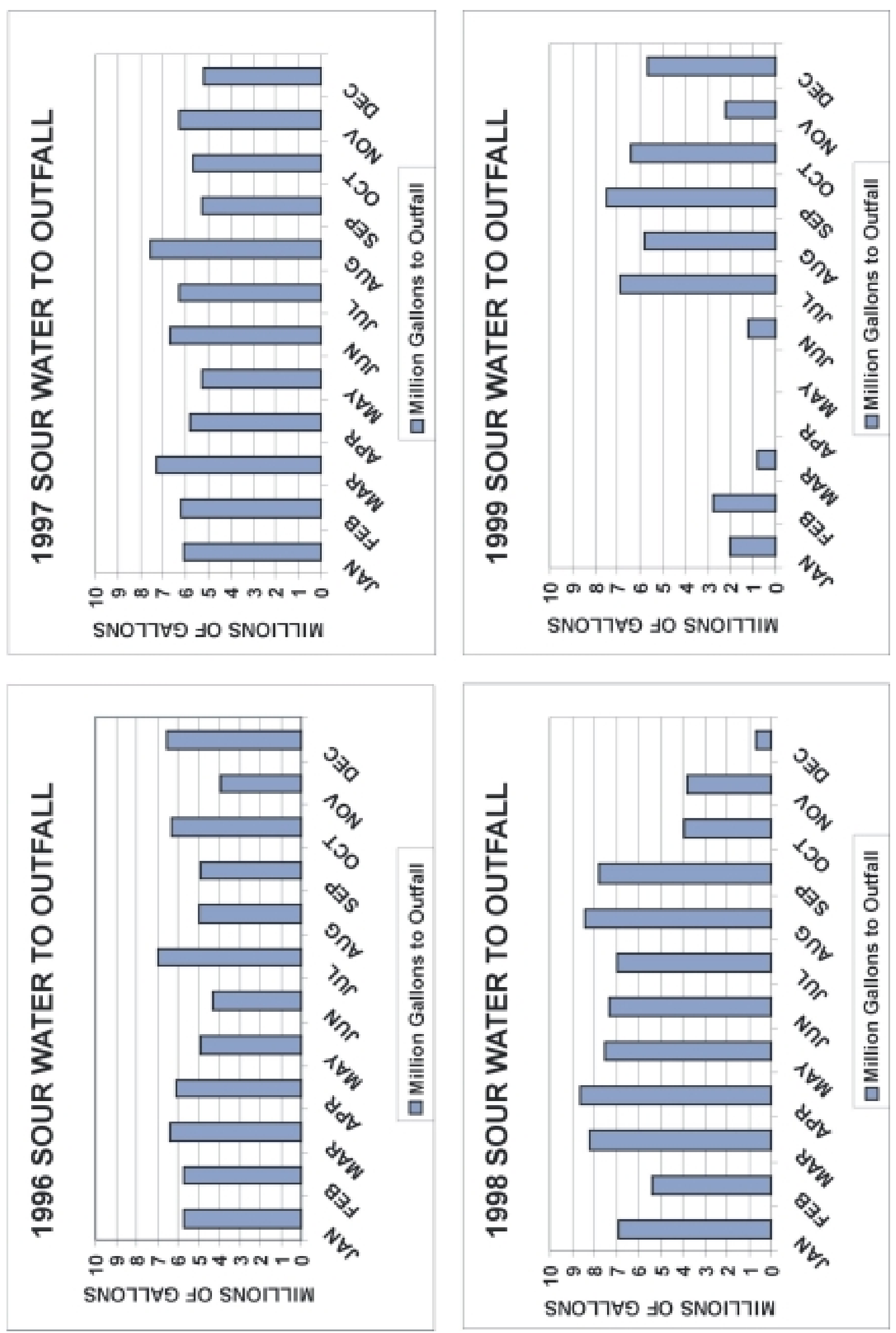

Wabash River Coal Gasification Repowering Project Final Technical Report DE-FC21-92MC29310 
In the third quarter of 1997, a sour water carbon-filter vent containment system was installed to prevent fugitive odors. This project enhances both safety and environmental stewardship by eliminating another source of fugitive emissions. Fourth quarter enhancements to the system included the conversion of an existing activated carbon storage tank to serve as a caustic tank. Caustic has been added to the ammonia stripping column to further reduce the concentration of ammonia to the permitted outfall. Until this project, the caustic source was the caustic feed to the MDEA reclaim unit. Recognizing that a lower, less expensive grade of caustic could be used, a drum was retrofitted to serve as the supply for the ammonia-stripping column. This project should serve to significantly lower operating costs for the sour water unit.

In the second quarter of 1998, a significant amount of work was done on the carbon beds. High differential pressures across the beds caused damage to the vessel internals. During the June outage, structural modifications were made to ensure the vessel could withstand the higher differential pressures.

The sour water treatment system operated very well except for the aforementioned items. 


\subsubsection{Power Block}

Table 4.1.4A illustrates power production by quarter for the duration of the Demonstration Period.

Table 4.1.4A: Power Block Production

\begin{tabular}{|c|c|c|c|c|c|}
\hline & $\begin{array}{c}\text { Combined Cycle } \\
\text { Operating Hours } \\
\text { On Syngas }\end{array}$ & \begin{tabular}{|c|} 
Longest \\
Continuous Run \\
Hours On Syngas
\end{tabular} & $\begin{array}{l}\text { Maximum CT } \\
\text { Output (MW) }\end{array}$ & $\begin{array}{l}\text { Maximum ST } \\
\text { Output (MW) }\end{array}$ & $\begin{array}{l}\text { Total Gross } \\
\text { Generation } \\
\text { (MWHours) }\end{array}$ \\
\hline 1996 1QTR & 535 & 127 & 192 & 96 & 163,088 \\
\hline 1996 2QTR & 148 & 115 & 189 & 89 & 45,332 \\
\hline 1996 3QTR & 289 & 152 & 186 & 92 & 80,230 \\
\hline 1996 4QTR & 580 & 130 & 180 & 90 & 95,710 \\
\hline 1996 TOTAL & 1,552 & & & & 384,360 \\
\hline 19971 QTR & 870 & 330 & 192 & 96 & 240,000 \\
\hline 1997 2QTR & 730 & 185 & 192 & 100 & 205,000 \\
\hline 1997 3QTR & 1,329 & 360 & 192 & 100 & 307,274 \\
\hline 1997 4QTR & 766 & 230 & 192 & 100 & 189,410 \\
\hline 1997 TOTAL & 3,695 & & & & 941,684 \\
\hline 19981 QTR & 1,270 & 475 & 192 & 98 & 359,689 \\
\hline 1998 2QTR & 1,449 & 510 & 192 & 98 & 395,683 \\
\hline 1998 3QTR & 993 & 257 & 192 & 98 & 254,000 \\
\hline 1998 4QTR & 1,427 & 427 & 192 & 98 & 420,188 \\
\hline 1998 TOTAL & 5,139 & & & & $1,429,560$ \\
\hline 19991 QTR & 821 & 425 & 192 & 98 & 229,814 \\
\hline 1999 2QTR & 199 & 179 & 192 & 98 & 54,052 \\
\hline 1999 3QTR & 1,621 & 1,115 & 192 & 98 & 444,364 \\
\hline 1999 4QTR & 780 & 318 & 192 & 98 & 203,713 \\
\hline 1999 TOTAL & 3,421 & & & & 931,943 \\
\hline
\end{tabular}

During 1996, the power generation block required no improvement projects or major equipment modifications. Equipment operated as designed and the only key area of change was the identification of proper operating parameters for the combustion turbine and steam turbine during the first commercial year. 
In 1996, the water treatment systems processed over 420.8 million gallons of water from the Wabash River for use in the gasification and re-powering areas of the facility. Of this total, approximately 110.6 million gallons were demineralized for use within the High Temperature Heat Recovery Unit (HTHRU) of the gasification process and the Heat Recovery Steam Generator (HRSG) at the exhaust of the combustion turbine.

The third quarter of 1997 produced the largest total power output for that year. In the month of August, figures for total gross generation exceeded 160,000 megawatts for the first time since Project start-up. The months of March, May, July, August, September, November and December show generation in excess of 60,000 megawatts on the combustion turbine with syngas. Electricity production for the year realized an increase of over 200\% over 1996.

The fourth quarter of 1998 produced the largest total power output for that year. October and November were back-to-back high peak months, the best two consecutive months accomplished by the facility since beginning operation in 1995. Additionally, 1998 was another record power production year for the Project.

During 1999, July, August and September were high peak months of operation. Second quarter activities were severely curtailed when, on March 13 a vibration alarm was detected on the \#1 combustion turbine bearing seismic probe. The unit ultimately tripped 6 minutes later from high exhaust temperature. Following investigation, it was determined that the compressor had failed. PSI decided at that time to inspect all machine components due to the level of teardown required. The inspection for all components, except the compressor, indicated normal wear for the number of starts and run-time on the machine. The turbine had experienced 412 starts and over 14,000 hours of operation prior to this failure.

The compressor failure actually occurred in the $14^{\text {th }}$ stage stator blades and propagated downstream. Damage from the $14^{\text {th }}$ stage downstream was catastrophic in nature and required complete replacement of all rotating and stationary material. Due to schedule considerations and opportunities to upgrade the compressor, PSI decided to purchase and install a new upgraded 
compressor from General Electric. The unit was returned to service on June 12, 1999 and has run successfully since that time. 


\subsection{General Information}

\subsubsection{Stream Data}

Table 4.2.1A lists the main process streams for the Wabash River Coal Gasification Repowering Project and their Proprietary/Non-Proprietary classification as agreed to in the Environmental Monitoring Plan (EMP). Figure 4.2.1A illustrates the location of these streams within the

process. A complete summary discussion and an analysis review of these streams can be found under Section 6.0 Environmental Performance of this Final Technical Report. Additional information, on a year-by-year basis, can be found in the Annual EMP reviews reported to the DOE for the years 1995-1999. 
Table 4.2.1A: Key to Monitoring Locations

\begin{tabular}{|c|c|c|}
\hline $\begin{array}{c}\text { Location } \\
\text { Designator }\end{array}$ & $\begin{array}{c}\text { Proprietary }(\mathbf{P}) \\
\text { Non-Proprietary (NP) } \\
\text { Status }\end{array}$ & Description of Monitoring Location \\
\hline 1 & $\mathrm{NP}$ & "Coal Slurry \\
\hline 2 & $\mathrm{P}$ & Raw Syngas \\
\hline 3 & $P$ & Sour Syngas \\
\hline 4 & $P$ & Sour Water \\
\hline 5 & $\mathrm{P}$ & Acid Gas \\
\hline 6 & $\mathrm{P}$ & Tail Gas \\
\hline 7 & $\mathrm{NP}$ & Tail Gas Incinerator Stack Gas \\
\hline 8 & $\mathrm{NP}$ & Sweet Syngas \\
\hline 9 & $\mathrm{NP}$ & GT/HRSG Stack Gas \\
\hline 10 & $\mathrm{NP}$ & Slag \\
\hline 11 & $\mathrm{NP}$ & Sulfur \\
\hline 12 & $\mathrm{NP}$ & Non-Contact Cooling Water (Outfall 001) \\
\hline 13 & NP & Process Waste Water (Gasification Plant) \\
\hline 14 & $\mathrm{NP}$ & Treatment Pond Discharge to Ash Pond (Outfall 102) \\
\hline 15 & $\mathrm{NP}$ & Ash Pond Effluent (Outfall 002) \\
\hline 16 & $\mathrm{NP}$ & Equipment Leak Fugitive Emissions \\
\hline 17 & NP & Slurry Facility Fugitive Emissions \\
\hline 18 & $\mathrm{NP}$ & Slag Handling Fugitive Emissions \\
\hline 19 & $\mathrm{NP}$ & Coal Handling Fugitive Emissions \\
\hline 20 & $\mathrm{NP}$ & Slag Transport and Storage Fugitive Emissions \\
\hline
\end{tabular}




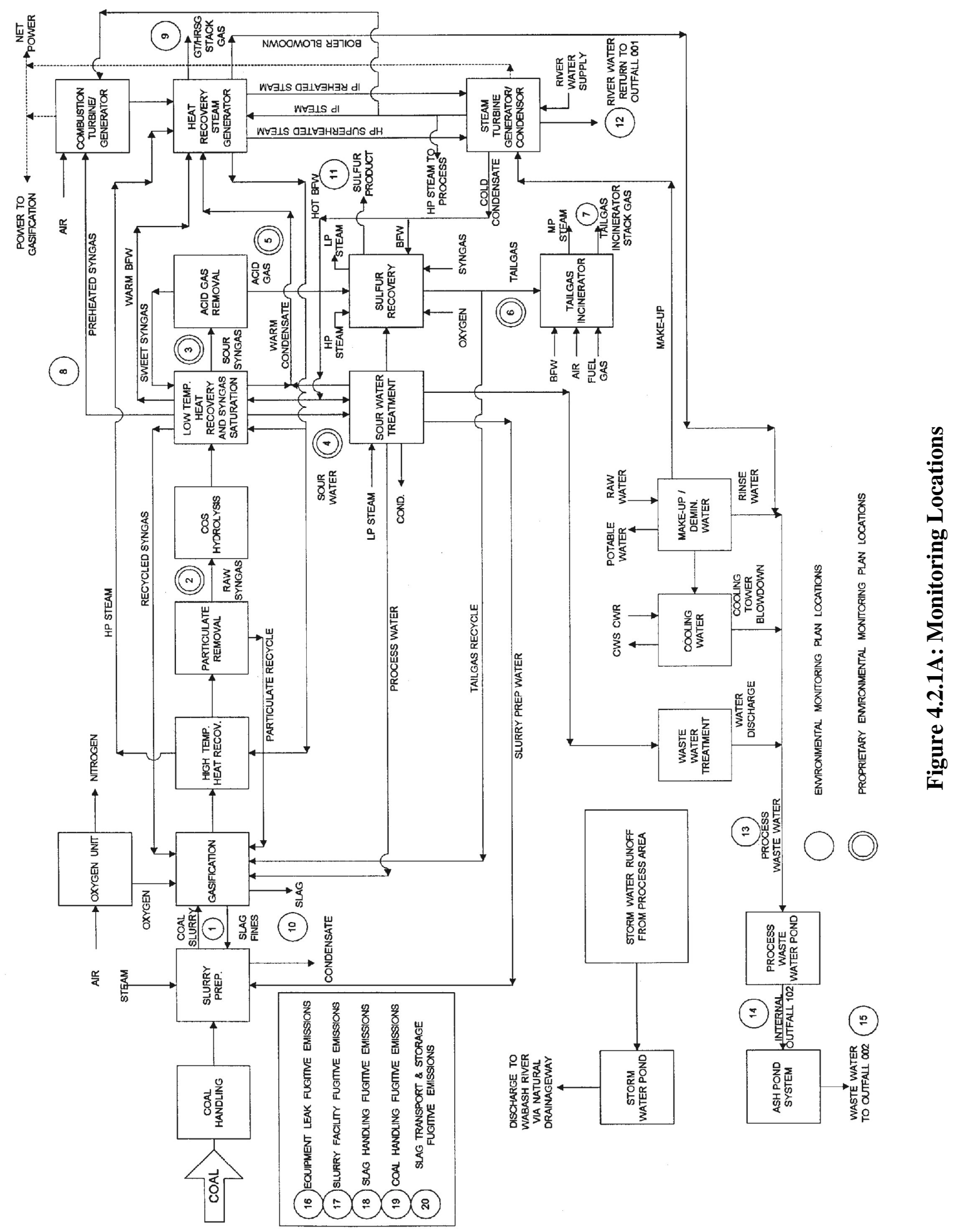

Wabash River Coal Gasification Repowering Project Final Technical Report 


\subsubsection{Alternative Fuel Testing}

This section presents the results from testing of an alternate fuel, petroleum coke (also referred to as coke or pet coke). Approximately 20,000 tons of a 5\% sulfur petroleum coke was processed in the Wabash River plant with favorable performance and environmental results. Plant efficiency, emissions of $\mathrm{SO}_{2}$ and other air contaminants, trace metals balance, performance of the COS hydrolysis catalyst, and sulfur removal system, are presented. Observations on plant operation, including slurry preparation, flux addition, ash deposition, and gas stream metallurgical testing are discussed. Results indicate that future projects that utilize this alternate fuel could be implemented at a lower cost than Wabash River by reduction in the size or elimination of some of the equipment. Global Energy believes this demonstration of the inherent fuel flexibility of its E-Gas ${ }^{\mathrm{TM}}$ gasification technology will result in applications with other opportunity fuels, including coal fines, renewables, or waste materials.

\section{$\underline{\text { Introduction }}$}

Because of the availability of relatively low cost natural gas, coal-based integrated gasification combined cycle (IGCC) power is not currently economical in areas where natural gas is available. Low cost natural gas also impacts the use of coal to produce chemicals. For example, steam reforming of natural gas is the leading source of hydrogen in North America. This has led to the current trend in the advancement of gasification technology in the global market, to utilize "low value" or opportunity fuels. Petroleum coke, a main by-product of refineries, is a prime candidate fuel to link the gasification and refining industries.

Petroleum coke is produced in the processing of oil residue where lighter components are extracted from the heavier fractions to maximize the yield of high value products such as gasoline and jet fuel. For many refiners, this is economically more attractive than the alternative option of selling the heavy fraction as residual fuel oil. Petroleum coke possesses energy content equivalent to, or higher than, bituminous coal and is sold as a fuel to utilities and cement producers. Even though petroleum coke is an undesired by-product in the refining process, its production in the U.S. increased dramatically over the last decade. A dwindling supply of highquality, low-sulfur crude has driven refiners towards heavier and higher sulfur crude. 
According to the Energy Information Administration (EIA), as of January 1, 1997 there were 152 operating refineries in the U.S., with an aggregate total capacity of 16.3 million $\mathrm{bbl} / \mathrm{d}$. Of these refineries, 54 operate coking units, and represent $59 \%$ of the total domestic crude oil distillation capacity. In 1996 they produced 31.7 million tons of coke, which was 95\% of total U.S. coke production and roughly $70 \%$ of world coke production. Of this tonnage, 66\% (roughly 22 million tons of coke) was exported, with Europe, Japan, Canada, and Turkey being the lead importers.

Over the ten year period between 1987 and 1996, the trend in feedstock to U.S. refineries has been toward heavier crude, from an average API gravity of $32.3^{\circ}$ to $31^{\circ}$, and higher sulfur content from an average 1.02 wt. $\%$ to $1.2 \mathrm{wt}$. \%. Both of these trends have the impact of increasing coke production per barrel of oil processed. It has been estimated that U.S. petroleum coke production could easily reach 32.9 million tons/year by the year 2000 .

As coke production has increased, the coke market has become more constrained due to the higher sulfur content. There also has been an increase in the number of refineries constructed and installation of coker units overseas. Environmental restrictions on air emissions, especially in developed and developing countries where much of the offshore refining capacity exists, has also become more stringent. These facts lead to the conclusion that the already volatile coke market is shrinking for U.S. exporters. This presents a unique opportunity for gasification technology, which can effectively convert the low value petroleum coke to power or higher value chemicals. Locating a gasification plant adjacent to a refinery also offers many synergistic advantages to both the power and refining industries.

With these facts in mind, the significance of implementing this test program on the future marketability of the E-Gas ${ }^{\mathrm{TM}}$ gasification process is obvious.

\section{$\underline{\text { Wabash River Petroleum Coke Test }}$}

The idea behind the Wabash River test was to utilize petroleum coke as the primary feed, while operating in a commercial environment. A rigorous program of preparation for the petroleum 
coke test was followed. This included: laboratory analysis of coke properties and ash characteristics; bench scale testing to determine the reactivity, grinding and slurrying characteristics of the petroleum coke; computer simulations of process and thermal performance; industrial hygiene review; and development of coke/flux blending equipment.

Eighteen thousand tons of a delayed sponge coke (Table 4.2.2A) were processed from November 17 through November 27, 1997. The plant switched from coal to pet coke feed "on-the-fly" without interrupting operation. As-received $100 \%$ petroleum coke was used with no coal blend. The coke had a sulfur content of $5 \%$, which is well within the sulfur design limit of the Wabash River plant. Laboratory ash composition and ash fusion analyses indicated the pet coke would be difficult to slag-tap at typical gasifier operating temperatures. This necessitated the addition of a fluxing compound to the feed prior to slurry preparation. Slag from an earlier coal run was chosen because of its availability and its known ash flow characteristics. In the gasifier, the slag captures most trace metals such as vanadium and nickel into its matrices. Encapsulated in the inert, non-leaching slag, these trace metals were rendered safe for non-hazardous disposal or reuse.

Table 4.2.2A: Fuel Analyses

\begin{tabular}{|c|c|c|}
\cline { 2 - 3 } \multicolumn{1}{c|}{} & Typical Coal & Petroleum Coke \\
\hline Analyses: Moisture, \% & 15.2 & 7.0 \\
\hline AsH, \% & 12.0 & 0.3 \\
\hline Volatile, \% & 32.8 & 12.4 \\
\hline Fixed Carbon, \% & 39.9 & 80.4 \\
\hline Sulfur, \% & 1.9 & 5.2 \\
\hline Metals in Ash: $\quad$ & Trace & 11.8 \\
\hline NiO, \% of ash & Trace & 28.4 \\
\hline $\mathrm{V}_{2} \mathrm{O}_{5}, \%$ of ash & & 14,282 \\
\hline
\end{tabular}




\section{$\underline{\text { Overall Plant Performance }}$}

Plant operation was steady during the petroleum coke testing period, although the plant tripped twice for brief periods: once because of a slurry feed pump trip, and once due to the dry char particulate filtration system. Neither of these trips was related to the change in feedstock. Operation at full load was achieved with $100 \%$ petroleum coke fuel supply while meeting all environmental emission criteria. Operation was maintained at approximately $90 \%$ of syngas facility capacity for the greater part of the test to match the combustion turbine fuel requirements (Figure 4.2.2A).

Overall thermal performance (Table 4.2.2B) was slightly improved during petroleum coke operation, with overall plant efficiency at 40.2\% (HHV). The syngas consumption by the combustion turbine in the "actual cases" was somewhat lower than predicted by the computer simulation.

\section{Figure 4.2.2A: Wabash River Plant Performance on Pet Coke}

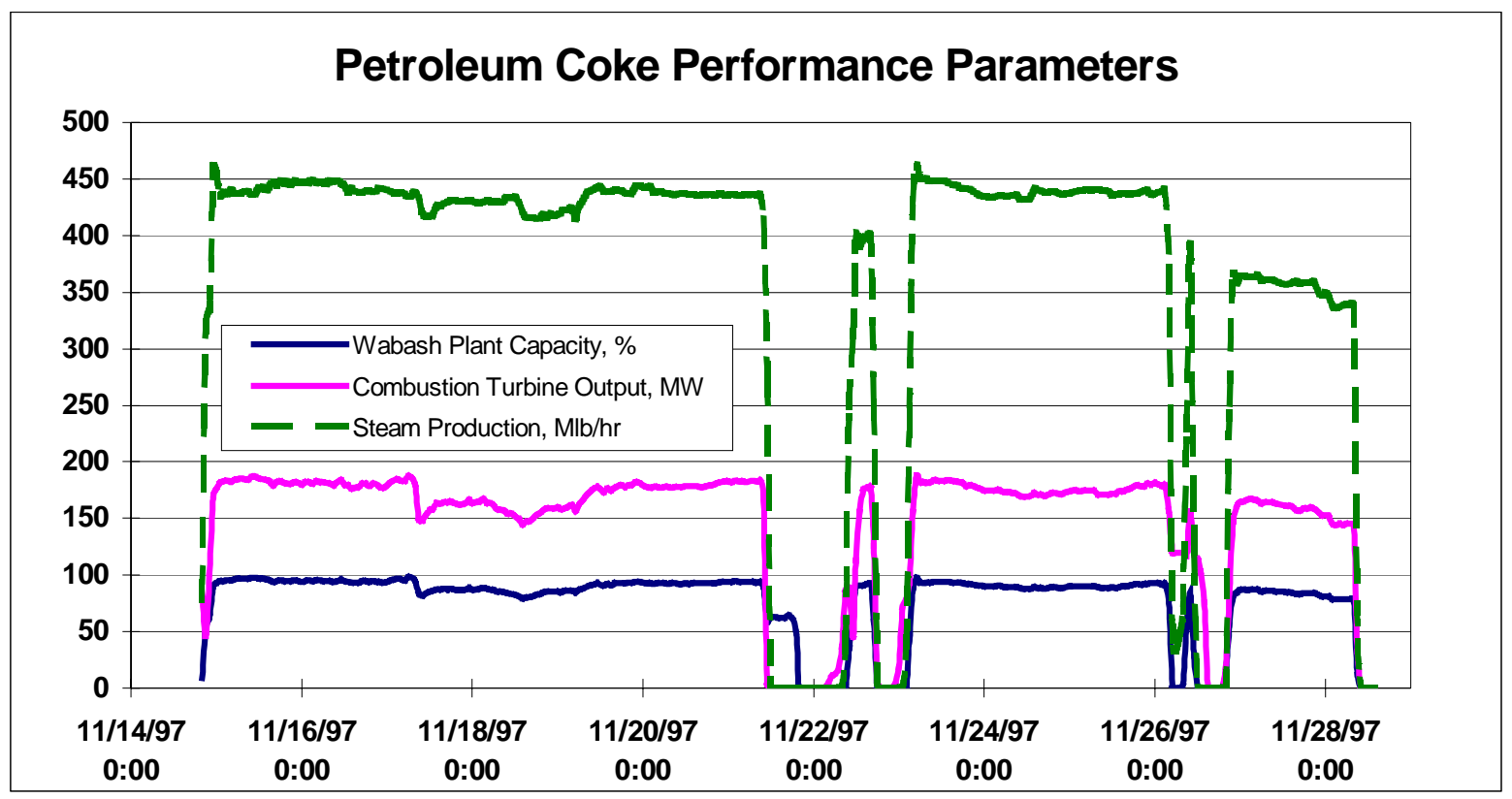


Table 4.2.2B: Thermal Performance Summary

\begin{tabular}{|l|c|c|c|}
\cline { 2 - 4 } \multicolumn{1}{c|}{} & \multirow{2}{*}{\begin{tabular}{c} 
Design \\
\multicolumn{1}{c|}{}
\end{tabular}} & \multicolumn{2}{c|}{ Actual } \\
\cline { 3 - 4 } \multicolumn{1}{c|}{} & & Coal & Pet Coke \\
\hline Nominal Throughput, tons/day & 2550 & 2450 & 2000 \\
\hline Syngas Capacity, MMBtu/hr & 1780 & 1690 & 1690 \\
\hline Combustion Turbine MW & 192 & 192 & 192 \\
\hline Steam Turbine MW & 105 & 96 & 96 \\
\hline Auxiliary Power MW & 35 & 36 & 36 \\
\hline Net Generation, MW & 262 & 252 & 252 \\
\hline Plant Efficiency, \% (HHV) & 37.8 & 39.7 & 40.2 \\
\hline Sulfur Removal Efficiency, \% & $>98$ & $>99$ & $>99$ \\
\hline
\end{tabular}

\section{Process Observations}

Slurry: Grinding of the petroleum coke proceeded with no problem for the duration of the testing. Slurry with a solids content of approximately 63\%, and good flow characteristics for pumping, was consistently produced. Additional rods were added to the rod mill midway through the test to further reduce the particle size of the slurry, but no significant change in the solids content was noticed.

Reactivity: Laboratory tests prior to on-line operation, showed that the petroleum coke would be much less reactive than the coal fuels. Initially, an average carbon conversion rate of about 97.5\% was seen during the petroleum coke operation. Following the addition of the grinding rods discussed above, and a resultant smaller particle size, overall carbon conversion improved to above 99\% (Figure 4.2.2B). 
Figure 4.2.2B: Petroleum Coke Test Overall Carbon Conversion

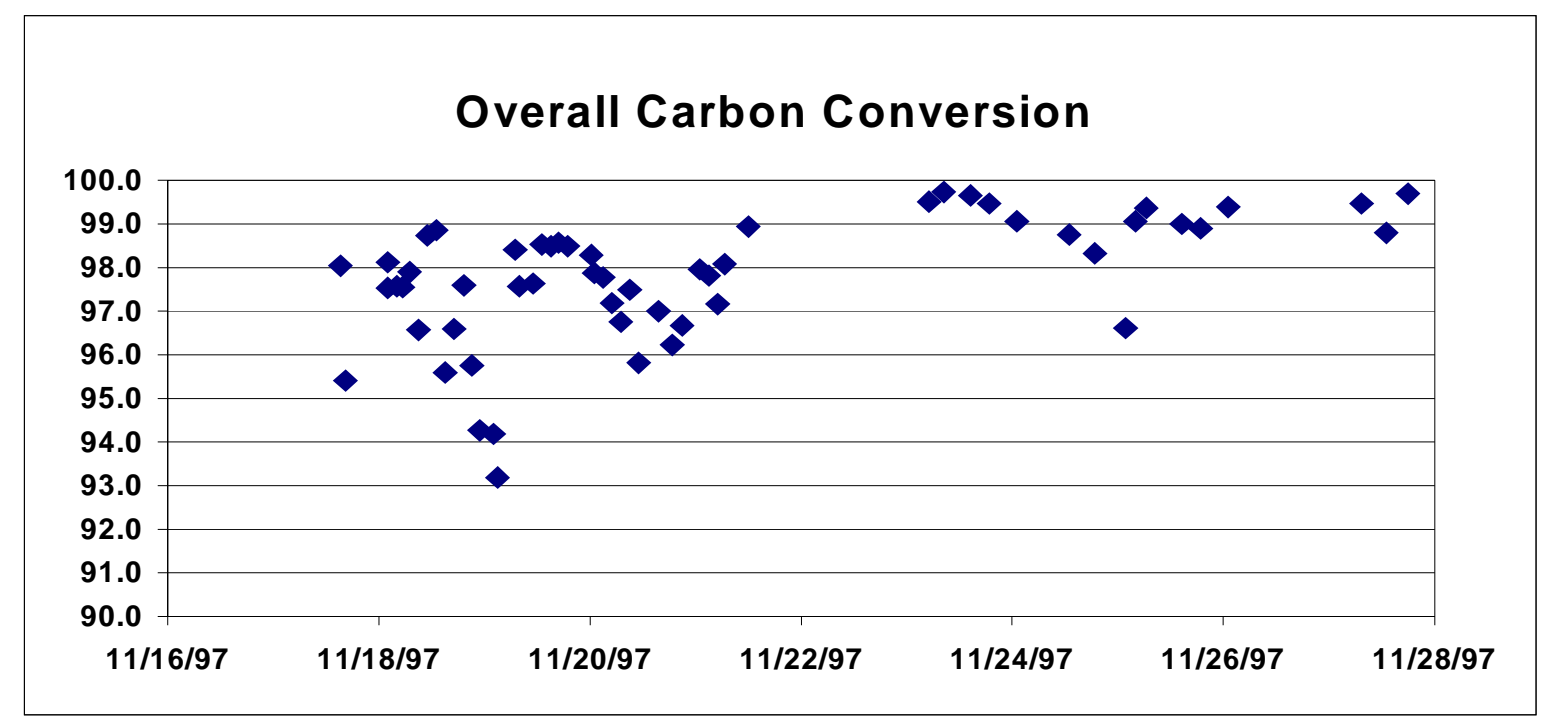

Flux Addition and Slag Flow: Based on laboratory ash fusion and high temperature slag viscosity tests, a range of flux addition of 5 to 10 tons of slag per 100 tons of petroleum coke was targeted for the test. However, problems with the blending equipment resulted in the test starting at a ratio of about 20 tons/100 tons, or about $20 \%$ flux. This was corrected to the target ratio by the third day of testing. Near the end of the test, the flux ratio was purposely reduced to about 2 tons/100 tons (Figure 4.2.2C). No slag-tapping problems were encountered during the test.

Figure 4.2.2C: Petroleum Coke Test Flux Content

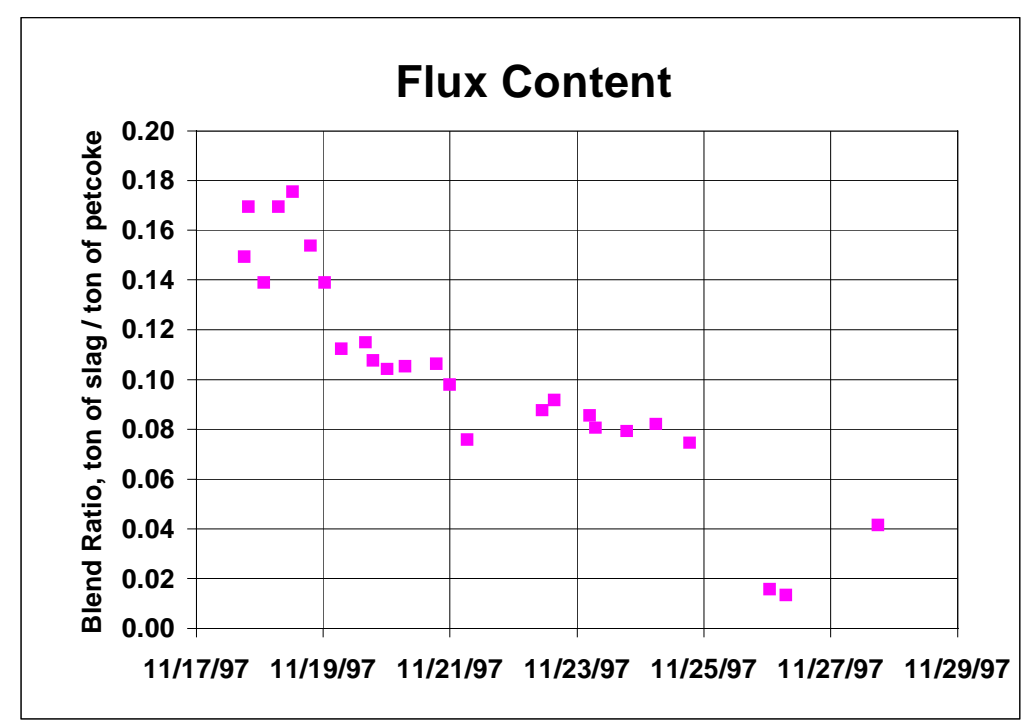

Wabash River Coal Gasification Repowering Project Final Technical Report 
Syngas Quality: Product syngas characteristics were very similar to operation utilizing bituminous coal feeds, as shown in Table 4.2.2C.

Table 4.2.2C: Product Syngas Analyses

\begin{tabular}{|l|c|c|}
\cline { 2 - 3 } \multicolumn{1}{c|}{} & Typical Coal & Petroleum Coke \\
\hline Nitrogen, $\left(\mathrm{N}_{2}\right)$ Vol. \% & 1.9 & 1.9 \\
\hline Argon $(\mathrm{Ar})$, Vol. \% & 0.6 & 0.6 \\
\hline Carbon Dioxide $\left(\mathrm{CO}_{2}\right)$, Vol. \% & 15.8 & 15.4 \\
\hline Carbon Monoxide $(\mathrm{CO})$, Vol. \% & 45.3 & 48.6 \\
\hline Hydrogen $\left(\mathrm{H}_{2}\right)$, Vol. \% & 34.4 & 33.2 \\
\hline Methane $\left(\mathrm{CH}_{4}\right)$, Vol. \% & 1.9 & 0.5 \\
\hline Total Sulfur, ppmv & 68 & 69 \\
\hline Higher Heating Value, $(\mathrm{HHV})$ Btu/scf & 277 & 268 \\
\hline
\end{tabular}

Trace Metals: The ash component of the petroleum coke contained approximately $12 \% \mathrm{NiO}$ and $28 \% \mathrm{~V}_{2} \mathrm{O}_{5}$. The nickel and vanadium trace metal species are often of great concern in utility boiler operation. Vanadium pentoxide has been found to aggressively attack boiler metals, and nickel vapor is a known toxic even at very low levels. Process samples from solid, liquid and gas streams were taken at various points in the process during testing in order to quantify trace metal contents. About $80 \%$ of the nickel and $99 \%$ of the vanadium were captured in the silicate matrix of the slag and rendered inactive in the inert, non-leaching solid, as confirmed by the TCLP environmental leachate test. Some nickel components were found in ash depositions as expected. Liquid and product gas streams contained less than $1 \mathrm{ppm}$ levels of nickel and vanadium species. The process, as currently configured, handles the trace metals more than adequately.

Refractory: Based on analysis of slag samples from the gasifier, refractory wear rate, even at the elevated temperatures required for pet coke operation, was similar to that while on coal operation. No unusual chemical interactions were observed. 
Corrosion: No adverse impact on the metallurgy of the existing equipment was observed. Analysis of test coupons placed throughout the system indicated that corrosion conditions were not much different than coal operation. In particular, the metallic filters showed approximately the same corrosion rates as had been evidenced during coal runs.

Ash Deposition: Ash deposition at the boiler inlet was slightly higher than normal operation, especially when temperatures within the second stage of the gasifier were increased. No additional deposition was noted in other areas.

Char and Tar Characteristics: Because of the lower reactivity of the petroleum coke, char loading to the dry char particulate removal filters was higher than coal operation at similar rates. No filtration problems due to the higher solids loading were observed. Sampling of the syngas at the gasifier outlet showed negligible amounts of tar formation. This may indicate that the second stage of the gasifier could operate at lower temperatures than during the test, which would enhance conversion efficiencies.

Sulfur Removal: Although designed to operate with up to $5.9 \%$ sulfur content coal, most of the Wabash River plant operation has been with coals having 2-3\% sulfur content. As expected, both $\mathrm{H}_{2} \mathrm{~S}$ and COS levels in the raw syngas were much higher during the petroleum coke test due to the greater amount of sulfur in the feed. However, total sulfur in the product syngas was maintained at levels similar to coal operation (Table 4.2.2C and Figure 4.2.2D). No problems were encountered with sulfur removal or recovery. In particular, the COS catalyst performed well and higher conversion rates were indicated. No adverse impact on the catalyst was detected in post-test analysis of catalyst core samples.

Air Emissions: Extensive testing was conducted at two stack locations: the gasification facility incinerator stack and the combustion turbine HRSG stack. Tests were made during both coal and petroleum coke operation. Particulate emission levels were low in both coal and coke cases, totaling about $30 \mathrm{lb} / \mathrm{hr}$ for both stacks. No nickel or vanadium components were detected at the incinerator stack. No testing for these components was done in the HRSG stack since the product syngas was being tested. Unburned hydrocarbon emissions were nearly identical for 
both coal and coke operation (both were less than $1 \mathrm{ppm}$ ). Overall combined sulfur dioxide emissions were significantly less than $0.2 \mathrm{lb} \mathrm{SO}_{2}$ per MMBtu of coal.

Figure 4.2.2D: Total Sulfur in Product Syngas

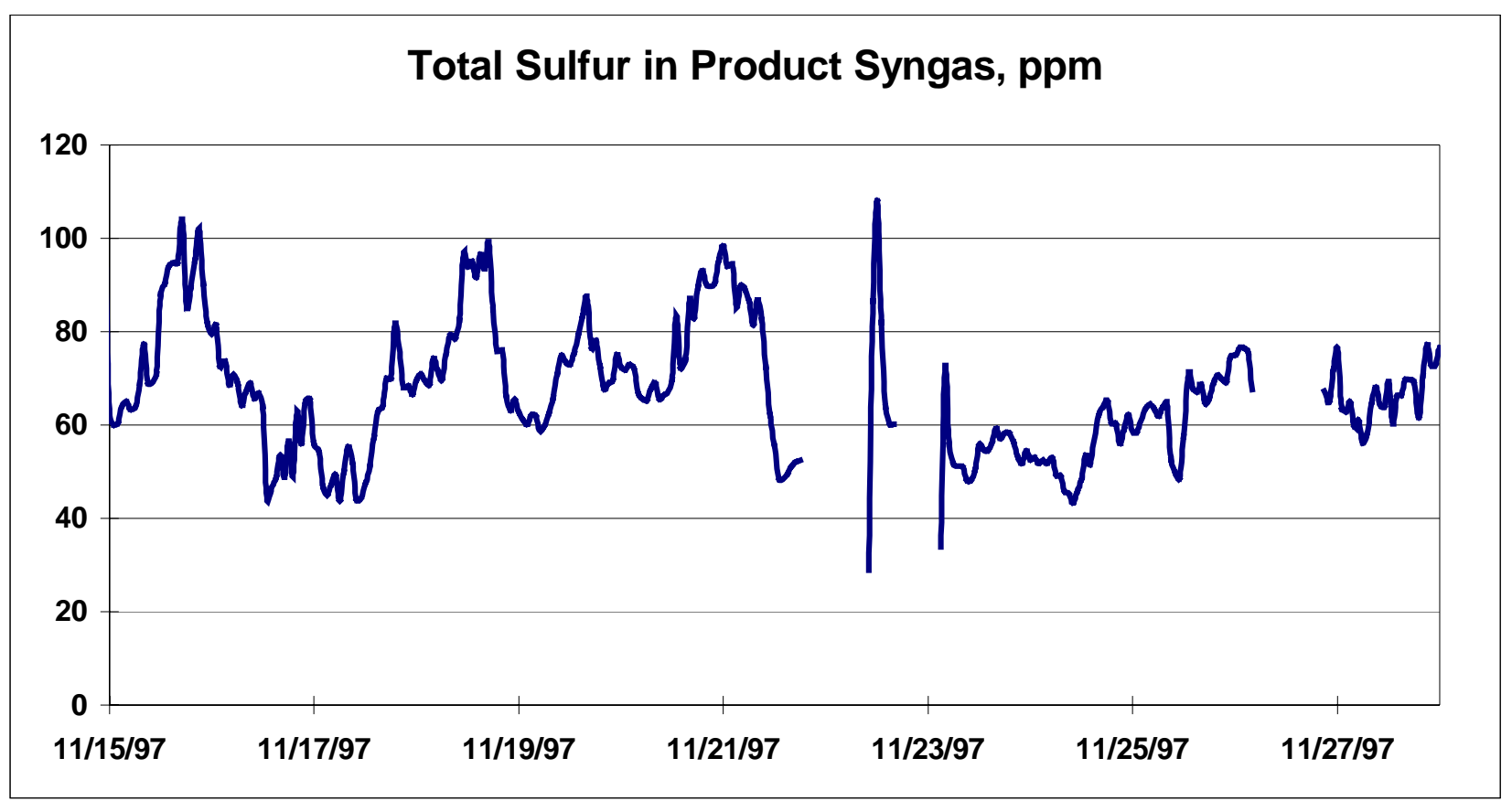

\section{Conclusions}

The overall conclusion from the testing is that petroleum coke operation was not significantly different than coal operation, and that the equipment and systems in place at Wabash River were adequate for this operation without modification. Other observations:

- Thermal efficiency greater than $40 \%$ was demonstrated at Wabash River with an "F" class combustion turbine and a repowered steam turbine. Future facilities should be able to approach $42-44 \%$ efficiency with the " $\mathrm{H}$ " class turbines.

- Gasifier operation on petroleum coke, although requiring somewhat higher temperatures, was much simpler than coal operation, primarily due to the reduced volume of ash components. Gasifier operation was proven down to a level of $2 \%$ flux addition. 
- Trace metal components were captured in the slag, which passed leachate testing and thus is a non-hazardous material. Nickel and vanadium did not appear in the liquid or gas streams resulting from gasification of the pet coke.

- Tar presence in the syngas was negligible.

- Industrial hygiene considerations were the same as for coal operation.

- Additional char was produced, but can be handled utilizing dry char particulate removal systems of the current design.

It appears that future units designed to utilize petroleum coke as their primary fuel source can be similar to Wabash River, but with some improvements to reduce costs or improve operability. Low flux requirements demonstrated at Wabash River mean that the slag, ash and flux systems in future plants can be downsized considerably. The low reactivity of the petroleum coke will mean elimination of certain equipment at Wabash River intended to minimize tar formation. Because of the higher energy content and less tonnage requirement for petroleum coke, the coal handling and slurry preparation systems can be downsized as well. Operation should continue to be smoother than coal, indicating improved availability and capacity factors for a petroleum coke facility.

\section{Future Alternative Fuel Testing}

Similar tests of other alternative fuels are also being planned. Coal fines, a promising fuel in the locality of the Wabash River facility, are being produced by existing mine operations and also are available from surface reserves where the fines have been landfilled in the past. Coal fines may be available at $40-60 \%$ less than the delivered cost of coal to the facility. Major plant modifications may not be necessary to utilize the coal fines fuel. A survey on coal fines availability in the area has been completed and initial laboratory analysis has begun.

Biomass or "renewables" and various waste materials are other alternate fuels being investigated. With concern on global climate changes, there will be more emphasis to reduce emission of greenhouse gases such as $\mathrm{CO}_{2}$ from fossil fuel use. Materials such as sewage sludge, municipal solid waste (MSW), refuse derived fuel (RDF), wood residues, railroad ties, and used tires are potential feedstock candidates. Since most biomass materials are relatively reactive, the two- 
stage design of the Global Energy E-Gas ${ }^{\mathrm{TM}}$ gasifier is uniquely suitable for co-feeding with coal. Coal will still be fed to the high temperature first stage with oxygen, and the alternate fuels will be fed to the lower temperature and longer residence time second stage. A high conversion of the reactive alternate fuel will still be achieved utilizing the thermal energy from the first stage.

The biomass feedstock will also be prepared and handled separately from the coal and coal slurry. Because biomass has characteristics different from coal in terms of handling, a method to prepare and feed the biomass material to the gasifier is being investigated.

Building on the lessons learned and the many successes to date, the Wabash River Coal Gasification Repowering Project gasification plant looks forward to continued demonstration of the viability of the technology in its use of alternate fuels. The advanced gasification technology demonstrated at the Wabash River facility has met the objectives of the Clean Coal Technology Program as outlined in this Final Technical Report and is well positioned to provide the solution to the growing global demand for efficient, environmentally superior, competitive energy conversion to power from coal or alternate feedstocks. Additionally, efforts are underway to incorporate and pursue value-added uses for syngas produced, such as is envisioned through forward-thinking concepts like the DOE's "Vision 21" initiative. 


\subsection{Critical Component Failure Report}

A critical component is defined as any piece of equipment whose failure, or failure of the equipment's associated piping, valving or instrumentation, has resulted in a coal interruption. The likelihood of a critical component failure is substantially higher during a transient condition such as plant start-up or shut-down than during steady operation on coal. Consequently, understanding the root cause of a coal interruption is not only key to reducing future occurrences but also key to reducing other component failures brought on by the transient condition of the interruption. A summary of the causes for coal interruptions by plant area for the four-year Demonstration Period is shown in Table 4.3A.

Table 4.3A: Summary of Critical Components by Plant Area

\begin{tabular}{|c|c|c|c|c|c|}
\hline \multirow{2}{*}{ Plant Area } & \multicolumn{5}{|c|}{ Number of Coal Interruptions } \\
\hline & 1996 & 1997 & 1998 & 1999 & Total \\
\hline Power Block & 11 & 12 & 5 & 5 & 33 \\
\hline Particulate Removal & 10 & 6 & 6 & 3 & 25 \\
\hline First Stage Gasifier & 8 & 5 & 6 & 2 & 21 \\
\hline Slurry Feed & 2 & 3 & 4 & 7 & 16 \\
\hline High Temperature Heat Recovery & 8 & 7 & 1 & & 16 \\
\hline Air Separation Unit & 1 & 2 & 10 & 1 & 14 \\
\hline Slag and Solids Handling & 2 & 3 & & 3 & 8 \\
\hline Low Temperature Heat Recovery & 6 & & 2 & & 8 \\
\hline Sulfur Recovery & 3 & & 1 & 1 & 5 \\
\hline Chloride Scrubber & & 2 & 1 & 1 & 4 \\
\hline Scheduled Maintenance & & 2 & 3 & 1 & 6 \\
\hline Acid Gas Removal & & 3 & & & 3 \\
\hline \multirow{3}{*}{$\begin{array}{r}\text { Total } \\
\text { Total hrs on Coal } \\
\text { Average coal hours/run }\end{array}$} & 51 & 45 & 39 & 24 & 159 \\
\hline & 1,915 & 3,886 & 5,278 & 3,496 & \\
\hline & 38 & 86 & 135 & 146 & \\
\hline
\end{tabular}

The greatest improvements in key component failures have occurred in the areas where the most attention has been focused, namely the power block, the particulate removal system, the first stage gasifier, and the high temperature heat recovery unit. Interface problems between the gasification block and the power block resulting in coal interruptions were frequent in the first two years of operation. For example, 10 coal interruptions were caused by the loss of boiler feedwater supply from the power block to the gasification block in the first two years. Only 1 interruption occurred in the subsequent two years. A significant effort to improve the particulate removal system has resulted in one of the most reliable particulate removal systems in the world. The reliability of the first stage gasifier continues to improve, and since system modifications in 
the fall of 1997, the high temperature heat recovery unit has been nearly trouble-free. More detailed information on the improvements in these areas can be found in Section 5.0 of this report.

Three exceptions to the flat or decreasing number of interruptions for most of the areas are worth noting. First, the slurry feed system has seen an increasing number of interruptions. Eight of the eleven interruptions in the last two years have been due to valve failures or a plugged suction line between the low-pressure slurry pump and the slurry storage tank. By early 2000, both of these problems should be greatly reduced if not eliminated. The valve failures resulted from poor material specifications that will be upgraded and the occurrence of plugged suction lines will be reduced with the installation of a larger diameter agitator in the primary slurry storage tank. Second, the air separation unit has not been as reliable as anticipated. However, several improvements, discussed in more detail in Section 5.0, were made in the summer of 1999 that should increase reliability. Third, the scheduled maintenance interruptions are increasing. This increase indicates that the process is becoming more predictable. It is not coincidental that the best production year for the plant was also the year of the most scheduled outages. Had the combustion turbine rotor failure not occurred, a similar trend in 1999 could have been noted.

The average hours per campaign demonstrate a steady increase and should continue as future improvements to the process and operating practices are completed.

\section{Coal Interruptions Prioritized by Downtime Severity}

Since the duration of the downtime associated with each of the interruptions noted in Table 4.3A ranged from 46 minutes to 101 days, a second summary, Table 4.3B, prioritizes the downtime severity for each of the coal interruptions. Table 4.3B divides the downtime associated with a coal interruption into five types. These types are defined as follows;

A Coal interruptions that result in downtime greater than two weeks.

B Coal interruptions that result in downtime greater than one week but less than two.

C Coal interruptions that result in downtime greater than 72 hours but less than one week.

D Coal interruptions that result in downtime greater than 24 hours but less than 72 hours.

E Coal interruptions that result in downtime less than 24 hours. 
In Table 4.3B, as in Table 4.3A, improvement trends are evident. However, four critical opportunities are noteworthy, some of which are not obvious from the data presented. These four areas constitute the primary critical areas where teams have been formed to address the specific problems mentioned. Although other areas force the plant off line, these interruptions are addressed primarily by improving the preventative maintenance program or the plant's operating discipline.

\section{$\underline{\text { First Stage Gasifier }}$}

First, plugging of the taphole associated with the first stage gasifier must be eliminated. Plugged tapholes accounted for 4 of the 5 first stage gasifier coal interruptions with downtime severity of A or B. These incidents are avoidable and improved operating guidelines have been instituted that should eliminate these occurrences. Second, of the 21 coal interruptions for the first stage gasifier in the last four years, 11 were due to slurry mixer failures. Fortunately, continuous root cause investigations into failures, design improvements of the slurry mixer and control logic enhancements are reducing the trips associated with failed slurry mixers. In 1999, only one coal interruption was due to a slurry mixer failure.

\section{$\underline{\text { Particulate Removal }}$}

The particulate removal system is a critical component that has driven overall plant availability. In years such as 1998 and 1999, when the particulate removal system brought the plant down less than twice per year, overall plant availability was high. An aggressive improvement effort coupled with a disciplined quality assurance process has contributed to the improved availability of the particulate removal system. The type A downtime event in 1999 was not associated with the filter elements, but with the char return piping system to the first stage gasifier. The type B downtime event was associated with an experimental filter cluster. With the char return piping system permanently fixed and more conservative risk management with respect to experimental filters, future coal interruptions attributed to this system should be minimal. 


\section{Table 4.3B: Downtime Consequences of Critical Components by Operational Area}

\begin{tabular}{|c|c|c|c|c|c|}
\hline Plant Area & \multicolumn{5}{|c|}{ Number of Trips } \\
\hline A - Downtime Consequence Greater than 2 weeks & 1996 & 1997 & 1998 & 1999 & Total \\
\hline Scheduled Maintenance & & $2 *$ & 3 & 1 & 6 \\
\hline Particulate Removal & 4 & 1 & 1 & 1 & 7 \\
\hline High Temperature Heat Recovery & 4 & 1 & & & 5 \\
\hline Power Block & & & & 2 & 2 \\
\hline First Stage Gasifier & 1 & 1 & 1 & & 3 \\
\hline Chloride Scrubber & & 1 & & & 1 \\
\hline *Forced into an outage early. & 9 & 6 & 5 & 4 & 24 \\
\hline B - Downtime Consequences 1 to 2 weeks & 1996 & 1997 & 1998 & 1999 & Total \\
\hline First Stage Gasifier & 1 & 2 & & 1 & 4 \\
\hline Low Temperature Heat Recovery & 2 & & & & 2 \\
\hline Particulate Removal & & & & 1 & 1 \\
\hline Total & 3 & 2 & $\mathbf{0}$ & 2 & 7 \\
\hline C - Downtime Consequences 72 hours -7 days & 1996 & 1997 & 1998 & 1999 & Total \\
\hline Air Separation Unit & 1 & & 4 & & 5 \\
\hline First Stage Gasifier & & 1 & & 1 & 2 \\
\hline High Temperature Heat Recovery & 1 & 1 & & & 2 \\
\hline Acid Gas Removal & & 1 & & & 1 \\
\hline Low Temperature Heat Recovery & 1 & & & & 1 \\
\hline Power Block & 1 & & & & 1 \\
\hline Slag and Solids Handling & 1 & & & & 1 \\
\hline Slurry Feed & 1 & & & & 1 \\
\hline Total & 6 & 3 & 4 & 1 & 14 \\
\hline D - Downtime Consequence 24-72 hours & 1996 & 1997 & 1998 & 1999 & Total \\
\hline First Stage Gasifier & 2 & & 4 & & 6 \\
\hline Air Separation Unit & & 1 & 4 & & 5 \\
\hline Particulate Removal & 2 & & 1 & 1 & 4 \\
\hline Slag and Solids Handling & & 2 & & 2 & 4 \\
\hline High Temperature Heat Recovery & & 3 & & & 3 \\
\hline Power Block & 1 & 2 & & & 3 \\
\hline Acid Gas Removal & & 1 & & & $\mathbf{1}$ \\
\hline Chloride Scrubber & & 1 & & 1 & 2 \\
\hline Slurry Feed & & 1 & & 1 & 2 \\
\hline Low Temperature Heat Recovery & 1 & & & & $\mathbf{1}$ \\
\hline Sulfur Recovery & 1 & & & & 1 \\
\hline Total & 7 & 11 & 9 & 5 & 32 \\
\hline E - Downtime Consequences Less than 24 hours & 1996 & 1997 & 1998 & 1999 & Total \\
\hline Power Block & 9 & 10 & 5 & 3 & 27 \\
\hline Particulate Removal & 4 & 5 & 4 & & 13 \\
\hline Slurry Feed & 1 & 2 & 4 & 6 & 13 \\
\hline First Stage Gasifier & 4 & 1 & 1 & & 6 \\
\hline High Temperature Heat Recovery & 3 & 2 & 1 & & 6 \\
\hline Air Separation Unit & & 1 & 2 & 1 & 4 \\
\hline Low Temperature Heat Recovery & 2 & & 2 & & 4 \\
\hline Sulfur Recovery & 2 & & 1 & 1 & 4 \\
\hline Slag and Solids Handling & 1 & 1 & & 1 & 3 \\
\hline Acid Gas Removal & & 1 & & & 1 \\
\hline Chloride Scrubber & & & 1 & & $\mathbf{1}$ \\
\hline Total & 26 & 23 & 21 & 12 & 82 \\
\hline
\end{tabular}

Wabash River Coal Gasification Repowering Project Final Technical Report 


\section{$\underline{\text { Air Separation Unit }}$}

This reliability of this system has not been near that expected. In 1998, the air separation unit was responsible for 10 coal interruptions and more than 16 days of downtime. Although the air separation unit caused only one coal interruption in 1999, over 14 days of downtime was associated with this system. Since the demonstrated industry reliability of air separation units is relatively high compared to gasification processes, the Project's air separation unit should cause no coal interruptions. Although several improvements have been implemented to enhance the unit's reliability, this air separation unit is still not up to industry standards and additional improvements are being pursued.

\section{High Temperature Heat Recovery}

Coal interruptions due to this system have been virtually eliminated with only one incident in the last two years. However, the length of scheduled outages is often determined by the time required to clean the boiler tubes and perform the associated maintenance. Tube side deposits are tenacious and very hard. Mechanical and chemical cleaning methods have been improved to dramatically reduce the cleaning time, but improvements are still needed in this area and are being pursued.

The team approach utilized to address the four critical components outlined above, coupled with the plant's continually improving operating discipline, will ensure that fewer and fewer critical components show up on future critical component reports. 


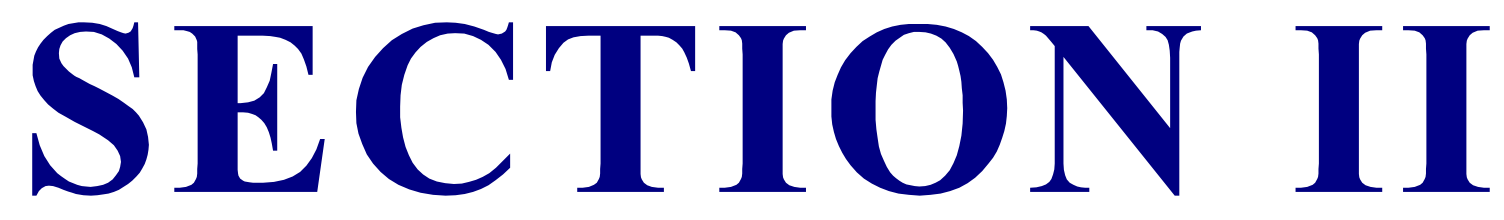

\section{Operations \& Economics}




\subsection{TECHNICAL PERFORMANCE}

The technical performance of the plant has been evaluated within this section primarily by a review of system and equipment reliability, availability and maintainability. Each major piece of equipment and process step has been evaluated over the best 12 months of operation during the Demonstration Period. At Wabash River this time period covers March 1, 1998 through February 28, 1999 and is referred to throughout the following section as the "Operating Period". It is significant to note that this period represents the final full 12-month period of operations within the Demonstration Period and is immediately preceding the 100-day outage for the combustion turbine failure.

As the entire Operating Period is encompassed within the defined Demonstration Period for the Project, some of the information contained within this section is redundant when compared with information in Section 4.0 Demonstration Period. This redundancy is intentional, allowing these two sections of the Final Technical Report to be reviewed independently.

Reliability discussions included in Section 5.0 address the consistency in operation of specific equipment items, while the maintainability discussions are associated with specific equipment maintenance issues, which prevented consistent operation. The availability of all subsystems is defined as the percentage of hours that a subsystem was available for operation when compared to the total hours in the Operating Period minus the "scheduled" facility downtime hours. These numbers are compiled and reviewed in detail in Table 5.0A. 
Table 5.0A: WRCGRP Operating Period Downtime and Availability

\begin{tabular}{|c|c|c|c|c|}
\hline $\begin{array}{l}\text { Section } 5 \\
\text { Reference }\end{array}$ & Area & $\begin{array}{c}\text { Non- } \\
\text { Scheduled } \\
\text { Downtime } \\
\text { Hours } \\
\end{array}$ & $\begin{array}{l}\% \text { of Non- } \\
\text { Scheduled } \\
\text { Downtime }\end{array}$ & Availability \\
\hline 5.1 & Air Separation Unit* & 285 & $12.5 \%$ & $96.32 \%$ \\
\hline 5.1.1 & Air Compression System & 87 & $3.8 \%$ & $98.87 \%$ \\
\hline 5.1.2 & Water Wash System & 61 & $2.7 \%$ & $99.21 \%$ \\
\hline 5.1 .3 & Air Purification System & 10 & $0.4 \%$ & $99.87 \%$ \\
\hline 5.1 .4 & Air Cooling and Liquefaction System & 0 & $0.0 \%$ & $100.00 \%$ \\
\hline 5.1 .5 & Cryogenic Distillation System & 77 & $3.4 \%$ & $99.00 \%$ \\
\hline 5.1.6 & Oxygen Mixing System & 0 & $0.0 \%$ & $100.00 \%$ \\
\hline 5.1.7 & Nitrogen Handling and Storage System & 15 & $0.7 \%$ & $99.81 \%$ \\
\hline 5.1.8 & Oxygen Compression System & 70 & $3.1 \%$ & $99.09 \%$ \\
\hline 5.2 & Coal Handling & 36 & $1.6 \%$ & $99.54 \%$ \\
\hline 5.2 .1 & Coal Hopper System & 0 & $0.0 \%$ & $100.00 \%$ \\
\hline 5.2 .2 & Rod Mill System & 0 & $0.0 \%$ & $100.00 \%$ \\
\hline 5.2.3 & Slurry Storage Tank System & 3 & $0.1 \%$ & $99.96 \%$ \\
\hline 5.2 .4 & Slurry Feed System & 33 & $1.4 \%$ & $99.58 \%$ \\
\hline 5.3 & Gasification & 1590 & $69.9 \%$ & $79.45 \%$ \\
\hline 5.3.1 & First Stage Gasifier & 1001 & $44.0 \%$ & $87.06 \%$ \\
\hline 5.3.2 & Second Stage Gasifier & 169 & $7.4 \%$ & $97.82 \%$ \\
\hline 5.3.3 & Raw Syngas Conditioning & 0 & $0.0 \%$ & $100.00 \%$ \\
\hline 5.3.4 & Slag and Solids Handling & 66 & $2.9 \%$ & $99.15 \%$ \\
\hline 5.3.5 & $\begin{array}{l}\text { Syngas Cooling/Steam Generation } \\
\text { System }\end{array}$ & 158 & $6.9 \%$ & $97.96 \%$ \\
\hline 5.3.6 & Particulate Removal System & 152 & $6.7 \%$ & $98.03 \%$ \\
\hline 5.3.7 & Chloride Scrubbing System & 10 & $0.4 \%$ & $99.87 \%$ \\
\hline 5.3.8 & COS Hydrolysis System & 0 & $0.0 \%$ & $100.00 \%$ \\
\hline 5.3.9 & $\begin{array}{l}\text { Low Temperature Heat Recovery } \\
\text { System }\end{array}$ & 7 & $0.3 \%$ & $99.90 \%$ \\
\hline 5.3.10 & Syngas Moisturization System & 0 & $0.0 \%$ & $100.00 \%$ \\
\hline 5.3.11 & Acid Gas Removal System & 22 & $1.0 \%$ & $99.72 \%$ \\
\hline 5.3 .12 & Sulfur Recovery System & 5 & $0.2 \%$ & $99.94 \%$ \\
\hline 5.3 .13 & Sour Water Treatment System & 0 & $0.0 \%$ & $100.00 \%$ \\
\hline 5.3.14 & Cooling Tower System & 0 & $0.0 \%$ & $100.00 \%$ \\
\hline 5.4 & Power Block & 363 & $16.0 \%$ & $95.30 \%$ \\
\hline 5.4 .1 & Combustion Turbine & 140 & $6.1 \%$ & $98.19 \%$ \\
\hline 5.4 .2 & Heat Recovery Steam Generator & 201 & $8.8 \%$ & $97.40 \%$ \\
\hline 5.4 .3 & Water Treatment Facility & 13 & $0.6 \%$ & $99.83 \%$ \\
\hline \multirow[t]{6}{*}{$\begin{array}{l}5.4 .4 \\
\end{array}$} & Steam Turbine & 9 & $0.4 \%$ & $99.88 \%$ \\
\hline & Totals & 2274 & $100.0 \%$ & $70.61 \%$ \\
\hline & Coal Hours & 5462 & & \\
\hline & Hours for 3 scheduled outages & 1022 & & \\
\hline & Non-scheduled downtime hours & 2274 & & \\
\hline & Period Hours & 8760 & & \\
\hline
\end{tabular}

*Thirty-five hours of downtime affected both sections 5.1.1 and 5.1.8. It has been counted only once in the ASU total but in each section independently. 
Each of the plant areas shown in Table 5.0A are discussed from three perspectives in this section of the report. First, system modifications, which include significant mechanical, procedural or process operating changes made to the system prior the Operating Period. Second, operating overview, which summarizes operation, downtime and maintenance associated with each piece of equipment in an area during the Operating Period. Third, summary and conclusions, which highlight past and present operation, describe changes made within the system after the Operating Period, and recommends changes for future plants. 


\subsection{Air Separation Unit}

\subsubsection{Air Compression System}

Air, utilized as feedstock in the air separation plant, is harvested from the atmosphere and pressurized by a three-stage, centrifugal, main air compressor. Subsystems for the main air compressor include a three-phase, high-voltage, AC synchronous motor driver, lube oil system with vapor recovery, anti-icing protection and vibration monitoring equipment, an inlet air plenum that filters particulate prior to compression, inlet guide vanes, discharge vent valves and inter-stage cooling air coolers that remove heat of compression after each of the three compressor stages.

The flow of air through the compressor is controlled via modulation of guide vanes on each of the three compressor stages. The machine is protected from surge via automatic vent valves on the discharge.

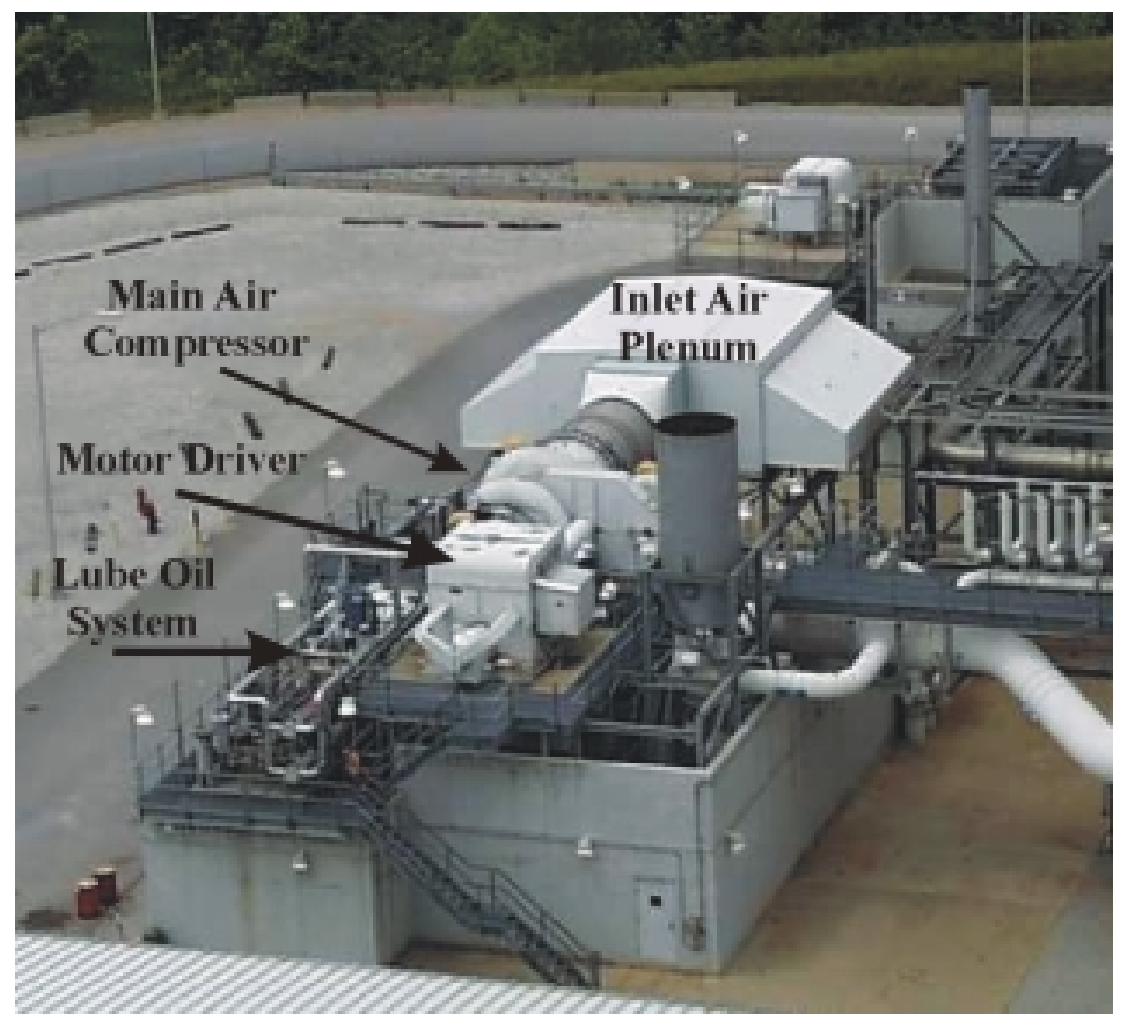

Figure 5.1.1A: Main Air Compressor 


\subsubsection{System Modifications}

No system modifications were made to the air compression system prior to the Operating Period. However, as a result of reliability issues with the main air compressor's inlet guide vane and surge protection subsystems, several procedural changes were made in an attempt to increase the main air compressor's reliability. Also, concerns over moisture detected within the motor driver enclosure prompted steps to guard against a potential future failure of the motor windings. Details of these significant procedural changes and preventative actions taken prior to the Operating Period follow.

\section{$\underline{\text { Inlet Guide Vanes }}$}

The inlet guide vane subsystem was recognized very early in system operation as the biggest reliability issue for the main air compressor. Specifically, guide vane corrosion as a result of moisture, infrequent guide vane movement, and inadequate weatherproofing of the guide vane actuators and their controllers were all noted as concerns resulting from improper design. Fiftythree hours of downtime were suffered beginning on January 25, 1998 due to the inlet guide vane subsystem. In addition to this specific downtime incident, maintenance performed on the guide vane subsystem was frequent and costly. On one occasion prior to the Operating Period, one of the three guide vanes required complete extraction from the compressor in order to allow repair to a twisted actuator shaft suffered while attempting to stroke the guide vanes after a prolonged period of inactivity.

The following actions were taken prior to the Operating Period in order to address concerns over the inlet guide vane subsystem of the main air compressor. First, usage of the subsystem's capability to provide an on-line wash of the inlet guide vanes via a water spray was abandoned. Results from lab analysis of both the supply and return water indicated that on-line washing might have been increasing, rather than decreasing, the amount of deposits on the guide vanes. Second, a policy of exercising the guide vanes periodically during outages was instituted in order to prevent them from binding due to long periods of inactivity. Third, inspections of all critical components of the inlet guide vane subsystem were performed during extended outages. Weatherproofing efforts were undertaken as needed during those inspections. Finally, efforts to upgrade or procure a replacement for the inlet guide vane subsystem were initiated. 


\section{Discharge Vent Valves}

Failure of the main air compressor's discharge vent valves caused 35 hours of downtime beginning on January 11, 1998. These valves provide surge protection for the main air compressor and are normally held in their fully closed position while the machine is running. These surge valves are subjected to extended time periods without being exercised, and therefore, are susceptible to corrosion that causes them to be stiff and difficult to operate. The experienced downtime as a result of their non-responsiveness prior to the Operating Period prompted the implementation of a preventative maintenance plan. The plan includes lubrication of the valve actuators and periodic stroking of the valves through their full range of motion during outages.

\section{Motor Driver}

A routine inspection of the main air compressor's motor driver prior to the Operating Period showed evidence of moisture within the motor enclosure. The moisture was visible in the bottom of the enclosure as well as detected in the insulation of the motor windings through standard electrical testing. Although it did not lead to downtime, moisture within the windings of such a large, high-voltage motor was addressed with top priority due to its potential to cause a catastrophic failure of the windings. It was determined that the fiberglass motor enclosure was inappropriately designed for outdoor service. Hairline cracks and pinholes around the rivet points and seams in the enclosure provided possible entrance points for moisture. As an immediate action, care was taken to seal the enclosure by application of a commercially available sealant. Further investigation of the system revealed that the electric heaters within the motor enclosure were improperly installed during construction and had never functioned. The installation error was rectified, and the heaters began functioning as designed. As an added precaution, a procedural change was made to include removal of the cooling water flow from the motor immediately after a shutdown of the machine. Cooling water flow significantly counteracted the positive effects of the motor enclosure heaters, and may have promoted moisture condensation during the winding cooldown period immediately following the shutdown of the main air compressor. 


\subsubsection{Operating Experience Overview}

The total downtime associated with the air compression system during the Operating Period was 87 hours. Operating experience for individual pieces of equipment follows.

On August 9, 1998 an electronic card supplying power to the programmable logic controller for the inlet guide vane actuator subsystem failed causing 47 hours of downtime. The failed card was sent to the original equipment manufacturer for analysis. Their investigation concluded that the failure resulted from a high voltage surge consistent with a lightning strike. This analysis seems reasonable due to the fact that the incident occurred during severe weather. No corrective actions other than a like-for-like replacement of the card were undertaken.

On August 15, 1998 a blown $15 \mathrm{kV}$ electrical fuse in a potential transformer located in the motor control center's high-voltage switchgear triggered a trip of the main air compressor (the oxygen compressor also tripped for the same reason). The incident led to 35 hours of plant downtime. The driver motors for both the main air compressor and the oxygen compressor rely upon a signal from this potential transformer in order to control their synchronous fields. Loss of the transformer's fuse forced them both to trip instantaneously. Rigorous electrical testing of the potential transformer confirmed no perceivable problem with the transformer. The possibility of a defective fuse was also ruled out, as this was the second incident involving the same fuse location in just over eight months (the first caused 33 hours of downtime prior to the Operating Period on February 5, 1998). Although no definitive explanation could be found for the blown fuse, the potential transformer was swapped with an identical one from a less critical service. No further problems with this device have been experienced or are anticipated.

On October 8, 1998 an interruption in the power supply to the vibration monitoring subsystem for the main air compressor was experienced causing 5 hours of plant downtime. Investigation revealed that power was accidentally shutoff by a technician working inside the cabinet housing of the power source. Work in that cabinet is now restricted to plant outages and a caution sign has been posted on the cabinet door in order to warn of the shutdown potential. 
A project to maximize the effectiveness of the main air compressor's inlet air plenum de-icing mechanism was implemented during the Operating Period. This mechanism operates by routing a small slipstream of warm air from the compressor discharge back to the inlet air plenum. The piping for this slipstream had been exposed to ambient weather conditions since the completion of plant construction. The addition of insulation to the line minimized the flow of air required for de-icing the plenum, thus increasing the amount of air available for feedstock to the cryogenic plant during cold weather.

A vibration data collection system was installed on the main air compressor during the Operating Period. The new system added historical archiving, event capturing, and analytical tools to the already existing vibration monitoring equipment. The increased functionality of the vibration equipment now allows for predictive maintenance techniques to be employed through monitoring of data trends and enhances the accuracy of troubleshooting in response to vibration related events.

Maintenance on the main air compressor during the Operating Period was limited to normal preventative maintenance procedures (PM's) performed during planned outages. Some of the tasks performed during these PM's included: inspection, cleaning, and replacement of the air intake filters, electrical measurements on the motor, motor enclosure inspections and weatherproofing, coupling and bull-gear inspections, lube oil system inspection and minor leak repair, pressure safety valve calibrations, inspection of surge valves, and inlet guide vane actuator calibrations.

\subsubsection{Summary and Conclusions}

In summary, the overall reliability of the main air compressor has been disappointing. Specifically, the inlet guide vane subsystem has been a point of almost constant concern leading up to and through the Operating Period. Several aspects of the subsystem were poorly designed by the original equipment manufacturer.

Actuators have been highly susceptible to weather conditions, the electronic controllers for the actuators have proved to be imprecise and difficult to manage, critical components have worn 
quickly and repeatedly and replacement parts that should be commonplace have been difficult to procure. Furthermore, all of these difficulties have been compounded by the fact that the original equipment manufacturers for both the compressor and guide vane actuators have not been cooperative with regard to corrective actions. Future gasification projects requiring the installation of air compressors of this magnitude need to pay particularly close attention to the detailed design of the main air compressor's inlet guide vane subsystem.

The actuators on the inlet guide vane subsystem for the main air compressor were replaced in October 1999, with a new third party design (Figure 5.1.1B). Some of the benefits of the new actuators include the following. The new system is designed for all weather conditions, which should eliminate plant downtime associated with moisture. The new design completely eliminates the field electronics inherent with the old system, thus simplifying guide vane control. The new actuators are designed for more cycles of operation than the plant could reasonably require in the course of several decades. All three actuators have a mechanism to allow them to be manually positioned and locked anywhere within their full range of motion providing the capability to perform actuator maintenance while the main air compressor remains on line. The new system incorporates only parts made in the USA, thus reducing cost and delivery lead-times. All three stages now utilize identical components affording a reduction of spare inventory. The actuators have caused no downtime since installation, and are expected to eliminate the air separation unit's largest source of downtime.

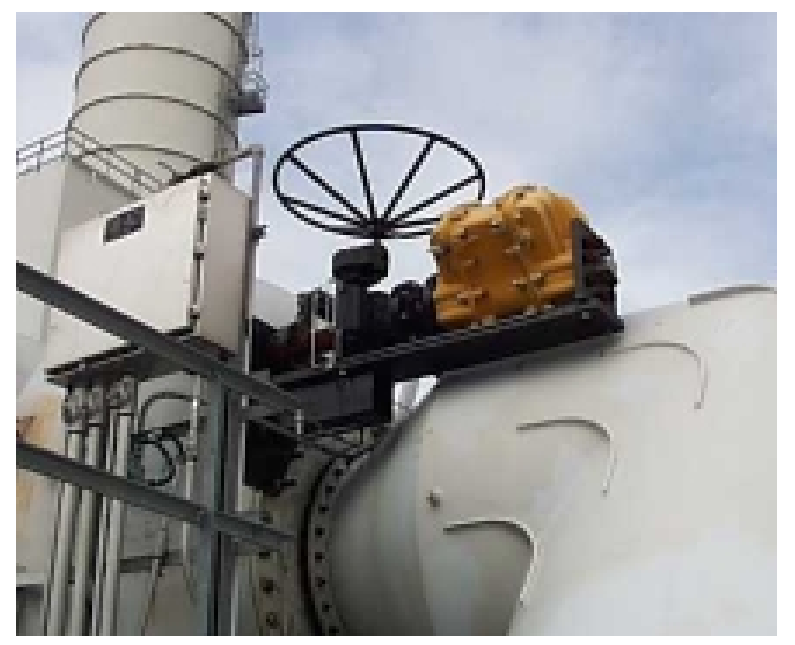

Figure 5.1.1B: Close-up of a Newly Installed Guide Vane Actuator 
While installing the new inlet guide vane project for the main air compressor, all three of the guide vanes needed to be removed from the compressor for inspection and repairs. During this process several small improvement projects were implemented in order to prevent damage to the inlet guide vanes and reduce costs of future guide vane repairs. They include the addition of lift points to the large diameter second and third stage air pipe spools to reduce rigging and lifting efforts while increasing safety and the addition of drain valves for each guide vane flange to prevent internal guide vane corrosion. Also, new flanges were added to the compressor oil return line to improve access for future guide vane extractions. Finally, proper mechanical design was implemented via materials selection for the guide vane shaft and shaft key, providing future equipment protection.

In addition to the problems related to the inlet guide vane subsystem, difficulties in preventing moisture from penetrating the motor enclosure have been a serious concern with regard to protecting against a costly motor rewind. A dry gas purge installed in the motor enclosure during the first quarter of 1999 coupled with heater repairs, enclosure-weatherproofing efforts, and procedural changes pertaining to cooling water flows have brought the moisture problem under control. Future gasification projects requiring the installation of outdoor air compressors need to pay particularly close attention to the quality of design and material selection used in the motor driver's enclosure.

One other point of concern with regard to the reliability of the main air compressor involves the lack of redundancy of vibration probes located within the machine. On February 26, 2000, a total of 15 hours of downtime was suffered due to a false vibration trip of the main air compressor. Investigation identified that loose electrical connections and moisture penetration into those connections were the root causes of the downtime. The problem has been rectified with precautions that should prevent a repeated occurrence. However, this incident coupled with sporadic vibration-related nuisance trips suffered prior to the Operating Period have prompted evaluation of the need for added redundancy in the vibration monitoring subsystem. The evaluation is currently underway. 
Major maintenance that has occurred with the main air compressor since the Operating Period has been limited to leak repairs within the inter-cooler between the first and second stages. During the course of leak repairs, evidence clearly identified a design flaw associated with the internal mist elimination equipment. A robust brace assembly was designed and implemented in order to prevent similar future failures. Minor leaks with the main air compressor's inter-stage coolers continue, but they are currently of no detriment to the performance of the plant. They will be addressed in future outages, but only if they become more severe. All other maintenance performed since the end of the Operating Period, and anticipated in the future, is limited to the preventative maintenance work discussed at the end of Section 5.1.1.2. 


\subsubsection{Water Wash System}

The water wash system within the ASU includes:

\begin{tabular}{|l|l|}
\hline Water chiller tower (Figure 5.1.2A) & Water chiller pumps (Figure 5.1.2A) \\
\hline Wash water tower (Figure 5.1.2A) & \\
\hline
\end{tabular}

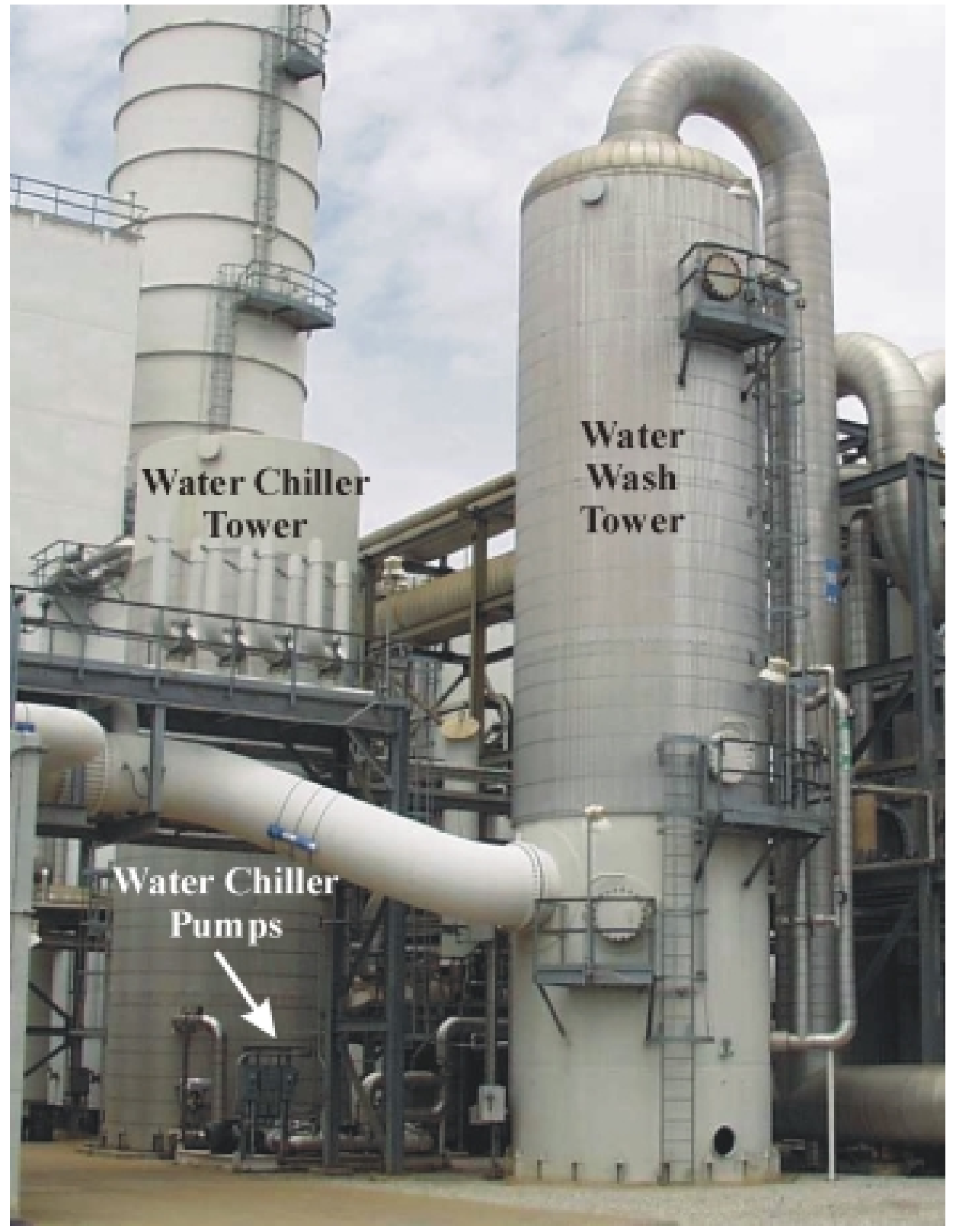

Figure 5.1.2A: Water Wash System 


\subsubsection{System Modifications}

No system modifications were made and no downtime was attributed to the water wash system prior to the Operating Period.

\subsubsection{Operating Experience Overview}

The total downtime associated with the water wash system during the Operating Period was 61 hours. Operating experience for individual pieces of equipment follows.

\section{Water Chiller Tower}

On June $8^{\text {th }}$ and $9^{\text {th }}$, 1998 packing fires inside the water chiller tower were accidentally ignited from welding slag during vessel entry work. These fires accounted for all 61 hours of downtime attributed to the water wash system during the Operating Period. Evidence suggested the fires to be the result of inadequate usage of fire barriers while work was being performed, as well as failure to utilize a low energy welding technique. The use of heli-arc type welding in place of common stick welding and better usage of fire barriers will prevent recurrence of this incident if weld repairs inside the vessel ever need to be repeated.

The scope of work being performed in the water chiller tower at the time of the aforementioned fires was to correct oversight in the water distribution system design, repairing and reinforcing hardware within the tower. The water distribution system increases the efficiency of the water chiller tower by maximizing the contact between the water and the waste nitrogen. Years of operation with inadequate design had taken a toll upon the distribution system to the point that warmer water temperatures were beginning to limit the production of the air separation unit. As a result of the maintenance to the water chiller tower, water temperatures were significantly reduced, thus increasing oxygen and nitrogen production in the air separation unit.

\section{Water Chiller Pumps}

There were no major maintenance, downtime or operational problems associated with the water chiller pumps during the Operating Period. However, minor maintenance during the Operating Period included periodic replacement of suction strainers and typical preventative maintenance inspections and procedures. 


\section{Water Wash Tower}

There was no maintenance, downtime or operational problem associated with the water wash tower during the Operating Period.

\subsubsection{Summary and Conclusions}

The water wash system has been a very reliable system. With the exception of delays caused by accidental fires in June of 1998, the water wash system has caused no plant downtime. However, the system does struggle to maintain cool water temperatures during unusually hot summer conditions. These periods have the potential to limit plant production because warmer water temperatures increase moisture carryover to the downstream air purification adsorber beds. This increased carryover can occasionally limit the throughput capabilities of the adsorber beds.

The occasional difficulties in cooling the chiller water are attributed to the following. First, the air temperature from the discharge of the main air compressor is elevated during the summer, because cooling tower water used in the compressor inter-coolers is warmer than desired. Secondly, rust and corrosion products tend to build up, over time, in the water distribution system within the water chiller tower. This allows channeling of the water through portions of the tower, thus reducing contact between the water and the waste nitrogen. Periodic cleaning and repair of the distribution system is all that is anticipated in order to prevent channeling. However, limits in the capabilities of the cooling tower are more difficult to overcome. As these limits are present only during periods of higher ambient temperatures, a cost versus benefit analysis for designing the cooling tower for these conditions should always be performed for any future projects.

It is also worth mentioning that corrosion of the vessel walls within the water chiller tower is occurring and will likely necessitate the replacement of the vessel several years in the future. It is unlikely that very much of the corrosion is taking place during plant operation, because the vessel is padded with waste nitrogen during those times. However, plant shutdowns allow air to contact the wet vessel internals. It would be wise to evaluate the cost of using an alternative material for the internals of the water chiller tower for future gasification projects. 


\subsubsection{Air Purification System}

The air purification system includes:

Adsorber beds (Figure 5.1.3A)

Regeneration heater (Figure 5.1.3B)

The adsorbers are two-stage, radial-flow media beds with one adsorber on line at all times while the other is being regenerated off line. Once regenerated and cooled, the off-line bed is brought on line and the other is heated for regeneration. This batch cycle is repeated constantly during plant operation.

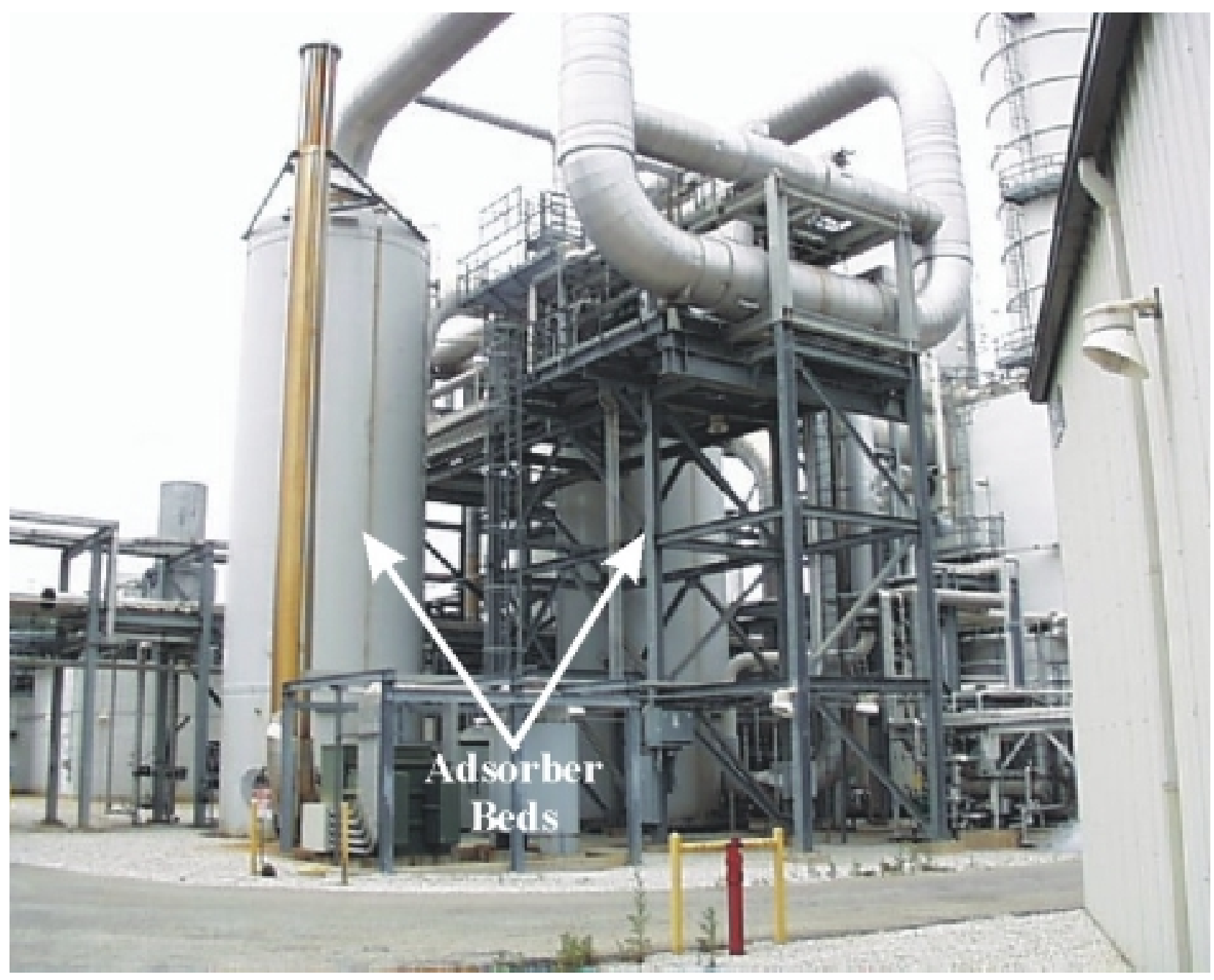

Figure 5.1.3A: Adsorber Beds for the Air Purification System 


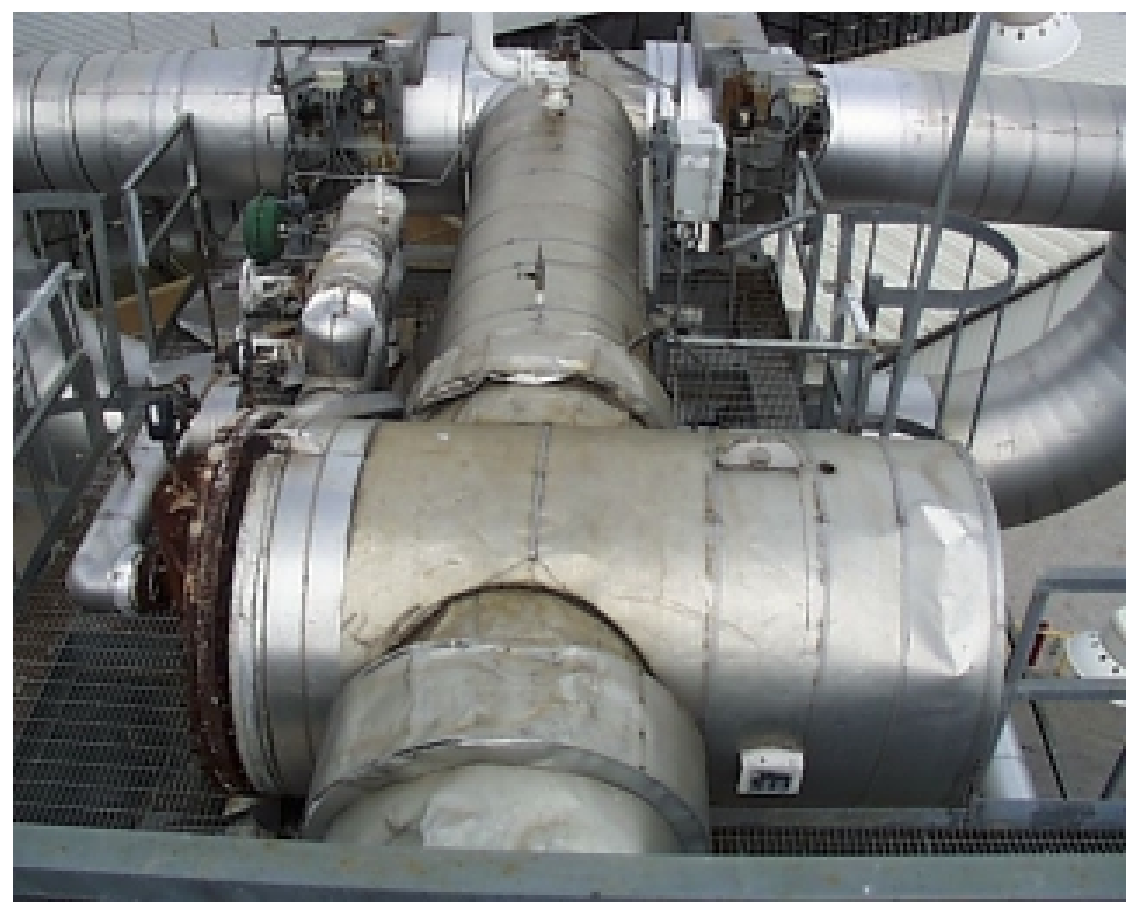

Figure 5.1.3B: Regeneration Heater for the Air Purification System

\subsubsection{System Modifications}

Modifications in the air purification system prior to the Operating Period were limited to the adsorber vessel valves. Several large, automated block valves are employed by the air purification system to control the adsorption and regeneration cycles of each adsorber bed. These must operate several times per day and their performance is critical to plant operation. Each valve must stroke quickly when operation is requested and valves in the closed position must maintain a seal even with high differential pressure across them. Failures in the performance of these valves were frequent and often threatened the production of the facility prior to the Operating Period. Investigation of the failures concluded that the valve bushing material utilized by the original equipment manufacturer was inadequate. The material was upgraded in response to the investigation findings.

\subsubsection{Operating Experience Overview}

The total downtime associated with the air purification system during the Operating Period was 10 hours. Operating experience for individual pieces of equipment follows. 


\section{Adsorber Beds}

On October 27, 1998 ten hours of downtime were suffered as the result of actuator problems on one of the automatic block valves that control the adsorber batch cycle. The actuator apparently worked itself loose from the valve. When the valve was called close, the loose actuator did not allow the valve's limit switch to prove the valve closed and prevented a successful regeneration of the off-line adsorber bed. The regeneration delay went unrecognized by operating personnel until monitoring equipment detected carbon dioxide breakthrough in the air purification system. This initiated a manual halt of operation until a full regeneration cycle could be completed for each of the adsorber beds. All of the following action items were identified and completed in response to the downtime. The valve actuator was repaired; new control system alarms were implemented to detect similar problems; and operating personnel were trained in techniques that would have allowed them to recognize valve issues before they become a threat to the process. No further downtime of this type is expected in the future.

A project was implemented during the Operating Period to reduce noise levels produced during the venting step of the regeneration cycle of the off-line adsorber bed. An ancillary silencer was placed on the common adsorber bed, high-pressure exhaust vent. This reduced peak noise levels in the area from 105 decibels $(\mathrm{dB})$ to below $87 \mathrm{~dB}$. After the project was implemented it became difficult to accurately measure the noise produced by venting because it was at, or below, the normal plant background noise. There was no major maintenance associated with the adsorber beds during the Operating Period.

\section{$\underline{\text { Regeneration Heater }}$}

The gas distribution hardware of the regeneration heater was modified during the Operating Period to include enhanced stiffening supports to prevent collapse of the regeneration heater gas baffles. The additional support restored the proper gas contact and thus increased the efficiency of the regeneration heater, resulting in improved regeneration heat peaks on the absorber beds. Prior to the modification, the air separation unit struggled to maintain production levels during periods of hot and humid weather as a result of increased moisture carryover to the adsorber beds. The increase in heater efficiency relieved production limitations during those times by providing more heat energy to drive off the excess moisture in the regeneration cycle. During all 
other periods of time, the improved heater performance allowed regenerated adsorber beds to remain on line for longer periods, thus reducing the number of equipment cycles per year and operating energy requirements.

In addition to the gas distribution design remediation project, the regeneration heater required extensive and regular maintenance to repair leaking steam tubes. The regeneration gas exchanger has an external pass-partitioned collector box and the tube segments connecting the external collector box to the exchanger body are exposed to high thermal stresses and were prone to fatigue failures. Although no downtime was attributed to the regeneration heater during the Operating Period, multiple and regular tube repairs were required.

\subsubsection{Summary and Conclusions}

Several large block valves in the air purification system have made the system difficult to operate almost from the beginning of plant operation. Bushing material upgrade implemented prior to the Operating Period temporarily alleviated problems, but was conceived as a patch while the valve manufacturer committed to correct the design flaw for all valves under warranty. The patch did not eliminate operational difficulties entirely. In fact, problems with these valves caused the only downtime associated with the air purification system during the Operating Period (see Section 5.1.3.2 for details) and instances of production curtailment in the air separation unit have been experienced after the Operating Period as a result of valve performance issues.

An example of valve problems immediately following the Operating Period occurred in the $3^{\text {rd }}$ quarter of 1999 when fifteen hours of downtime resulted from failure of an air purification valve to properly seal. The valve leak prevented depressurization of one absorber bed causing the regeneration cycle to go into hold. This briefly interrupted the feedstock of clean dry air into the front end of the plant, ultimately resulting in the gasifier coming off coal due to a lack of oxygen supply. In response to the incident, a third bushing design was implemented, within that specific valve, after inspection revealed failed valve bushings that placed the internal mechanism in a bind, which prevented the valve from closing. The new design incorporates the use of oxygencompatible grease with free-floating bushings and is the plant's second attempt at improving the 
life span of these bushings (the first attempt was the material upgrade implemented prior to the Operating Period, see Section 5.1.3.1 for details). It is expected that this design, or a minor modification thereof, will be a permanent, long-term fix for all valves in the air purification system should their bushings begin to fail in the future.

Other significant problems were attributed to the actuators that automate the batch sequencing valves. One problem involved the actuator solenoids, which were not designed for outdoor service and used substandard foreign coil voltage. Weak coil response resulted in poor solenoid activation reliability and consequently poor valve actuation. At each activation event, manual intervention was required to operate the valve and to maintain the solenoids. A retrofit dual solenoid with upgraded coil voltage, more compatible with the ASU control system, was implemented on all actuators.

A second problem involved the actuator support design. When actuating, the pneumatic cylinder encounters rotational displacement against the supporting trunnion bushings. The bushing design was inadequate for outdoor service and utilized ineffective materials. The trunnions of one actuator actually sheared off, completely preventing valve operation, and other actuators experienced similar problems related to these bushings. A new trunnion bushing design was specified utilizing a grease-able trunnion, a grease pocket in the bushing, and increased bushing clearances.

Solutions pertaining to these valve issues have been progressively developed and implemented throughout the history of the plant. It is now believed modifications to the materials and design of the valve actuator bushings and trunnions and upgrades to the electrical solenoids that modulate the instrument air signals for the valves will greatly increase the reliability of the valves, and, hence, the entire air purification system. The instrument air solenoid upgrades have been installed for all air purification valves; however, the new bushing and trunnion design will be progressively implemented on an as-needed basis for valves that show signs of wear. It is also worth noting that efforts to develop and implement solutions to issues surrounding these valves have been significantly hampered over the years due to a lack of cooperation from the 
original equipment manufacturer. Future gasification projects should be very selective with regards to choosing a valve type and manufacturer for this particular application.

Other projects and modifications within the air purification system that have been implemented since the completion of the Operating Period have included the following: the outlet tubes of the regeneration heater were sleeved in the areas of thermal stress and tube fatigue to prevent high O\&M costs associated with thermal fatigue and leaking tubes; automatic bottle switchers were installed on the analyzer subsystem in an effort to reduce nuisance analyzer problems; and thermowells and RTD's were installed at selected locations within the air purification system in order to facilitate data collection during the plant derime procedures. All of these system modifications are worthy of consideration for any potential future gasification project.

Finally, the impact of process transients induced by swapping adsorber beds at the end of every regeneration cycle is typically felt throughout the air separation plant. The consequence is that the Operations team often must operate the air separation plant at slightly below capacity in order to brace the plant for these periodic upsets. Although these transients have never caused downtime, they do represent a bottleneck in the air separation process. Future gasification projects should take the transient affects of a batch-type air purification process into account when sizing plant equipment. 


\subsubsection{Air Cooling and Liquefaction System}

The air-cooling and liquefaction system includes:

\begin{tabular}{|l|l|}
\hline Main cryogenic exchangers (Figure 5.1.4A) & $\begin{array}{l}\text { Compressor/Expander refrigeration system } \\
\text { (Figure 5.1.4B) }\end{array}$ \\
\hline Nitrogen vaporizer (Figure 5.1.4B) & \\
\hline
\end{tabular}

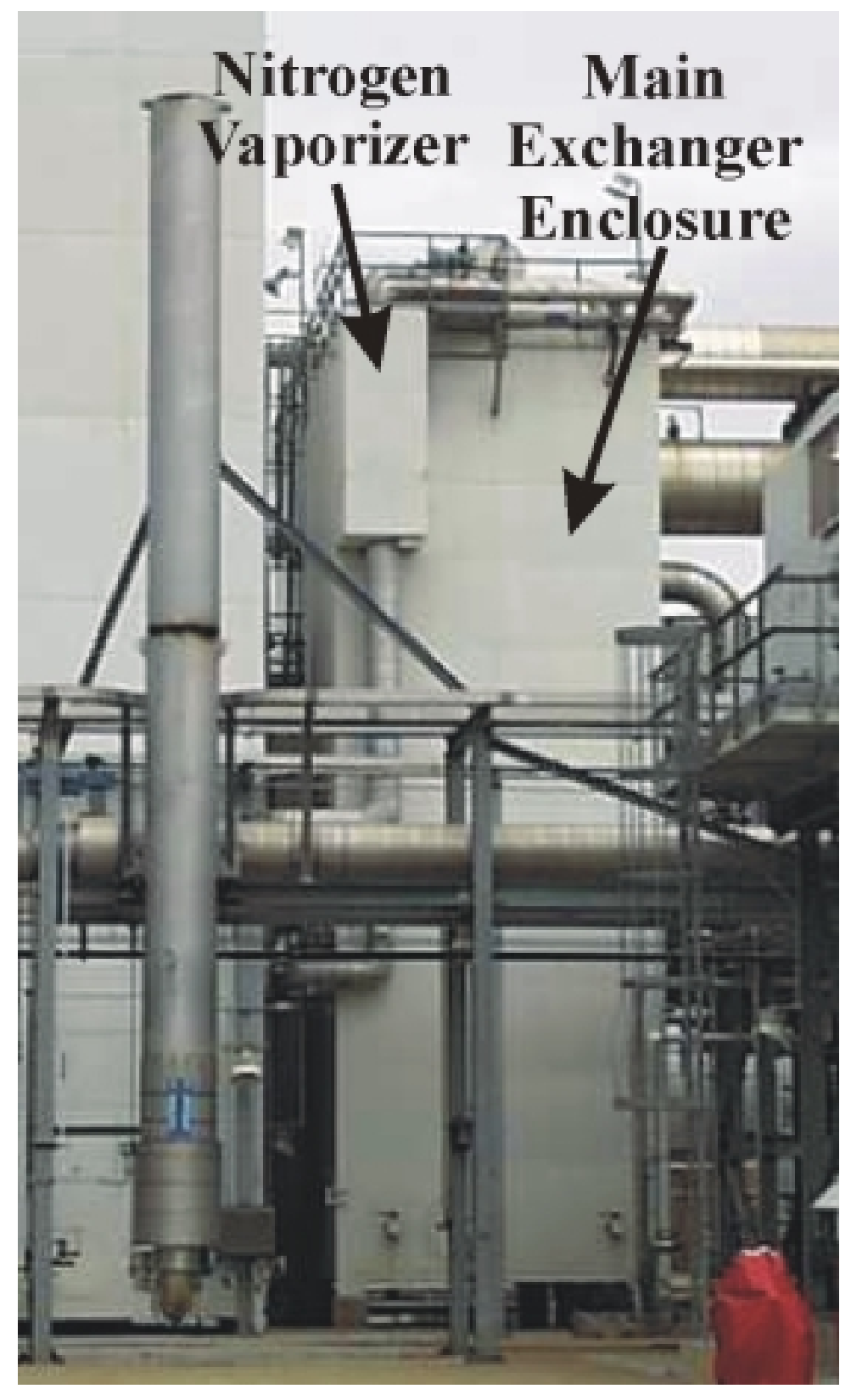

Figure 5.1.4A: Nitrogen Vaporizer and Enclosure for Main Exchangers 


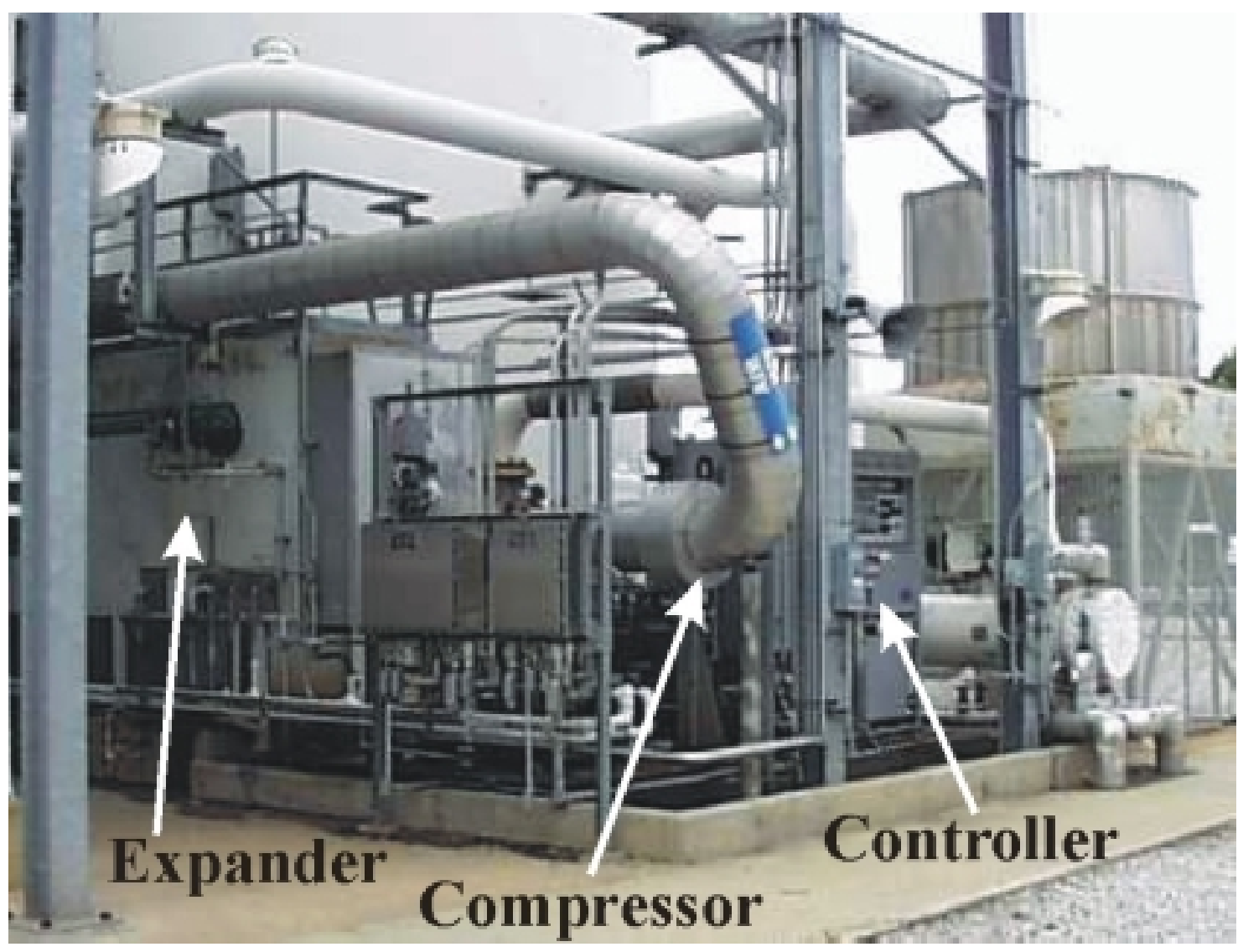

Figure 5.1.4B: Compressor/Expander Skid

\subsubsection{System Modifications}

Two major modifications were made to the air-cooling and liquefaction system very early in the Project. The first modification was the addition of a supplemental liquid nitrogen vaporizer attached to the main exchanger cold box, utilizing warm, purified air from the air purification system to vaporize liquid nitrogen (LIN) from the nitrogen storage and handling system (Figure 5.1.4A). Prior to this equipment installation, LIN vaporization for the purpose of supplying the facility's gaseous nitrogen requirements was insufficient. Only a fraction of the LIN vaporization was handled through the main exchangers. The bulk of the high-energy required to generate LIN was discarded with an increased energy penalty by utilizing a steam vaporizer. The installation of the ancillary nitrogen vaporizer increased the efficiency of nitrogen vaporization and provided an additional refrigeration stream for a portion of the air feedstock to the air separation plant. 
After installation of the ancillary LIN vaporizer, a significant problem arose. Refrigeration being placed back into the purified air stream via the ancillary exchanger resulted in unexpected air stream condensation and imbalance in the main exchanger hot and cold approach temperatures. Additionally, feed to the refrigeration expander from the main exchangers was too cold for proper expansion. Hot, boosted air bypass was necessary to keep the expander operational resulting in inefficient expander operation and lost refrigeration.

To restore the main exchanger approach temperatures and restore refrigeration expander performance, a second major modification was made to the air-cooling and liquefaction system with the addition of a high-pressure oxygen recycle line. The ancillary LIN vaporizer performed well enough to reconfigure the smaller vaporizer within the main exchanger as a condenser to remove surplus refrigeration. To achieve this, a side-stream of warm high-pressure oxygen from the discharge of the oxygen compressor system, when available, is now condensed in the main exchangers. Its pressure is dropped across a control valve, and it is routed into the low-pressure column as a feedstock. This re-established the temperature approaches of the main exchanger, restored operating efficiency to the refrigeration expander and recycled the otherwise lost refrigeration (in the condensed oxygen), directly to the low-pressure column. The net result is increased liquid nitrogen production for the air separation unit.

The only major maintenance job performed in the air-cooling and liquefaction system prior to the Operating Period was the replacement of the refrigeration expander's rotating assembly. An incident that occurred prior to commercial operation severely damaged the expander assembly. Root cause investigation revealed two possible causes of the incident. The unit may have been operating at a rotational speed that coincided with its natural resonance frequency, hence promoting catastrophic internal vibrations. Another possibility is that the unit's performance may have been pushed to the point at which liquefaction began occurring in the air stream prior to exiting the expander. Either condition could have quickly caused the type of damage that was found in the post-incident investigation. The unit was repaired and procedural changes were instituted to prevent a re-occurrence. The unit is now operated at a different rotational speed in order to avoid resonance frequencies, and the outlet temperature is closely monitored and controlled in order to prevent liquefaction within the expander. 


\subsubsection{Operating Experience Overview}

There were no major maintenance, downtime or operational problems associated with any of the air-cooling and liquefaction equipment during the Operating Period. Minor maintenance performed during this time included periodic removal of ice build-up around the control actuator of the expander guide vanes, instrumentation calibrations and lubrication oil changes.

\subsubsection{Summary and Conclusions}

The implementation of the ancillary nitrogen vaporizer and high pressure oxygen condensing recycle line and the procedural changes regarding operation of the compressor/expander allowed the air cooling and liquefaction system to be very reliable and efficient in the period leading up to and through the Operating Period.

However, an air leak inside the enclosure that houses the main exchangers forced an unplanned outage resulting in 299 hours of lost production during the $3^{\text {rd }}$ quarter of 1999. Repair of the leak required the complete removal of insulation inside the exchanger housing. The leak was the result of three failed welds on one of four identical headers within the exchanger enclosure (Figures 5.1.4C\&D). The three process piping welds on each of the four headers provided the only structural support for the headers, causing the welds to be under constant stress. Furthermore, close inspection of the welds determined that they were not held to acceptable quality control standards during the original installation. Even the welds that had not yet failed displayed the potential for future problems if left uncorrected. The fact that these low quality welds were responsible for both the physical support of the headers as well as maintaining pipe integrity led the investigation team to conclude that equipment design and poor quality control methods employed during installation were the root causes of the incident. As a result, all twelve welds were re-worked and additional structural supports for each of the four headers were installed. No future downtime as the result of similar failures is expected, but it is worth noting that future installations of similar exchanger systems need to incorporate designs that provide sufficient structural support and maintain strict quality control standards when making cryogenic welds. 


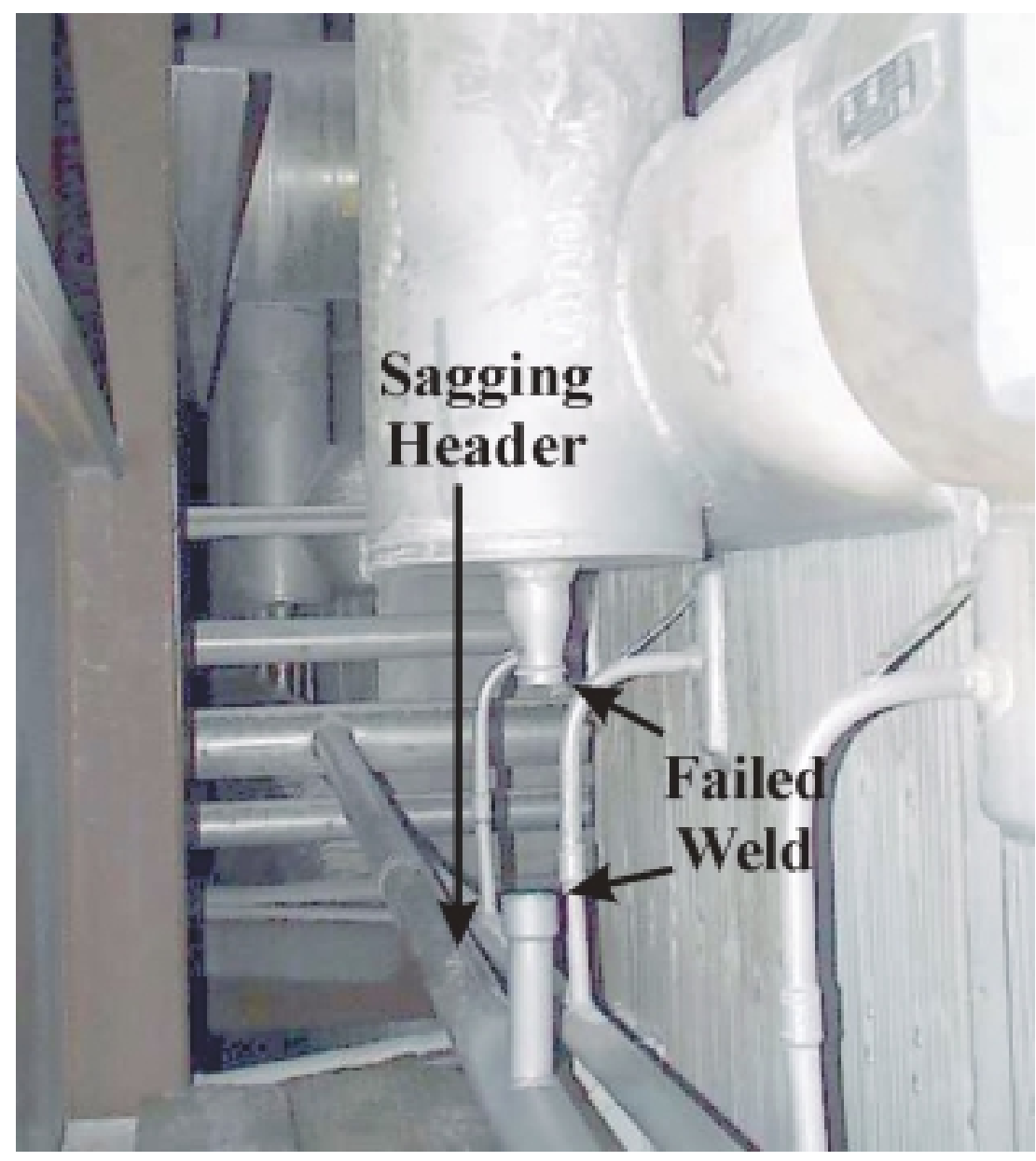

Figure 5.1.4C: Damage Inside Enclosure for Main Exchangers

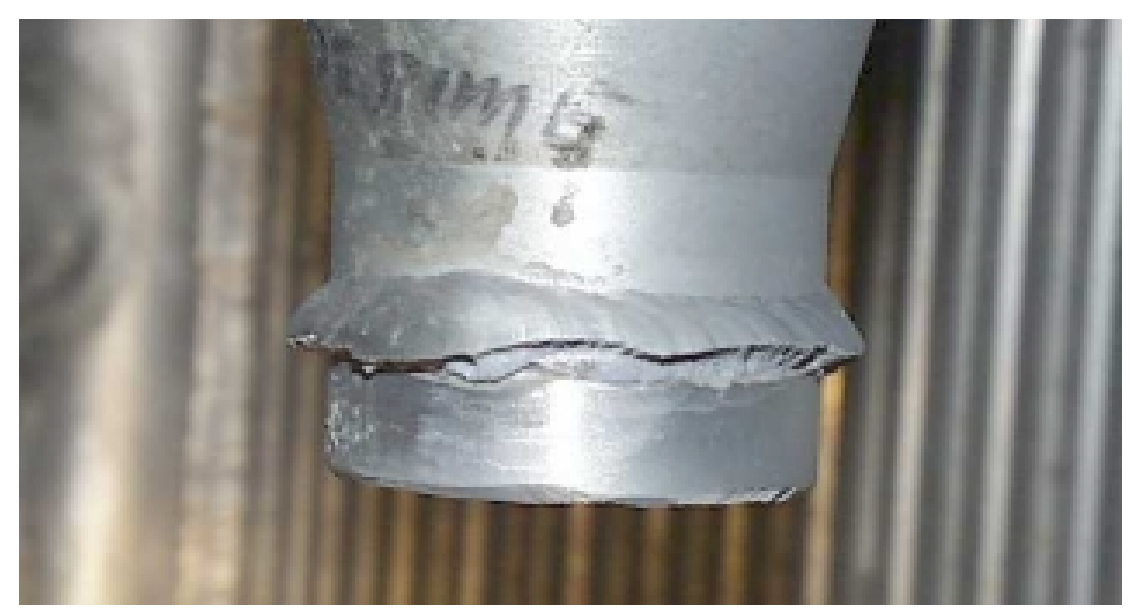

Figure 5.1.4D: Derime Header Failed Weld 
Other suggestions for future installations of air cooling and liquefaction systems include added instrumentation redundancy with regard to temperature monitoring around the main exchangers and a more reliable means for automatic control of the compressor/expander system outlet temperature. The currently installed temperature instrumentation for the main exchangers is buried deep within the insulation of the enclosure and is inaccessible for troubleshooting, repair or replacement. Over time, the temperature instrumentation has begun to fail, making plant startups increasingly more difficult. Considering the low cost of temperature instrumentation when compared to the value of accurately knowing the temperature of a cryogenic process, it would be appropriate to install as many as two times the current number of indicators in future projects. Another suggestion concerns the importance of very tight expander outlet temperature control. It is absolutely critical to maintain the temperature above the point of liquefaction (see Section 5.1.4.1 for details), but operation too far above liquefaction prevents the plant from being optimized. However, a manual throttling valve that allows some of the flow to bypass subcooling in the main exchangers is the only means for controlling the expander outlet temperature. An automated method of temperature control should be specified as part of the design package of the next compressor/expander subsystem.

With the exception of the main exchanger leak that occurred after the Operating Period, the air cooling and liquefaction system has been reliable and relatively maintenance-free for the entire commercial operation of the Project. The air cooling and liquefaction system is not expected to cause any further downtime or lost production. Furthermore, maintenance performed in the future is expected to be limited to minor periodic jobs similar to the ones presented in Section 5.1.4.2. 


\subsubsection{Cryogenic Distillation System}

The cryogenic distillation system includes:

\begin{tabular}{|l|l|}
\hline $\begin{array}{l}\text { High/Low pressure distillation columns } \\
\text { (Figure 5.1.5A) }\end{array}$ & Vaporizer/Condenser (Figure 5.1.5A) \\
\hline Nitrogen reflux sub-cooler & Rich liquid sub-cooler \\
\hline Rich liquid separator & Lean oxygen separator \\
\hline
\end{tabular}

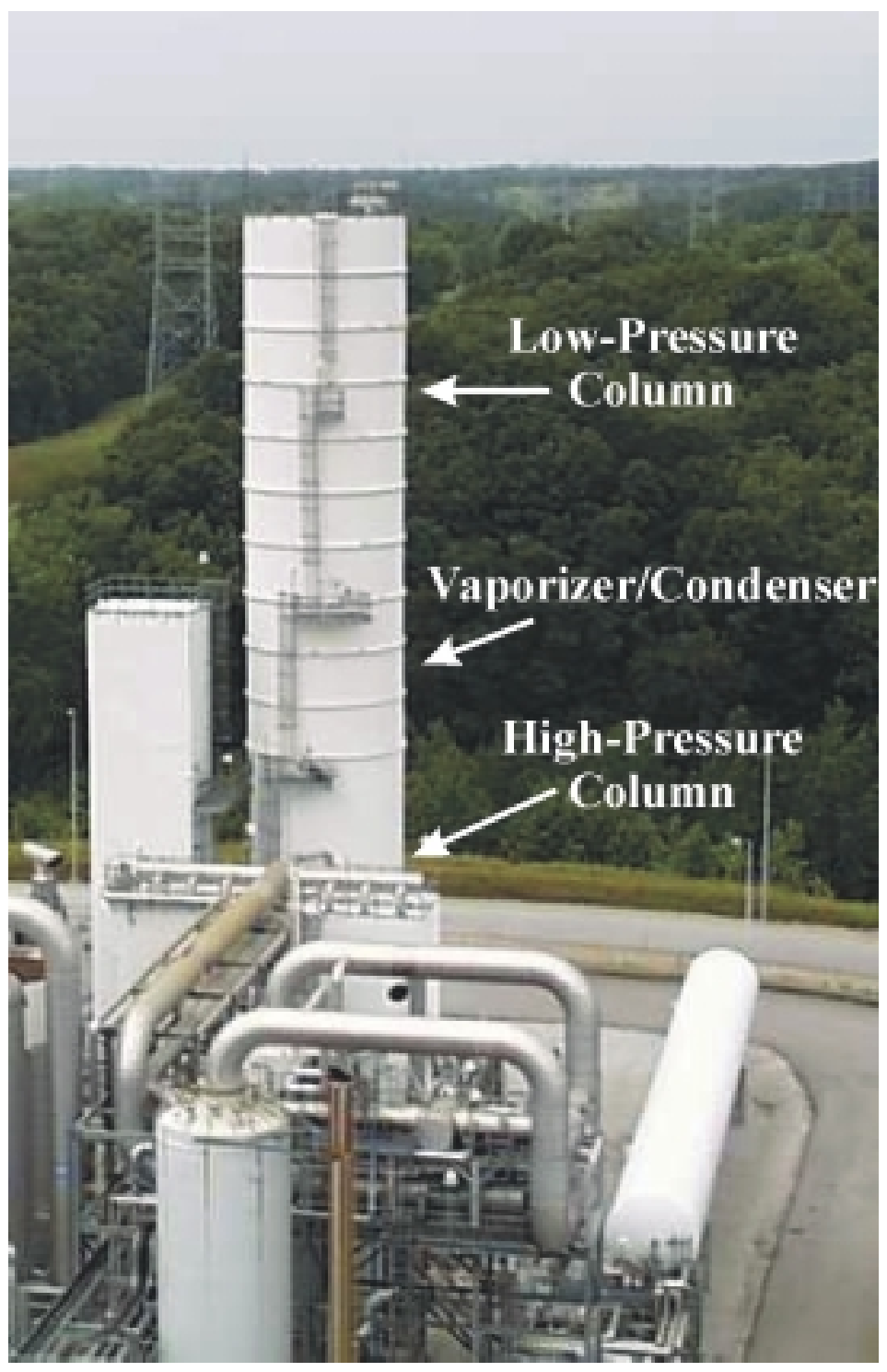

Figure 5.1.5A: High-Pressure and Low-Pressure Columns 


\subsubsection{System Modifications}

The only system modification implemented in the cryogenic distillation system was the addition of a high-pressure oxygen recycle line from the oxygen compression system to the low-pressure column. This modification allows a slip-stream of product oxygen to be taken from the discharge of the oxygen compressor, condensed in the main exchanger, expanded to the point of liquefaction, and emptied into the low-pressure column (see Section 5.1.4.1 for more details.). The modification was implemented early in 1995, prior to the commercial operation of the plant.

No downtime was attributed to the cryogenic distillation system and no major maintenance was performed on any of the system equipment prior to the Operating Period.

\subsubsection{Operating Experience Overview}

The total downtime associated with the cryogenic distillation system during the Operating Period was 77 hours. Operating experience for individual pieces of equipment is given below.

\section{$\underline{\text { Low-pressure Column }}$}

On July 19, 1998 four hours of lost production were experienced as a result of a loss of level indication for the low-pressure column. Investigation revealed that the transmitter level tap had plugged with solid carbon dioxide. The level indication began reading normally after the level tap was bled to atmosphere. It was common for this particular level tap to periodically plug and require a purge to atmosphere as a corrective action. However, a level tap plug had not been experienced for an extended period prior to this incident, consequently, the Operations team failed to recognize this action as a viable response and manually initiated a production interruption. The root cause was determined to be human error and training was performed in order to prevent a recurrence. There were no other significant operational problems nor any major maintenance performed in association with the low-pressure column during the Operating Period.

\section{$\underline{\text { Rich Liquid Separator }}$}

Sixty-two (62) hours of lost production were experienced beginning on August 11, 1998 due to difficulties and delays in recovering from a plant upset that had occurred as a result of an 
incident in the air compression system on August 9, 1998. (See Section 5.1.1.2 for details of the August 9, 1998 incident.) There were several contributing factors to the difficulties and delays and they spanned more than one system within the air separation plant. However, two problems localized to the cryogenic distillation system are noteworthy. Specifically, the flow of rich liquid effluent from the sump of the high-pressure column to the low-pressure column was interrupted due to either carbon dioxide pluggage or vapor-lock within the rich liquid separator. Flow interruption upset operation of both the low-pressure and high-pressure columns for several hours before efforts to re-establish flow proved to be successful. Also, an actuator failure on the pressure control valve for rich liquid feed to the low-pressure column resulted in a significant period of time where column pressure control could be achieved only through manual throttling of the valve. Although no downtime was suffered as a result of the actuator failure, the increased difficulty in pressure controlling the low-pressure column contributed to inefficiencies and delays in getting the overall air separation plant back into full production. Corrective actions identified and implemented in response to the lost production included personnel training on methods for re-establishing flows and improved preventative maintenance for control valve actuators. No other operational difficulties were experienced nor was there any maintenance associated with the rich liquid separator during the Operating Period.

\section{Vaporizer/Condenser}

Ten (10) hours of lost production were voluntarily sacrificed on February 2, 1999 in order to perform a safety procedure known as a "vaporizer wash". The vaporizer wash was recommended by the original equipment manufacturer of the air separation plant. The procedure was developed in response to a relevant explosion incident at an international air separation plant owned and operated by other parties. The plant suffering the explosion operated a falling film vaporizer/condenser similar to the equipment employed within the cryogenic distillation system. The purpose of the vaporizer wash was to investigate and quantify hydrocarbon accumulation on the oxygen-side heat exchange surface of the vaporizer/condenser.

Results of the vaporizer wash clearly showed that safe levels of hydrocarbon accumulation had occurred. Safe levels for hydrocarbons are determined to be within the solubility limits of liquid oxygen at operating conditions after the wash test, ruling out the potential for hydrocarbon 
precipitation and deposition. Operation of the vaporizer/condenser was completely trouble free and no maintenance was required during the Operating Period.

\section{Other Equipment}

There was no maintenance, downtime or operational problem associated with the following equipment during the Operating Period: the high-pressure column, the nitrogen reflux subcooler, the rich liquid sub-cooler and the lean oxygen separator.

\subsubsection{Summary and Conclusions}

Operation of the cryogenic distillation system has been very reliable and efficient throughout the life of the plant. The only lost production associated with the system occurred during the Operating Period, and most of it was the result of minor problems that are not expected to reoccur and are due to voluntary performance of a safety procedure. No major maintenance has been required and no system modifications have been performed in the cryogenic distillation system since commercial operation of the plant began in 1995.

A total plant "derime" of the cold end of the plant was optionally performed during the $2^{\text {nd }}$ quarter of 1999 as a safety precaution following the vaporizer wash test performed during February of 1999 (see Section 5.1.5.2 for details of the vaporizer wash). Derime is a procedure in which the cryogenic distillation, air cooling and liquefaction, and oxygen mixing systems are warmed with hot, dry, purified air in order to purge all traces of moisture, carbon dioxide, and hydrocarbons from the cold end of the plant. It is a costly procedure in terms of energy consumption and time commitment. However, it must be performed any time there is a potential for moisture, carbon dioxide, or hydrocarbons to be present within the plant. Opening of process equipment and failure to maintain a pressure above ambient within the cold end of the plant during an outage are examples where derime may be necessary. In this particular case, derime was voluntarily performed as a result of the plant's high commitment to safety. However, derime was again performed during the $3^{\text {rd }}$ and $4^{\text {th }}$ quarters of 1999.

The $3^{\text {rd }}$ quarter derime was in response to a leak repair within the air-cooling and liquefaction system (see Section 5.1.4.3 for details of this incident). The $4^{\text {th }}$ quarter derime was due to a long 
outage where loss of liquid level in both the high-pressure and low-pressure columns prevented the ability to maintain positive pressure on the plant.

The addition of better instrumentation redundancy is a noteworthy suggestion for future plants requiring a cryogenic distillation system. A redundant level transmitter tap would have prevented four hours of lost production during the Operating Period. Also, a redundant pressure indication for the low-pressure column would have facilitated production optimization on a few occasions. Finally, redundant temperature indications on process streams around the highpressure and low-pressure columns would promote long-term operability of the plant. The currently installed temperature instrumentation in the cryogenic distillation system has begun to fail, making efficient start-up and operation of the plant difficult. The fact that the temperature indicators are inaccessible for troubleshooting, repair, or replacement, means that the difficulties will probably only worsen with time. Redundancy should have been designed and installed prior to plant start-up, and definitely needs to be considered for future projects.

One final suggestion for future installations is the addition of an improved means for filling the low-pressure column with liquid nitrogen. Currently, liquid nitrogen can be transported into the low-pressure column only if the main air compressor is available to provide the motive force. Several instances occurred during outages, indicating the benefit of filling the low-pressure sump without the aid of the main air compressor (e.g., addition of liquid nitrogen dilutes sump liquid increasing hydrocarbon solubility and prevents the need to purge during outages). However, it is difficult to justify the energy consumption as well as the additional start imposed upon the large air compressor motor just to prevent disposal of the liquid. 


\subsubsection{Oxygen Mixing System}

The oxygen mixing system includes:

\begin{tabular}{|l|l|}
\hline Liquid oxygen pumps & Mixing column (Figure 5.1.6A) \\
\hline Liquid oxygen filter (Figure 5.1.6A) & Reactivation filter \\
\hline Lean oxygen sub-cooler & Liquid oxygen reactivation heater \\
\hline
\end{tabular}

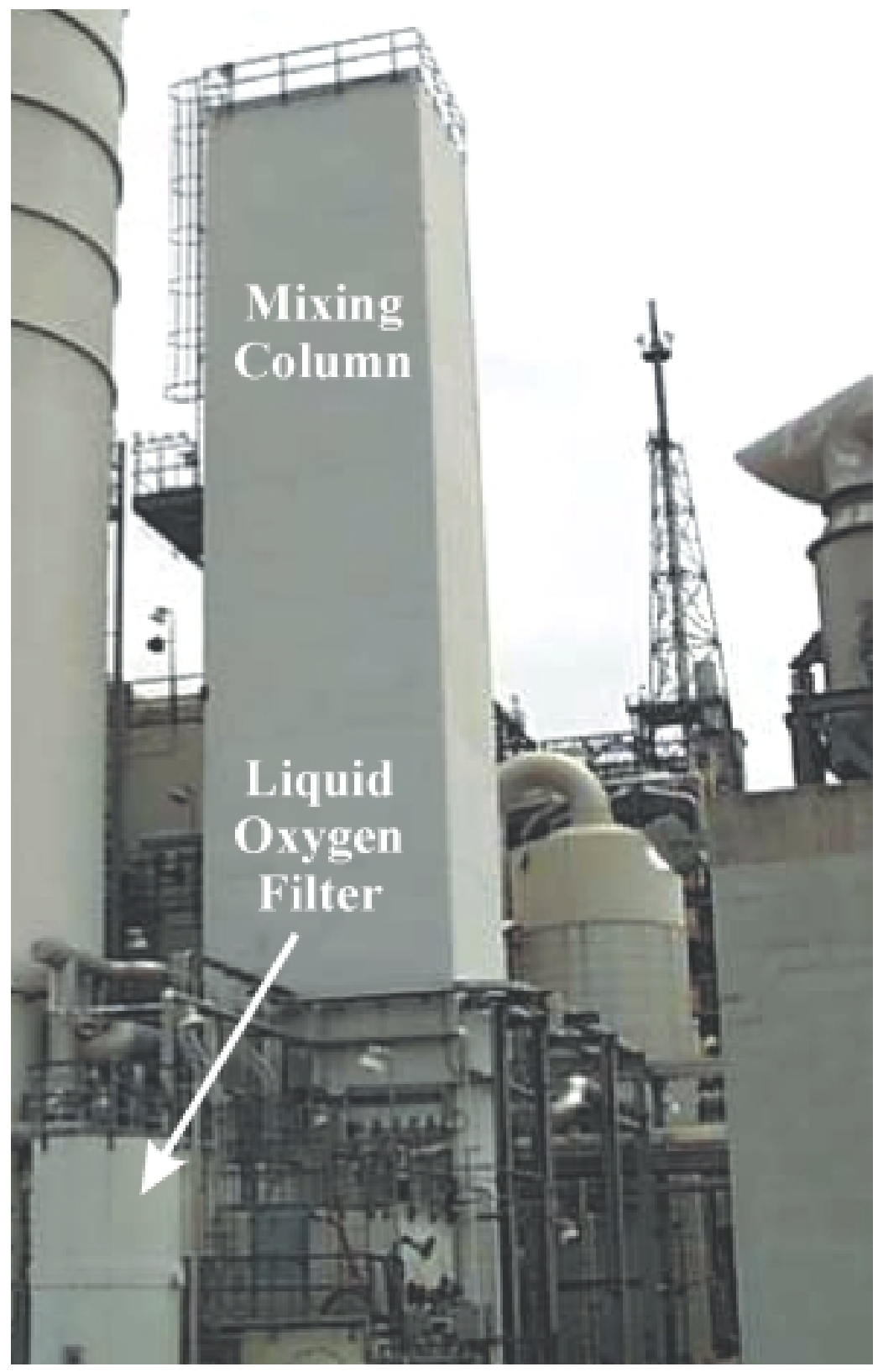

Figure 5.1.6A: Equipment Associated with Oxygen Mixing System 


\subsubsection{System Modifications}

The only system modifications and maintenance performed in the oxygen mixing system prior to the Operating Period were limited to the liquid oxygen pumps, the flanges and valves immediately surrounding the pumps, and the pump enclosures. Both of the liquid oxygen pumps necessitated re-builds near the end of 1997 as a result of bearing failures. The original equipment manufacturer of the pumps was unable to determine the failure mode from postmortem investigation. The first pump that failed was re-built and returned to operation without modification. However, a new impeller shaft bearing design was available at the time of the second pump failure, and was implemented as an upgrade prior to placing it back in service.

In addition to pump re-builds, the insulated pump enclosures were entered on several occasions in order to repair valves and flange leaks. Leaks occurred so often that portions of the enclosures were damaged due to thermal stresses and received metallurgy upgrades in an effort to minimize future damage. Other minor modifications were made to the enclosures in order to facilitate better access for pump extractions and leak repairs.

\subsubsection{Operating Experience Overview}

There was no downtime associated with the oxygen mixing system during the Operating Period. Operating experience for individual pieces of equipment follows.

\section{Liquid Oxygen Filter}

Inspection of the liquid oxygen filter, performed on a routine outage during the Operating Period, revealed attrition of the hydrocarbon adsorption media. Analysis by the original equipment manufacturer of this and similar problems at other plants resulted in the conclusion that fracturing of the filter media might have occurred during periodic filter regeneration. A new filter media with a higher thermal shock and fracture resistance was installed while the filter regeneration procedure was modified to minimize the thermal stresses contributing to fracture. 


\section{Liquid Oxygen Pumps}

Maintenance issues surrounding the liquid oxygen pumps continued throughout the Operating Period. Only one year after the first pump re-build, both pumps required a second re-build. Once again, the original equipment manufacturer was unable to determine a root cause for the failures. However, the redesigned bushing arrangement was implemented in one of the pumps in order to evaluate its potential as a permanent solution.

Operational problems with the liquid oxygen pumps also persisted throughout the Operating Period. Several instances of high differential pressure across the suction strainers for the liquid oxygen pumps during operation forced frequent on-line swaps of the pumps. Possibilities for the source of the suction strainer restrictions included build-up of sublimated carbon dioxide, moisture (as ice), or the presence of solids suspended within the liquid oxygen. However, it was often possible to temporarily alleviate the suction strainer differential pressure by means of liquid oxygen back-flush through the suction strainer. Had the source of the differential pressure been carbon dioxide or ice, then a complete derime procedure (in which the pump circuit is warmed and purged with dry, hot gas) would have been required in order to significantly affect the differential pressure. Those back-flush experiences, coupled with the fact that small amounts of solids were recovered from the suction strainers during maintenance procedures, suggested that the source of the differential was indeed solids and may have been contributing to the poor reliability of the liquid oxygen pumps. Lab analysis performed on solids removed from the suction strainers of the liquid oxygen pumps showed that the properties of the solids were somewhat consistent with the properties of the hydrocarbon-adsorption filter media contained within the liquid oxygen filter. It is feasible that the attrition of fractured filter media observed during the Operating Period may have resulted in filter media re-circulating back into the suction of the liquid oxygen pumps (see the operating experience for the liquid oxygen filter for more details regarding how this attrition was addressed.). However, it is also feasible that carbon dioxide adsorption media contained in the air purification system may have migrated through the cold end of the plant and found its way into the suction of the pumps. Regardless of the source of the solids, a project was implemented on both pumps during the Operating Period to allow solids purge from the suction strainer through a low-point drain to the cryogenic liquid disposal system during a back-flush of the pump. 


\section{Other Equipment}

There was no maintenance, downtime or operational problem associated with the following equipment during the Operating Period: the mixing column, the lean oxygen sub-cooler, and the liquid oxygen reactivation heater.

\subsubsection{Summary and Conclusions}

All equipment within the oxygen mixing system, with the exception of the liquid oxygen pumps and their isolation valves, has been reliable, maintenance-free, and easy to operate throughout the history of the plant. However, the extremely poor reliability of the liquid oxygen pumps, coupled with the fact that they are not easily accessible for maintenance due to their cryogenic service, has made them a recurring source of expensive maintenance as well as an ever-present threat to plant availability. Both pumps were re-built prior to the Operating Period, re-built again

one year later during the Operating Period, re-built a third time during the $3^{\text {rd }}$ quarter of 1999 , and a fourth re-build was required in the $1^{\text {st }}$ quarter of 2000 . Despite efforts to eliminate solids within the liquid oxygen stream (see the operating experience for the liquid oxygen filter for more details), manufacturer recommended bushing modifications, and continuing investigation efforts involving the original equipment manufacturer, the reliability of these pumps has not increased over the life of the plant. Thus far, an effective means for increasing the reliability of the pumps has neither been implemented nor developed.

Future installations of oxygen mixing systems within gasification plants should closely scrutinize the design and configuration of the liquid oxygen pumps. Specifically, the ability to perform an on-line swap of a liquid oxygen suction strainer and a finer mesh size for the suction strainer quite possibility could extend the life of the pumps. Also, selection of a fracture resistant adsorption media for the liquid oxygen filter, as well as a conservative regeneration procedure, should help to prevent solids accumulation in the first place. 


\subsubsection{Nitrogen Handling and Storage System}

The nitrogen handling and storage system includes:

\begin{tabular}{|l|l|}
\hline Liquid nitrogen storage tank (Figure 5.1.7C) & Liquid nitrogen pumps (Figure 5.1.7A) \\
\hline Nitrogen steam vaporizer (Figure 5.1.7B) & $\begin{array}{l}\text { High-pressure nitrogen fill pump } \\
\text { (Figure 5.1.7B) }\end{array}$ \\
\hline $\begin{array}{l}\text { High-pressure nitrogen cylinders } \\
\text { (Figure 5.1.7C) }\end{array}$ & \\
\hline
\end{tabular}

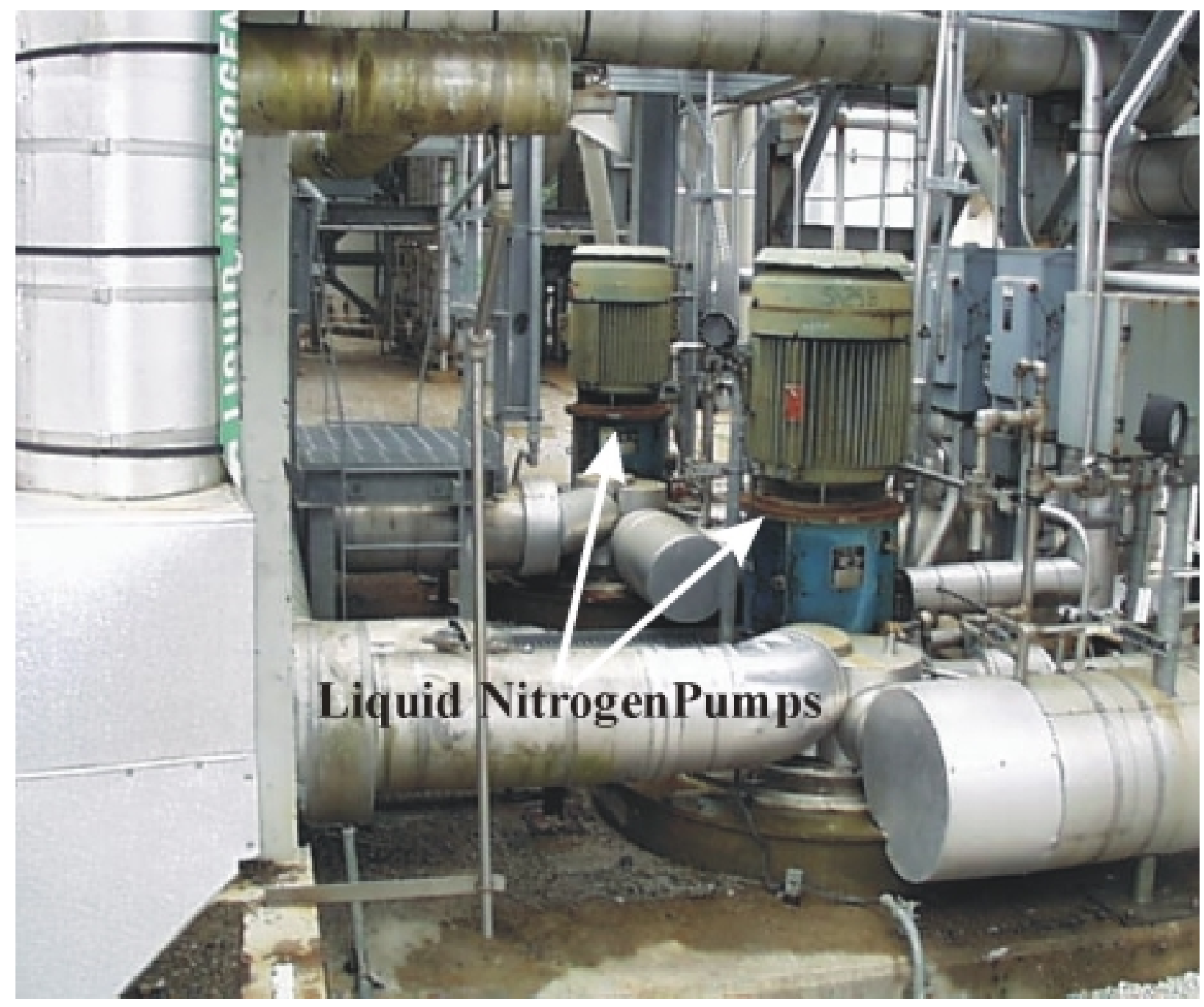

Figure 5.1.7A: Liquid Nitrogen Pumps 


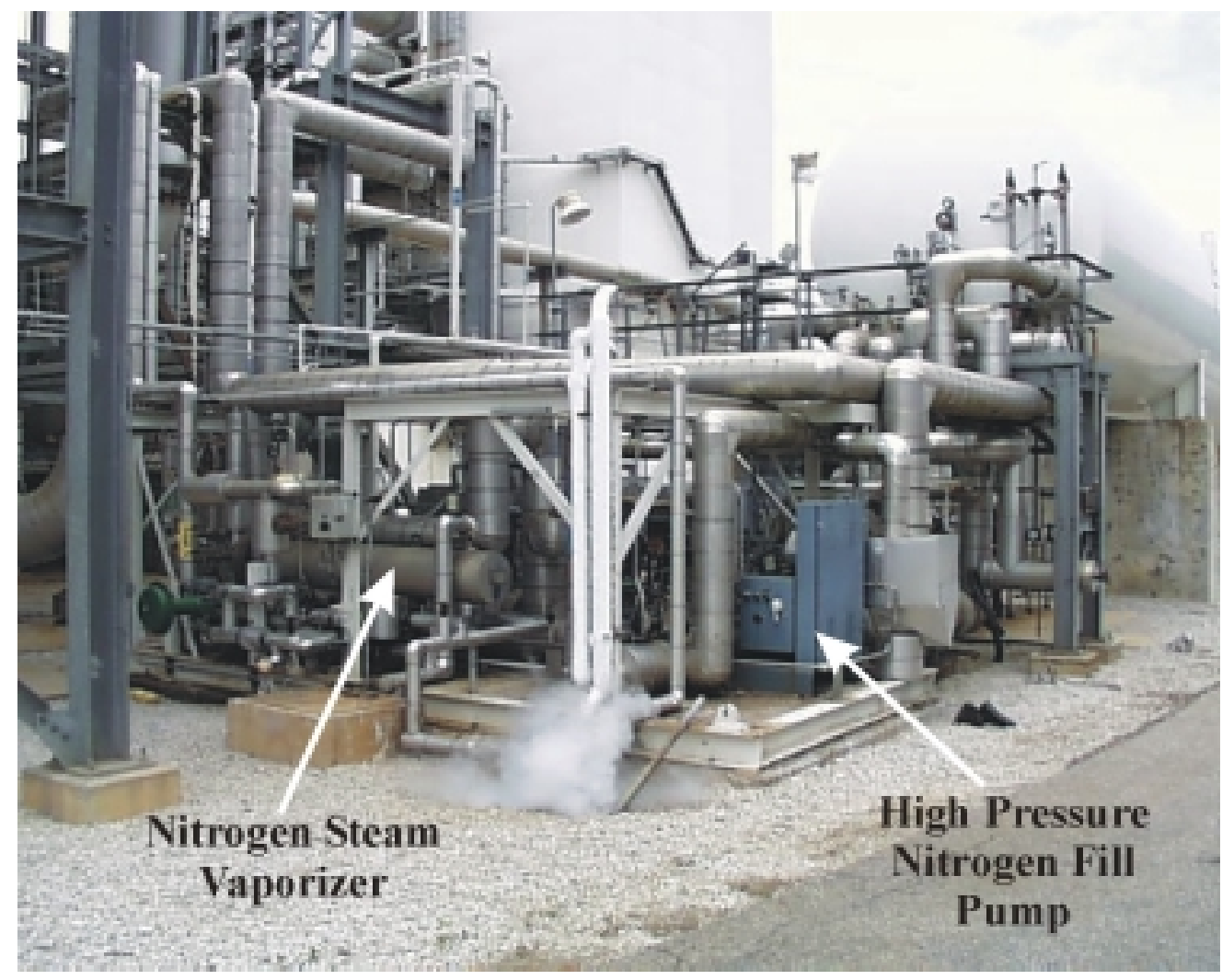

Figure 5.1.7B: Liquid Nitrogen Pump Skid

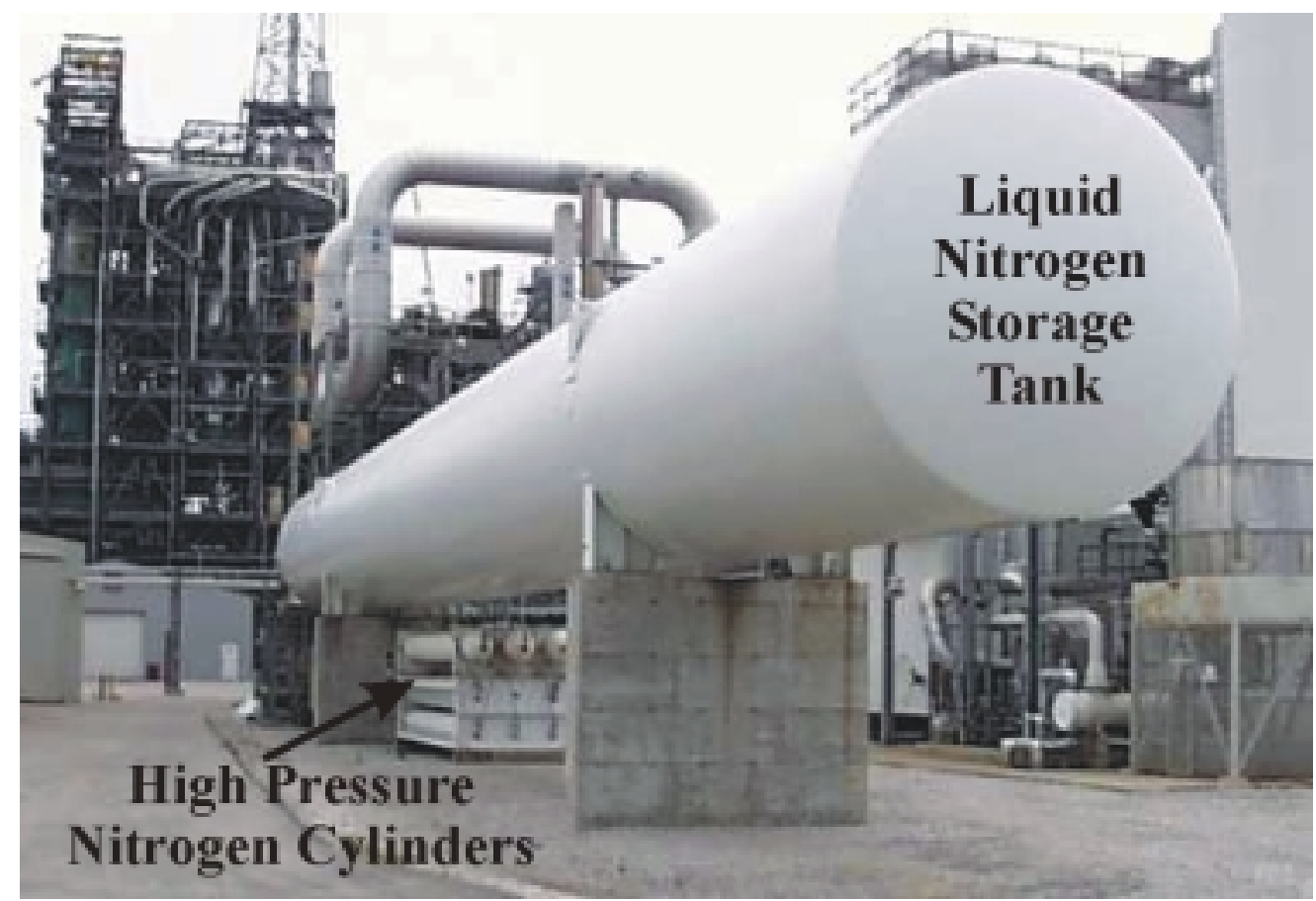

Figure 5.1.7C: Liquid Nitrogen Storage Tank and High-pressure Cylinders 


\subsubsection{System Modifications}

Several small modifications were made in the nitrogen handling and storage system prior to the Operating Period. Most of them were very minor in nature and included: enlarging drains on pressure safety valve vents; additions of small manual block valves for better isolation; condensate piping modifications; temporary hoses replaced with permanent pipe; addition of insulation; purge valve improvements; and firewater sprinkler system improvements.

Major maintenance performed in the nitrogen handling and storage system prior to the Operating Period was limited to re-builds of both liquid nitrogen pumps due to bearing failures. Other minor maintenance included: repair of oil leaks; valve repairs; pressure safety valve calibrations; repair of seal leaks on the high-pressure nitrogen fill pump; and replacement of the original vaporizer condensate sump pump due to temperature rating.

Although the nitrogen handling and storage system was very reliable prior to the Operating Period, difficulty maintaining sufficient inventory of liquid nitrogen was recognized early in the Project. Lack of nitrogen availability often caused production delays for the plant. For example, one such documented incident occurred on January 16, 1998 just prior to the start of the Operating Period. The liquid nitrogen storage tank was depleted of inventory on that day, resulting in delayed heat-up of the dry char system for a total of 12 hours lost production. Poor management of liquid nitrogen reserves coupled with frequent periods of high volume nitrogen consumption within the gasification plant preceding the incident were the identified root causes. In general these root causes were the same issues that plagued the plant from the early days of the Project and needed to be overcome. A third-party nitrogen supplier was contracted to supply liquid nitrogen to the plant when low reserves and high volume usage necessitated purchase of

liquid nitrogen. Also, it was assumed that periods of high volume nitrogen usage would become less frequent over time as operating experience was gained in the gasification process.

\subsubsection{Operating Experience Overview}

The total downtime associated with the nitrogen handling and storage system during the Operating Period was 15 hours. Operating experience for the entire system follows. 
On January 4, 1999, the effects of a severe snowstorm culminated with the only lost production attributed to the nitrogen handling and storage system during the Operating Period. Several weather-related problems in the Gasification Island and a utility power blackout forced the plant into an extended period of abnormally high nitrogen consumption. Unfortunately, the utility power blackout also placed the entire air separation plant into an upset condition, restricting its ability to produce nitrogen. The high level of consumption coupled with the production difficulties led to a depletion of the liquid nitrogen tank inventory. Efforts to procure liquid nitrogen through third-party suppliers were unsuccessful due to emergency road conditions consisting of ice and snow. Fifteen hours of lost production were suffered as a result of the delays in nitrogen availability. However, it is worth reiterating that the production loss did not occur as a result of any operational, reliability, or performance issue related to equipment within the nitrogen handling and storage system, but rather was fully attributable to weather conditions beyond the control of plant personnel. As a result of this event, agreements were secured with two backup liquid nitrogen suppliers to facilitate delivery if the contracted supplier failed to meet plant needs.

A telemetry system was installed on the liquid nitrogen storage tank during the Operating Period in order to allow the contracted third-party liquid nitrogen supplier to monitor the tank's inventory. The system allows the nitrogen supplier to better anticipate the plant's delivery needs, thus helping to alleviate production delays suffered as a result of liquid nitrogen unavailability.

A project to reduce maintenance costs as well as to increase efficiency in the nitrogen handling and storage system was implemented during the Operating Period. The nitrogen steam vaporizer bellows trap and condensate pump systems were eliminated in favor of a float and thermostatic steam trap. The bellows trap system required sub-cooled condensate for effective steam separation, which resulted in poor vaporizer performance due to condensate holdup within the vaporizer shell. In addition, the condensate sump pump, which had been replaced prior to the Operating Period, continued to suffer poor reliability and high maintenance cost. The new steam trap system installation provided a less complicated system that is easier to operate, enhances nitrogen delivery, results in energy and maintenance savings from the elimination of the unreliable condensate pump, sump and field control station. 
A final project, implemented during the $4^{\text {th }}$ quarter of 1998 , positively affected safety in the nitrogen handling and storage system. The vent for the liquid nitrogen storage tank discharges vaporous nitrogen to atmosphere at a very cold temperature (as low as $-250^{\circ} \mathrm{F}$ ). As the vapor is vented, moisture condenses on all the surrounding cold surfaces and on the ground near the discharge point. Frequent pluggage of the vent often resulted in intervention by the Operations team utilizing steam hoses to remove ice from the vent release area. The potential for burns resulting from ruptured steam hoses was significant. Installation of a steam-jacketed tip on the vent now prevents discharge vapor from promoting ice formation. A jet of steam is also directed to the ground in the discharge vicinity to prevent buildup from below. It is not safe to discharge from a vent above ground as the potential for cryogenic liquid spray and serious burns is unacceptable, though this approach would more easily have remedied the tip frosting problems.

There was no downtime or operational problems associated with any specific piece of equipment within the nitrogen handling and storage system during the Operating Period. Maintenance performed was limited to a minor leak repair on the high-pressure nitrogen cylinders.

\subsubsection{Summary and Conclusions}

The nitrogen handling and storage system has been very reliable and reasonably easy to operate over the history of the Project. The only major maintenance performed thus far has been limited to a re-build of both liquid nitrogen pumps prior to the Operating Period. The only other modification to the system that has occurred since the end of the Operating Period involves the addition of flanges on the discharge piping of the liquid nitrogen storage tank in order to eliminate the need to make line cuts for minor pressure safety valve maintenance.

Operating experience has revealed two specific opportunities for future improvements of the nitrogen handling and storage systems. First, a larger capacity storage tank may have provided significant dollar savings over the life of this facility. Several occurrences of a shortage of nitrogen caused great difficulties for the entire plant. Although deficiency in nitrogen availability rarely culminated in documented production losses, availability problems were quite 
often the source of heat-up delays during plant start-ups and cooldown delays when entering outages.

Furthermore, extended plant run-time often afforded excess nitrogen production to the point that the storage tank was filled to the limit. Production excesses in those cases had to be wastefully vented for the remainder of the run-time due to a lack of storage capacity. Finally, when nitrogen consumption exceeds generation capability, typically during heat-up, cooldown and occasionally during outages, a package nitrogen generating system independent of the ASU could have proven cost effective and warrants consideration for the next plant.

Secondly, the addition of a smaller capacity liquid nitrogen pump has the potential to greatly reduce nitrogen consumption on frequent occasions. The currently installed pumps have a minimum turndown associated with them. In other words, the pump must flow a minimum amount of liquid nitrogen or it will trip off line. If operation of a liquid nitrogen pump is required in order to provide vaporized nitrogen for plant consumption, then either an amount of liquid nitrogen greater than the minimum turn-down must be vaporized or some of the pump discharge must be recycled back to the nitrogen storage tank. In cases where consumption requirements are very small, it is wasteful to do either. Excess vaporized nitrogen is vented to the atmosphere and high-pressure liquid nitrogen recycled back to the tank promotes flashing, which is also vented. However, it would not be wise to replace the current pumps with smaller ones, because their full capacity is often required. Installation of an additional smaller pump whose maximum capacity is slightly greater than the minimum turndown of the current pumps would be ideal. 


\subsubsection{Oxygen Compression System}

The oxygen compression system includes:

\begin{tabular}{|l|l|}
\hline $\begin{array}{l}\text { AC synchronous motor driver } \\
\text { (Figure 5.1.8A) }\end{array}$ & Lube oil system (Figure 5.1.8A) \\
\hline Vibration monitoring equipment & Two inter-process-stage coolers \\
\hline Oxygen bypass cooler & \\
\hline
\end{tabular}

Product oxygen that has been purity controlled in the mixing column and warmed in the main exchangers is received and pressurized by a six-impeller, three-process-stage radial turbocompressor for oxygen service (each process stage contains two impellers).

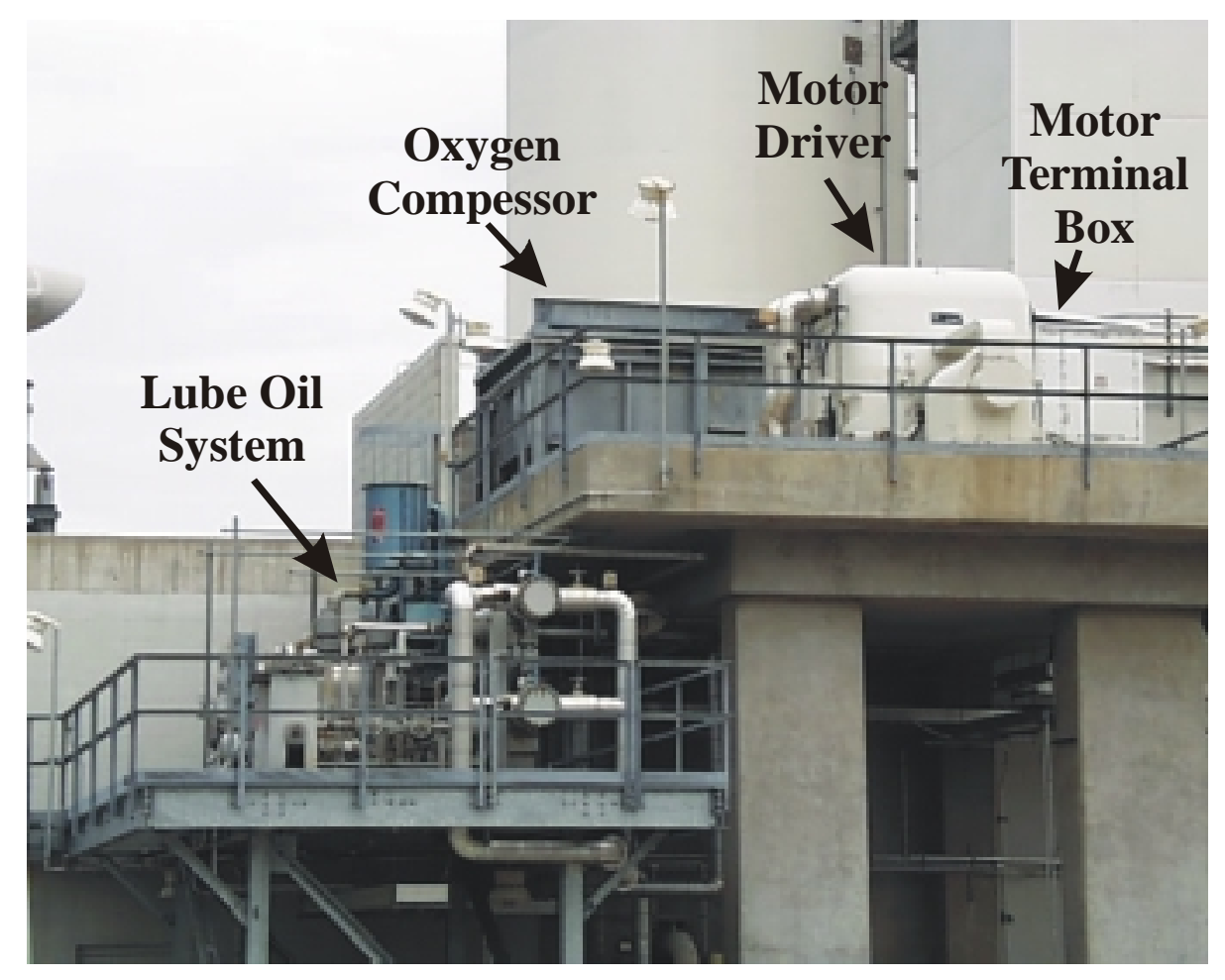

Figure 5.1.8A: Oxygen Compressor

\subsubsection{System Modifications}

No system modifications were made to the oxygen compression system prior to the Operating

Period. However, concerns over moisture detected within the motor driver enclosure prompted 
steps to guard against a potential future failure of the motor windings. Also, several instances of plant downtime prior to the Operating Period caused by electrical fuse failures within the control and instrumentation subsystem prompted a full audit of fuse coordination within the entire subsystem. Details of these significant procedural changes and preventative actions taken prior to the Operating Period follow.

A routine inspection of the oxygen compressor's motor driver prior to the Operating Period showed evidence of moisture within the motor enclosure. The moisture was visible in the bottom of the enclosure as well as detected in the insulation of the motor windings through standard electrical testing. Although it did not lead to any downtime prior to the Operating Period, moisture within the windings of such a large, high-voltage motor was addressed with top priority due to its potential to cause a catastrophic failure of the windings. It was determined that the fiberglass motor enclosure was inappropriately designed for outdoor service. Hairline cracks and pinholes around rivet points and seams in the enclosure provided possible entrant points for moisture. As an immediate action, care was taken to seal the enclosure through the application of a commercially available sealant. The moisture presence was severe enough that steps were also taken to dry out the insulation of the motor windings via a process in which direct electrical current was forced through the windings. The current generated heat within the windings driving off the moisture. Further investigation revealed that the electric heaters within the motor enclosure were improperly installed during construction and had never functioned. The installation error was rectified, and the heaters began functioning as designed. As an added precaution, a procedural change was made to include removal of the cooling water flow from the motor immediately after a shutdown of the machine. It is believed that the cooling water flow significantly counteracted the positive effects of the motor enclosure heaters, and may have promoted moisture condensation during the winding cooldown period immediately following the shutdown of the oxygen compressor.

Blown electrical fuses within the control and instrumentation subsystem prior to the Operating Period caused several instances of downtime and production delays for the oxygen compression system. Exact numbers for the amount of lost production related to these fuses are not known for the time prior to the Operating Period. This is mainly because many of them occurred very early 
in the Project and most of the production delays were just a few hours in duration as well as spread across several of the air separation systems. Nevertheless, all incidents of fuse failures prior to the Operating Period can be attributed to one overall root cause: the control and instrumentation subsystem was poorly designed and improperly installed by the project subcontractor. This is evidenced by the fact that instances of undersized fuses resulted in nuisance trips of critical valves. Instances of oversized fuses allowed minor instrumentation issues to overload upstream power supplies resulting in cascading trips of equipment. Also, instances where the wrong fuses were installed, even though the proper fuse size was specified in the design, resulted in similar failures. Load imbalance also played a role in production loss. It was found that some power supply circuits were overloaded while others were under-utilized. A full audit of fuses, coordinated with redistribution of some power supply circuits within the air separation unit's control and instrumentation subsystem, was performed prior to the Operating Period in response to the multiple failures. All fuse issues pertaining to the original design and installation of the control and instrumentation subsystems were addressed prior to the commencement of the Operating Period.

\subsubsection{Operating Experience Overview}

The total downtime associated with the oxygen compression system during the Operating Period was 70 hours. Operating experience for the oxygen compressor follows.

On June 17, 1998 a total of 26 hours of lost production occurred as a result of a blocked orifice in the oil return line from the oxygen compressor coupling. This return line allows oil to drain out of the coupling housing and flow back to the oil reservoir, under gravity, assisted by the vacuum oil recovery system. The orifice in the line had become blocked with debris promoting oil accumulation within the coupling housing.

The rotation of the coupling at over 11,000 rpm (revolutions per minute) churned and agitated the pooled oil to the point that boiling oil vapor began to spray from the coupling guard vent. No damage to the machine was encountered, but the presence of an oil cloud in the immediate vicinity of pressurized high-purity oxygen resulted in shutdown of the oxygen turbo-compressor in the interest of safety. Investigation determined that placement of the orifice at the bottom of 
the orifice plate had allowed residual debris from previous preventative coupling maintenance to obstruct the flow path of the oil. The situation was remedied by locating a second orifice in the center of the plate. No further downtime as a result of similar causes is expected.

On August 4, 1998 a trip of the oxygen compressor caused by a loose power supply connection resulted in 9 hours of production loss. Several of the trip interlocks for the oxygen compressor are fed from the same power supply. According to high-speed data archived by the control system, all of those interlocks tripped the oxygen compressor at precisely the same instant. Investigation revealed that the power supply wire to the interlocks had come loose from its termination point. The location of that particular terminal strip is in a high vibration area of the plant. The power supply wire was re-secured and all relevant termination points were tightened.

On August 15, 1998 a blown $15 \mathrm{kV}$ electrical fuse in a potential transformer located in the motor control center's high-voltage switchgear triggered a trip of the oxygen compressor (the main air compressor also tripped for the same reason). The incident led to 35 hours of plant downtime. The driver motors for both the oxygen compressor and the main air compressor rely upon a signal from this potential transformer in order to control their synchronous fields. Loss of the transformer's fuse forced them both to trip instantaneously. Rigorous electrical testing of the potential transformer confirmed no problem with the transformer. The possibility of a defective fuse was also ruled out, as this was the second incident involving the same fuse location in just over eight months (the first caused 33 hours of downtime prior to the Operating Period on February 5, 1998). Although no definitive explanation could be found for the blown fuse, the potential transformer was swapped with an identical one from a less critical service. No further problems with this device have been experienced or are anticipated.

A vibration data collection system was installed on the oxygen compressor during the Operating Period. The new system added historical archiving, event capturing, and analytical tools to the already existing vibration monitoring equipment. The increased functionality of the vibration equipment now allows for predictive maintenance techniques to be employed through monitoring of data trends and enhances the accuracy of troubleshooting in response to vibration related events. 
Maintenance on the oxygen compressor during the Operating Period was limited to normal preventative maintenance procedures (PM's) performed during planned outages. Some of the tasks performed during these PM's included: electrical measurements on the motor, motor enclosure inspections and weather proofing, coupling and bull-gear inspections, lube oil system inspection and minor leak repair, and pressure safety valve calibrations.

\subsubsection{Summary and Conclusions}

In summary, the oxygen compressor has been very reliable with regard to all of the physical hardware associated with it. However, the overall reliability of the oxygen compression system has suffered tremendously as a result of issues surrounding electrical fuses and power supplies. Most of the downtime credited to the oxygen compression system prior to, within, and after the Operating Period could have been avoided had more care been exercised in the design and installation of the control and instrumentation subsystem. Future gasification projects should pay particularly close attention to quality control in the detailed design and installation of the control and instrumentation subsystem, especially if the work is to be contracted to a third party.

In addition to the problems related to fuses and power supplies in the control and instrumentation subsystem, difficulties in preventing moisture from penetrating the oxygen compressor's motor enclosure have been a serious concern with regard to protecting against a costly motor rewind. A dry gas purge installed in the motor enclosure during the first quarter of 1999, enclosure heater repairs, enclosure weatherproofing efforts, and procedural changes pertaining to cooling water flows have all been credited with preventing moisture from entering the motor enclosure.

One noteworthy project that has been implemented in the oxygen compression system since the Operating Period is the installation of baffle plates in the oxygen compressor coupling guard. The purpose of these new baffle plates is to prevent heat buildup caused by air friction with the wall of the coupling guard resulting from high-speed coupling rotation (known as windage). High coupling guard temperatures tend to carburize (or coke) the oil, reducing its lubrication properties. The new baffle plates rectified the problem by breaking up the airflow that causes the heat build up (eliminating windage). 
One last point of concern with regard to the reliability of the oxygen compressor involves the lack of redundancy of vibration probes located within the machine. A few sporadic, vibration related, nuisance trips suffered throughout the history of the oxygen compressor have prompted evaluation of the need for added redundancy in the vibration monitoring subsystem. The evaluation is currently underway.

All maintenance performed on the oxygen compression system since the end of the Operating Period, and anticipated in the future, is limited to the preventative maintenance work discussed at the end of Section 5.1.8.2. The system is expected to be very reliable in the future. 


\subsection{Coal Handling}

\subsubsection{Coal Hopper System}

The coal hopper system includes:

\begin{tabular}{|l|l|}
\hline Coal sampler & Coal hopper (Figure 5.2.1A) \\
\hline Weigh belt feeder (Figure 5.2.1A) & \\
\hline
\end{tabular}

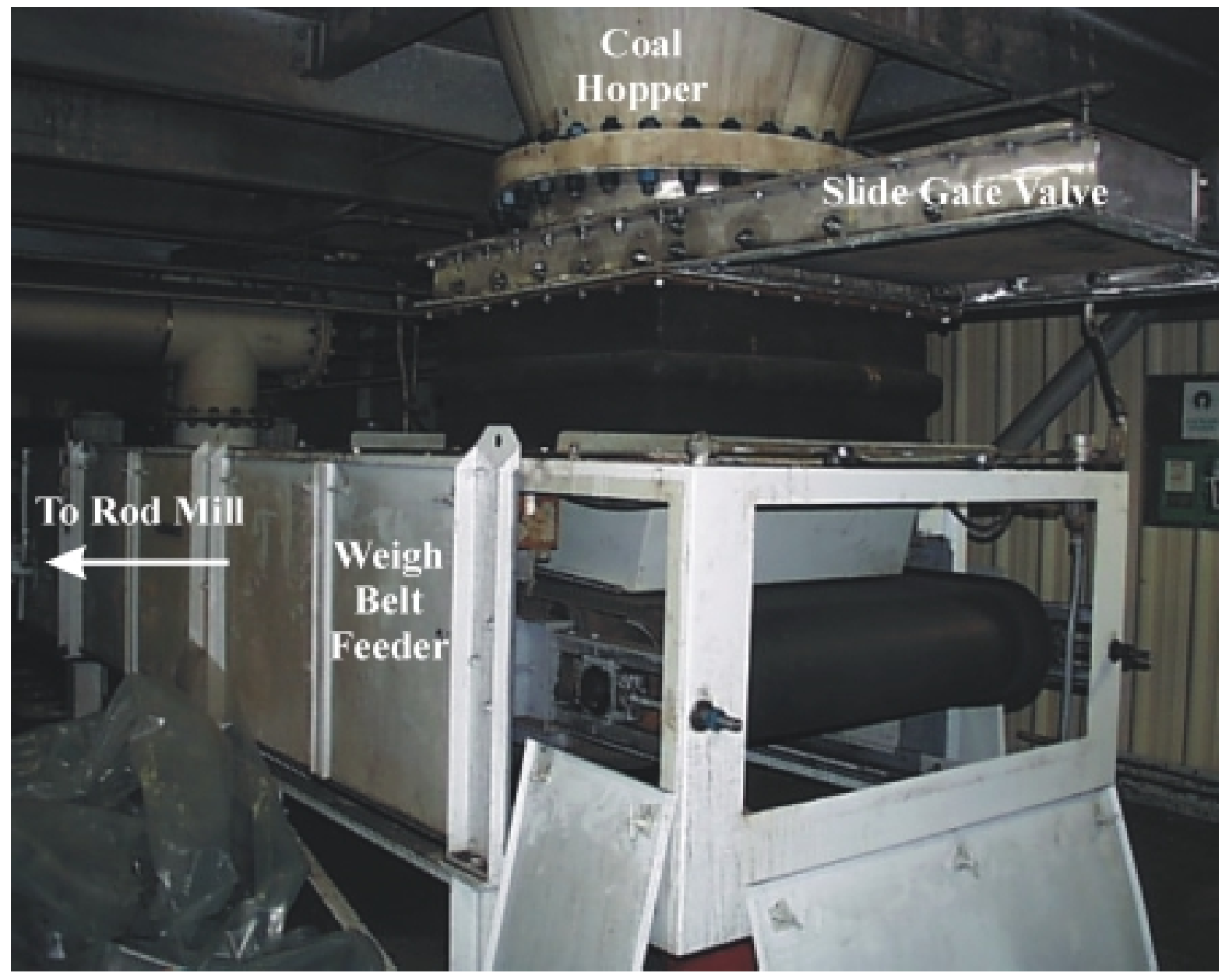

Figure 5.2.1A: Weigh Belt Feeder 


\subsubsection{System Modifications}

The coal hopper system performed as expected since plant start-up in 1995 with only minor modifications. This might be expected, as all of the types of equipment used in this process system are well proven in previous gasification plants operated in the development of the E$\mathrm{Gas}^{\mathrm{TM}}$ technology, as well as in similar solids processing industries. No plant downtime or production turndown has been attributed to this system. However, erosion of the coal hopper inlet chute was a recurring maintenance problem throughout the first two years of operation. In August of 1997, the inlet chute was replaced and lined with an erosion-resistant material, eliminating the erosion problem and subsequent near-term maintenance expenditures.

The weigh belt feeder motor required extensive maintenance attention in late 1996 and early 1997 due to failure of the coal hopper bottom outlet isolation slide gate valve. The resulting weight of the coal residing on the weigh belt feeder belt created an overload condition for the weigh belt feeder motor and subsequent attempts to start the motor resulted in motor failure. To address the overload condition, operating procedures for shutting down the plant were modified to empty the coal hopper and, thus, avoid starting the weigh belt feeder under load. Since replacement of the motor in August of 1997 and implementation of the new plant shutdown procedures, the problem has not recurred.

Although the coal sampler resulted in no plant downtime, it had a history of poor reliability and unacceptably high operating and maintenance costs. The coal sampler was taken out of service (i.e., bypassed) in late 1997. To provide process stream data and to ensure sufficient quality control for operating the plant, procedures were modified and slurry samples from the slurry storage tank were utilized after the removal of the automated coal sampler.

\subsubsection{Operating Experience Overview}

There was no downtime associated with the coal hopper system during the Operating Period. Operating experience for individual pieces of equipment follows. 


\section{Coal Sampler}

The coal sampler was returned to service in the summer of 1998 when a new coal was introduced to the plant. Plugging problems continued with the unit, but were not as severe as in the past. This was due to almost continuous "hands-on" operation of the coal sampler by laboratory and Operations personnel. Once an analytical baseline was established for the new coal, the sampler was again taken out of service.

\section{Coal Hopper}

A small leak occurred on the inlet chute in May of 1998. It was repaired without incident during a subsequent outage. Later in the Operating Period, the coal sampler, although out of service, began promoting erosion at the inlet of the coal hopper due to impingement caused by the disruption of the coal dropping from the coal feed belts. This problem was addressed following the Operating Period.

\section{Other Equipment}

There was no maintenance, downtime or operational problem associated with the weigh belt feeder during the Operating Period.

\subsubsection{Summary and Conclusions}

The coal hopper system has operated satisfactorily since its commissioning in 1995. Erosion problems were mitigated by the addition of erosion-resistant linings. Following the Operating Period, the coal sampler was physically dismantled and removed from the system to allow the installation of an erosion-resistant inlet chute to the coal hopper.

Early problems with the weigh belt feeder were resolved procedurally until replacement of the hopper slide gate valve was initiated during the fall of 1999. Corrosion of the slide gate valve carbon steel components started becoming evident throughout 1999 and was identified as a factor in the failure of the slide gate valve to be able to be operated through normal means. Critical slide gate valve components have been upgraded with improved metallurgy to better deal with the corrosive environment, which is likely attributable to the acidic water drainage from the high sulfur coal stored in the hopper above the isolation slide gate valve. 


\subsubsection{Rod Mill System}

The rod mill system includes:

\begin{tabular}{|l|l|}
\hline Rod mill (Figure 5.2.2A) & Recycled solids tank \\
\hline Recycled solids pumps & Recycled water tank \\
\hline Recycled water pumps & Rod mill product tank \\
\hline Rod mill product pumps (Figure 5.2.2B) & \\
\hline
\end{tabular}

The rod mill system was installed as part of the original plant design. It has operated as designed with only minor modification.

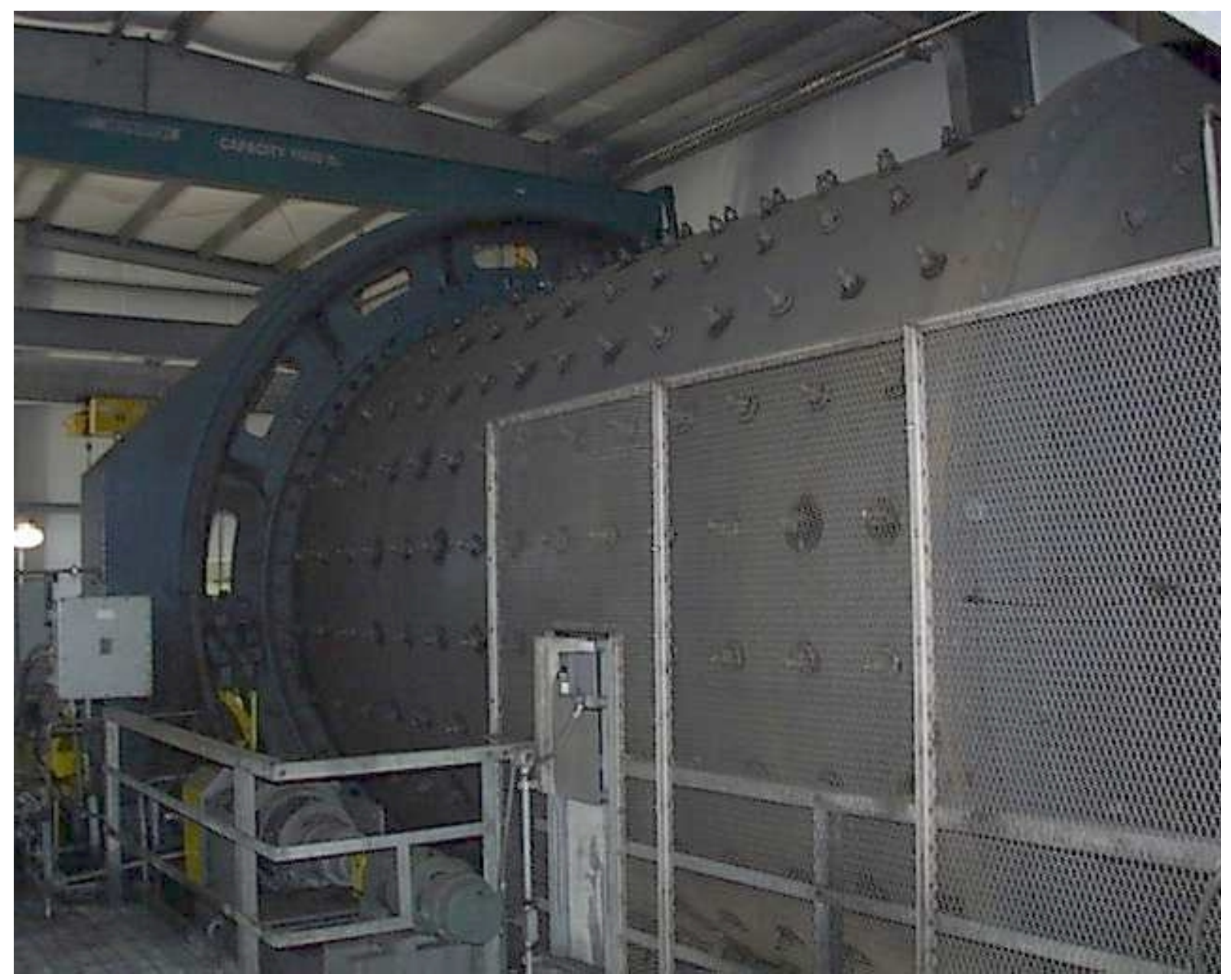

Figure 5.2.2A: Rod Mill

Wabash River Coal Gasification Repowering Project Final Technical Report 


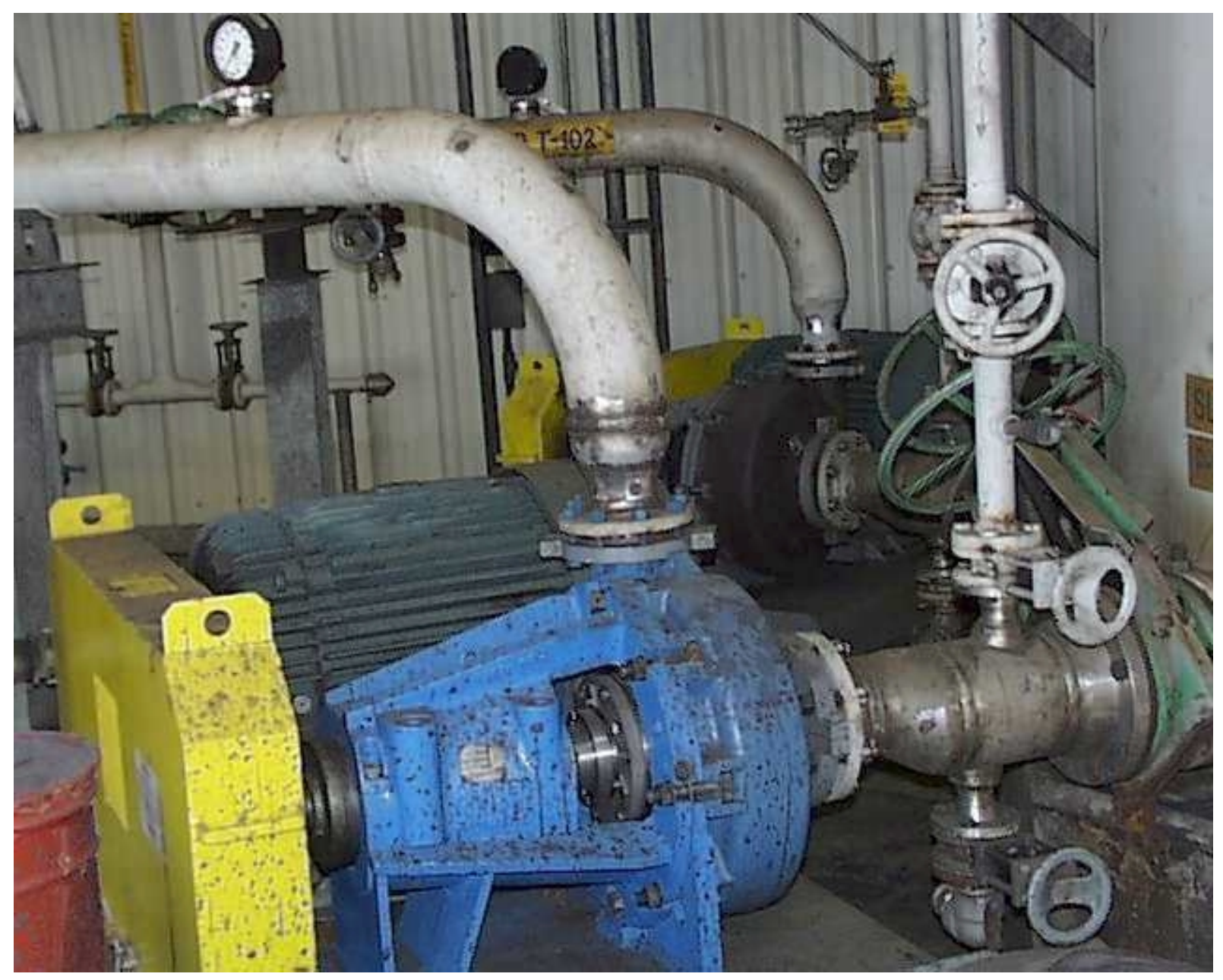

Figure 5.2.2B: Rod Mill Product Tank Pumps

\subsubsection{System Modifications}

Modifications to this system were limited to installation of erosion-resistant materials in high wear areas due to erosive nature of the coal and coal slurry and installation of covers over the rod mill outboard trunnion bearing and lube oil reservoir (Figure 5.2.2C) to prevent solids contamination of the rod mill bearing lube oil system. 


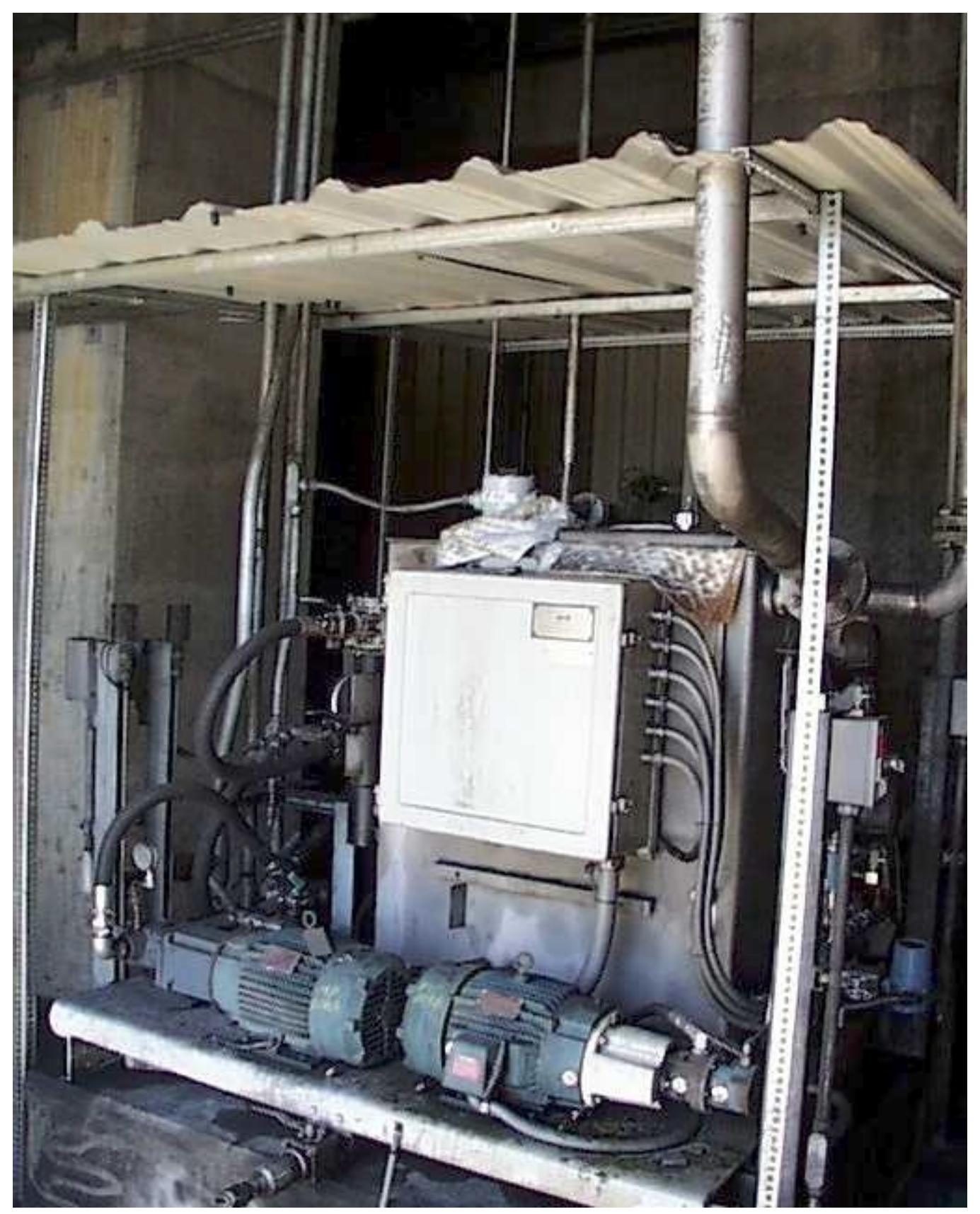

Figure 5.2.2C: Rod Mill Lube Oil Skid

\subsubsection{Operating Experience Overview}

There was no downtime associated with the rod mill system during the Operating Period. Operating experience for individual pieces of equipment follows. 


\section{$\underline{\text { Rod Mill }}$}

The rod mill operated as expected during the Operating Period with the exception of holes being worn into the inlet and outlet chutes due to erosion, and contamination of the bearing lube oil system with solids. Erosion-resistant materials were added to the chutes to alleviate the wear and have performed satisfactorily to date. The covers installed over the outboard trunnion bearing and lube oil reservoir (Figure 5.2.2C) to prevent solids contamination of the rod mill lube oil system have also performed satisfactorily. Routine preventative maintenance during the Operating Period included removing of worn grinding rods, installation of new grinding rods, refilling of gaps between the rod mill liner plates, inspection and measurement for wear of the rod mill liner plates, and tightening of rod mill liner plate bolts that loosen over time.

\section{$\underline{\text { Recycled Solids Pumps }}$}

During the Operating Period, the common discharge piping on these pumps required cleaning, during a plant shutdown, due to accumulation of scale in the piping from minerals dissolved in the water. The scale buildup resulted in diminished flow rates. The diminished flow rates caused some concern while operations ensued, but did not result in downtime for the plant.

\section{$\underline{\text { Rod Mill Product Pumps }}$}

The pumps operated as expected during the Operating Period. Other than preventative maintenance, the only maintenance required was replacement of some fluid end parts due to erosive wear from coal slurry. This is within expectations and is considered normal for the type of service that these pumps are performing.

\section{Other Equipment}

There was no maintenance, downtime or operational problem associated with the following equipment during the Operating Period: recycled solids tank, recycled water tank, recycled water pumps, and the rod mill product tank.

\subsubsection{Summary and Conclusions}

The rod mill system has operated as designed since plant start-up in 1995. With the exception of having to install wear-resistant materials in high wear areas, only routine and preventative 
maintenance has been required to this system. After the Operating Period concluded, repairs were required to the agitator in the rod mill product tank as well as repairs to the floor of the tank. In both cases damage was due to abrasion from the coal slurry. Abrasion-resistant material was also installed on the floor of the rod mill product tank beneath the agitator. With this modification, only routine maintenance is anticipated for this system in the foreseeable future. 


\subsubsection{Slurry Storage Tank System}

The slurry storage tank system includes:

\begin{tabular}{|l|l|}
\hline Slurry storage tank & Slurry storage tank agitator (Figure 5.2.3A) \\
\hline Slurry recirculation pumps (Figure 5.2.3B) & \\
\hline
\end{tabular}

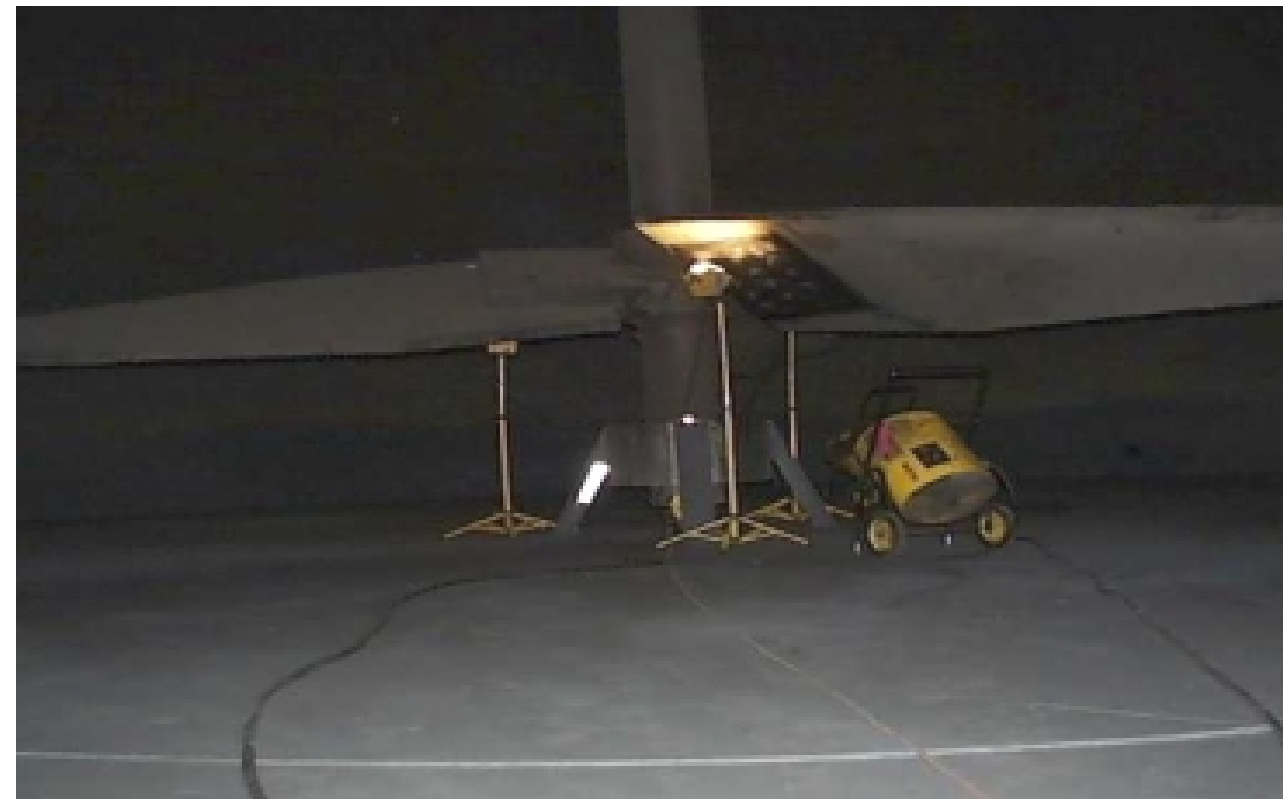

Figure 5.2.3A: Slurry Storage Tank Agitator

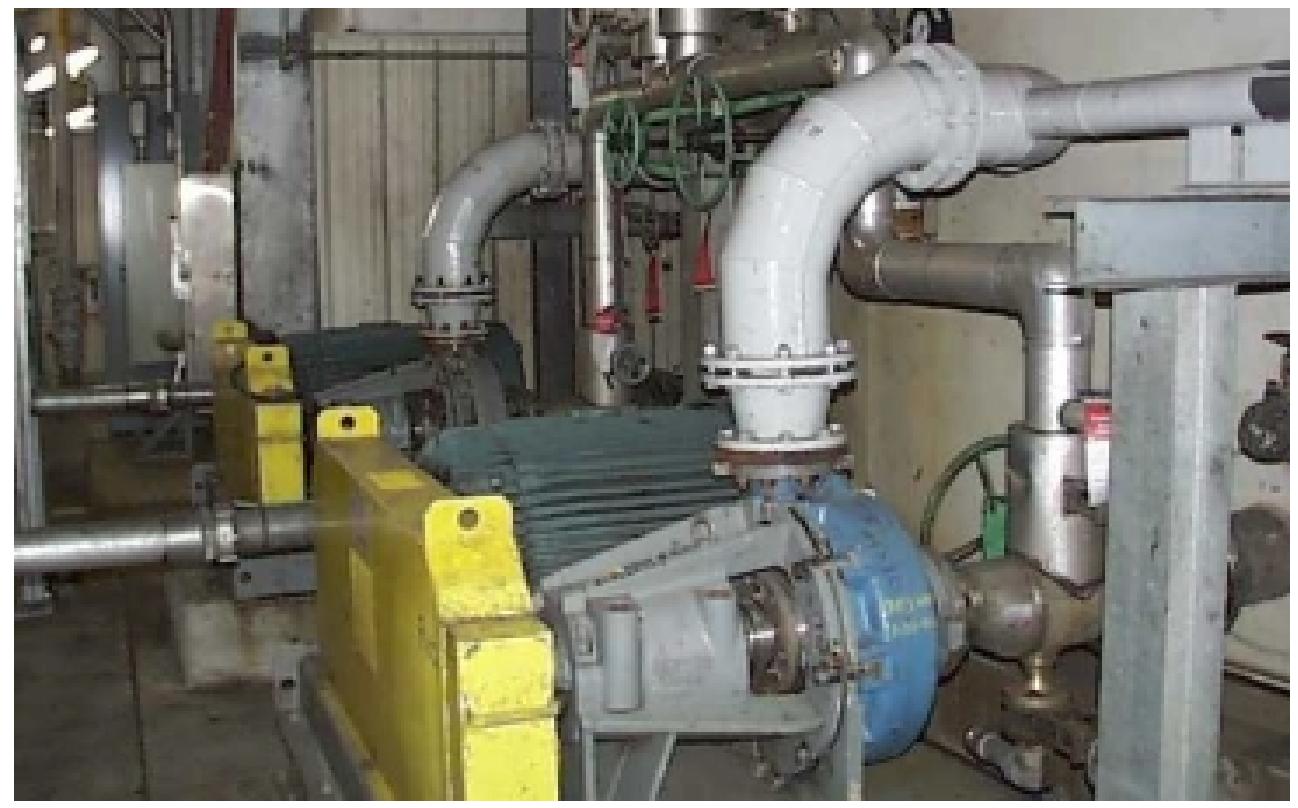

Figure 5.2.3B: Slurry Recirculation Pumps

Wabash River Coal Gasification Repowering Project Final Technical Report 


\subsubsection{System Modifications}

No modifications were made since commissioning and start-up of the system prior to the

Operating Period. Prior to the Operating Period, on one occasion, the slurry storage tank was emptied for removal of settled solids. Erosion damage to the blades on the slurry storage tank agitator was repaired at that time.

\subsubsection{Operating Experience Overview}

The total downtime associated with the slurry storage tank system during the Operating Period was 3 hours. Operating experience for individual pieces of equipment follows.

\section{$\underline{\text { Slurry Recirculation Pumps }}$}

The slurry recirculation pumps caused a total of 3 hours downtime during the Operating Period due to settled solids plugging the pump suction. Also, wear-resistant material was applied to the discharge piping of the pumps to combat erosive wear from the coal slurry. Normal, expected replacement of some fluid end parts due to wear from coal slurry was also necessary during this period.

\section{Other Equipment}

There was no maintenance, downtime or operational problem associated with the following equipment during the Operating Period: slurry storage tank, slurry storage tank agitator.

\subsubsection{Summary and Conclusions}

The slurry storage tank system operated as designed during the Operating Period, with the exception of some unwanted settling of solids in the slurry storage tank, creating a "fillet" around the inner circumference of the tank wall. This situation is not uncommon in industries that process solids-containing slurries. However, to address the situation, after the Operating Period, the blades on the slurry storage tank agitator will be replaced with larger diameter blades to increase the agitation of the coal slurry, within the horsepower limitations of the existing agitator drive motor, in an effort to mitigate the amount of solids settling along the tank walls. 


\subsubsection{Slurry Feed System}

The slurry feed pump system includes:

\begin{tabular}{|l|l|}
\hline $\begin{array}{l}\text { First stage gasifier feed pumps } \\
\text { (Figure 5.2.4A) }\end{array}$ & Second stage gasifier feed pumps \\
\hline Primary slurry heater & Secondary slurry heaters \\
\hline
\end{tabular}

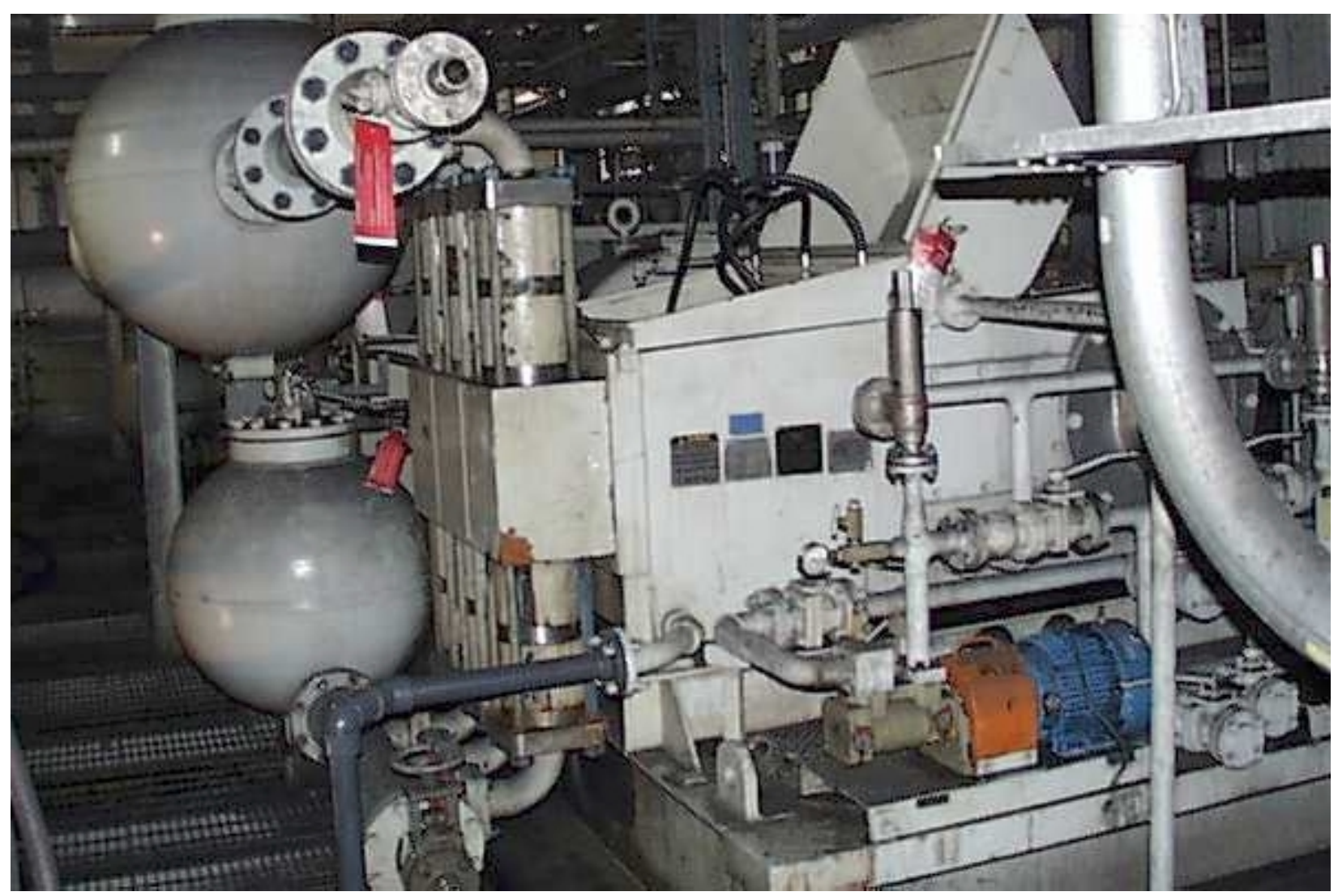

Figure 5.2.4A: Typical First Stage Reactor Feed Pump

\subsubsection{System Modifications}

During the Operating Period, two modifications were made to this system. Selected valves in the system were replaced with upgraded metallurgy and some of the flow meters in hot slurry service were removed and other means to monitor the slurry flow to the gasifier were initiated.

The slurry heater system performed adequately with minimal modifications. No plant downtime or production turndown has been attributed to this system. Fouling of the slurry heaters began to 
manifest itself during the second year of operation. The deposits were readily removed by hydro-blasting with a high-pressure water source in August of 1997.

\subsubsection{Operating Experience Overview}

The total downtime associated with the slurry feed pumps system during the Operating Period was 33 hours. Operating experience for individual pieces of equipment follows.

\section{First Stage Reactor Feed Pumps}

The first stage reactor feed pumps were responsible for a total of 30 hours of downtime for the Operating Period. The pumps operated as expected during the Operating Period, but several problems unrelated to the core gasification technology resulted in loss of syngas production. Slurry lines that froze during a winter outage were not completely thawed after the shutdown and accounted for 18 hours of downtime. Rupture disks, installed to protect the reactor feed pumps' discharge piping from overpressure situations, blew on two occasions, resulting in 3 hours of loss production. Leaking slurry flow meters accounted for 3 hours of downtime. A failed piston flush on one of the pumps also contributed 5 hours of downtime.

\section{$\underline{\text { Second Stage Gasifier Feed Pumps }}$}

The second stage gasifier feed pumps were responsible for 3 hours of downtime during the Operating Period. This downtime was due to a leaking pump discharge slurry flow meter.

\section{$\underline{\text { Secondary Slurry Heaters }}$}

Hydro-blasting was repeated on the slurry heaters in May of 1998. In June of 1998, the softening of the process water supply was discontinued. This resulted in increased fouling of the slurry heaters, especially secondary heaters due to their higher operating temperature. In an effort to reduce maintenance costs, the slurry flow meters downstream of the slurry heaters were removed from service in the fall of 1998 and were replaced with an alternate means of slurry flow measurement. Removal of these temperature-limited flow meters allowed higher slurry operating temperatures. This allows for more efficient operation of the gasifier. 


\section{Other Equipment}

There was no maintenance, downtime or operational problem associated with the primary slurry heater during the Operating Period.

\subsubsection{Summary and Conclusions}

The slurry feed pumps have operated as designed since the plant went on line. This is partly due to the vast amount of operating and maintenance experience obtained from operating a pilot plant, a prototype plant and another commercial-scale demonstration plant in Louisiana in the course of the development of the current E-Gas ${ }^{\mathrm{TM}}$ technology. Other than routine maintenance and replacement of fluid-end parts due to erosion from the coal slurry, no changes were made during the Operating Period. Since the Operating Period ended, metallurgical upgrade of a minor portion of the piston flush lines on each pump was made. It is anticipated, also, that in the future, some of the coal slurry piping will require replacement due to the erosive effects of transporting coal slurry.

The slurry heater system has operated satisfactorily since its commissioning. Fouling of the tubes continues to be a problem and is only aggravated by the hard water supplying the slurry preparation system. Hydro-blasting is required during every major plant outage to mitigate the problem. Chemical treatments to control the rate of scale formation are currently being investigated. 


\subsection{Gasification}

\subsubsection{First Stage Gasifier System}

The first stage gasifier system includes:

\begin{tabular}{|l|l|}
\hline First stage gasifier & Slurry mixers \\
\hline Methane burners & Water-cooled device system \\
\hline Dry char recycle nozzles & \\
\hline
\end{tabular}

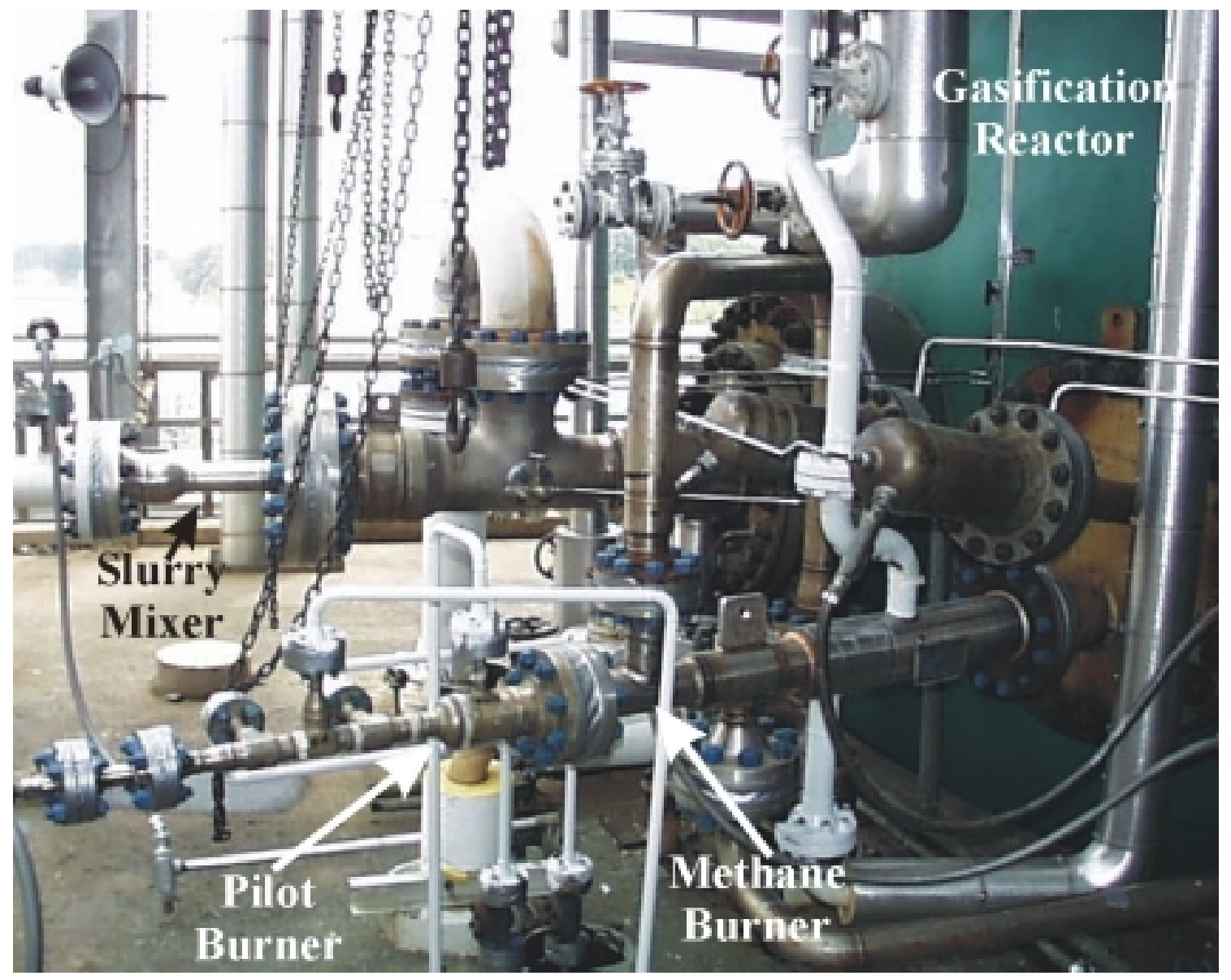

Figure 5.3.1A: First Stage Gasifier Feed Nozzles 


\subsubsection{System Modifications}

In the first year of operation, the gasifier refractory required extensive maintenance, which included 559 hours of downtime for partial re-bricking. Due to the nature of first year plant operations, the initial gasifier refractory was subjected to an above-normal number of thermal cycles contributing to the extensive damage. While a gasifier cooldown after a gasifier trip and purge could not be optimized further, the methane operation cooldown after a transfer off of coal operation was lengthened to minimize the thermal stresses caused by cycling operations. This procedural enhancement lengthened refractory life of the initial liner while subsequent gasifier liners benefited from this enhancement as well as improved plant operations.

Slurry mixer failures prior to the Operating Period were continually addressed for cause and corrective actions were implemented to extend mixer life as described below. Although slurry mixers can be replaced in less than 24 hours, this requires an interruption in syngas delivery.

During 1996, 353 downtime hours were attributable to slurry mixer failures. The major cause of failures during this period was due to hot gasifier contents backing up into the mixer during startups and shutdowns, which was corrected through improved control valve sequence timing during these transitions. In 1997, mixers were replaced proactively based on projected life and, as a result, downtime from slurry mixer failures was reduced to 11 hours. Premature slurry mixer failures caused 92 hours of downtime in the first two months of 1998. Investigation revealed that the transition to coal operations was being made at rates nearly $40 \%$ higher than in the past. Slurry flow instability caused by flow meter problems contributed to the flow deviations and resulted in higher than normal flame temperatures during start-up, which accelerated slurry mixer failures. Flow meter calibration and a modification to the coal transfer procedure eliminated these types of failures. In late 1996 and early 1997, the slurry mixers were modified to inject slurry into the gasifier at a different angle, attempting to improve carbon conversion and reduce ash deposition downstream of the first stage gasifier. No appreciable improvement was attributed to this change and the slurry mixers were restored to the previous injection angle. In early 1997 , the slurry mixer was modified to allow full oxygen flows at lower backpressures. 
System modifications were also required to correct problems in the gasifier water-cooled device

system. Excessive flashing across the make-up water control valve resulted in piping failures in October of 1996 and March of 1997, accounting for 288 and 79 hours of downtime, respectively. During a subsequent outage in the spring of 1997, the make-up water supply was altered, which eliminated the destructive flashing.

Although it made no contribution to downtime, the dry char recycle nozzles often required expensive repairs due to cracking and pitting of the nozzle tip. The fact that the nozzles were water-cooled contributed to the expense of the repairs due to the precise internal clearances required for adequate water flow distribution. An uncooled nozzle was installed in December 1997 on a trial basis. An inspection during an outage prior to the Operating Period revealed little damage after about 900 operating hours. The cost advantage of the uncooled design was readily apparent; fabrication costs for a new (uncooled) unit were about the same as the repair cost for a water-cooled dry char nozzle.

\subsubsection{Operating Experience Overview}

The total downtime associated with the first stage gasifier during the Operating Period was 1001 hours. Operating experience for individual pieces of equipment follows.

\section{First Stage Gasifier}

The largest single contributor to gasifier downtime during the Operating Period was slag removal difficulties (plugged taphole). Plugging was a result of the introduction of higher ash-fusion temperature coal to the gasifier and constant changing of the feedstock blend. Taphole plugs resulted in 762 hours of downtime during the Operating Period. Gasifier operation was modified to include higher operating temperatures when operating on the new coal and additional training was given to operators to provide for better recognition of which coal blends were being fed to the gasifier, thus ensuring adequate slag flow.

Improper shutdown of the gasifier in December of 1998 resulted in refractory damage in the unit. The need for controlled cooldown was re-iterated to Operations personnel and specific instructions added to the shutdown procedure. Preventative repairs to the refractory extended an 
outage and resulted in 42 hours of downtime in early 1999, but probably averted greater downtime in the future.

\section{$\underline{\text { Slurry Mixers }}$}

During the Operating Period, 134 hours of downtime were attributed to the slurry mixers. In early March of 1998, an internal failure of a slurry mixer caused by erosion forced a transfer off of coal operations resulting in 27 hours of downtime. The problem was addressed by proactively changing the internal parts at a higher frequency while more erosion-resistant metallurgy was evaluated. Three scheduled mixer changes occurring in April, October and November of 1998 resulted in 58 hours of downtime. Proactive mixer changes progressively reduced downtime associated with this activity through improved planning and preparation. In August of 1998, following a slurry mixer trip forced by loss of oxygen, numerous attempts to return the plant to coal operation were ended by excessive temperatures in the gasifier. Investigation and correction of this problem resulted in 49 hours of downtime. The cause was attributed to slag accumulation

at the discharge of the mixer, which prevented proper mixing of the coal slurry and oxygen. The oxygen preferentially reacted with the syngas, resulting in the internals of the mixer being exposed to excessive temperatures. This problem has been addressed by automating a trip of the slurry mixers at the onset of an oxygen loss. This minimizes the addition of unburned coal and ash, which can obstruct the mixer's flow path on a subsequent start-up.

\section{Methane Burners}

Prior to transferring the first stage gasifier to coal operations, the methane burners are used to pre-heat the gasifier system to operating temperatures. Methane burner light-off failures increased during the Operating Period, resulting in 43 hours of downtime. The worst occurrence was in January of 1999 when multiple failed light-off attempts resulted in excessive nitrogen consumption due to the introduction of unreacted oxygen to the system. The root cause of the problem was frozen syngas condensation in the methane lines, which completely obstructed methane flow. The problem has been addressed through improved operating discipline as well as some nuisance alarm elimination. A nuisance alarm during light-off attempts was a causal factor in the methane flow problems going undetected. 
Following a taphole-plugging incident in January of 1999, a methane burner failed externally. This resulted in 20 hours of downtime to repair piping components associated with the failed burner. An insufficient purge of the burners during the transfer off of coal operation was a key factor in the incident. The purge has been modified to maintain a positive forward flow at all times when the burners may be exposed to a slagging environment.

\section{$\underline{\text { Water-Cooled Device System }}$}

Although it made no contribution to downtime during the Operating Period, the cooler in the water-cooled device system required maintenance during every outage in 1998 to repair tube leaks. The root cause of the tube leaks was corrosion caused by high operating temperatures with the water-cooled device system in early 1997. Due to the increasing frequency of repairs, the exchanger tube bundle was replaced during the winter 1998 outage. Cooler operating temperatures have prevented any repeat failures.

\section{Dry Char Recycle Nozzles}

The uncooled design proved to be largely successful, as it required no maintenance during the Operating Period other than routine inspections. During an outage in May 1998, the face of the remaining water-cooled dry char nozzle was found partially melted. It was replaced with a spare from inventory and remained in place during the remainder of the Operating Period.

\subsubsection{Summary and Conclusions}

The first stage gasifier in and of itself has met, if not exceeded, reliability expectations. The refractory life has improved to the point that the necessity of a spare gasifier in future projects should be evaluated carefully as it presents an opportunity to significantly decrease total plant installed capital cost. Following the Operating Period, neither the gasifier nor its refractory were the cause of any downtime. Refractory work in the original gasifier was completed shortly after the Operating Period and the unit was cured out in the fall of 1999, preparatory to removing the spare gasifier from service and swapping back to the original unit in the spring of 2000.

Slurry mixer reliability has proven to be a major challenge due to the abrasive characteristics of the coal, coupled with being exposed to a hostile environment (i.e., high temperatures, slagging 
conditions). Early on, typical mixer lives were well under half that achieved at Dow/Destec's LGTI facility. A major breakthrough was made in slurry mixer design following the Operating Period. A modification was made to the mixer throat and face that more than doubled the best mixer life to that point. Additional mixer improvements under evaluation include the addition of erosion-resistant materials to mixer parts contacting slurry and reduction of pressure drop while maintaining adequate atomization.

The reliability of methane burners has been adequate, although some improvements on purges during coal operation are in order. In the slagging environment present during coal operations, the burners tend to get plugged with slag, making subsequent attempts to return them to service difficult. Additional burner purges during coal operation are being evaluated and will be given due consideration in future designs. Additionally, the use of oxygen to fire the methane burners warrants re-evaluation in future projects. Using oxygen makes the operation of the methane burners contingent on oxygen being available from the air separation unit. This can be both costly due to utility usage to power the ASU and can add to the start-up time when the ASU is on the shutdown maintenance critical path. Air-blown burners would not have this limitation and could provide a more effective heat-up of the gas path due to the higher mass flow.

The reliability of the pilots for the methane burners has been somewhat disappointing. Part of the problem is obstruction of the flame scanner sight paths that occurs during coal operations. The vulnerability of flame scanner systems in a slagging environment is a problem that needs to be addressed in future projects. The pilots themselves are of a rather complicated design; four different feeds supply the pilot, which makes troubleshooting a rather complex task. Like the methane burners, the pilots are dependent on oxygen from the air separation unit. For future projects, a simpler pilot design, capable of running without enriched oxygen, should be evaluated. Of course, both the methane burners and the pilots operating on air versus oxygen would add new equipment in the form of a pressurized air source, so the trade-offs would need to be thoroughly evaluated from an economic perspective.

The uncooled dry char nozzle was deemed a success. It remained in service until fall 1999 (a period of nearly two years) when the dry char recycle piping was rebuilt (the nozzle was sent out 
for rebuild and replaced with a new uncooled nozzle). At this time, the remaining water-cooled nozzle was permanently removed from service and likewise replaced with an uncooled nozzle. Some opportunity still exists to further simplify the design of the nozzles, as thermal growth is no longer a consideration in the absence of water-cooling. 


\subsubsection{Second Stage Gasifier System}

The second stage gasifier system includes:

\begin{tabular}{|l|l|}
\hline Second stage gasifier & Second stage gasifier slurry feed nozzle \\
\hline Second stage gasifier quench nozzles & Soot blowers \\
\hline
\end{tabular}

\subsubsection{System Modifications}

The second stage gasifier performed adequately with minimal modifications. During the first year of operation ash deposition in the second stage was a continual maintenance problem. Reduction of the operating temperature had a very positive effect and decreased the deposition to the point that it was no longer a run-limiting concern. Failure of the slurry feed and quench nozzles by backflow of hot gas was a problem in early operation. Installation of nitrogen purge lines to ensure forward flow when the nozzles are not in service, but are exposed to high temperatures, has prevented this problem from recurring.

Soot blowers were installed in the original second stage gasifier due to a history of severe ash deposition problems at the LGTI facility. Repeated failures resulted in two of the four being removed from service in 1996. No adverse effect on ash deposition severity was noted following the change. Ash management efforts (i.e. reduced operating temperature) were so successful that the remaining two soot blowers were permanently removed from service when the new post gasifier pipe spool (See 5.3.3 for details) was installed in late 1997.

The spare second stage gasifier was rebricked to a larger diameter to reduce gas velocities, thus minimizing impingement of molten ash. This new configuration was brought on line in November 1997 and resulted in a reduction of ash deposition. The redesigned refractory lining also created one "hot spot" (i.e., overheating) on the vessel shell resulting from insufficient refractory lining at an expansion joint. While the hot spot caused no operational problem, cooling water applied to one side of the gasifier shell created uneven thermal growth causing the vessel to shift. The movement of the gasifier caused misalignment of the quench reactor and slag grinders, resulting in a failed fluid coupling on the grinder and a subsequent 40-hour shutdown. To prevent recurrence, hot spot water is added only as a mist so as to prevent 
differential thermal growth. In re-bricking the original gasifier, this particular expansion joint was modified to avoid the occurrence of any hot spots due to the thinner refractory.

Immediately prior to the Operating Period, 13 hours of downtime was attributed to the second stage gasifier slurry feed nozzle. During start-up of the gasification plant, it was noted that the recycle syngas flow into the nozzle was restricted. The clearance for gas flow was found to be tighter than specification due to a manufacturing error. An additional root cause of the problem was identified as overheating of the nozzle due to disabling of the nitrogen purge valve to limit excessive nitrogen use. This problem has been addressed by throttling non-critical purges before introducing nitrogen to the recycled syngas system, thus alleviating concerns of excessive nitrogen use.

\subsubsection{Operating Experience Overview}

The total downtime associated with the first stage gasifier during the Operating Period was 169 hours. Operating experience for individual pieces of equipment follows.

\section{$\underline{\text { Second Stage Gasifier }}$}

The second stage gasifier was responsible for 169 hours of downtime during the Operating Period. During start-up in December of 1998, an ash deposit that had formed dropped from the second stage gasifier and covered the gasifier taphole. The remedy has been removal of large ash deposits from the second stage gasifier during outages. Prior to December 1998, maintenance activities were mainly limited to routine refractory inspections.

\section{$\underline{\text { Second Stage Gasifier Slurry Feed Nozzle }}$}

Maintenance of the second stage gasifier slurry feed nozzle was limited to routine inspections and periodic replacements during the Operating Period. The replacement is dictated by the wear caused by the coal slurry and atomizing gas flows. No downtime was attributed to this equipment during the Operating Period. 


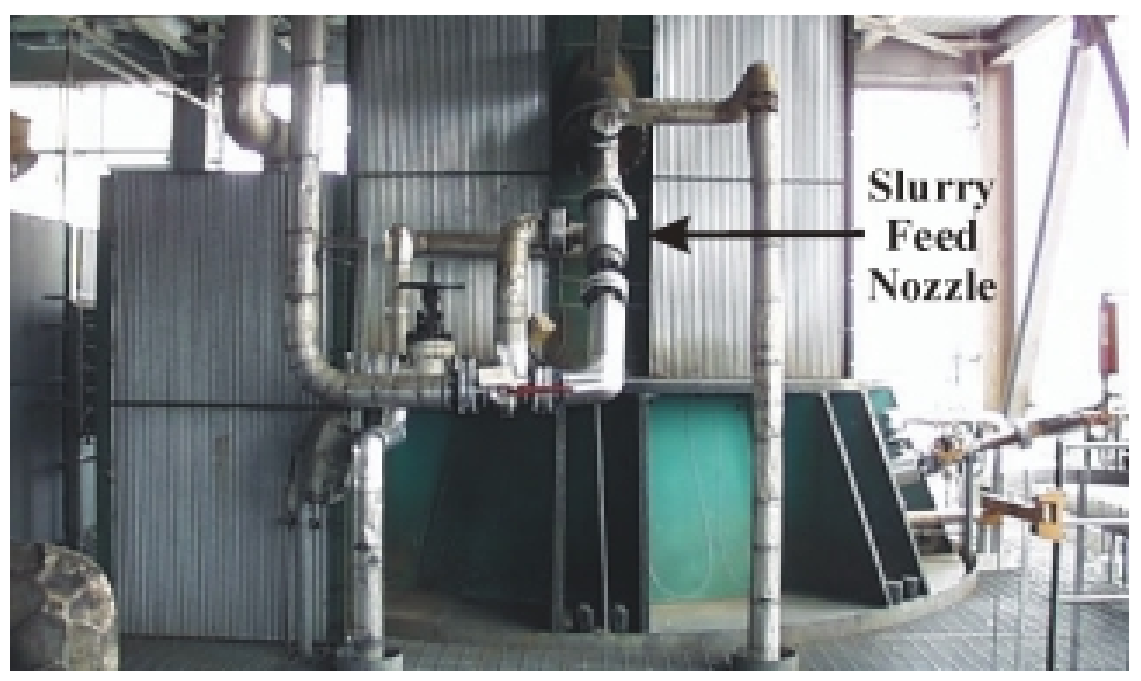

Figure 5.3.2B: Second Stage Gasifier Slurry Feed Nozzle

\section{Other Equipment}

There was no maintenance, downtime or operational problem associated with the second stage gasifier quench nozzles during the Operating Period.

\subsubsection{Summary and Conclusions}

The second stage gasifier has operated satisfactorily, both during and following the Operating Period. The unit continues to be $100 \%$ reliable, maintenance is limited to preventative inspections of the second stage gasifier and the slurry feed nozzle. The quench nozzles have exhibited outstanding reliability without need for maintenance. 


\subsubsection{Raw Syngas Conditioning System}

The raw syngas conditioning system includes:

\begin{tabular}{|l|l|}
\hline Post gasifier pipe spool & Post gasifier residence vessel \\
\hline Raw syngas de-superheater & Boiler inlet transfer piping \\
\hline
\end{tabular}

\subsubsection{System Modifications}

In the first year of operation, 567 hours of downtime were associated with ash deposition in this section of the plant. The post gasifier pipe spool that connects the second stage gasifier to the post gasifier residence vessel caused the majority of this downtime. The post gasifier pipe spool was an abrupt transition between the two connecting vessels resulting in high velocity zones where molten ash could accumulate due to impingement upon gas flow direction change. Accumulation of these deposits in the spool increased the differential pressure across the spool, which would lead to hot gas $\left(1800^{\circ} \mathrm{F}\right)$ flowing behind the refractory and contacting the carbon steel shell. Hot spots on the shell required that water and steam be applied to the external vessel wall to cool the metal. The refractory in the spool was changed in November of 1996 to a type of refractory that did not form as tenacious a bond with the molten ash. Although the accumulation of deposits in the post gasifier pipe spool were slightly decreased with the refractory change, ash deposits continued to form in the pipe spool and on the upper sections of the post gasifier residence vessel. As the deposit mass increased, and as the gasification system went through thermal cycles, deposits would break free, shatter and be carried downstream where they caused plugging in the boiler inlet transfer pipe and boiler tubes. This deposition caused 381 hours of downtime in the second year of operation.

Flange leaks associated with the post gasifier pipe spool were also common during the first two years of operation due to differences in thermal growth between the second stage gasifier and the post gasifier residence vessel. Several attempts to alleviate the problem were met with limited success.

By early 1997, it was clear that a major piping change would be required to eliminate the foregoing problems with this system. In September of 1997, the post gasifier pipe spool was 
permanently removed from service and replaced with a new post gasifier pipe spool, which incorporated a long sweeping refractory lined 180-degree bend. The new spool provides significantly lower velocities between the second stage gasifier and the post gasifier residence vessel than the previous pipe spool and is lined with refractory that does not form tenacious bonds with the ash. The new spool also accommodates more thermal growth between the second stage gasifier and the post gasifier residence vessel. Consequently, since this modification, not a single hour of downtime has been attributed to ash deposition in this system and syngas leaks from this area have been virtually eliminated.

\subsubsection{Operating Experience Overview}

There was no downtime associated with the pre-boiler gas conditioning system during the Operating Period. Operating experience for individual pieces of equipment follows.

\section{Post Gasifier Pipe Spool}

During three routine outages within the Operating Period, the manway on the post gasifier pipe spool was opened for inspection and to facilitate equipment ventilation. In each case, only small

amounts of ash were removed from the vessel walls. A thermocouple inserted in the spool to monitor gas temperature was replaced during one of those outages. No other maintenance, downtime or operational problems have been associated with this piece of equipment.

\section{$\underline{\text { Post Gasifier Residence Vessel }}$}

During three routine outages within the Operating Period, the manway on the post gasifier residence vessel was opened for inspection and to facilitate equipment ventilation. During these outages, minor amounts of ash were removed from the vessel and the refractory expansion joints were packed with insulating material. The thermocouple inserted in the post gasifier residence vessel to monitor gas temperature was replaced twice during the Operating Period. No other maintenance, downtime or operational problems have been associated with this piece of equipment. 


\section{$\underline{\text { Raw Syngas De-superheater }}$}

During each of the three routine outages within the Operating Period, the raw syngas desuperheater was removed from service, refurbished and returned to service. Plugging in the desuperheater occurs over time, which limits its ability to quench the gas prior to the heat recovery boiler. Although no downtime was associated with the de-superheater during the Operating Period, plugging in the de-superheater occasionally resulted in elevated gas temperatures at the boiler inlet, which contributed to a higher fouling rate for the boiler and a higher blinding rate for the primary char filters.

\section{Boiler Inlet Transfer Piping}

During three routine outages within the Operating Period, the manway and the top head of the boiler inlet transfer piping were opened for inspection and to facilitate equipment ventilation. Solids are routinely removed from the bottom manway of this pipe during outages, however the accumulation of solids is manageable. In March of 1998, a refractory breach in this piping system directly opposite the raw syngas de-superheater resulted in a hot spot on the steel piping wall. The hot spot was cooled with steam on line and the refractory was repaired in a subsequent outage. None of these events resulted in any downtime or operational problems associated with this piece of equipment.

\subsubsection{Summary and Conclusions}

Since the installation of the new post gasifier pipe spool in September of 1997, the pre-boiler gas conditioning system has not been responsible for a single hour of downtime. With the exception of the raw syngas de-superheater, there have been no operational problems. Since the Operating Period, the strainers on the water feeding the de-superheater have been replaced with a finer mesh material. Preliminary run-time since the replacement indicates less plugging of the desuperheater, which has enabled the boiler inlet temperature to be controlled at the desired set point. Routine maintenance associated with this system is now limited to routine inspections and cleaning of the equipment during scheduled outages. 


\subsubsection{Slag and Solids Handling System}

The slag and solids handling system includes:

\begin{tabular}{|l|l|}
\hline Slag pre-crusher & $\begin{array}{l}\text { Slag fines settler bottoms pumps } \\
\text { (Figure 5.3.4C) }\end{array}$ \\
\hline Slag crusher & Slag recycle water tank \\
\hline Slag dewatering tanks & Slag recycle water pumps \\
\hline $\begin{array}{l}\text { Slag water storage tank } \\
\text { (Figure 5.3.4A) }\end{array}$ & Slag recycle water cooler \\
\hline Slag water pumps & $\begin{array}{l}\text { Slag quench feedwater pumps } \\
\text { (Figure 5.3.4D) }\end{array}$ \\
\hline Slag fines settler (Figure 5.3.4B) & \\
\hline
\end{tabular}

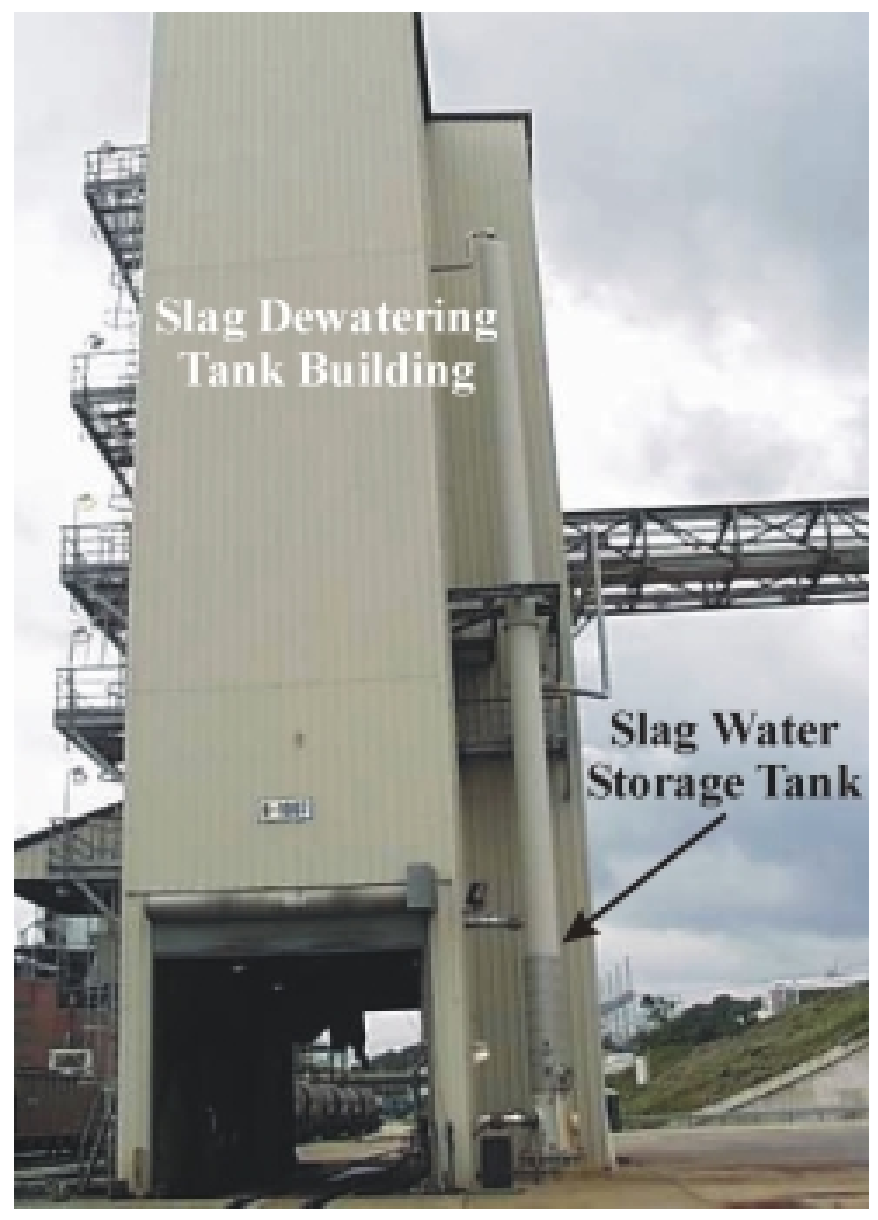

Figure 5.3.4A: Slag Dewatering Tank Building and Slag Water Storage Tank 


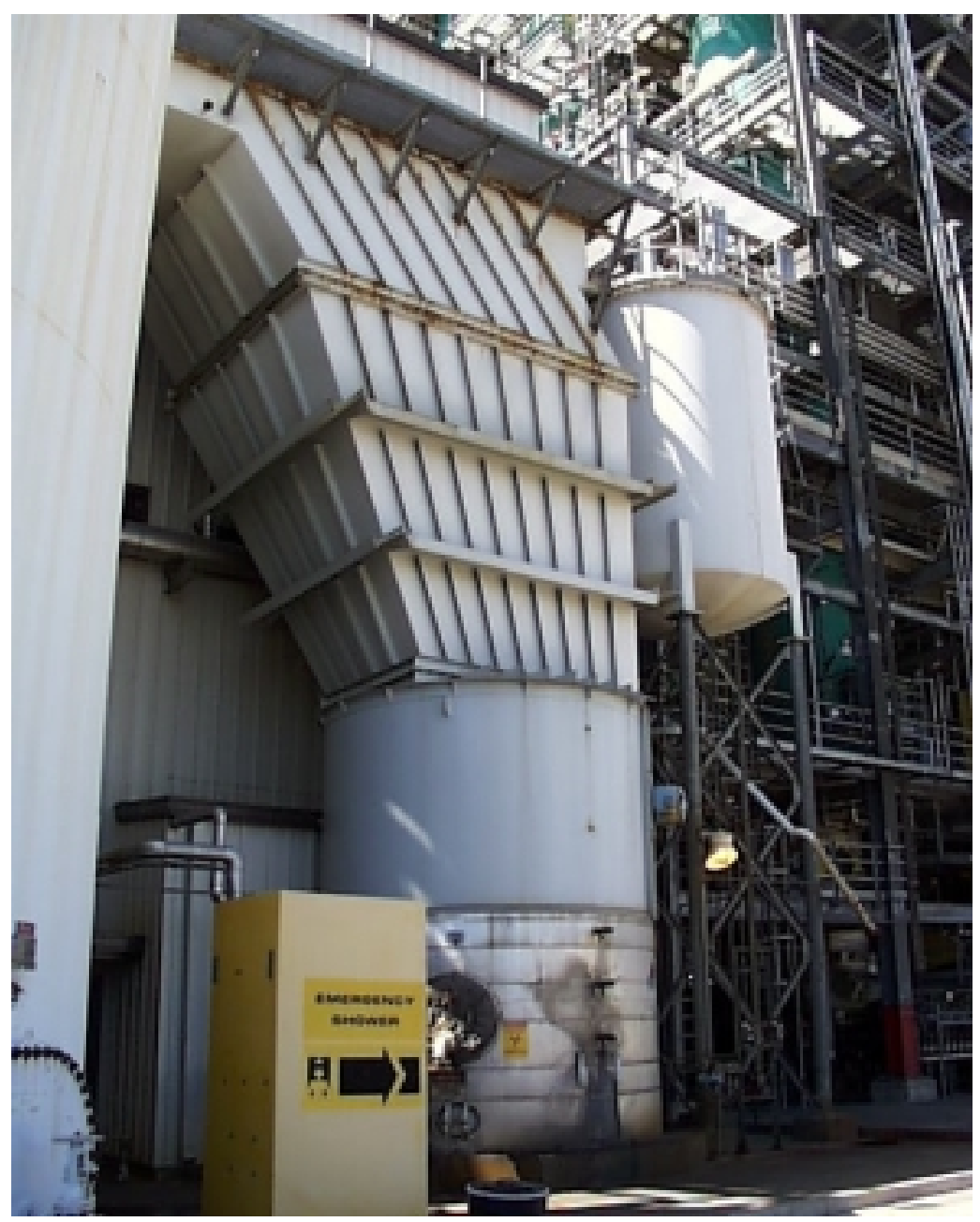

Figure 5.3.4B: Slag Fines Settler

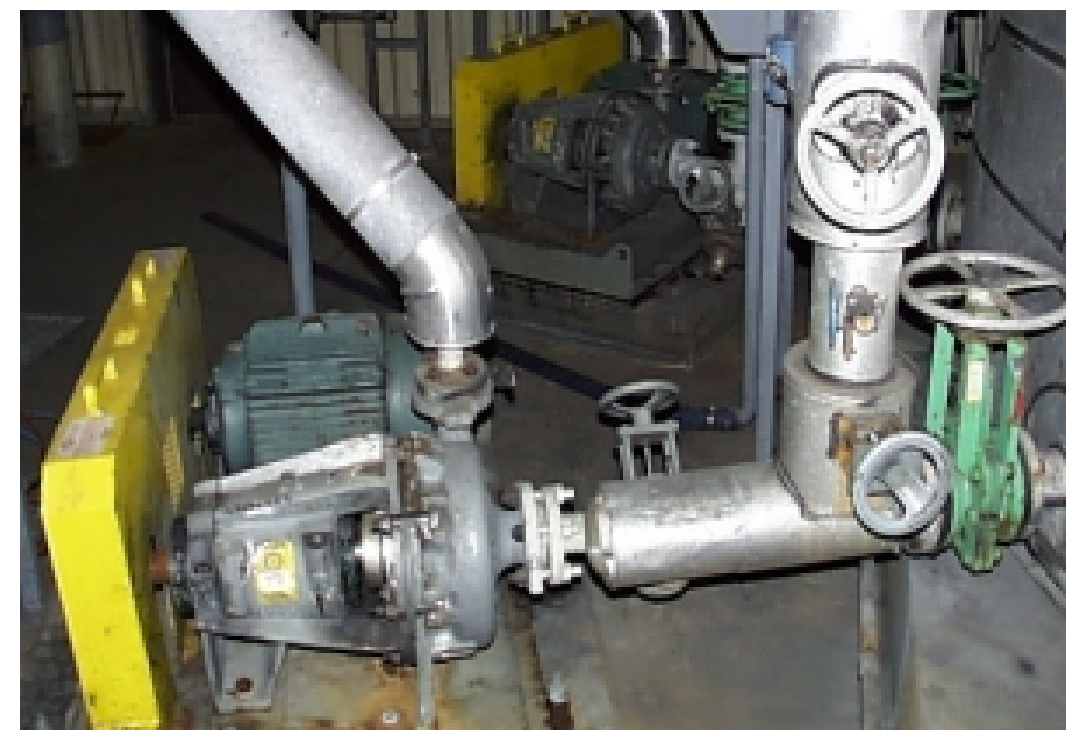

Figure 5.3.4C: Slag Fines Settler Bottoms Pumps

Wabash River Coal Gasification Repowering Project Final Technical Report 


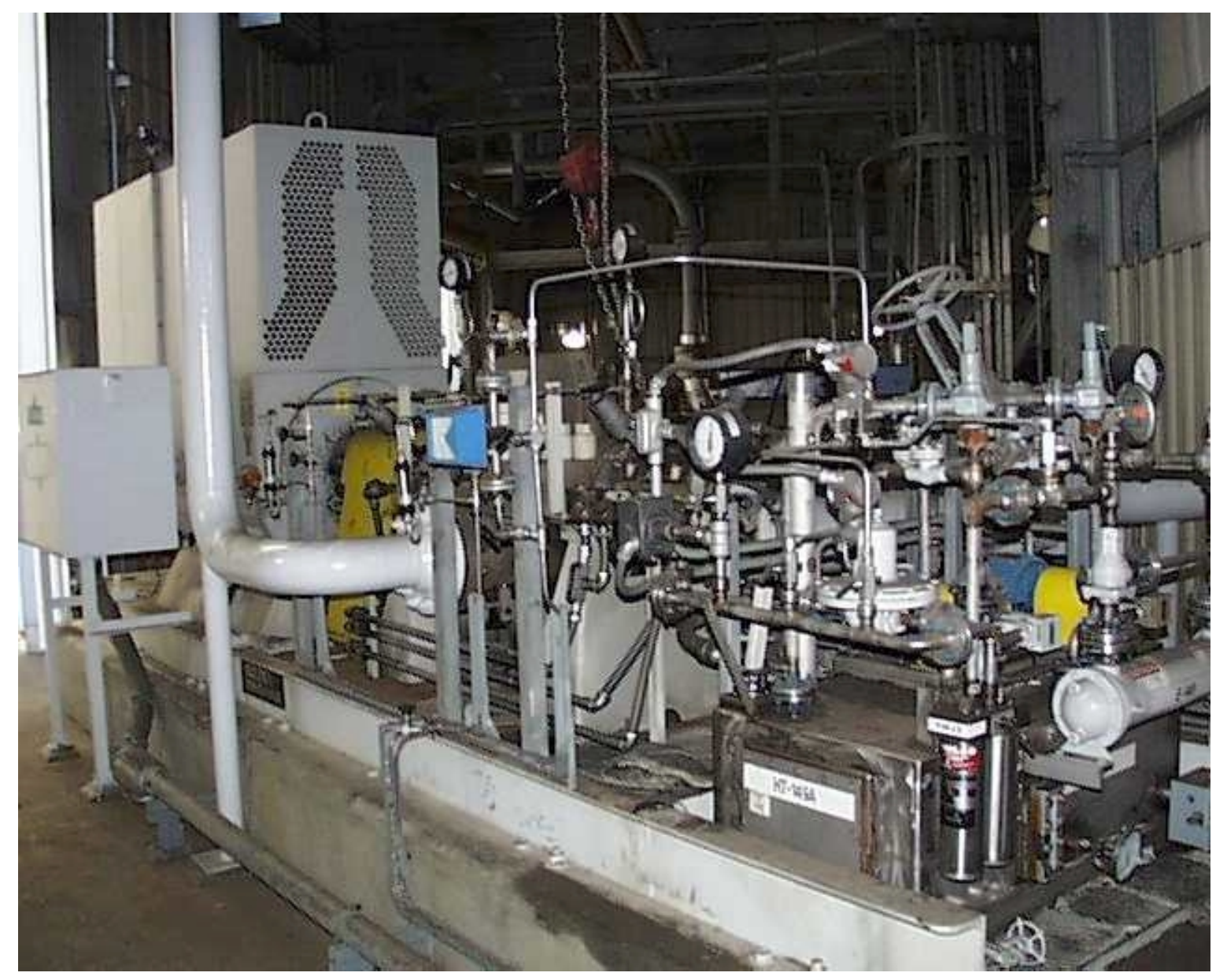

Figure 5.3.4D: Slag Quench Feedwater Pumps

\subsubsection{System Modifications}

Prior to the Operating Period, an anti-scale treatment system was added to slag and solids handling to help prevent scale build up in the piping associated with the slag water piping. This addition proved to be effective in preventing excessive scale build up in this area.

\subsubsection{Operating Experience Overview}

The total downtime associated with slag and solids handling during the Operating Period was 66 hours. Operating experience for individual pieces of equipment follows. 


\section{$\underline{\text { Slag Pre-Crusher }}$}

The slag pre-crusher was responsible for 66 hours of downtime during the Operating Period. An incorrect wiring installation for the slag pre-crusher electrical motor caused it to run in reverse. As a result of this error, that occurred some time during construction of the plant, oversized slag or refractory chunks would not pass through the pre-crusher and caused slag to fill the quench section of the gasifier. This eventually caused the plant to be shutdown to take corrective action.

\section{$\underline{\text { Slag Fines Settler }}$}

The slag fines settler did not cause any downtime during the Operating Period, but maintenance was required on the slag fines settler solids rake due to a failed bearing in the rake gearbox and also on a failed stud on the rake steady bearing.

\section{$\underline{\text { Slag Recycle Water Tank }}$}

The slag recycle water tank did not cause any downtime during the Operating Period, but had to be emptied and cleaned of solids during scheduled outages. The accumulation of solids was due to process upsets and failure of the decant filters in one of the slag dewatering tanks.

\section{Slag Recycle Water Cooler}

The slag recycle water cooler did not cause any downtime during the Operating Period, but had to be cleaned on several scheduled outages. Fouling of the tubes and accumulation of solids on the tubesheet resulted in higher-than-desirable water temperature in the system and necessitated the cleaning.

\section{Other Equipment}

There was no maintenance, downtime or operational problem associated with the following equipment during the Operating Period: slag dewatering tank, slag fines settler bottom pumps, slag crusher, slag water storage tank, slag water pumps, slag recycle water pumps, slag quench feedwater pumps. 


\subsubsection{Summary and Conclusions}

The slag and slag handling area of the plant continued to run as designed after the Operating Period with one notable exception. A metallurgical problem with the shaft sleeves on the slag crusher caused 104 hours of downtime after the Operating Period. The root cause of the problem was a poor metallurgical bond between the slag crusher shaft coating and the shaft base metal. Delamination of the coating resulted in a rough surface, which destroyed the crusher shaft packing necessitating a shutdown to facilitate repairs. The problem was addressed with a change in metallurgy and further problems have not been experienced.

Piping and, valve material loss from erosion by the slag continues to be a problem in the slag piping that is not lined with materials designed specifically to combat erosion. However, this is currently being addressed with use of more abrasion-resistant materials than those used in the original plant design. 


\subsubsection{Syngas Cooling/Steam Generation System}

The syngas cooling/steam generation system includes:

\begin{tabular}{|l|l|}
\hline Heat recovery boiler & High-pressure steam drum \\
\hline
\end{tabular}

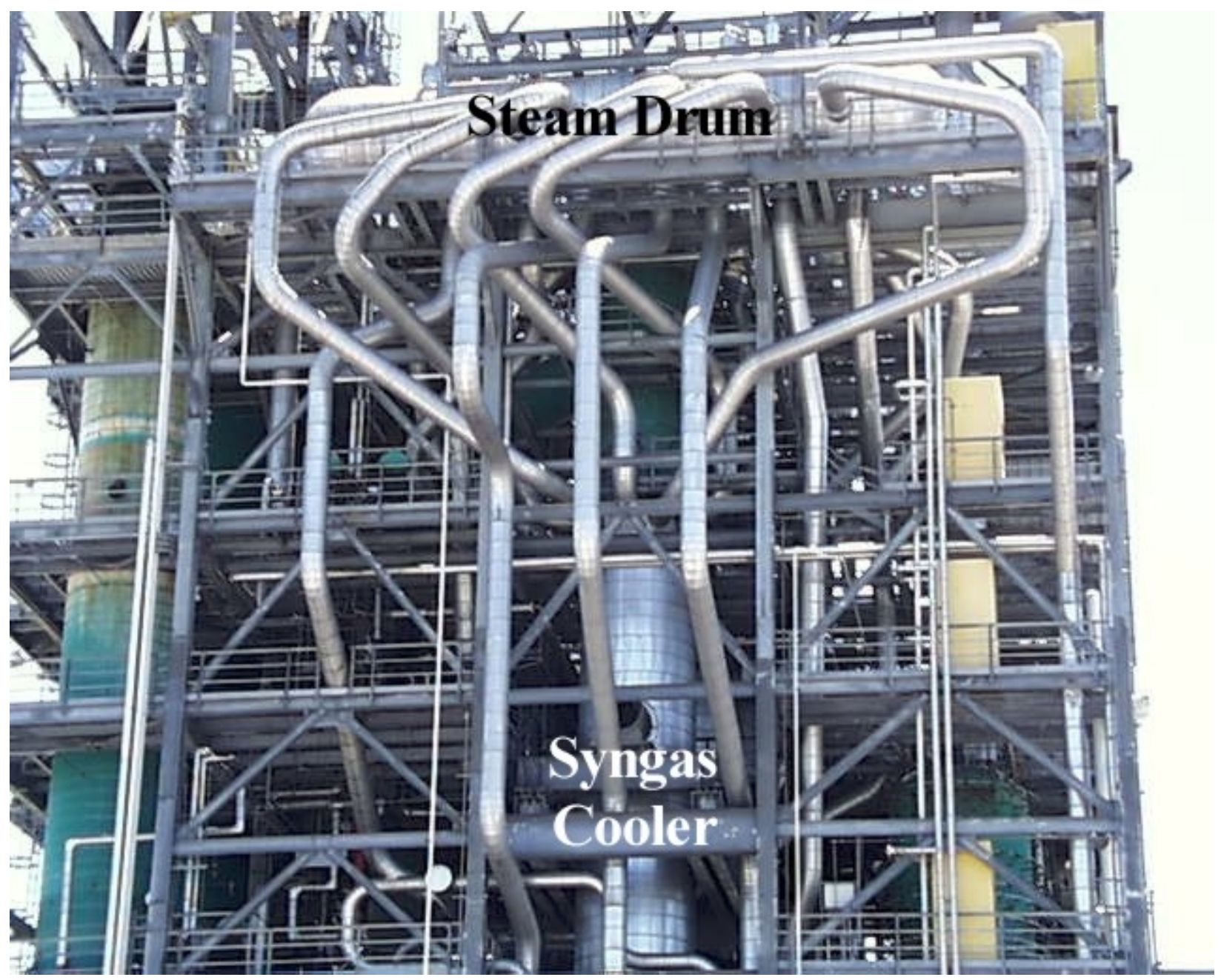

Figure 5.3.5A: Syngas Cooler and Steam Drum

The syngas cooling/steam generation system is used to remove high-level heat from the syngas stream as it exits the raw syngas conditioning system. The heat removed is used to produce high-pressure saturated steam. Major equipment in the syngas cooling/steam generation system includes a firetube heat recovery boiler and high-pressure steam drum. Refer to the process description section for additional details concerning the operation of this system. 


\subsubsection{System Modifications}

Prior to the Operating Period, one of the leading contributors to gasification plant downtime associated with the syngas cooling/steam generation system was plugging in the boiler tubes. The plugging was a result of ash deposits spalling off of upstream piping and equipment and being carried downstream into the gas inlet of the boiler. (See Section 5.3.3.1) Particles too large to pass through the boiler tubes would then lodge in them and restrict flow through them. As the boiler tubes plug, the velocity in the least-restricted tubes could increase to a level at which erosion from the entrained char begins to occur. To avoid excessive tube wall thinning, the gasification plant is forced to terminate operation once a predetermined differential pressure across the gas side of the boiler is reached.

To help manage ash-particle-plugging of the boiler tubes, a screen was installed in the gas inlet to the boiler. The screen was modeled after a similar device used in the LGTI plant and designed to capture ash particles too large to pass through the boiler tubes. Due to the high operating temperature and corrosive nature of the syngas, extensive metallurgical testing was undertaken to find materials of construction that could provide acceptable life for the boiler screen. Several design enhancements and material changes were implemented to achieve a high level of reliability and useful life for the screen. Implementation of the screen and reducing the likelihood of forming large ash deposits upstream of the boiler has virtually eliminated boiler tube plugging due to ash particulate deposition spalling.

Another cause of gasification plant downtime associated with the syngas cooler/steam generation system is boiler tube fouling. Trace metals contained in the gasifier feedstock are vaporized during the gasification process. A portion of these volatile trace metals is present in the syngas exiting the gasifier system. As the gas stream flows through the boiler tubes, some trace metal compounds condense onto the inner tube wall surfaces reducing boiler heat transfer. The loss in heat transfer can eventually cause the gas temperatures exiting the boiler to exceed the design temperature of downstream equipment.

Prior to the Operating Period, it was determined that the boiler inner tube wall deposition was so tenacious and hard that conventional cleaning methods such as high-pressure hydro-blasting, mechanical scraping and impact drilling could not effectively remove the deposits. As a result, 
special cleaning methods were developed to remove these deposits in a minimal amount of time. Additional methods that were evaluated to remove these deposits are discussed in more detail in Section 5.3.5.2

Plant thermal cycles exacerbated the spalling of ash deposition upstream of the boiler and accentuated installation flaws with the piping system on the outlet of the heat recovery boiler. A flanged piping spool piece on the boiler outlet was particularly problematic, developing gas leaks on several occasions. Enhancements to the spool flange torquing procedure were incorporated to improve the reliability of this system. This was only moderately successful. As a permanent solution, both flanged joints in this spool were replaced with welded connections to eliminate this potential leak point.

The high-pressure steam drum pressure transmitter sensing lines were upgraded as a result of several plant trips caused by erratic measurements in this equipment. As most of these occurrences took place during extremely cold weather conditions, improved heat trace and insulation systems were added to maximize the reliability of these systems. Additionally, control logic for the steam drum was upgraded to make the level control less sensitive to the idiosyncrasies of flow measurement.

Material upgrades were required for several nozzles located on the boiler gas inlet channel to control excessive corrosion at dissimilar metal welds. The alloy enhancements eliminated the aggressive corrosion present at these locations. Upgrades in alloy materials were also implemented at the boiler gas inlet channel manway insulation plugs to extend the service life of these components.

In 1997, syngas leakage through a valve located in a line connected to the boiler gas outlet piping eroded a small hole in the valve body forcing the plant off line for a short period of time. The valve was rebuilt with enhancements to the materials of construction. Plant operating procedures for this system were also changed to provide additional means of isolation downstream of this valve. 
Excessive gas side boiler tube fouling resulted from a brief operating test period on a petroleum coke feedstock in late 1997. Inadequate temperature control for the gas entering the boiler was determined to be the root cause for accelerated tube fouling. Changes to plant operating procedures and control set points were incorporated to minimize tube fouling while on this feedstock.

\subsubsection{Operating Experience Overview}

The total downtime associated with the syngas cooling/steam generation system during the Operating Period was 158 hours. Operating experience for individual pieces of equipment follows.

\section{Heat Recovery Boiler}

The heat recovery boiler contributed to plant downtime during the Operating Period on two occasions. The first occasion was an operational trip of the recycle syngas compressor that caused an interruption in cooling at the boiler gas inlet. This interruption resulted in a brief acceleration in the tube-fouling rate for the unit, which required 6 additional hours of downtime to remove the deposition created from this temperature excursion. The second occasion extended a planned outage by 152 hours to remove process-side tube fouling.

Just prior to the Operating Period, fouling deposits previously removed from the boiler tubes were used to evaluate a number of tube cleaning methods. The most effective method was selected for a small-scale field test on one boiler tube during an outage in February of 1999. Data taken from this study was used to design a full-scale chemical cleaning system that was used to remove a significant amount of process-side tube deposition during July 1998 of the Operating Period. The chemical cleaning was effective in restoring the boiler heat transfer to new conditions.

From an operational point of view the chemical cleaning method was deemed quite successful. However, when evaluating the economics, timeliness and disposal issues associated with this process, it was evident that there needed to be another method. As a result, another method of mechanically cleaning the tubes was developed and tested during the Operating Period. This 
particular method proved to be much more effective and less costly than the chemical cleaning method. Process and equipment optimization continues to be an ongoing high priority for this method of cleaning as cleaning of the boiler can be on the shutdown maintenance plan critical path.

\section{$\underline{\text { Steam Drum }}$}

Other than routine inspections, there was no maintenance, downtime, or operational problem associated with the steam drum during the Operating Period.

\subsubsection{Summary and Conclusions}

During the Operating Period, the significant contributor to plant downtime and maintenance expenditures associated with the syngas cooling/steam generation system was deposition in the gas side of the boiler tubes. An acceptable mechanical cleaning method was developed to effectively remove these deposits. Optimization of this process continues to be made to further reduce the time required when performing this procedure. Studies also continue to determine if an additive in the gas stream prior to the boiler can be used to mitigate deposition in the unit. The major challenge for reliable operation of the syngas cooling/steam generation system is to effectively manage deposition on the gas side of the boiler tubes. 


\subsubsection{Particulate Removal System}

The particulate removal system includes:

\begin{tabular}{|l|l|}
\hline Primary char filters & Primary char recycle ejectors \\
\hline Secondary char filters & Secondary char ejectors \\
\hline Pulse gas accumulator drum & \\
\hline
\end{tabular}

The particulate removal system is used to remove char and ash from the syngas stream and recycle it back to the first stage gasifier. The system is located in the syngas path just downstream of the syngas cooler/steam generation process. The particulate removal system consists of two parallel-configured primary filter vessels with char recycle ejectors, secondary or backup char filters with char ejectors, and a pulse gas accumulator drum. Refer to the process description section for additional details concerning the operation of this system.

\subsubsection{System Modifications}

Prior to the Operating Period, problems in the particulate removal system contributed significantly to the total plant downtime. This section will describe modifications made to this system to improve its reliability and reduce operating and maintenance expenditures.

During the 1995-1996 start-up and commercial Operating Period, a number of hot gas filter system reliability problems were quickly identified and corrected. During the initial plant startup char breakthrough was experienced in the primary candle filter system, which initially incorporated ceramic candles mounted to fixing hardware in a tie-rod type system. The source of this leakage was found to have occurred from inadequate sealing gasket at both the tie-rod element hardware and filter tubesheet flange connections. These problems were easily resolved by changing gasket materials in the tie-rod elements and by implementing a number of small changes in the tubesheet flange design. As run-time accumulated, more difficult challenges were realized as ceramic candle failure and bridging of solids between the filters began to occur.

During plant start-up, it was soon realized that backpulse pressures measured within the candle filters were insufficient and therefore could not provide the proper amount of backflow necessary 
to effectively remove the char cake from the filters. As a result, the filter elements were not cleaned sufficiently and solids accumulated and bridged between the elements. This eventually led to a loss of filter area, high system differential pressures and failures of multiple filter elements.

Investigation into this problem showed that a number of key components within this system were undersized in the original design. To provide optimal system operation, the backpulse system components were re-designed and replaced.

Bridging of solids between the elements also occurred as a direct result of mixing filters with various hours of operation on them. This practice also led to failures in the elements. It was soon realized that elements of different operating "age" have different permeabilities, i.e., resistances to flow through them. Mixing these elements led to flow imbalances within the filter system. This flow imbalance could be quite severe immediately following the backpulse event. As a result, both bridging and failures occurred in the newer elements. Filter conditioning periods during plant start-up and changes in vessel element loading practices were used to mitigate this problem.

Frequent element failures during the first year of operation caused at least five (5) major plant outages. Element breakage resulted from a number of sources, such as those mentioned in the preceding paragraphs as well as improper handling during maintenance, and design problems in the hardware used to affix the filters to the tubesheets. After many attempts to improve the filter hardware system, it became evident that many of these design problems were quite complex and, as a result, the system was retrofitted with metal candles late in 1996. Metal candles immediately improved the reliability of the particulate removal system. Several years of operating experience were necessary to develop an optimal metal alloy and filter construction to provide adequate filter life.

Certain types of candle filters display a much more rapid blinding rate (loss of permeability) than others when operated in the particulate removal process. Two factors have been found to contribute significantly to this phenomenon. They are vapor phase condensation of trace metal 
compounds on the element surface, and small particle penetration into the element surface pore structure.

The mechanism for how these two interact to blind the candle continues to be an area of intense study. This blinding results in a gradual increase in the baseline differential pressure across the primary filter vessels. At some point, the differential pressure becomes so high that effective backpulsing cannot be achieved. The "seasoning" or "conditioning" of a new filter in operation involves the accumulation of char on the candle surface that is not dislodged during the backpulse event. This permanent, or residual, layer causes the upward shift in baseline differential pressure across the filter during the conditioning period. During normal candle filter operation, once the conditioning period is over, the increase in baseline differential pressure across the primary filter should be minimal. However, when operating certain types of filters in the Wabash River process, the permeability is reduced rather rapidly in both the residual char layer and the filter substrate as a result of condensation of metal compounds. This rapid rise in primary filter differential pressure has forced the plant into a number of unplanned outages. Numerous blinding studies have been conducted for virtually all commercially available filters to determine which ones will provide an optimal life. As a result, filters that provide adequate operating time between scheduled plant outages have been found. Off-line cleaning methods have also been developed to allow many of these filters to be re-used.

Another form of filter blinding that happened on at least one occasion prior to the Operating Period was caused by condensation of organics (tars) on the primary candle filter surface. This resulted in a rapid loss in filter permeability. Tars were removed from the filters utilizing offline cleaning techniques. Improved procedures were used to reduce tar production and eliminate this type of blinding.

Another source of candle breakage and bridging was caused by inadequacies within the primary vessel internal gas/solids distribution system. High filter impingement velocities from the particulate-laden syngas exiting the internal gas distributor caused erosion of filter surface and resultant element blinding at certain locations. Filter permeability was totally lost in these high wear areas on the element surfaces. High erosion rates on some distributor parts also yielded 
low component life. Computational flow dynamics (CFD) modeling was used to optimize the design of the existing distributor system. A number of improvements were implemented to this system to significantly improve component life and reduce filter impingement velocities.

Operational problems in several backpulse valves caused some plant downtime prior to the Operating Period. Sticking instrument air slider/solenoid mechanisms were the first major problem areas to develop in these valves. The valves were retrofitted with an alternate manufacturer's slider/solenoid assembly to eliminate this problem. Pre-start-up audits to verify normal backpulse valve operation also helped to minimize outage time caused by this equipment. Additional backpulse valve problems developed as a result of a number of control disk seat failures that happened prior to the Operating Period. Refer to the next section for more detail concerning the seat failures.

Prior to the Operating Period, high erosion rates in the char recycle ejectors and associated piping systems caused a number of plant outages. High solids loading in the char recycle gas was found to be the root cause for this problem. Since design recycle gas velocities were already at the minimum required to keep the solids moving, material changes were necessary in the piping systems at key high wear locations. Harder, more abrasion-resistant materials were incorporated in the piping at these locations to mitigate this problem.

Most char ejector failures were caused by interference problems between internal parts caused by thermal expansion differences and design problems in the interlocking mechanisms of these parts. The life-limiting internal components were redesigned and upgrades in materials of construction were used to improve char recycle ejector life.

The secondary filtration system is designed to serve as a backup to the primary filter vessels. Its purpose is to contain any solids that may breakthrough the primary filter system due to filtration inefficiencies or failures. This system was installed to protect downstream equipment such as COS catalyst beds and heat exchangers from char particulate contamination. Early on in plant operation, several key design problems became evident. The holding mechanism that affixed the filters within their containing vessels was found to be inadequate. Filters were also being 
damaged during the backpulse event. Stronger holding mechanisms and better filter element constructions were implemented to improve the reliability of this system.

Another problem that became evident early on in this system was low filter internal pressures being generated during the backpulse event. As in the primary filter system, this resulted in low reverse flows and resultant poor cleaning efficiencies. Key backpulse system components were resized to overcome this problem.

\subsubsection{Operating Experience Overview}

The total downtime associated with the particulate removal system during the Operating Period was 152 hours. Operating experience for individual pieces of equipment follows.

\section{Primary Char Filter}

During the Operating Period, there were two separate events in which primary filters failed and forced the plant to be taken off line. The first event that forced the plant into an outage was caused by a failure, and subsequent char breakthrough, of several metal candle filters. The initial char breakthrough was first noticed approximately two weeks prior to a scheduled plant outage and, as a result, only accounted for 25 hours of plant downtime. The plant remained on line for a period of time until the solids breaking through finally overwhelmed downstream equipment. In an effort to gather additional data on metal filter corrosion rates, a test panel of two previously operated filters was installed in one of the primary vessels prior to the campaign. All other filters in the primary vessels were new. Metallurgical support personnel had predicted the filters could last well beyond the Operating Period. However, the filters became weakened by corrosion and eventually failed during a backpulse event. During this campaign it became evident that changes in process conditions had accelerated corrosion rates and rendered the previous data used for life predictions inaccurate. Knowledge gained from this experience was used to implement a number of process changes to better control the rate of corrosion in these metal filters. The use of failsafe devices was also implemented for all test filters in subsequent operating campaigns. A failsafe is a device that protects against particulates entering downstream equipment in the event of a primary filter element failure. 
During the second forced plant outage caused by solids breaking through a primary filter a failsafe device was used. This particular event involved a test panel of ceramic filters. A new and novel way to affix these filters into the tubesheet had been developed and was being tested during this campaign. Several days into the campaign, a small amount of char was found to be breaking through the primary filter. It remained fairly steady at a low rate and was manageable. After approximately 35 days of operation the fail-safe located over the leaking filter failed and the solids breaking through quickly overwhelmed downstream equipment. The plant downtime associated with this failure was approximately 61 hours. The root cause for the filter failure was determined to be from dimensional interferences in the hardware used to affix the ceramic elements into the tubesheet. The manufacturer of these parts supplied a number of them out of dimensional specifications. As a result, one test filter was damaged during assembly and the location of the damage was such that it could not be detected during assembly and installation. Evaluation and restructuring of supplier quality control procedures were implemented to mitigate these problems. A manufacturing method to increase fail-safe media strength was also developed to enhance the reliability of these devices.

Repairs to the primary filter internal gas distributor system also accounted for 18 hours of lost production during the Operating Period. Improvements made to this system prior to the Operating Period have increased component life significantly. However, high erosion rates remain in certain key locations within the distributor system. New areas of wear that had previously not been detected were found during a scheduled plant outage. Gas impingement from holes in the distributor system was directed toward the vessel walls and resulted in unanticipated repairs that extended the scheduled outage time. Panels of wear-resistant materials were installed in these locations to extend component life and mitigate this problem.

During the Operating Period, approximately 24 hours of downtime was associated with a flange leak and subsequent fire that developed in the gas inlet piping to the primary char filter vessel. The leak was found to have been caused by movement in the piping system encountered when new inlet ball valves were installed during a previous outage. Installation of the new valves did not include inspection or pressure testing of flange connections that were not disturbed. Inspection procedures were changed to prevent this sort of problem from occurring again. 
The original installation used butterfly valves to provide isolation in the gas inlet piping to the primary filters. These valves suffered high rates of erosion resulting from the gate being located in the center of the particulate laden gas stream when in the open position. Additionally, high erosion rates were found in the piping just downstream of these valves. Gas turbulence from flow around the butterfly gates was determined to be the root cause for this high rate of material loss. Excessive repairs were required for both the butterfly valves and associated downstream piping during scheduled plant outages. The isolation valves were replaced with new high alloy full-port ball valves thereby eliminating the associated maintenance requirements. During the initial campaign with these new valves, problems were encountered with the hydraulic actuators that accounted for 6 hours of additional plant downtime. The supplier implemented a number of changes to the hydraulic system to improve its reliability.

There were 6 hours of plant downtime that were attributable to problems in the backpulse system for the primary particulate removal filter. A backpulse valve failed early in an operating campaign resulting in the above-mentioned downtime. The valve was found to be leaking pulse gas through at an excessive rate. The valve was found to have a damaged control disk seat. Earlier investigation into similar problems had determined that valve body distortion caused by thermally induced pipe stress was the most likely cause of these failures. A pulse gas pre-heater used during system start-up was left in operation and the elevated temperature likely contributed to higher induced stresses and the resultant seat failure. New and improved valve seats were installed in the valve to make them more reliable. The new seats are designed to better handle this valve body distortion and, as a result, there have been no failures since they were installed.

Another problem associated with these backpulse valves was in the retaining nut that connects the control disk to the stem. When replacing the control disk and seat with new and improved parts, this nut was removed, reinstalled and tightened to within the manufacturer's specifications. Several of the nuts came loose during operation. This problem did not force the plant to be taken off line or cause a capacity reduction, but it did result in removal of some filtration area for the campaign. New higher torque specifications and replacement nuts and lock washers were used to rectify this problem. 


\section{Primary Char Recycle Ejectors}

On three separate occasions during the Operating Period, problems in the char recycle ejectors contributed to plant downtime. The first event, which accounted for 6 hours of plant downtime, resulted from a manufacturing error in one of the ejector internal components. A dimensional discrepancy and resultant thermally induced interferences led to a premature failure in this ejector. More stringent quality control was implemented to address this problem. The last two events were a result of degradation in ejector performance caused by high wear rates in key internal motive gas section parts. These two events combined accounted for 7 hours of plant downtime. Upgrades in materials of construction were used to extend the life of these parts.

\section{Secondary Char Filters}

There was no downtime attributable to the secondary filter system during the Operating Period. However, continued failures in the filter holding mechanisms led to investigations into better ways to backup the primary filter. Fail-safe devices are continuously being evaluated both for reliability and efficiency in the particulate removal slipstream and primary systems. Through accumulated operating experience and design enhancements, a reliable and efficient fail-safe was developed. During the Operating Period, fail-safes began to be used regularly in all filters of questionable reliability and eventually replaced the secondary filter system.

\section{Other Equipment}

There was no maintenance, downtime or operational problem associated with the pulse gas accumulator drum during the Operating Period.

\subsubsection{Summary and Conclusions}

Figure 5.3.6A is a chart that shows the percentage of total downtime hours attributable to the particulate removal system as well as plant outage hours caused by other gasification plant processes and the combined cycle power generation facility. In 1996, difficulties in the particulate removal system made up over $39 \%$ of the total plant downtime. As particulate removal system improvements were implemented, its operation improved in 1997 with the total attributable downtime being reduced to around 17\%. Additional improvements in 1997 and 
early 1998 have further reduced the particulate removal system downtime hours to less than 6\% of the total.

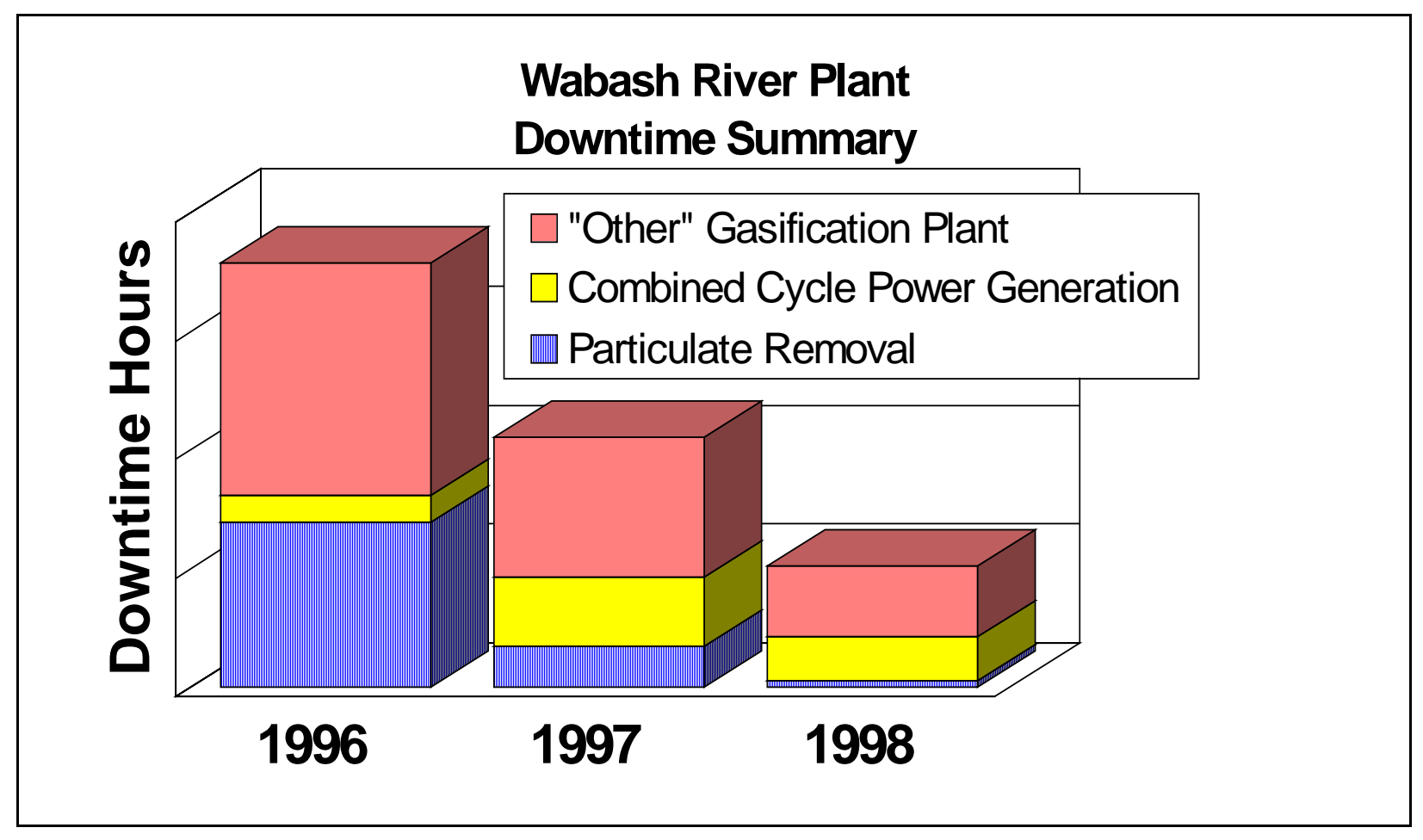

Figure 5.3.6A: Wabash River Plant Downtime Summary

Since plant start-up, there have been many design and materials of construction changes that have been implemented to significantly increase the reliability of the Wabash River particulate removal system. However, opportunities remain for improving the system in order to meet specific performance goals that will further reduce operating and maintenance expenditures. A number of key areas continue to be intensely studied and improved. Accelerated filter blinding continues to be a concern and is an area of keen interest in filter development work. Filter corrosion is also a concern when operating with metal candle filters, especially if higher sulfurcontaining feedstocks are used. There is still a need to further improve the internal gas distribution system to extend component life and minimize filter gas impingement velocities. 


\subsubsection{Chloride Scrubbing System}

The chloride scrubbing system includes:

\begin{tabular}{|l|l|}
\hline Syngas cross-exchanger (Figure 5.3.7A) & Syngas cooler (Figure 5.3.7A) \\
\hline Chloride scrubber (Figure 5.3.7A) & Knockout drum (Figure 5.3.7A) \\
\hline Scrubber knockout level control drum & Sour water cross-exchangers \\
\hline
\end{tabular}

The chloride scrubbing system was installed in September of 1996 to eliminate two problems. First, chloride in the gas stream was causing chloride stress-corrosion-cracking of the low temperature heat exchangers and piping systems. Second, the chlorides and trace metals, primarily arsenic, were blinding the carbonyl sulfide (COS) hydrolysis catalyst. Installation of the system successfully eliminated both of these problems.

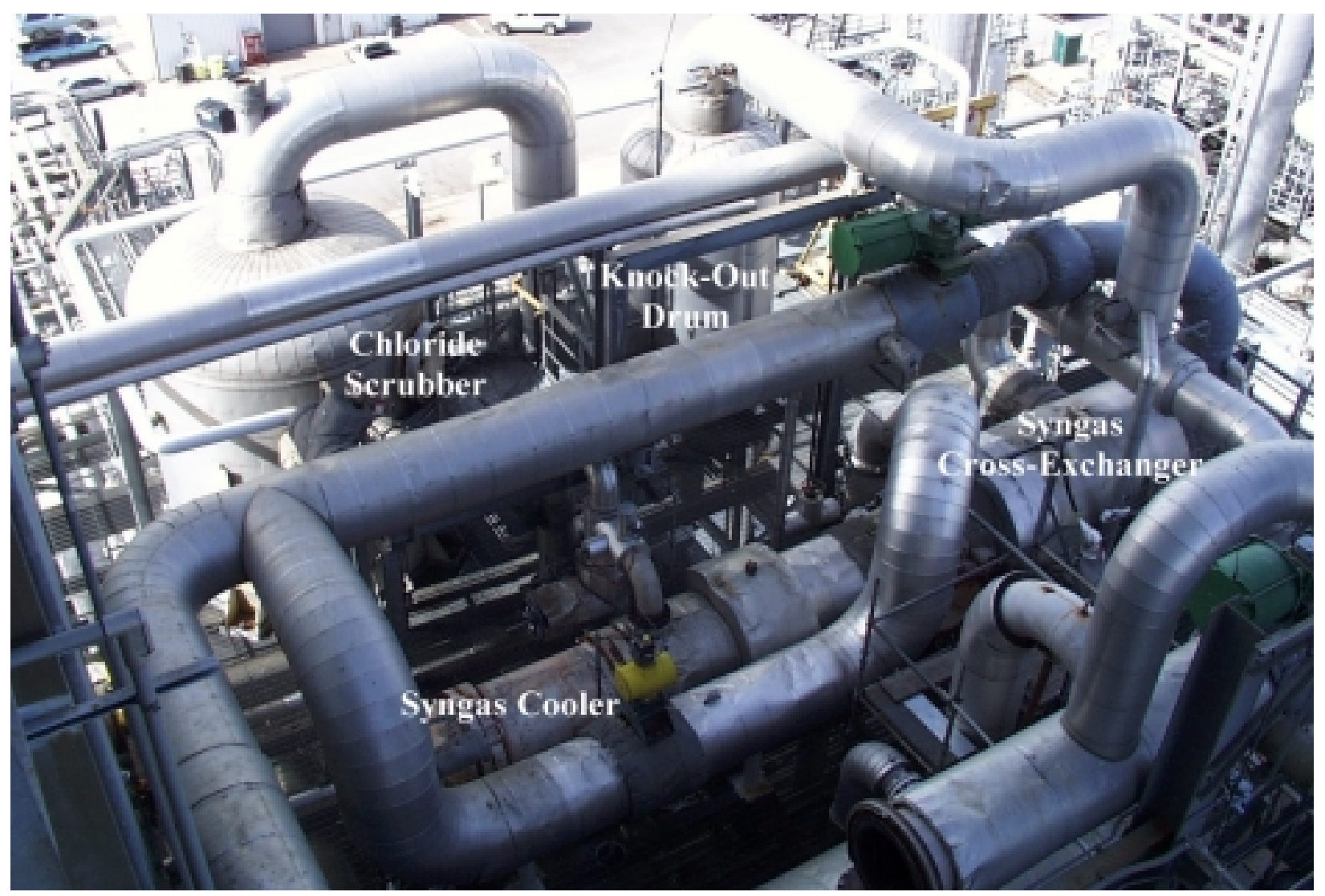

Figure 5.3.7A: Major Equipment Associated with the Chloride Scrubbing System 


\subsubsection{System Modifications}

The chloride scrubbing system came on line in October of 1996. The system performed as expected with very few modifications. In the first seventeen months of operation, the packing in the chloride scrubber required removal for cleaning three times due to the accumulation of tars. On one occasion, the differential pressure across the vessel forced the plant off line, resulting in 249 hours of downtime to clean the packing. In early 1998, process conditions upstream of the scrubber were altered to reduce the formation of tars. Since that time, the packing has not required removal for cleaning. Several syngas leaks from the inlet piping flange of the chloride scrubber resulted in 38 hours of downtime and one additional syngas leak from an improper gasket on the outlet flange of the syngas cross-exchanger resulted in 8 hours of downtime in the first year of its operation. During a planned outage in December of 1997 the chloride scrubber inlet piping flange was removed, re-worked to ensure a proper gasket-sealing surface, and placed back in the piping system. As a result of the re-work, this piping flange has operated trouble-free since that time.

\subsubsection{Operating Experience Overview}

The total downtime associated with this chloride scrubbing system during the Operating Period was 10 hours. Operating experience for individual pieces of equipment follows.

\section{Syngas Cross-Exchanger}

With one exception, the syngas cross-exchanger operated as expected during the Operating Period. In December of 1998, the cross-exchanger experienced tube fouling that prevented it from maintaining the desired syngas superheat temperature entering the COS hydrolysis system. Allowing a small amount of particulate-laden syngas to bypass the dry char system into the cross-exchanger facilitated on-line cleaning of the cross-exchanger but the downstream sour water carbon filter was quickly plugged. Fortunately, the spare sour water carbon filter was available so that the plugged filter could be back-washed without interruption to syngas production. Consequently, no downtime was associated with this equipment in the Operating Period. 


\section{$\underline{\text { Syngas Cooler }}$}

The original installation included a water spray at the inlet of the syngas cooler, which could be used for cleaning the exchanger tubes on line. This system proved to be unsuccessful in cleaning on more than one occasion. Use of the water spray resulted in syngas leaks at the exchanger flanges due to thermal growth difference caused by the cold spray on the hot exchanger. This system was completely removed after a failure of the spray nozzle caused the plant to come off line in January of 1999, resulting in 10 hours of downtime. With the exception of this failure, the system operated without incident for the Operating Period.

\section{Chloride Scrubber}

Other than routine inspections, maintenance associated with the chloride scrubber during the operation period was limited to two repairs to the outlet piping. A defective piping ell, combined with downtime corrosion, led to polythionic stress-corrosion-cracking in the ell. The sour water leaking from the ell was stopped with the placement of a temporary pipe repair clamp while the plant was on line and then replaced during a subsequent outage. No downtime was associated with this equipment during the Operating Period.

\section{$\underline{\text { Scrubber Knockout Level Control Drum }}$}

Although no downtime was associated with this equipment during the Operating Period, three sour water leaks from the outlet piping system required repair. These piping failures occurred in the welds as a result of high mechanical stresses on this line. The outlet isolation valve on the drum was relocated to allow on-line maintenance of the piping system and an additional piping support was added to reduce the line stress. In addition, debris is routinely cleaned from this drum during planned outages.

\section{$\underline{\text { Sour Water Cross-Exchangers }}$}

During the three planned outages in the Operating Period these two exchangers were flushed and cleaned by Operations personnel to remove sludge that accumulates during operation. No downtime or operational problems were associated with these exchangers during the Operating Period. 


\section{Other Equipment}

There was no maintenance, downtime or operational problem associated with the knockout drum during the Operating Period.

\subsubsection{Summary and Conclusions}

The chloride scrubbing system has proved effective in removing chlorides and trace metals that damage downstream equipment and piping and that deactivates the COS hydrolysis catalyst. The system has operated as expected since it was installed in September of 1996. Early problems with excessive tar formation in the chloride scrubber were resolved early in 1998. Occasional removal of the packing from the chloride scrubber for cleaning will still be necessary but should not be required more frequently than biennially. After the Operating Period, a shutdown procedure was developed to flush the liquid outlet piping from the chloride scrubber so that downtime corrosion could be minimized. Flanges were also installed in this piping to facilitate inspections of the piping to insure downtime corrosion is under control. Routine maintenance associated with this system is now limited to routine inspections of the equipment and piping and cleaning of the sour water cross-exchangers and the sour water level control drum. 


\subsubsection{Carbonyl Sulfide (COS) Hydrolysis System}

The carbonyl sulfide (COS) hydrolysis system includes two COS reactors. Refer to the process description for more process details of this system.

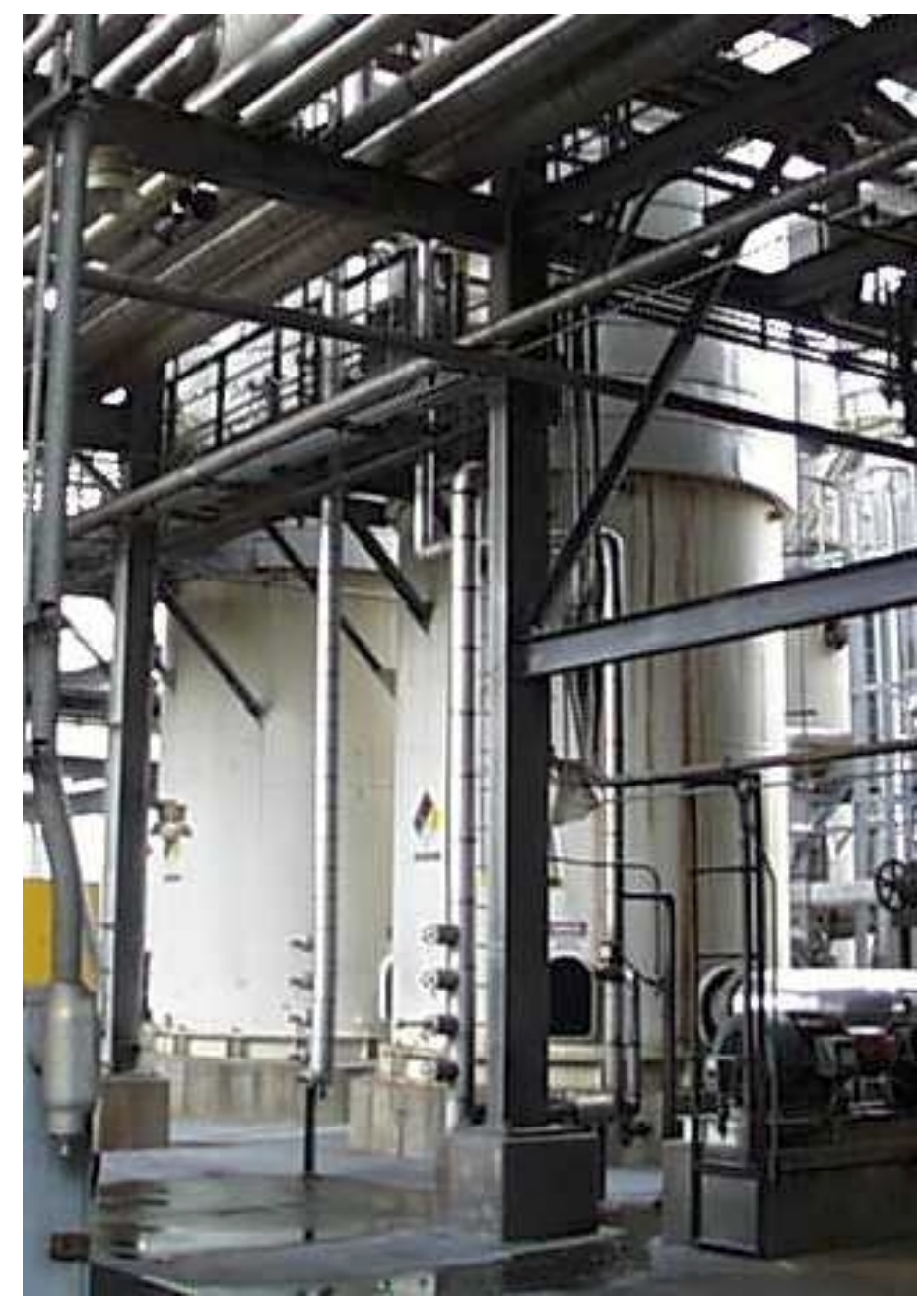

Figure 5.3.8A: Carbonyl Sulfide Reactors

\subsubsection{System Modifications}

The chlorides and trace metals contained within the coal caused premature equipment failures downstream and deactivation of the original COS hydrolysis catalyst. The catalyst used at startup lasted approximately 700 hours due to chlorides and trace metals occupying active sites on the catalyst. The sampling and replacement of the catalyst occurred frequently prior to the successful implementation of the chloride scrubbing system (Refer to Section 5.3.7). The 
chloride scrubbing system installed in September of 1996 effectively addressed these concerns as well as metallurgy concerns with chlorides further downstream in the process.

Additional efforts were undertaken in early 1996 to identify cost-effective catalysts for the carbonyl sulfide reactors. To test and evaluate the COS hydrolysis catalyst of various manufacturers, a small slipstream unit was implemented at the Wabash River site. Several manufacturers' COS hydrolysis catalysts were tested in the slipstream unit to provide additional data into the selection of a replacement COS hydrolysis catalyst.

Other process improvements were implemented on the COS reactors prior to the Operating Period that reduced downtime and maintenance. These process modifications targeted improvements to the COS reactors' heat-up and cooldown system, extension of COS catalyst life, and equipment reliability.

The COS reactors are in the critical path during maintenance outages due to the duration of time required to heat and cool these vessels. The COS hydrolysis system logged 277 hours of downtime associated with the heat-up and cooldown of equipment prior to the Operating Period. The reactors were modified in October 1995 to accommodate activated carbon in addition to the COS hydrolysis catalyst. The carbon acts as a guard bed to prevent trace compounds in the syngas from fouling the catalyst and downstream equipment. Improvements were implemented on the COS reactors heat-up and cooldown system in April of 1997 to increase plant availability, decrease maintenance expenses, and reduce nitrogen consumption. Nitrogen is used for heat-up and cooldown of the system. The improvements included the addition of a heat exchanger and permanent piping system. The addition of this equipment reduces the heat-up and cooldown duration, which conserves nitrogen and eliminates the need to install temporary equipment each maintenance outage, resulting in a safer operation. An additional piping modification was made to this system in December of 1999 that enables gasifier maintenance to commence while the COS reactors continue in the cooldown process. This improvement further reduces the plant maintenance outage duration. 
The manual block valves on the COS reactors' inlet and outlet piping were modified to improve the operability of the valves. Bearing protectors and flush connections to inject grease were added to prevent the build-up of solids and to assist the smooth operation of the valves.

\subsubsection{Operating Experience Overview}

There was no downtime associated with the COS hydrolysis system during the Operating Period. Operating experience for individual pieces of equipment follows.

\section{Carbonyl Sulfide Reactors}

Other than routine inspections, the maintenance associated with the COS hydrolysis system during the Operating Period was limited to replacement of the activated carbon and a piping modification that enables the carbon to be removed in an inert atmosphere. When the carbon was replaced during the June 1998 outage, additional carbon was added to each of the COS reactors. This additional volume of carbon, plus improvements made in plant operations, has tripled the useful carbon bed life and decreased the frequency of change outs. No downtime was associated with this equipment during the Operating Period.

\subsubsection{Summary and Conclusions}

Since start-up of the chloride scrubber system and replacement of the COS hydrolysis catalyst, this system has performed per design. The process improvement plan to identify alternative hydrolysis catalysts, less prone to poisoning from both chlorides and trace metals within the syngas was successful. An alternative catalyst was identified and installed in October of 1996 and has demonstrated high performance in the hydrolysis process with minimal degradation in performance over extended run-time. Routine maintenance associated with this system is now limited to the replacement of COS catalyst and activated carbon. The operating life projection for the COS catalyst and activated carbon is 5 years and 1.5 years, respectively. 


\subsubsection{Low Temperature Heat Recovery System}

The low temperature heat recovery system includes the following equipment:

\begin{tabular}{|l|l|}
\hline Amine boiler (Figure 5.3.9A) & $\begin{array}{l}\text { Sour gas condensate condenser } \\
\text { (Figure 5.3.9A) }\end{array}$ \\
\hline Sour water level control drum & $\begin{array}{l}\text { Sour water cooling tower water condenser } \\
\text { (Figure 5.3.9A) }\end{array}$ \\
\hline Sour water condenser (Figure 5.3.9A) & Sour gas knockout pot (Figure 5.3.9B) \\
\hline Sour water receiver (Figure 5.3.9B) & $\begin{array}{l}\text { Syngas Recycle compressor knockout drum } \\
\text { (Figure 5.3.9B) }\end{array}$ \\
\hline Second stage gasifier quench water pumps & Syngas recycle compressor (Figure 5.3.9B) \\
\hline
\end{tabular}

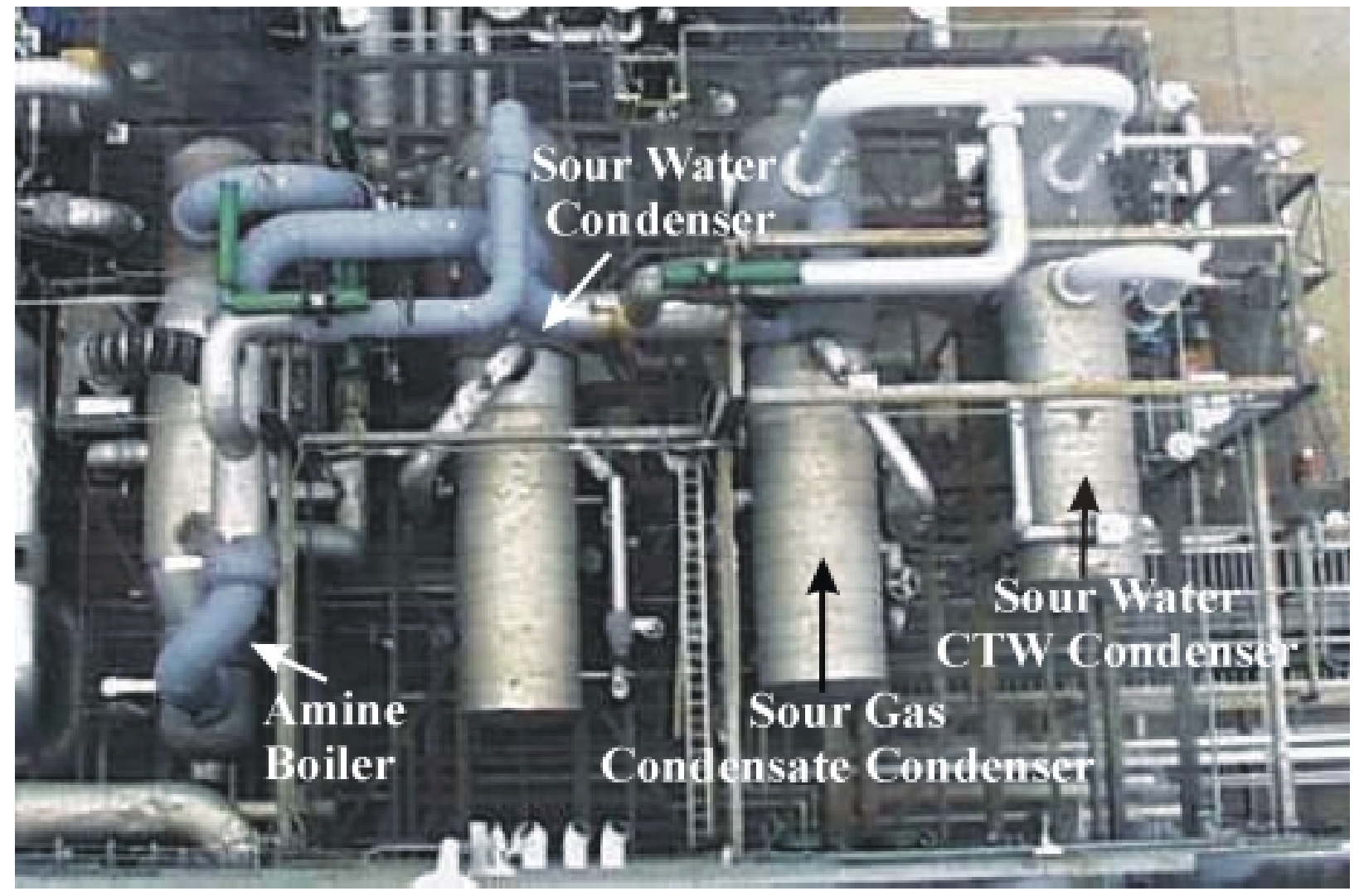

Figure 5.3.9A: Heat Exchanger Deck for Low Temperature Heat Recovery

\subsubsection{System Modifications}

During the first year of operation, the low temperature heat recovery system accounted for 1,682 hours of plant downtime. Fouling of exchangers in this system was frequent and the location and 
size of these exchangers required large cranes every time maintenance was needed. Obtaining tight seals on the exchanger heads after maintenance also proved difficult, resulting in syngas leaks on more than one occasion. Chlorides in the syngas aggressively attacked the exchanger tubes and tube leaks often brought the plant off -line. In June of 1996, a new amine boiler, constructed from tube material impervious to chloride stress-corrosion-cracking, was installed. A month later the tube bundle in the sour water condenser was replaced and, in September of 1996, the chloride scrubbing system was installed. The chloride scrubbing system virtually eliminated all of the chloride problems in the low temperature heat recovery system. The chloride scrubbing system also removed the material that caused the exchangers to foul, thus eliminating the need for frequent and expensive exchanger cleaning.

During the first year of operation, the sour water cooling tower water condenser (the last of the exchangers in this system) developed several tube leaks not associated with chlorides. The inlet velocity to the exchanger was so high that the tubes near the entrance vibrated, resulting in mechanical fatigue failures of the tubes. In June of 1996, an impingement baffle was installed to disperse the incoming gas flow. There have been no tube failures following the installation of the baffle.

Of the total downtime listed, 642 hours was associated with the syngas recycle compressor. Much of this downtime resulted from the failure of one of the impellers of this 10,500-rpm machine. The root cause of the failure could not positively be identified, but was likely due to off-spec dimensional properties on the failed impeller coupled with fatigue loading in a corrosive environment. Installation of the chloride scrubbing system significantly reduced the corrosiveness of the syngas environment and thus has increased the reliability of this machine.

The machine was also subjected to severe fouling on several occasions, ultimately necessitating disassembly of the machine to replace the fouled rotor with a spare. Repeated failure of one of the seals in the machine also prompted the original equipment manufacturer to redesign the seal and install the modifications in the compressor. Operating procedures on the compressor were modified to mitigate fouling and a procedure was developed to clean the machine on line. Additionally, the recycle compressor knockout drum was fitted with a mist eliminator to reduce 
liquid entrainment into the machine further reducing the fouling potential of the syngas. Prior to the Operating Period, the recycle compressor knockout drum occasionally experienced high liquid levels due to partial plugging in the outlet line. An atmospheric blowdown line was installed from the drum to the waste water sump to allow restrictions in the line to be safely cleared while the plant was on line.

The syngas recycle compressor also experienced high vibrations that caused the machine to trip on several occasions. Replacement of some components on the high-speed coupling alleviated the vibration, although the coupling manufacturer could not find any defects in the part returned for failure analysis

\subsubsection{Operating Experience Overview}

The total downtime associated with the low temperature heat recovery system during the Operating Period was 7 hours. Operating experience for individual pieces of equipment follows:

\section{$\underline{\text { Amine Boiler }}$}

Although no downtime, maintenance or operational problems were associated with the amine boiler during the operational period, the piping connected to this exchanger was removed and inspected for residual cracks that were formed prior to the installation of the chloride scrubbing system. The cracks that were inspected did not show appreciable growth since they were last measured.

\section{Sour Water Level Control Drum}

During a vessel inspection in December of 1998, severe pitting below the normal liquid level of the sour water level control drum was discovered. The pitting was initiated by high chlorides in the gas prior to installation of the chloride scrubber. The lower section of the vessel was re-clad and no additional pitting has been noted since the repair. There was no downtime or operational problems associated with this piece of equipment during the Operating Period. 


\section{$\underline{\text { Sour Water Receiver }}$}

During the three planned outages in the Operating Period, the sour water receiver was flushed and cleaned by Operations personnel to remove sludge that accumulates during operation. No downtime or operational problems were associated with this equipment during the Operating Period.

\section{Second Stage Quench Water Pumps}

During the Operating Period, the mechanical seal failed once on each pump and the coupling on one of the pumps was also replaced. During a routine outage, the pump was disassembled for inspection and the wear rings were replaced. No downtime or other operational problems were associated with this equipment during the Operating Period.

\section{$\underline{\text { Sour Gas Condensate Condenser }}$}

During the Operating Period the outlet temperature transmitter from this exchanger failed, which caused the syngas to completely bypass the exchanger. Since the bypass valve is much smaller than the main syngas valve, the downstream syngas recycle compressor was starved of gas and tripped on low-low first stage flow. The plant lost 4 hours of production due to the transmitter failure. The control code was re-written to prevent total closure of the main syngas valve, which will prevent recurrence of this problem. No other downtime, maintenance or operational problems were associated with this equipment during the Operating Period.

\section{Syngas Recycle Compressor Knockout Drum}

Early in the Operating Period the level transmitter on the recycle compressor knockout drum failed and, during the ensuing troubleshooting, the syngas recycle compressor was inadvertently tripped due to the human error. The resulting downtime was 3 hours. The recycle compressor knockout drum was opened one time during the Operating Period for inspection and to remove solids from the drum. No other downtime, maintenance or operational problems were associated with this equipment during the Operating Period. 


\section{Syngas Recycle Compressor}

The syngas recycle compressor shutdown during methane operations on three different occasions. The compressor tripped each time on low-low first stage flow as a result of start-up conditions, which starved flow to the machine. Because the plant was not on coal operation, none of the trips resulted in downtime. Modification to the start-up procedure as well as operator awareness of the potential low flow condition has alleviated this problem. As mentioned previously, instrument problems associated with the sour gas condensate condenser and the recycle compressor knockout drum forced the syngas recycle compressor off line two times during coal operation. During the latter of these two incidents, the syngas recycle compressor failed to restart on three successive attempts due to high thrust conditions. The root cause of the high thrust could not be determined and the machine started normally on the next attempt after allowing the motor windings to cool for one hour. During a subsequent routine outage, the axial thrust proximity probe was reset in an effort to mitigate the forgoing problem. No other downtime, maintenance or operational problems were associated with the syngas recycle compressor during the Operating Period.

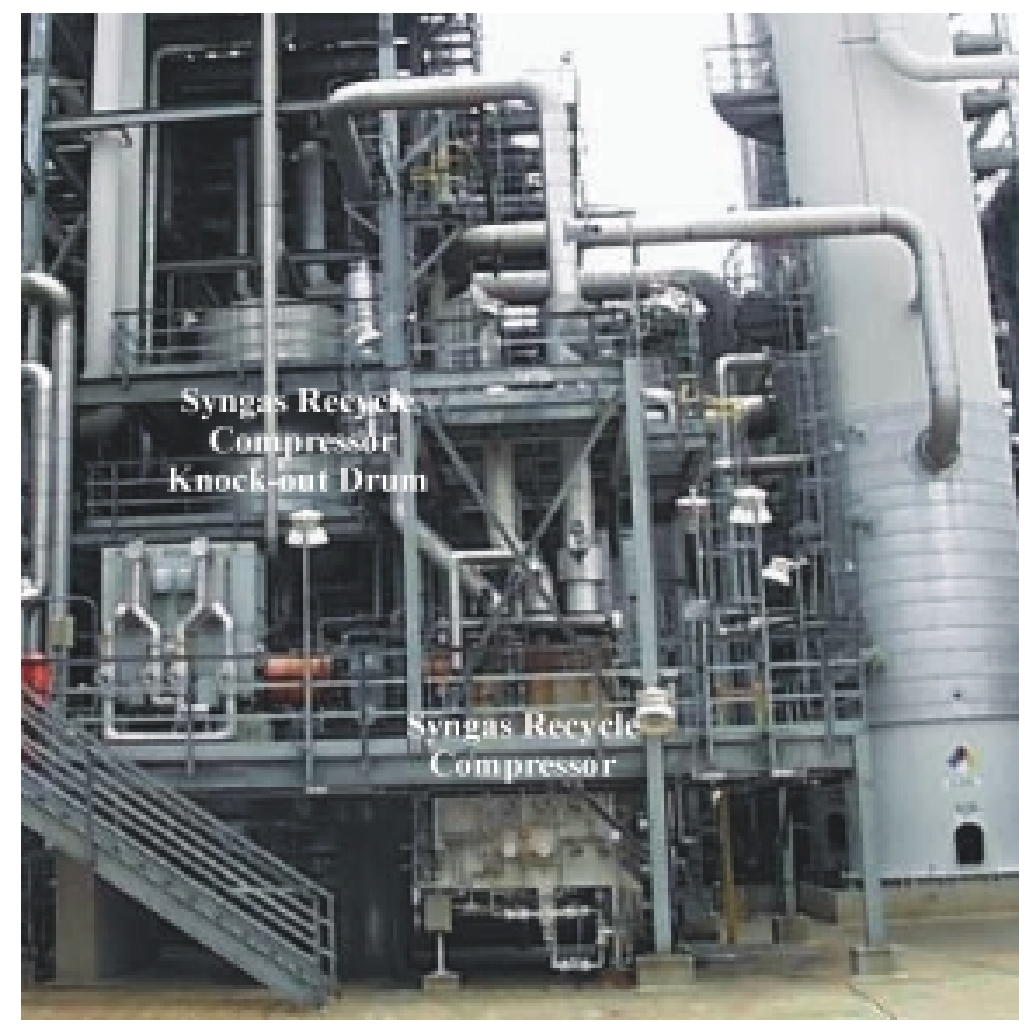

Figure 5.3.9B: Syngas Recycle Compressor and Knockout Drum 


\section{Other Equipment}

There was no maintenance, downtime or operational problem associated with the following equipment during the Operating Period: the sour water condenser, the sour water cooling tower water condenser, and the sour gas knockout pot.

\subsubsection{Summary and Conclusions}

During the first operating year, the low temperature heat recovery system experienced significant maintenance and was responsible for 1,682 hours of plant downtime. The root cause of most of this downtime was the high chloride content in the gas that caused rapid failures of the exchanger tubes and contributed to corrosion in the syngas recycle compressor. Since installation of the chloride scrubbing system in September of 1996 and other modifications made to the low temperature heat recovery system, the total downtime associated with this system has only been seven hours. Likewise, operational problems have been very few, and recent maintenance in this system has been limited to minor repairs to rotating equipment and cleaning and inspections of vessels during routine outages. 


\subsubsection{Syngas Moisturization System}

The syngas moisturization system includes:

\begin{tabular}{|l|l|}
\hline Syngas water saturator & Syngas water saturator recirculation pumps \\
\hline Syngas preheater & \\
\hline
\end{tabular}

Refer to the process description for more process details of this system.

\subsubsection{System Modifications}

Since start-up the syngas moisturization system has operated without any mechanical changes or process modifications to the system.

\subsubsection{Operating Experience Overview}

There was no downtime associated with the syngas moisturization system during the Operating Period. Operating experience for individual pieces of equipment follows.

\section{Syngas Water Saturator}

With one exception, the syngas water saturator has preformed flawlessly during the Operating Period. In February of 1999, the taps for the differential pressure transmitter froze. Operations personnel successfully thawed the taps by applying steam and no further problems were noted.

\section{Syngas Water Saturator Recirculation Pumps}

Other than replacement of the suction valve on one of the pumps and normal preventative maintenance, these pumps have operated trouble-free for the Operating Period.

\section{Syngas Preheater}

During the Operating Period, no maintenance or operational problems were associated with this piece of equipment. 


\subsubsection{Summary and Conclusions}

The syngas moisturization system has performed well since start-up. Occasionally the system

has had difficulty reaching the set point temperature but no other problems, downtime or operational concerns have been associated with this system since start-up. 


\subsubsection{Acid Gas Removal System}

The acid gas removal system includes:

\begin{tabular}{|l|l|}
\hline Acid gas absorber (Figure 5.3.11A) & Acid gas stripper (Figure 5.3.11A) \\
\hline Lean amine pumps & Acid gas stripper knockout drum \\
\hline MDEA storage tank & Acid gas stripper reflux drum \\
\hline MDEA cross-exchangers (Figure 5.3.11A) & Acid gas stripper quench pumps \\
\hline MDEA pre-filter & Acid gas stripper reboiler \\
\hline MDEA carbon bed (Figure 5.3.11A) & Acid gas stripper carbon beds \\
\hline MDEA post-filter & Acid gas stripper recirculation cooler \\
\hline MDEA CTW coolers & Acid gas preheater \\
\hline Lean amine transfer pumps & Acid gas stripper overheads filters \\
\hline MDEA reclaim unit & \\
\hline
\end{tabular}

Refer to the process description for more process details of this system. 


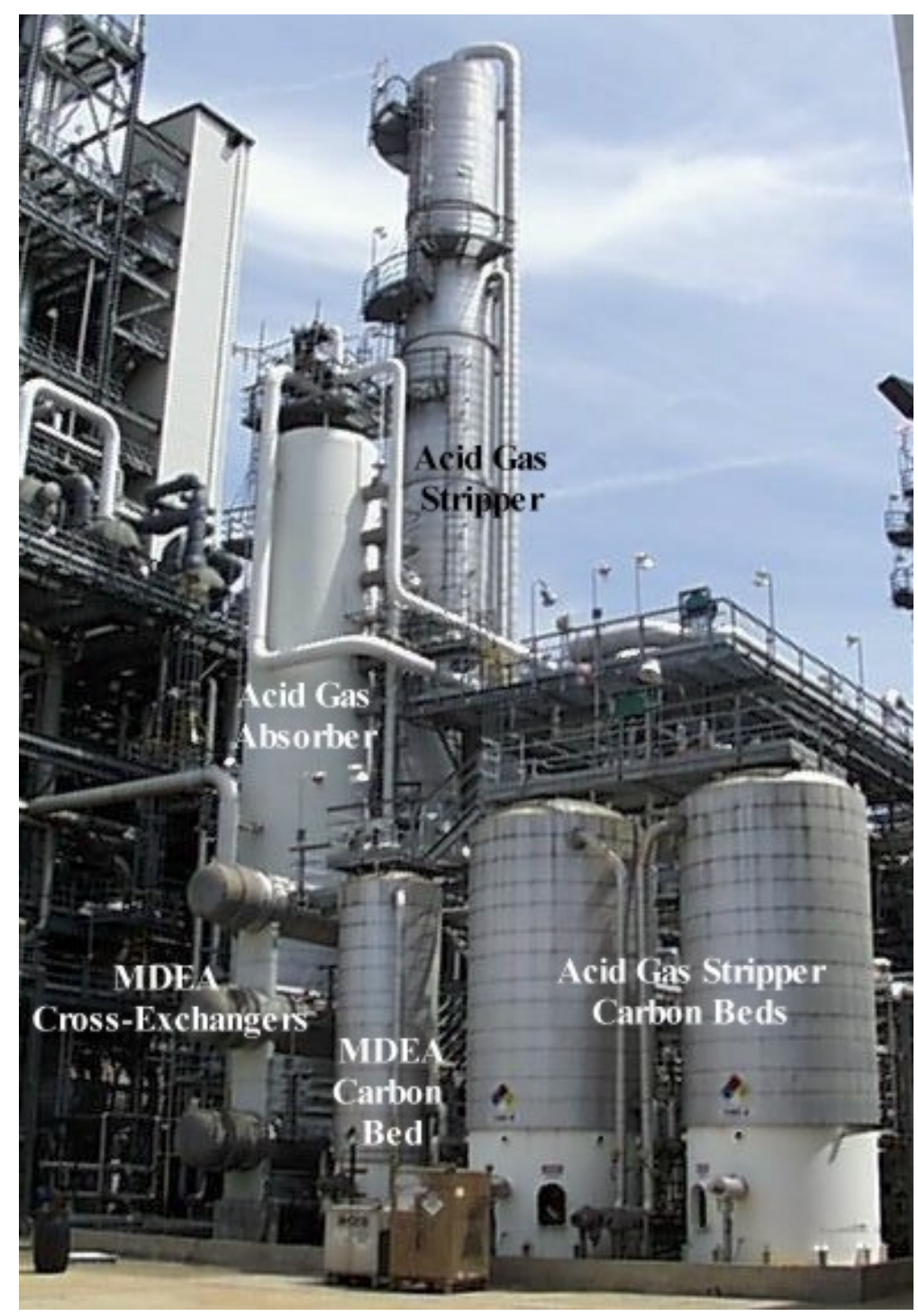

Figure 5.3.11A: Acid Gas Removal System Major Equipment

\subsubsection{System Modifications}

Prior to the Operating Period, modifications were made to the equipment within the acid gas removal system to increase reliability, decrease maintenance costs, or improve the safety of the equipment. Modifications to individual pieces of equipment are given below.

\section{$\underline{\text { MDEA Storage Tank }}$}

One significant process change prior to the Operating Period was the addition of an oxygen scavenger to the amine solution. Injected at the discharge of the MDEA storage tank, the oxygen scavenger serves two purposes. The oxygen scavenger consumes oxygen in the amine solution 
while also acting as a corrosion inhibitor by forming a thin passivation layer on the piping wall. Oxygen has been proven to breakdown amine, and leads to heat stable salt formation.

\section{Lean Amine Pumps}

Automatic recirculation valves were installed immediately downstream of the lean amine pumps to replace existing orifice plates in the lean amine pump recirculation line. When the $\mathrm{H}_{2} \mathrm{~S}$ concentration in the syngas is low, lower amine flow rates are required. Under this condition, the recirculation line passes a large fraction of the flow from the pump. With the original piping system, the pressure drop across the orifice plate created cavitation, which damaged the downstream piping creating a potential safety and environmental concern. Installation of the automatic recirculation valves eliminated the cavitation.

\section{$\underline{\text { Acid Gas Absorber }}$}

Stiffening members were added to four of the lower trays to increase the mechanical integrity. Under upset conditions, such as high differential pressure or high gas or liquid flow, the lower trays within the column suffered damage. Upon inspection, several of the trays were found to be resting on the tray below. Additional supporting members were installed to provide more resistance to the forces acting to collapse the trays.

To reduce heat stable salt accumulation, caustic was introduced into the amine solution. The caustic reacts with the heat stable salt liberating the MDEA for absorption of $\mathrm{H}_{2} \mathrm{~S}$. Excess addition of caustic; however, causes the system to reach the saturation concentration of sodium bicarbonate leading to salt precipitation onto the trays of the acid gas absorber creating high differential pressure. As a result of this type of incident, 30 hours of downtime were attributed to this system during the Operating Period. Consequently, the introduction of caustic as a means of reducing heat stable salt accumulation was terminated.

\section{MDEA Cross-Exchangers}

There are manual block valves located upstream and downstream on the rich amine side of the MDEA cross-exchangers. If these valves were to be closed, there existed the potential to overpressure the rich amine side of the exchanger as a result of thermal expansion of the amine. 
Therefore, a pressure safety valve was installed upstream of the block valve on the discharge side of the exchanger. The discharge from the pressure safety valve was directed to the MDEA storage tank to prevent any MDEA losses and personnel exposure.

\section{Acid Gas Stripper}

The acid gas stripper consists of a stripping section and a reflux section separated by a sump tray. In the stripping section, steam (generated by boiling water out of the amine solution) flows up through the column and strips the $\mathrm{H}_{2} \mathrm{~S}$ and $\mathrm{CO}_{2}$ from the amine. The amine solution is introduced on the tray below the sump tray. Upon start-up of the system, a significant amount of amine was being entrained with the steam and acid gas stream. The entrained amine solution caused appreciable MDEA losses and prevented proper blow down of the acid gas stripper reflux drum, which is necessary for ammonia control. Therefore, a demister pad was installed directly below the sump tray to knockout the entrained amine. Additionally, modifications were made to the sump tray to improve the seal and prevent quench water from falling into the stripping section and diluting the amine.

Prior to the Operating Period, a potential overpressure scenario was identified in the acid gas removal system. To protect these systems against this overpressure scenario, a pressure rupture disk was installed downstream of the acid gas stripper. Gases released from this pressure rupture disk would then be burned at the flare.

\section{MDEA CTW Cooler and Acid Gas Stripper Recirculation Cooler}

For personnel safety and environmental considerations, the pressure safety valves on these two heat exchangers were removed. The discharge of these pressure safety valves was directed to the grade in an area where operators frequently walk during their rounds. The liquid discharged would contain dangerous levels of $\mathrm{H}_{2} \mathrm{~S}$. Therefore, the pressure safety valves were removed and the manual block valves were locked open and tagged to prevent the possibility of overpressuring the respective equipment. 


\section{MDEA Reclaim Unit}

The MDEA reclaim unit uses an ion exchange resin that has a thermal degradation temperature of approximately $200^{\circ} \mathrm{F}$. The resin manufacturer warns that continuous exposure to temperatures in excess of $150^{\circ} \mathrm{F}$ will cause appreciable damage. Cold condensate is used to rinse the resin after the MDEA, displacing solution, and regenerating solution are passed over the resin. The cold condensate temperature at times can reach the $150^{\circ} \mathrm{F}$ limit recommended by the resin manufacturer. Therefore, a rinse water cooler was installed on the MDEA reclaim unit to avoid thermally degrading the resin. The heat stable salt regenerant solution originally recommended by the MDEA reclaim unit manufacturer was not able to remove completely the salts that have high affinity for the ion exchange resin. An alternate regenerant solution was used with good performance.

Several modifications were made to the piping configuration within the MDEA reclaim unit as well. The balance of resin canisters being fed by MDEA, heat stable salt displacing solution, regenerating solution, and rinse water were changed over several iterations to attain the maximum heat stable salt removal rate. The flow direction through the canisters was changed as well. The ion exchange resin within the canister frequently became packed. This created high differential pressure limiting the flow through the resin. At specific points in the cycle of the unit the flows were reversed to "fluff" the resin eliminating the high differential pressure condition.

Also prior to the Operating Period, a pump was installed at the MDEA storage tank to supply amine to the MDEA reclaim unit during plant outages. With the installation of the alternate pump, the reclaim unit could be operating and removing heat stable salts during plant outages, which was impossible with the previous equipment arrangement. 


\subsubsection{Operating Experience Overview}

The hydrogen sulfide removal efficiencies from the product syngas for the Operating Period were as follows:

\begin{tabular}{|l|l|l|l|l|l|}
\hline & $1^{\text {st }}$ Quarter & $2^{\text {nd }}$ Quarter & $3^{\text {rd }}$ Quarter & $4^{\text {th }}$ Quarter & $\begin{array}{c}\text { Average } \\
/ \text { Total }\end{array}$ \\
\hline $\mathrm{H}_{2}$ S Removal Efficiency (\%) & 98.9 & 98.5 & 98.5 & 98.5 & 98.6 \\
\hline Syngas Processed (MMscf) & 11,038 & 6,264 & 10,255 & 5,619 & 33,176 \\
\hline
\end{tabular}

The removal efficiency calculation uses total combustion turbine stack and flared syngas emissions (as sulfur) compared to the total sulfur feed to the gasification plant (dry weight percent), for the most conservative estimate of performance. Syngas processed is calculated from the monthly total produced syngas in MMBtu and the average syngas heating value (Btu/scf), while operating on coal. The total downtime associated with the acid gas removal system during the Operating Period was 22 hours. Operating experience for individual pieces of equipment follows.

\section{Acid Gas Absorber}

During the Operating Period, it was determined that by reducing the MDEA concentration in the circulating absorbent solution, higher recovery efficiency could be attained. At lower MDEA concentrations the properties of the amine solution become closer to those of water. The solution becomes less viscous, contributing to improved column hydraulics and, the composite heat capacity of the solution is increased allowing for more heat from the exothermic adsorption of $\mathrm{H}_{2} \mathrm{~S}$ to be absorbed without increasing the solution temperature. Since the amine solution becomes more selective toward $\mathrm{H}_{2} \mathrm{~S}$ than $\mathrm{CO}_{2}$ at lower temperatures, the $\mathrm{H}_{2} \mathrm{~S}$ removal efficiency is increased.

Upon start-up of the facility on January 5, 1999, a pressure test was delayed while Operations investigated and identified a premature pressure safety valve release. This delay constituted all 22 hours of downtime attributed to this system. Subsequent investigation revealed that moisture 
had condensed and frozen in the pilot sensing line for the pressure safety valve on the acid gas absorber causing the valve to relieve significantly below the relief set point. Additional insulation and heat tracing have been applied to this valve to reduce the probability of a repeated incident.

One significant project was implemented during the Operating Period. The acid gas absorber has six separate amine feedpoints. As the $\mathrm{H}_{2} \mathrm{~S}$ concentration in the product syngas increases, the amine solution is introduced at a higher feedpoint to provide more contact time between the syngas and the amine solution. Linkages between these feedpoint valves and remote operating stations were installed to allow for operation of these valves without utilizing a man-lift.

\section{MDEA Storage Tank}

A new level control philosophy for the MDEA storage tank was adopted during the Operating Period. During normal operation of the acid gas removal system, water is constantly removed from the amine solution as overheads from the acid gas stripper and blowdown from the acid gas stripper reflux drum. The old procedure for replacing this water was to "batch-in" a large amount of water when the operator noticed the tank level was low. However, this batching of water effectively reduced the amine concentration enough to cause upsets downstream in the sulfur recovery unit. To correct this problem an MDEA storage tank level controller was added to the system to automatically add water to maintain a constant MDEA storage tank level and, consequently, a constant MDEA concentration.

\section{MDEA Carbon Bed}

During the Operating Period, routine core samples taken from the MDEA carbon bed filter revealed carbon attrition and excess antifoam accumulation within the carbon bed were causing periods of high and/or increasing differential pressure. To alleviate this problem, the antifoam feed rate was reduced and the carbon bed was back-flushed with water to remove carbon fines.

\section{Acid Gas Stripper Reflux Drum}

One significant project was implemented on the acid gas stripper reflux drum during the

Operating Period. During plant start-ups and shutdowns, there is insufficient heat supplied to the 
column to generate the vapor necessary to maintain level in the acid gas stripper reflux drum. Therefore, the drum loses level. During the Operating Period, a dedicated line was installed to supply make-up water to the reflux drum to prevent a low-level condition.

\section{Acid Gas Stripper Reboiler}

During the Operating Period, Operations experienced difficulties starting up the acid gas stripper reboiler. Under low syngas flow conditions the amine boiler alone cannot supply the necessary heat for proper operation and the acid gas stripper reboiler must supply the additional heat duty. Often, the reboiler appears to be vapor-locked requiring Operations to vent it for several minutes before it will accept steam.

Additionally, the level control valve at the bottom of the reboiler has experienced leak-by during the Operating Period. This allows the level in the reboiler to drop and steam to flow in, adding heat to the column. Additional heat into the column results in an upset in the sulfur recovery system. The leak-by was repaired and no further problems have been experienced with this valve.

\section{Acid Gas Stripper Carbon Beds}

During the Operating Period, routine core samples were taken from the acid gas carbon beds. The results from activity tests revealed little tar accumulation on the carbon. Similar to the MDEA carbon bed, carbon attrition was contributing to slightly increasing differential pressure across the bed. This differential pressure has been resolved by employing a bed expansion procedure using nitrogen and water.

\section{$\underline{\text { MDEA Reclaim Unit }}$}

Although no plant downtime or turndown can be attributed to the MDEA reclaim unit during the Operating Period, this unit has experienced significant reliability and performance problems. The original canisters containing the ion exchange resin were of fiberglass construction. The MDEA acted as a solvent on the resin in the fiberglass exposing the fibers. Caustic, used to regenerate the ion exchange resin, would then attack the fibers. This process continued until the canister wall became weak and ruptured. A project was implemented which increased the 
volume of the canisters by approximately $20 \%$ and upgraded the material of construction. No further rupture problems have been experienced.

Over the Operating Period, several piping configuration changes were made to the MDEA reclaim unit, increasing the heat stable salt removal capacity by approximately $35 \%$. Also during the Operating Period, process changes were made which extended the life of the ion exchange resin from a few weeks to more than a year.

\section{Other Equipment}

There was no maintenance, downtime or operational problem associated with the following equipment during the Operating Period:

\begin{tabular}{|l|l|}
\hline Lean amine pumps & Acid gas stripper \\
\hline MDEA storage tank & Acid gas stripper knockout drum \\
\hline MDEA pre-filter & Acid gas stripper quench pumps \\
\hline MDEA post-filter & Acid gas stripper recirculation cooler \\
\hline MDEA CTW coolers & Acid gas preheater \\
\hline Lean amine transfer pumps & Acid gas stripper overheads filters \\
\hline
\end{tabular}

\subsubsection{Summary and Conclusions}

With a few exceptions, the acid gas removal system has high reliability and low maintenance, relative to other systems within the facility. The most significant maintenance issue, which continues to be a problem, is tray damage within the acid gas absorber. As discussed in the system modification section, stiffeners have been installed to provide extra support for the trays. However, damage continues to occur. The design of a future acid gas absorber for syngas sweetening should include tray support rings extending farther out to support more of the load on the tray. The tray design should include a stiffening device to aid in supporting the tray load. Finally, the design of the retaining clips securing the tray to the support ring should be evaluated. Because of vibration, these clips frequently work lose allowing the tray to shift. This created an unequal distribution of the load, which contributed to tray damage. 
Another significant maintenance issue within the acid gas removal system is the maintenance on the MDEA reclaim unit. The complexity of the continuous-feed and rotating-resin canister carousel design have contributed to poor reliability. Spatial limitations have also made maintenance difficult. Future designs for an MDEA reclaim unit should consider a three cell system employing sequenced automatic block valves for directing flow. The automatic block valves would swap the flow from the online, regeneration, and stand-by resin beds as heat stable salt breakthrough was detected.

In terms of cost of operation, the MDEA reclaim unit is also the most costly piece of equipment within the acid gas removal system. Since the Operating Period, installation of a new heat stable salt displacing solution storage tank has reduced the chemical costs associated with the reclaim unit, because shipments can now be received in bulk.

Since the Operating Period, optimization efforts on the MDEA reclaim unit have appreciably increased the heat stable salt removal capacity such that salt removal has exceeded salt generation. 


\subsubsection{Sulfur Recovery System}

The sulfur recovery system includes:

\begin{tabular}{|l|l|}
\hline Acid gas burner & Hydrogenation cooler (Figure 5.3.12A) \\
\hline Acid gas burner residence vessel & Hydrogenation steam drum \\
\hline Acid gas heat recovery boiler & Condensate flash drum \\
\hline Burner sulfur condenser (Figure 5.3.12A) & Tail gas quench column \\
\hline Sulfur storage tank (Figure 5.3.12A) & Quench column pumps \\
\hline Sulfur pump & Quench filter \\
\hline Sulfur loading arm & Quench strainers \\
\hline No. 1 gas heater & Quench column cooler \\
\hline Claus $1^{\text {st }}$ stage reactor (Figure 5.3.12A) & Tail gas recycle compressor \\
\hline No. 2 sulfur condenser (Figure 5.3.12A) & Tank vent blowers \\
\hline No. 2 gas heater & Combustion air blowers \\
\hline Claus $2^{\text {nd }}$ stage reactor (Figure 5.3.12A) & Suction vent gas blower knockout pot \\
\hline No. 3 sulfur condenser (Figure 5.3.12A) & Tail gas burner \\
\hline No. 3 gas heater & Tail gas incinerator residence vessel \\
\hline Claus $3^{\text {rd }}$ stage reactor (Figure 5.3.12A) & Tail gas quench cooler \\
\hline No. 4 sulfur condenser (Figure 5.3.12A) & Tail gas dispersion stack \\
\hline Hydrogenation gas heater & Low-pressure steam drum \\
\hline Hydrogenation reactor (Figure 5.3.12A) & \\
\hline
\end{tabular}




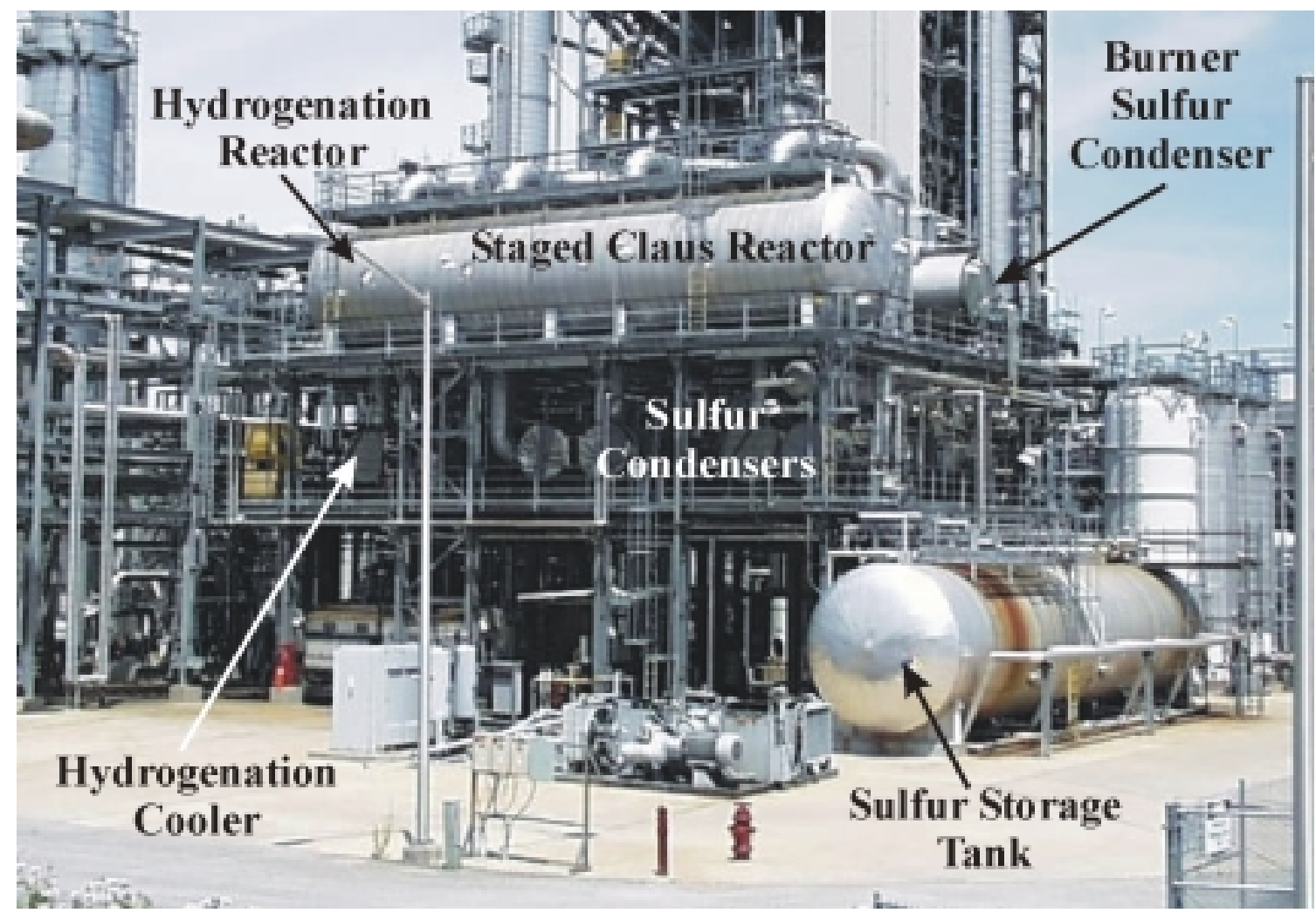

Figure 5.3.12A: Sulfur Recovery Unit Major Equipment

\subsubsection{System Modifications}

Prior to the Operating Period, many modifications were made to the sulfur recovery system. These modifications are discussed in order of upstream to downstream equipment.

\section{Acid Gas Burner}

Shortly after start-up of the facility, it was discovered that the automatic block valve in the acid gas line feeding the acid gas burner was severely leaking through. During a subsequent outage, the valve was pulled and inspected and the seat of the valve was found to be significantly corroded. At that time, the decision was made to change the seat material to a more corrosion resistant material. Since then, there have been no further leaking problems with the valve.

\section{No. 1 Gas Heater}

During winter conditions when the No. 1 gas heater was running on high-pressure steam and the block valves for the intermediate pressure steam feed were closed, the intermediate steam line froze and failed to function when needed. To prevent this from happening again, a steam trap 
was installed on the intermediate pressure steam header. Instead of accumulating and freezing in the header, condensing liquid will flow through the trap keeping the header steam filled and hot.

\section{No. 4 Sulfur Condenser}

During operation of the sulfur recovery system prior to the Operating Period, it was discovered that there was a moderate degree of entrainment of liquid sulfur from the No. 4 sulfur condenser to the hydrogenation gas heater. This entrainment occurred mainly during upset conditions. Therefore, a seal leg was installed at the entrance of the hydrogenation gas heater to drain the sulfur from the head of the exchanger. Though the sulfur flow from this seal leg is infrequent, if it were allowed to accumulate within the hydrogenation gas heater it could create excessive differential pressure within the sulfur recovery unit.

\section{Hydrogenation Reactor}

After changing the catalyst in the hydrogenation reactor, it is necessary to ensure the catalyst is in the sulfide state. To sulfide the hydrogenation catalyst, a dedicated line was installed from the acid gas inlet to the sulfur recovery system to the inlet to the hydrogenation reactor. Since startup, this line has been used on both catalyst replacement occasions.

\section{Sulfur Storage Tank}

The sulfur storage tank vent line was also modified prior to the Operating Period. Originally, the vent line from the sulfur storage tank tied into the inlet of the hydrogenation gas heater. However, this created a backpressure scenario, which caused sulfur to overrun the liquid sulfur inspection boxes whenever the level in the sulfur storage tank was greater than approximately $50 \%$. Consequently, the sulfur storage tank vent line was rerouted to the tail gas burner eliminating the backpressure.

\section{Sulfur Pump}

Due to thermal cycling of the sulfur storage tank and the suction piping leading to the sulfur pump, stresses were continually imposed on the pump coupling. These stresses eventually led to a failure of the coupling. Therefore, a flexibly mounted bedplate was installed to allow the pump and motor to move together as one unit. This eliminated the stress, preventing future failures. 


\section{Sulfur Loading Arm}

To prevent overfilling a sulfur railcar while pumping down the sulfur storage tank, an instrument air bubbler was installed on the sulfur loading arm. Previously, there were temperature elements protruding from the loading arm into the railcar. Once sulfur reached these temperature elements, the railcar fill would be terminated. With the addition of the bubbler, Operations had an analog indication of the level. This made the control system associated with preventing overfilled railcars more reliable.

\section{Tail Gas Quench Cooler}

Prior to the Operating Period, several modifications were made to the tail gas quench cooler. While operating the tail gas burner at elevated firing rates, a high level of vibration noise can be observed from the tail gas quench cooler. It is assumed that the noise is coming from vibration of the tubes inside the exchanger. Consequently, binding rods were installed to limit the movement of the tubes. The first set of binding rods was successful in reducing the vibration. However, the material of construction was inadequate to resist corrosion within the vessel. After selecting the proper metallurgy, the binding rods have continued to significantly dampen the vibration from the tail gas quench cooler.

Samples from the tail gas quench cooler drum need to be routinely tested to determine conductivity. The original sampler allowed part of the sample to boil off if a large amount of sample were taken. This boiling rendered the sample useless because it altered the contaminant concentrations. Therefore, a sample cooler was installed to allow Operations to withdraw a continuous sample without risk of boiling.

Changes were also made to two of the overpressure protective devices on the tail gas quench cooler prior to the Operating Period. Below two sets of pressure safety valves, rupture disks were installed to prevent leakage and multiple repairs to the pressure safety valve. 


\section{Tail Gas Recycle Compressor}

Related to the tail gas compressors, a piping change was necessary prior to the Operating Period. The original design had the compressor second and third stage suction drum liquid drain lines tied into the discharge of the area sump pump. When this pump was running, water could back flow through the compressor suction drum into the compressor. Once water reached the compressor, there would be a great risk of damaging the equipment as well as potential for personnel injury. Therefore, dedicated lines and control valves were installed routing the suction drum drains to the recycled solids tank.

\section{Suction Vent Gas Blower Knockout Pot}

Two minor modifications were made to the suction vent gas blower knockout pot before the Operating Period. A gate valve was installed on an unused nozzle on the knockout pot to be used for troubleshooting. Previously, water accumulation was thought to have contributed to the inadvertent shutdown of the tail gas burner. This gate valve could be used to quickly determine if any water was present and could be used to de-inventory the vessel if necessary. Additionally, the reference point for the liquid level transmitter on the knockout pot was changed. Originally, the transmitter was referenced to atmosphere. This resulted in unreliable and false drum level readings. Relocation of the high side tap to the knockout pot seal leg allowed for earlier detection of increases in level.

\section{Tank Vent Blowers}

The downstream explosive gas analyzer for the tank vent blower was moved to upstream of the suction vent gas blower knockout pot. Reliability of the analyzer was compromised by being under pressure during operation and calibrated under a vacuum. The analyzer downstream of the blowers typically recorded poor reliability compared to the redundant analyzer upstream of the knockout pot.

A final modification to the tank vent blowers was the alteration to the shrouds on the outboard bearing. This modification was to allow for vibration readings to be taken without removing the shroud. Shroud removal while the machine is in operation could cause overheating of the bearings, shortening bearing life in addition to presenting a personnel safety issue. 


\subsubsection{Operating Experience Overview}

The sulfur recovery unit and plant overall efficiencies for the Operating Period are as follows:

\begin{tabular}{|l|c|c|}
\hline \multicolumn{1}{|c|}{ Month } & Sulfur Recovery Efficiency & Overall Efficiency \\
\hline March 1998 & 98.7 & 97.8 \\
\hline April 1998 & 99.3 & 98.4 \\
\hline May 1998 & 99.6 & 98.5 \\
\hline June 1998 & 99.3 & 98.1 \\
\hline July 1998 & 99.8 & 98.5 \\
\hline August 1998 & 99.4 & 98.1 \\
\hline September 1998 & 99.3 & 98.3 \\
\hline October 1998 & 99.7 & 98.3 \\
\hline November 1998 & 99.7 & 98.1 \\
\hline December 1998 & 98.0 & 97.6 \\
\hline January 1999 & 99.6 & 98.2 \\
\hline February 1999 & 99.8 & 98.3 \\
\hline Operating Period Average & 99.4 & 98.2 \\
\hline
\end{tabular}

The efficiency calculation is the total stack emissions and acid gas flared emissions (as sulfur) compared to the total feed to the sulfur recovery system. The overall efficiency corresponds to the total project emissions (as sulfur) compared to the total sulfur feed to the gasifier.

The total downtime associated with the sulfur recovery system during the Operating Period was 5 hours. Operating experience for individual pieces of equipment follows.

\section{Acid Gas Burner}

There were no significant maintenance issues related to the acid gas burner during the Operating Period. However, there was a change in operating philosophy related to the firing rate for the burner. Previously, the operating philosophy was to achieve the complete destruction of ammonia. However, after receiving results from tests performed on the Claus $1^{\text {st }}$ stage reactor, ammonia destruction was no longer targeted. The results from the catalyst activity tests indicated a heavy amount of coking. The excessive supplemental fuel required to reach 
temperatures to completely destroy the ammonia causes uncombusted carbon to foul the Claus catalyst. Consequently, the philosophy was changed to one of fuel conservation.

One potentially serious operational incident did take place concerning the acid gas burner during the Operating Period when an operator, during a routine inspection, found a leak on the acid gas burner pilot. While attempting to tighten the pilot retaining nut the pilot became lose and the leak increased. The retaining nut was tightened, securing the pilot and gasket material was wrapped around the pilot. The gasket material slowed the leak enough for sulfur vapor, escaping from the acid gas burner, to condense and solidify, affecting a seal of the leak.

\section{$\underline{\text { Acid Gas Heat Recovery Boiler }}$}

A minor maintenance issue occurred related to the acid gas heat recovery boiler during the Operating Period. At the outlet of the boiler, there is a steam-jacketed plug valve used for troubleshooting. During periods of elevated pressure within the sulfur recovery system, valves such as these are used to determine where a flow restriction is likely. During a routine inspection round, an operator noticed a sulfur formation hanging from this valve indicative of an acid gas leak. An $\mathrm{H}_{2} \mathrm{~S}$ monitor was used to determine the severity of the leak and it was decided that the leak was minimal and the valve could be, and was, repaired on the subsequent outage.

\section{Burner Sulfur Condenser}

At the bottom of each of the sulfur condensers within the sulfur recovery system, there is a seal leg that prevents acid gas from reaching the sulfur storage tank. During the Operating Period, these seal legs routinely became plugged, requiring Operations to clear the obstruction by use of a hand held rod. The material accumulating in the seal legs has been analyzed and found to be an amorphous mixture of ammonia salts, iron corrosion products and soot from the excess firing of the acid gas burner. A clean-out flange has been installed on the bottom of the seal leg to minimize the maintenance costs of cleaning the seal leg on the burner sulfur condenser. Once an appreciable amount of material has accumulated in the bottom of the seal leg, the flange is removed on the following outage and the material is removed. This cleaning method has eliminated seal leg plugging in the burner sulfur condenser. 


\section{Sulfur Storage Tank}

There was little significant maintenance work during the Operating Period related to the sulfur storage tank. The notable exception was clearing of a restriction in the storage tank vent line. The liquid sulfur flow to the sulfur storage tank is saturated with $\mathrm{H}_{2} \mathrm{~S}$. Once the liquid reaches the storage tank, degassing occurs, liberating the $\mathrm{H}_{2} \mathrm{~S}$. This gas, in conjunction with a nitrogen purge placed on the tank, causes the tank pressure to rise if the sulfur storage tank vent line is not clear. During the Operating Period, a significant plug in the vent line occasionally created operational difficulty. In a major maintenance outage during the Operating Period, a sulfur plug was detected and cleared.

After the Operating Period, it was discovered that a portion of the steam-jacketed vent line had collapsed. It was thought that the steam jacketing froze. The force from the expansion of water turning to ice was great enough to crush the vent line. This restriction was contributing to the sulfur plugging during the Operating Period.

\section{$\underline{\text { Sulfur Pump }}$}

During the Operating Period, there was no maintenance activity related to the sulfur pump and only one notable operational concern. While attempting to transfer liquid sulfur from the sulfur storage tank to a sulfur railcar, a steam trap of the steam-jacketed line was misaligned. This created a cold spot in the transfer line allowing the sulfur to solidify and plug the line. Since the plug prevented sulfur flow from the pump, the liquid sulfur within the pump heated up. As the sulfur heated up, the viscosity increased. This is a unique characteristic of sulfur. Consequently, the sulfur pump continuously tripped because of high amperage. The misaligned steam trap was soon discovered, repaired, and proper operation resumed.

\section{$\underline{\text { Sulfur Loading Arm }}$}

During the Operating Period, the sulfur railcar supplier changed. The new railcar supplier had railcars within the fleet that were retrofitted corn syrup cars. To accommodate the change in fill level for the new cars, modifications to the sulfur loading arm and control code were necessary. The level bubbler tube on the sulfur loading arm was extended to protrude further into the railcar. This allowed the operators to accurately monitor the fill volume of the new railcars. 


\section{Claus $1^{\text {st }}$ Stage Reactor}

During the Operating Period, the performance of the Claus $1^{\text {st }}$ stage reactor degraded. The temperature profile of the bed began to drift deeper into the bed, indicating deactivation from the top. During the next major maintenance outage, the catalyst was replaced and tested. As previously mentioned, the test results indicated a high degree of coking on the catalyst.

\section{No. 2 Sulfur Condenser}

Two notable maintenance activities occurred relating to the No. 2 sulfur condenser during the Operating Period. First, a steam leak was observed coming from the jacketed condenser boot valve. During the next maintenance outage, a steam union was serviced and the leak was stopped. Second, a steam jacketed plug valve, similar to the valve on the acid gas heat recovery boiler, was found to be leaking. The valve was replaced on a subsequent outage and no further maintenance was necessary.

\section{No. 4 Sulfur Condenser}

The No. 4 sulfur condenser has been a source of significant maintenance costs within the sulfur recovery system. Because of temperature and ammonia concentration considerations, the ammonia salt formation is greatest in this condenser. It has not been uncommon to open the head of the condenser and find a few feet of solidified sulfur (Figure 5.3.12B). This sulfur is trapped because of a plug in the seal leg or the run down line to the seal leg. Routinely, during the Operating Period, the liquid sulfur piping downstream of the No. 4 sulfur condenser was disassembled and cleared of plugging deposits.

To reduce the maintenance costs associated with cleaning this piping, the welded steam unions to the steam jacketing were replaced with flanges. Additionally, to reduce costs associated with cleaning the seal leg, a clean out flange similar to that installed on the burner sulfur condenser seal leg has been installed. 


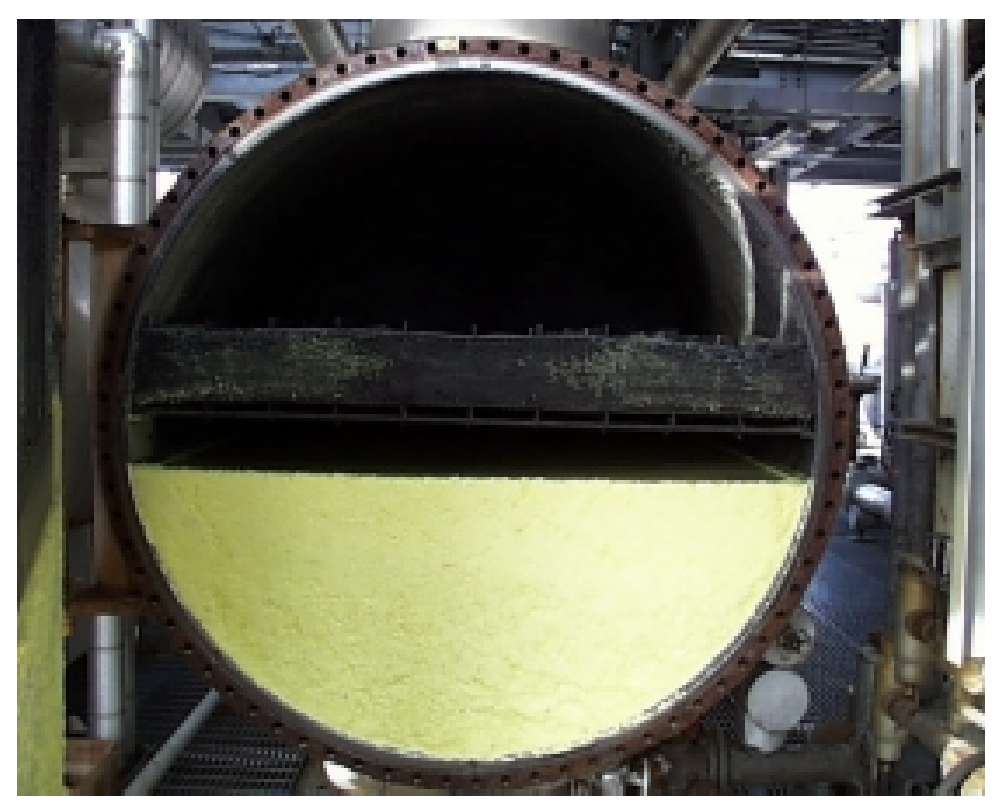

Figure 5.3.12B: Sulfur in No. 4 Sulfur Condenser as a Result of a Plugged Seal Leg

\section{Hydrogenation Reactor}

At the same time the catalyst was changed out in the Claus $1^{\text {st }}$ stage reactor, the catalyst was changed in the hydrogenation reactor. The temperature profile of the bed indicated a potential reduction in bed activity and downstream gas sampling confirmed the reduction. Upon start-up of the hydrogenation reactor, the catalyst needed to undergo a sulfiding process. During this process, the sulfur recovery efficiency was inadequate to maintain plant operation. Consequently, 5 hours of downtime was attributed to the hydrogenation reactor while the catalyst was being prepared. This constitutes all of the downtime associated with the sulfur recovery system during the Operating Period.

The hydrogenation reactor bypass valve experienced a leak during the Operating Period. Consequently, $\mathrm{SO}_{2}$ was allowed to bypass the reactor. Recombining with the $\mathrm{H}_{2} \mathrm{~S}$ from the outlet of the hydrogenation reactor, the $\mathrm{SO}_{2}$ underwent an aqueous Claus reaction within the tail gas quench column. This created significant operational difficulty as well as appreciable maintenance costs. The results will be further discussed in the tail gas quench column operating experience section. Once the leak was identified, the valve was serviced. Upon inspection, it was found that corrosion products formed a deposit and damaged the seat of the bypass valve preventing a proper seal. 


\section{$\underline{\text { Tail Gas Quench Column }}$}

As a result of the leaking hydrogenation reactor bypass valve, an aqueous phase Claus reaction occurred with the tail gas quench column forming a pale yellow paste of elemental sulfur. This paste plugged every piece of equipment, to some degree, within the tail gas quench column loop. The packing within the tail gas quench column was packed with the sulfur paste. This created high differential pressure across the column. The differential pressure across the column starved the tail gas compressors of flow causing them to trip on low suction pressure. This, in turn, created high pressure within the sulfur recovery unit causing elevated sulfur emissions at the tail gas dispersion stack.

After water flushing methods were exhausted, a costly chemical cleaning of the column and related equipment was performed. During this cleaning, hot caustic was circulated throughout the quench column loop to dissolve the elemental sulfur. The chemical cleaning was very successful, but the maintenance and caustic disposal costs were quite high.

\section{Quench Column Pumps}

Because of the elemental sulfur paste, the quench column pumps experience operational difficulty. The seal flush on these pumps typically comes from the discharge of the pump. However, the sulfur paste plugged the seal flush, contributing to failure of the pump seal. This occurred several times before the seal flush was replaced with a clean water source.

\section{Quench Filter and Quench Strainers}

These vessels are responsible for removing entrained particulate matter from the water in the tail gas quench column loop. Because of the sulfur paste incident, the operational cost of these vessels was high for a portion of the Operating Period. The additional load on the Operations team as a result of constant changing of the quench filters was the single greatest operational difficulty experienced in the sulfur recovery system during the Operating Period. As a result of constant use in a two-phase application, the isolation valves on the quench strainer became difficult to operate. Once the sulfur formation problem was solved, the valves were serviced. 


\section{Quench Column Cooler}

During the sulfur paste formation incident, the quench cooler became packed with sulfur. This created an appreciable flow restriction as well as significantly reducing the heat removal from the quench loop. A system of blowing down the cooler and making up with fresh water was devised to satisfy temperature requirements within the column.

\section{$\underline{\text { Tail Gas Recycle Compressor }}$}

The tail gas recycle compressors have been a source of significant maintenance during the Operating Period. Much of the maintenance has been related to the internal check valves within the compressor. Frequent check valve failures have contributed to poor compressor reliability. However, changes in check valve design throughout the Operating Period have helped increase the reliability of the machines.

During the Operating Period, the seal leg on the first stage suction drum to the compressors was extended. Due to small suction pressure fluctuations, the seal leg would de-inventory allowing tail gas to escape to a nearby sump. The seal leg was extended to provide greater resistance to the pressure fluctuations.

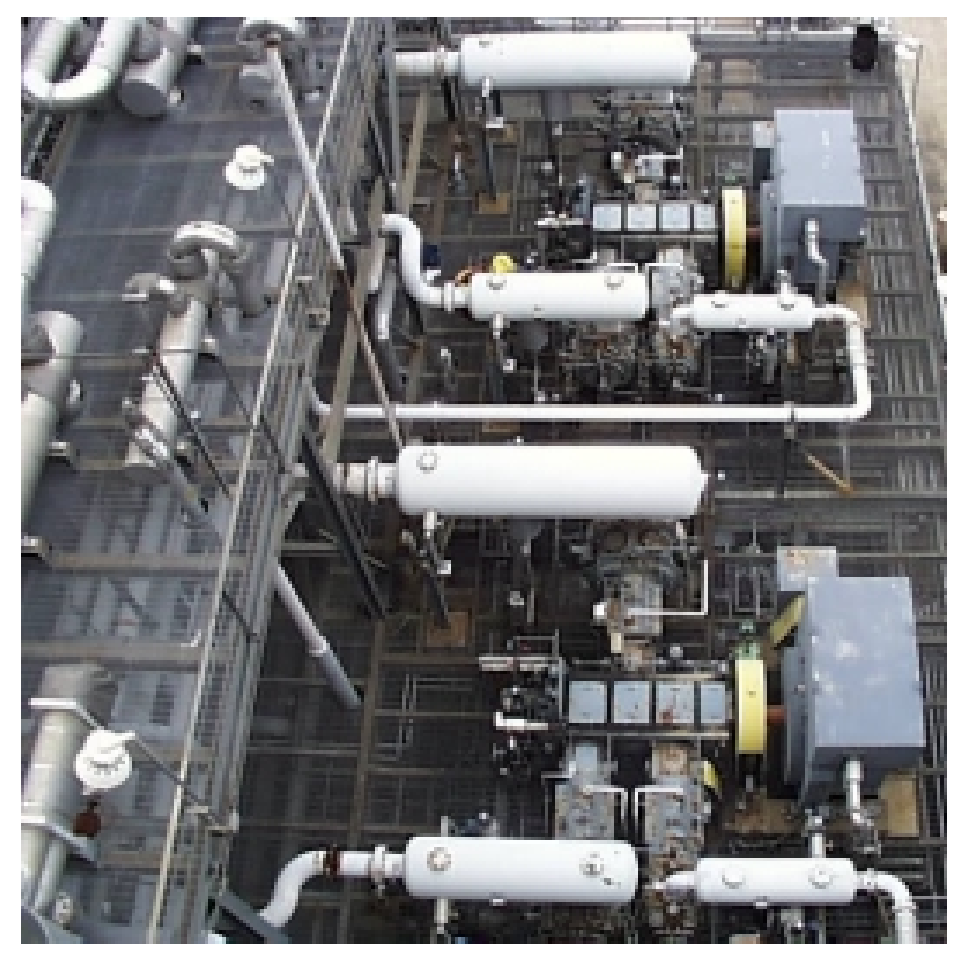

Figure 5.3.12C: Tail Gas Recycle Compressors 


\section{$\underline{\text { Tank Vent Blowers }}$}

During the Operating Period, the tank vent blowers also experienced appreciable operational reliability problems and high maintenance. A sulfur compound routinely fouled the impellers of these blowers. To reduce the fouling, an epoxy coating was applied. This coating proved unsuccessful; however, as corrosion underneath the coating loosened it, causing it to flake off.

\section{$\underline{\text { Tail Gas Burner }}$}

During the Operating Period, an alternate mode of operation was identified and tested for the tail gas burner. It was discovered that fuel costs could be reduced if the tail gas burner could be fired on syngas derived from natural gas during plant start-ups rather than burning the syngas at the flare and firing the burner on supplemental fuel gas. The test was successful in that the burner was able to sustain operation. However, because of piping limitations and reduced gas path pressures during start-up, Operations found it difficult to maintain the required temperature within the tail gas incinerator residence vessel.

\section{$\underline{\text { Tail Gas Dispersion Stack }}$}

During the Operating Period, one noteworthy maintenance activity occurred related to the tail gas dispersion stack. A large gap was discovered in a nozzle located on the stack. Upon inspection, it was determined that the combination of sulfur compounds and condensed moisture contributed to downtime corrosion of the nozzle. The nozzle was temporarily repaired until the next maintenance outage when it was replaced.

\section{Other Equipment}

There was no maintenance, downtime or operational problem associated with the following equipment during the Operating Period:

\begin{tabular}{|l|l|}
\hline Acid gas burner residence vessel & Condensate flash drum \\
\hline No. 1 gas heater & Hydrogenation gas heater \\
\hline No. 2 gas heater & Hydrogenation cooler \\
\hline Claus $2^{\text {nd }}$ stage reactor & Combustion air blowers \\
\hline
\end{tabular}




\begin{tabular}{|l|l|}
\hline No. 3 sulfur condenser & Suction vent gas blower knockout pot \\
\hline No. 3 gas heater & Tail gas incinerator residence vessel \\
\hline Claus $3^{\text {rd }}$ stage reactor & Tail gas quench cooler \\
\hline Hydrogenation steam drum & Low-pressure steam drum \\
\hline
\end{tabular}

\subsubsection{Summary and Conclusions}

Since the Operating Period there have been a few noteworthy system modifications. As a result of an analyzer failure, the plant experienced a release of a reportable quantity of $\mathrm{SO}_{2}$ from the permitted tail gas dispersion stack. To aid in troubleshooting the sulfur recovery system and detecting failures of the analyzer used for control of the acid gas burner, a secondary tail gas analyzer has been installed. Thus far, Operations personnel have not had an opportunity to utilize the new analyzer.

To prevent the sulfur tank vent line from plugging with corrosion products, a nitrogen sweep has been installed. Since installation, the sulfur tank has experienced no elevated pressure problems.

A new method of cleaning the tail gas dispersion stack has been developed and tested since the Operating Period. The inner wall of the dispersion stack continuously becomes layered with a sulfur compound as a result of the combustion of tail gas and subsequent natural cooling of the gas as it flows up the stack. Under upset plant conditions, high gas flow rates through the dispersion stack cause the sulfur compounds to dry and flake off and exit the stack.

To remove the layers of sulfur and prevent the flaking, an explosive expert team was contracted to clean the stack. The contractor constructed an assembly using wire hoops and approximately 500 feet of detonation cord and erected the assembly into the stack. Upon detonation, a small plume of fine dust exhausted from the top of the dispersion stack. However, the vast majority of the material fell to the bottom of the stack and collected in the tail gas quench cooler, from which it was collected and removed. The explosive cleaning of the tail gas dispersion stack was considered a complete success and will be employed in the future as a viable replacement for chemical or high-pressure water cleaning methods. 
Finally, there is currently a project under review, which would eliminate a large portion of the ammonia feeding the sulfur recovery system. The largest source of maintenance costs for the sulfur recovery unit is the continuous removal of debris in the seal legs. The plugging material is composed of two compounds, ammonia salt and an amorphous mixture of iron corrosion products and carbon. The temperature can be increased in the acid gas burner to effect the destruction of the ammonia thus preventing ammonia salt formation. However, this decreases the life of the No. 1 stage Claus reactor and increases the carbon residue. The ideal solution, which should be considered while designing future sulfur recovery systems within coal gasification facilities, would be to eliminate the ammonia source for the sulfur plant. 


\subsubsection{Sour Water Treatment System}

The sour water treatment system includes:

\begin{tabular}{|l|l|}
\hline Sour water carbon filter (Figure 5.3.13A) & Stripped water transfer pumps \\
\hline Sour water filter & Ammonia stripper bottoms cooler \\
\hline Condensate degassing column (Figure 5.3.13A) & Quench column (Figure 5.3.13A) \\
\hline Sour water transfer pumps & Quench water transfer pumps \\
\hline Degassing column reboiler & Quench column bottoms cooler \\
\hline Degassing column bottoms cooler & Supplemental quench column bottom cooler \\
\hline Ammonia stripper (Figure 5.3.13A) & Outfall water day tanks \\
\hline Ammonia stripper reboiler & Discharge water pumps \\
\hline
\end{tabular}

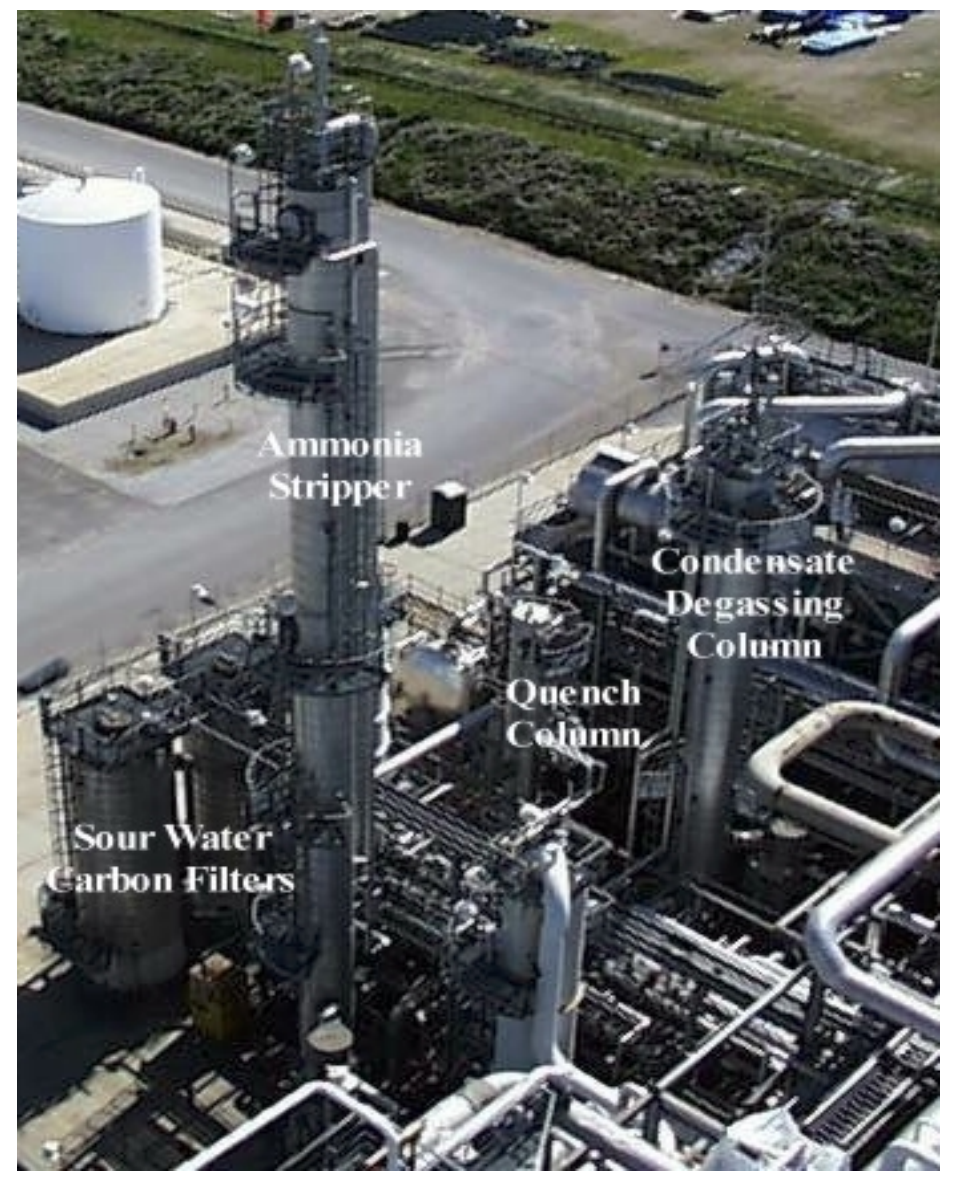

Figure 5.3.13A: Sour Water Treatment System Major Equipment

Wabash River Coal Gasification Repowering Project Final Technical Report 


\subsubsection{System Modifications}

Prior to the Operating Period, the sour water carbon filters routinely experienced periods of high differential pressure. Due to small amounts of vapor flashing in the sour water stream feeding the carbon beds, frequent venting of the vessel head spaces was required to avoid vapor-locking the beds. To remedy this problem, a dedicated line was installed from the top of the carbon bed vessels to the gas inlet of the quench column. This small project solved the vapor-locking problem and prevented operators from having to manually vent the vessels to atmosphere.

As a result of the installation of the chloride scrubbing system, the chloride concentration in the feed stream to the sour water treatment system was significantly increased. The chloride in the sour water formed complexes with the ammonia, preventing the ammonia from being stripped in the ammonia stripper. It was discovered that caustic addition would dissolve the ammonia chloride complexes allowing the ammonia to be stripped. Therefore, a metering pump was installed to supply a continuous feed of caustic. Later, a carbon storage vessel was converted into a caustic storage tank. This modification decreased the operating cost of the caustic feed system allowing caustic to be purchased in bulk.

The ammonia stripper experienced a small amount of damage to the top tray upon start-up. It was thought that this damage was the result of increased feed stream velocity because of twophase flow. To eliminate this mechanism of damage, an internal distribution system with an impingement plate was installed. Since installation, no further damage has been observed.

Finally, prior to the Operating Period, Operations experienced difficulty achieving adequate cooling of the quench column bottoms stream. Consequently, the quench column experienced high overhead ammonia flow. The effects of the elevated bottoms temperature within the rod mill building were of great concern.

The ammonia rich stream from the quench column is recycled to the rod mill to make coal slurry. Since the temperature of this stream was elevated, high levels of ammonia flashed from the liquid and entered the building housing the rod mill. To eliminate the personnel exposure concern, the supplemental quench column bottom cooler was installed. Although the installation 
of the supplemental cooler made a significant improvement, the ammonia concentration within the rod mill building has occasionally been problematic.

\subsubsection{Operating Experience Overview}

The water volume processed by the sour water treatment system during the Operating Period is as follows:

\begin{tabular}{|l|c|}
\hline \multicolumn{1}{|c|}{ Month } & Volume (millions of gallons) \\
\hline March 1998 & 8.2 \\
\hline April 1998 & 8.6 \\
\hline May 1998 & 7.5 \\
\hline June 1998 & 7.3 \\
\hline July 1998 & 7.0 \\
\hline August 1998 & 8.4 \\
\hline September 1998 & 7.8 \\
\hline October 1998 & 3.9 \\
\hline November 1998 & 3.8 \\
\hline December 1998 & 0.7 \\
\hline January 1999 & 2.0 \\
\hline February 1999 & 2.8 \\
\hline Operating Period Total & 68.0 \\
\hline
\end{tabular}

No downtime was associated with the sour water treatment system during the Operating Period. However, coal operation was terminated as a result of high differential pressure across the sour water carbon beds. The shutdown time for this incident was later attributed to the particulate removal system. Operating experience for individual pieces of equipment follows. 


\section{$\underline{\text { Sour Water Carbon Filter }}$}

The intent of the carbon beds is to absorb tars that have condensed along with the sour water in the low temperature heat recovery system. Because of the nature of the carbon beds; however, they also act as a filter to remove any particulate matter that is suspended in the sour water stream. During the Operating Period, a failure in the particulate removal system allowed char to pass into the particulate-free gas stream where it was then removed from the syngas by the chloride scrubber. When the water from the chloride scrubber reached the sour water carbon filter, the char was collected in the carbon beds. This char packed into the void spaces in the carbon beds, creating high differential pressure. As a result, the screens, responsible for retaining the carbon in the vessel, were crushed into the floor of both vessels. The distribution systems in each vessel were also severely damaged. Internals from both vessels were salvaged to reconstruct a complete set so that operations could continue with one vessel. The remaining vessel was isolated for repairs. Internals for the off-line vessel were fabricated and installed while the facility was operating. Built into the new distribution system were additional supporting members, which could withstand greater differential pressures. The carbon in this vessel was also replaced. Imbedded in the spent carbon from the damaged vessel were accumulations of tars that had been washed from the chloride scrubber. As discussed in the chloride scrubbing system section, tar accumulation was a problem in the chloride scrubber prior to the Operating Period.

As a result of using the carbon unload line on the sour water carbon filter, another maintenance issue arose during the Operating Period. Carbon from the vessel damaged the seats of the unload line block valves on each vessel. Shortly after placing both carbon filters in service, leaks were discovered from the unload lines of the vessels. These valves were serviced on a subsequent plant outage and have since been maintenance-free.

\section{$\underline{\text { Sour Water Filters }}$}

The water filters are designed to filter any particulate material that breaks through the screens of the sour water carbon filter. Because of the damage to the sour water carbon filter described previously in this section, large amounts of carbon filled and packed into the water filters. The filter cartridges collapsed and carbon was allowed to pass into the sour water treatment system. 
The carbon packed into the water filters caused minor damage to the filter cartridge supporting struts. The carbon was removed from these vessels and the damage was repaired. There were no other maintenance concerns with the water filters during the Operating Period.

\section{Condensate Degassing Column}

Carbon from the collapsed water filter, previously discussed, passed into the condensate degassing column. Although this caused no damage to the degassing column, it created operational difficulties. Over a period of several days frequent back-flushing of both sour water transfer pumps was necessary to prevent a high water level condition within the condensate degassing column.

\section{Sour Water Transfer Pumps}

Throughout the Operating Period, the sour water transfer pumps occasionally experienced poor performance. It was determined that the suction strainers were plugging with foreign material. Once the suction strainers were cleared of debris, the sour water transfer pumps exhibited acceptable performance.

\section{Degassing Column Reboiler}

During routine daily inspections, Operations discovered a small steam leak from the head of the degassing column reboiler. During the next planned outage, the head of the exchanger was removed and a small amount of pitting due to corrosion was discovered on the sealing surface between the head and the exchanger body. After the pitting was ground out, the gasket was replaced and the reboiler was placed back into operation without further leakage.

\section{Degassing Column, Ammonia Stripper, and Quench Column Bottoms Coolers}

Following the carbon breakthrough incident, each of the coolers was flushed to remove any remaining carbon. After flushing, each was opened for inspection. The degassing column bottoms and quench column bottoms coolers appeared to be in proper condition. The ammonia stripper bottoms cooler; however, was heavily covered with corrosion by-product deposition. The exchanger was satisfactorily chemically cleaned. 


\section{$\underline{\text { Ammonia Stripper }}$}

As with the level control problems in the degassing column following the carbon breakthrough incident, Operations was forced to frequently back-flush both stripped water transfer pumps in order to maintain proper level within the ammonia stripper.

Over the Operating Period, the pressure rupture disk on the ammonia stripper was replaced. Due to poor stripper water transfer pump performance, Operations experienced level control problems within the ammonia stripper. As a result of the variable level and abnormal overheads flow, the column experienced a high-pressure condition and relieved the pressure through the pressure rupture disk. The pressure rupture disk was replaced on the subsequent plant outage.

Because tray hardware, such as clamps, bolts and bubble caps, were occasionally found in the suction strainer to the stripped water transfer pumps, the ammonia stripper was inspected for tray damage. Upon inspection, minor tray damage was found and repaired. There was no other maintenance concern associated with the ammonia stripper during the Operating Period.

\section{$\underline{\text { Stripped Water Transfer Pumps }}$}

During the Operating Period, the sour water transfer pumps frequently experienced poor performance due to plugging of the suction strainers with foreign material. This phenomena was intensified during the carbon breakthrough incident. However, unlike the sour water transfer pumps, the stripper water transfer pump performance continued to suffer after the suction strainers were cleaned. To resolve the stripped water transfer pump poor performance problems experienced during the Operating Period, an epoxy coating was applied to the pump impeller casing. A significant amount of corrosion was discovered on the casing, which increased the clearance between it and the impeller. The additional clearance allows water to recirculate to the suction side of the pump instead of out the pump discharge, lowering performance. The coating reduced the clearance between the impeller and casing significantly reducing recirculation. The same coating was also applied to the sour water transfer pumps. 


\section{Discharge Water Pumps}

The upstream manual block valve for the discharge water pumps failed to provide a positive seal during the Operating Period. The valves were removed from the lines and inspection revealed that the seats of the valves were severely corroded. The seats on the valves were replaced likefor-like and the pumps were put back into service.

\section{Other Equipment}

There was no maintenance, downtime or operational problem associated with the following equipment during the Operating Period: quench column, quench water transfer pumps, supplemental quench column bottom cooler, and the waste water discharge day tanks.

\subsubsection{Summary and Conclusions}

Since the Operating Period, the sour water treatment plant has experienced few operational difficulties and a low level of maintenance activity.

Two noteworthy alternative modes of operation have been developed for the sour water treatment plant since the Operating Period. First, the continued operation of the treatment system during a plant outage was implemented. During major maintenance outages water management becomes a problem within the facility. Often, rented storage tanks are required due to the amount of water generated during shutdown and maintenance activities. To avoid the expense of these rented tanks, Operations developed a method to continue operation of the sour water treatment system during an outage to clean and discharge the water and eliminate the water management issue. Though Operations proved that this mode of operation was possible, it is not likely that it will be employed often. Because of flow limitations of the discharge water pumps, operation of the treatment plant proved to be quite labor intensive and water filter cartridge changes became relatively expensive.

The second alternative mode of operation proved to be far more successful. During periods of low plant throughput or during petroleum coke operation, the water feed to the sour water treatment plant is significantly reduced. This creates operational difficulties because proper column hydraulics are not maintained. However, Operations developed a method of recycling 
water from the ammonia stripper to the degassing column. This method creates a false loading of the sour water treatment plant and maintains proper column hydraulics.

Significant corrosion to the discharge check valves of these same pumps also contributed to poor pump performance. The corrosion damage to these check valves allowed water from the discharge of the on-line pump to flow through the back-up pump, back to the suction of the online pump. To eliminate this corrosion, the metallurgy of the check valves was changed.

The design of a sour water treatment system for a future coal gasification facility should consider the following alterations: the metallurgy of the system should be evaluated, considering the maintenance history and operational experience of this facility. Corrosion to the heat exchangers, pumps and piping within the treatment system has created operational difficulties and appreciable maintenance costs.

Finally, the destination of the overhead streams from the degassing column and the ammonia stripper should be re-evaluated. As discussed in the sulfur recovery system section of this document, ammonia salt formation in the sulfur recovery system has been a significant source of maintenance costs. A large fraction of the ammonia in the sulfur recovery system comes from the sour water treatment system. If this ammonia could be directed to an alternative destination, much of the maintenance within the sulfur recovery system could be avoided. 


\subsubsection{Cooling Tower System}

The cooling tower system includes the following equipment:

Cooling water pumps (Figure 5.3.14A)

Cooling tower (Figure 5.3.14A)

The cooling tower is a three-cell, induced-draft, counter-flow type tower used to remove lowenergy, non-recyclable waste heat from the air separation unit and gasification process equipment. Two cooling water pumps circulate cooling water to plant process equipment. Air is drawn through the packing by three induced draft fans, located atop each cell within a sealed plenum. Makeup water from PSI's water treatment system is used to replenish water losses from evaporation and cooling tower blowdown.

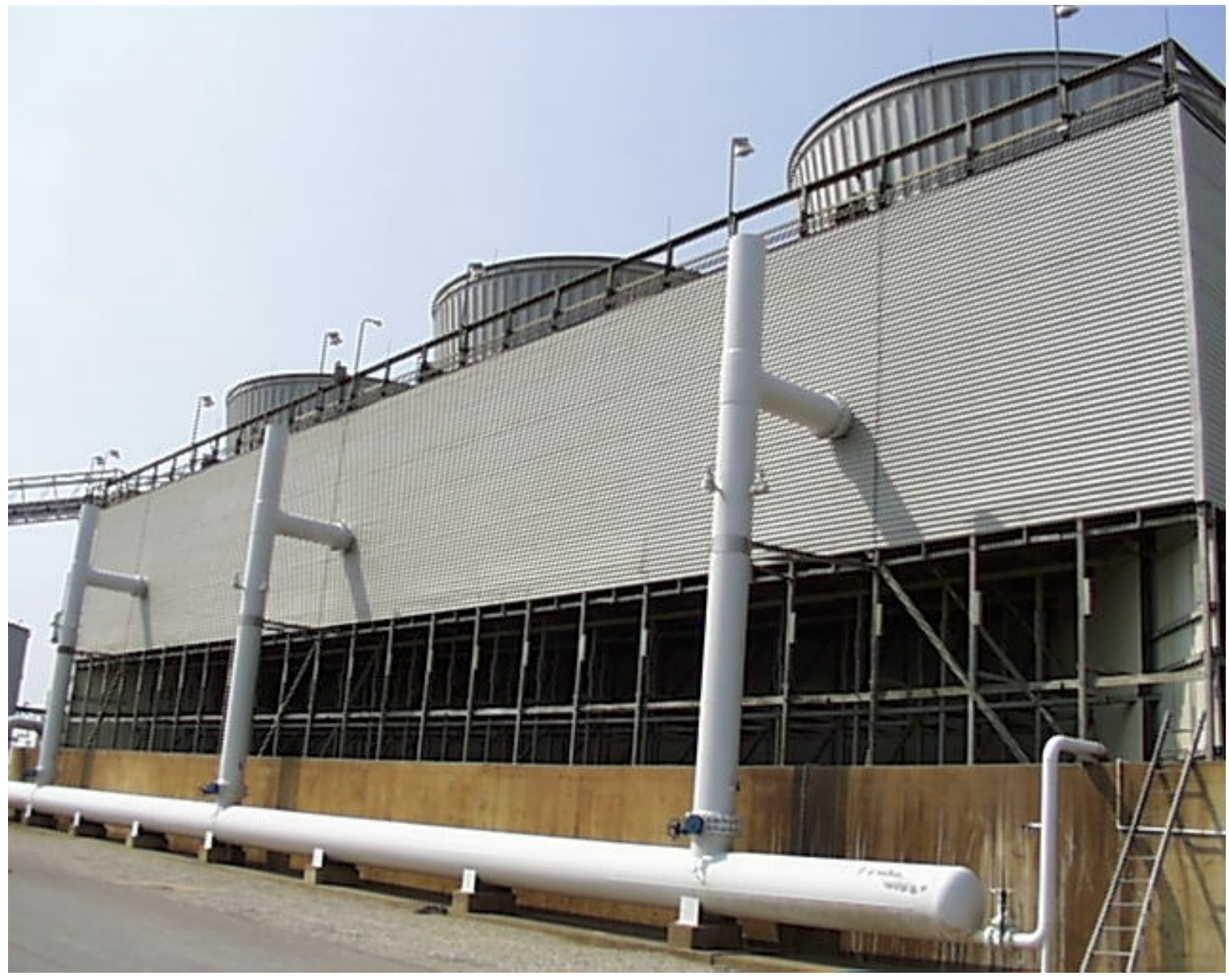

Figure 5.3.14A: Cooling Tower Water System 


\subsubsection{System Modifications}

Start-up of the cooling tower during plant commissioning in 1995 was mechanically uneventful. However, the supply water to the tower was high in total solids necessitating the use of sidestream filtration units to prevent fouling and corrosion of process equipment. Unexpectedly high corrosivity and solids levels in the supply water resulted in the complete revision of the planned treatment program for the cooling tower. Control of deposition and under-deposit corrosion was partially alleviated by use of an iron dispersing agent and tighter $\mathrm{pH}$ control by PSI's water treatment facility. The supply water quality to the cooling tower remained problematic through 1996, 1997 and 1998. Maintenance for the cooling tower equipment was limited to preventative and minor maintenance during the period 1996 through 1998.

\subsubsection{Operating Experience Overview}

There was no downtime associated with the Cooling Tower during the Operating Period. Operating experience for individual pieces of equipment follows.

\section{Cooling Tower Pumps}

The cooling tower pumps are set up with two operating pumps and an on-line spare. To maintain comparable operating hours on all three pumps, the operating pumps are rotated as part of an established predictive/preventive maintenance plan. The cooling tower pumps were in service without major maintenance for the entire Operating Period. Maintenance items were limited to preventative oil changes, packing gland leak repairs and lantern ring changes.

\section{Cooling Tower Fans}

The three cooling tower fans were in service for the entire Operating Period. Several fuses were replaced in fan motor speed controllers before a mismatch between the Programmable Logic Controller (PLC) language for the controllers and the Central Control System language was recognized as the cause of this problem. Other maintenance was preventative only during the Operating Period. 


\section{Other Equipment}

There was no maintenance, downtime or operational problem associated with the following equipment during the Operating Period: structural timbers, polymer honeycomb fill, drift eliminators, distribution system, fan stacks, casing, partitions and windwalls, sprinklers and hangers for the fire protection wet down system.

\subsubsection{Summary and Conclusions}

The cooling tower has performed to design specifications. However, the load placed on the system by a higher-than-expected ASU demand has limited the cooling capacity available for other parts of the facility. In particular, the higher-than-expected temperature of the cooling tower water curtails the amine unit absorption capacity during hot, summer days. This necessitates running the amine absorption system at a higher contact rate than desirable. A larger capacity cooling tower or a separate refrigeration unit for the amine system should be evaluated for the next plant. After the Operating Period, the entire cooling tower system was taken out of service and inspected. The only finding of significance was that the original carbon steel hangers for the fire protection distribution piping were badly corroded. The hangers were replaced. 


\subsection{Power Block}

\subsubsection{Combustion Turbine}

The combustion turbine (CT) is a General Electric MS-7001F single-shaft combustion turbine, designed for operation as a simple-cycle unit or in a combined steam and combustion turbine cycle. The MS-7001F combustion turbine assembly contains the following major sections:

\begin{tabular}{|l|l|}
\hline Air inlet plenum (Figure 5.4.1A) & Compressor \\
\hline Combustion system & Turbine/Generator \\
\hline Exhaust duct (Figure 5.4.1A) & \\
\hline
\end{tabular}

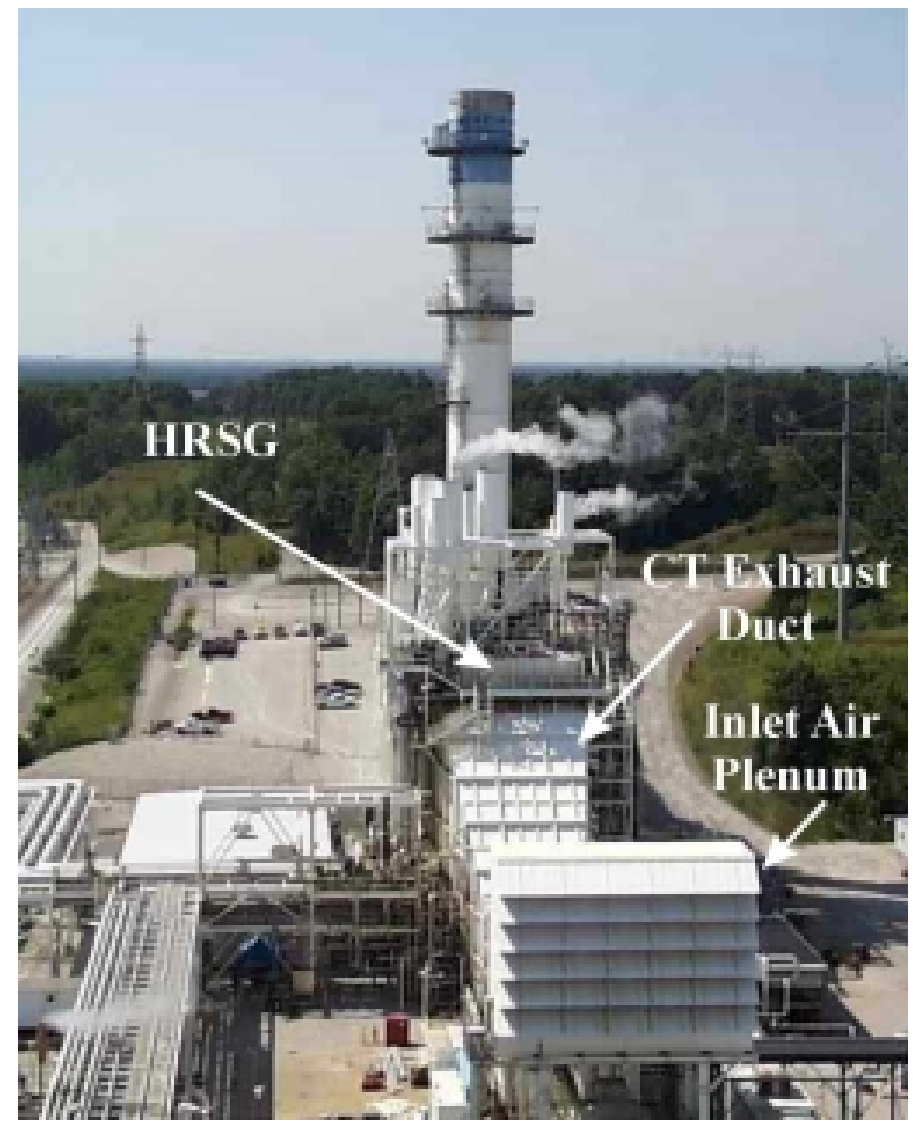

Figure 5.4.1A: Combustion Turbine 


\subsubsection{System Modifications}

Prior to the Operating Period, the combustion liners failed due to extensive cracking. The manufacturer was contacted and the liners were replaced with like-for-like material until an upgrade or resolution could be found. Recent inspection revealed continued cracking of the liner and deterioration of the coating material. Problems continue to plague the combustor liners in the turbine due to the elevated firing temperatures of the 7FA turbine. While the unit continues to operate within the temperature specifications outlined by the manufacturer, cracking and liner wear continue to be a problem. The manufacturer is currently working on a new liner design that will incorporate an upgraded liner coating, which should increase liner life.

The original $\mathrm{NO}_{\mathrm{x}}$ steam injection control valves have had a tendency to stick or become sluggish during operation. These valves play a critical role in the control of nitrogen oxide emissions and modulate to vary the amount of steam injection, depending on emission levels. To resolve the problem, the equipment manufacturer has recommended a change in these valves and they will be replaced with an upgraded version in 2000.

\subsubsection{Operating Experience and Overview}

\section{Combustion System}

In late March of 1998, a stop ratio fuel control valve failed on the combustion section of the CT due to failure of a hime joint actuator. The original equipment manufacturer was contacted and the hime joint design was changed. There have been no further failures of this valve since replacement of the hime joint; however, the OEM has recommended installation of an upgraded valve with an improved seal design be installed at a later date.

In mid-April, start-up of the facility was delayed due to an exhaust temperature differential warning that prevented synchronization of the turbine with the generator. Outlet temperature thermocouples are located around the circumference of the combustor exhaust to ensure even temperature distribution and proper fuel flow/ignition in the combustion section of the CT. During start-up on fuel oil, the temperature indications revealed an uneven distribution of temperature in the exhaust and the CT was prevented from synchronizing with the 
turbine/generator. Due to a delay in determining the cause of the failure, the gasification plant had to be taken off of coal operations. The exact cause of the uneven temperature distribution was never determined. The OEM recommended removal of all fuel inlet nozzles for inspection and flow testing before operation could be resumed. After conducting the inspection, the unit was restarted with no further problems.

\section{$\underline{\text { Other Equipment }}$}

There was no maintenance downtime or other operational problem associated with the air inlet plenum, compressor, turbine generator or exhaust ducting during the Operating Period.

\subsubsection{Summary and Conclusions}

Overall, the combustion turbine and its components have operated as expected since the project began operation in 1995. While increased operating temperatures on the 7FA turbine have identified areas requiring additional engineering, the unit has operated within the design specifications of the manufacturer. Operational difficulties associated with initial start-up and transfer procedures from fuel to syngas operation have been resolved and critical transferring equipment internal to the $\mathrm{CT}$ has been identified and put on appropriate preventative maintenance schedules based on operational history. Some combustion turbine systems merit discussion regarding continued concern or modifications that have taken place since the Operating Period.

It was recognized, early in the operation of the CT, that the temperature of the inlet air during the summer months curtailed power output. During the spring of 1999, PSI installed a water mist system in the inlet air plenum to cool the incoming air, thus regaining a portion of lost power output during the hottest months. This system ran only briefly during 1999 and will be further evaluated in 2000 .

In March 1999, the compressor section of the combustion turbine failed. Investigation revealed that the failure occurred in the $14^{\text {th }}$ stage stator blades and propagated downstream, causing extensive damage to the compressor section. Damage from the $14^{\text {th }}$ stage downstream was catastrophic in nature and required complete replacement of all rotating and stationary parts. 
Due to schedule considerations and opportunities to upgrade the compressor, the decision was made to purchase and install a new upgrade from the manufacturer. The root cause of this failure has not been made public by the combustion turbine manufacturer and PSI. Other 7FA combustion turbines operating on natural gas appear to have experienced similar failures, and it has been concluded and publicized that this failure was not related to operation on syngas.

The benefits of "off-line" versus "on-line" water washing of the compressor section continues to be evaluated. Currently, the compressor is water washed off line even though some minimum amount of power degradation is realized during continuous operation. This degradation is considered minimal at this time, but on-line washing will be re-evaluated as continuous run-time on the turbine increases. 


\subsubsection{Heat Recovery Steam Generator}

The heat recovery steam generator (HRSG) has a design steam flow of 753,180 lbs/hr at a superheater pressure of 1725 psig. The HRSG design is a bottom supported structure, which contains six circuits of convection heat transfer surfaces. There was no downtime attributable to the HRSG during the Operating Period.

\subsubsection{System Modifications}

Prior to the Operating Period it was determined by the equipment manufacturer that the feedwater heater section could not be operated. During start-up conditions the superheat, reheat and evaporator sections would not absorb sufficient heat from the combustion turbine exhaust to prevent boiling in the tubes of the feedwater heater. Additionally, when operating in full syngas operation, the feedwater heater would vaporize the water in this section which would create a flashing of steam and quenching of tube material which could eventually lead to tube damage. The feedwater heater was removed from service almost immediately after start-up in 1995 and has never been used in the HRSG.

\subsubsection{Operating Experience}

The total downtime associated with the HRSG during the operating period was 201 hours. In April, June, August and September, HRSG tube leaks prevented or interrupted gasifier operation for a total of 201 hours. All these leaks are similar due to a design oversight that did not allow for proper thermal expansion of the HRSG piping. Efforts to address these failures are further discussed in Section 5.4.2.3 below.

\subsubsection{Summary and Conclusions}

The superheat and reheat sections of the HRSG have experienced an abnormal number of tube leaks. In an effort to resolve the problems, the design engineering firm has engineered and installed several modifications; however, these modifications have not been successful to date. Engineering review of the original design has revealed that the superheater and reheater outlet headers and external piping did not allow for proper piping movement. The external piping had to have additional hangers and supports installed to ensure headers and piping move together. 
Another major design concern is support of all piping circuits within the HRSG. All of the piping circuits in the HRSG are bottom supported; consequently, movement of piping during heat-up and shutdown is limited and does not provide for sufficient expansion and contraction of the tubes without excess stress being applied at tube turns. This has been the cause of numerous failures during the life of the project. It is recommended that in the installation of future HRSG's of this type that tubes be hung from the ceiling of the upper shell rather than rigidly supported from the bottom of the unit. This should allow for proper expansion and contraction with a minimum of stress on the tube turns and piping. The plant is currently pursuing a replacement design for the superheat and reheat sections of the HRSG to limit further downtime associated with this design.

Another source of power block downtime has been the failure of superheat and reheat section header expansion joints at the HRSG casing. Manufacturer inspection revealed that the penthouse roof panels were binding the headers on these two sections. When these expansion joints have failed, it has caused fires in adjacent electrical cable trays. To correct this problem, the expansion joint design has been modified and heat shielding has been installed on the electrical cable trays and conduit to protect it against heat damage. Additionally, the roof panels and retaining clips were trimmed to allow for additional expansion and contraction. Currently, these expansion joints still leak and additional expansion joint design changes are planned to correct this problem.

The HRSG inlet duct and boiler casing have experienced several hot spots and the inlet duct liners have shifted in the past, causing gas leakage in the expansion joints. To correct the problem, the inlet duct was repositioned and new duct liner locating pins were installed. The expansion joint was repaired and additional insulation was installed in the overheated areas of the duct and casing to prevent further hot spot damage. 


\subsubsection{Water Treatment/Handling System}

The water treatment/handling system consists of the following equipment:

\begin{tabular}{|l|l|}
\hline Clarifier & Multimedia filtration \\
\hline Demineralization & Feedwater supply \\
\hline Pumping equipment & \\
\hline
\end{tabular}

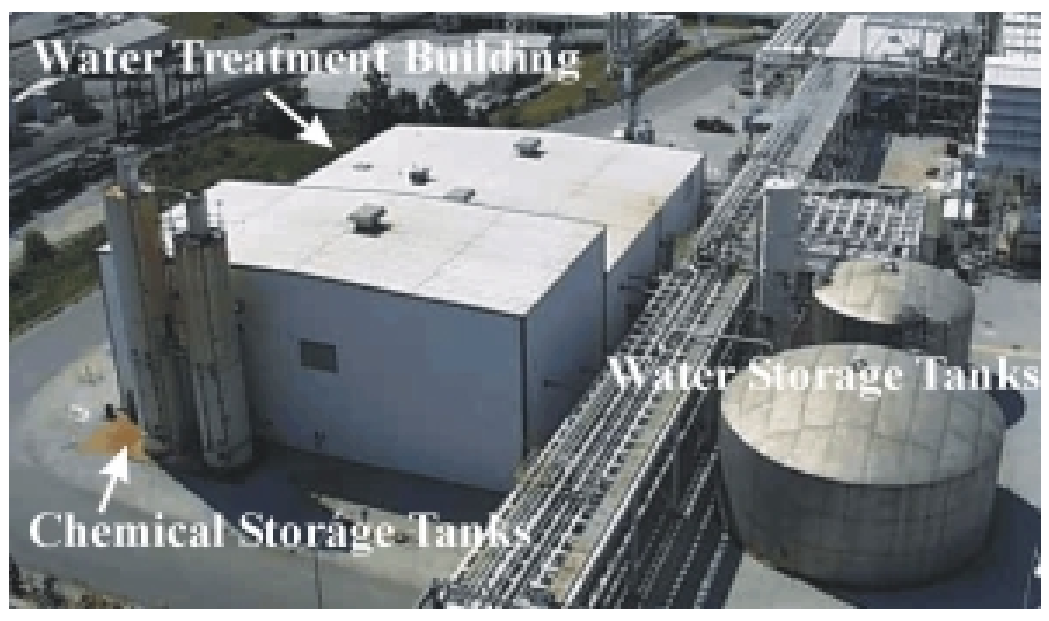

Figure 5.4.3A: Water Treatment/Handling System

\subsubsection{System Modifications}

With the exception of minor chemical treatment applications associated with the potable water system, there have been no major modifications to this system after the original start-up date.

\subsubsection{Operating Experience}

In mid-October 1998, 13 hours of downtime were due to a piping failure of the main feedwater line from the main power station to the repowering water treatment facility. Investigation revealed that the buried high-pressure feedwater supply line had split and operations at the site had to be suspended until it was repaired. The location of the failure was identified and a piping clamp was installed as a temporary measure to enable the facility to resume operation. The cause of the failure is suspected to be either isolated internal or external corrosion to the carbon steel line. The affected area of piping was repaired or replaced during the next outage. 


\subsubsection{Summary and Conclusions}

While the design and operation of this system has been adequate for the water demands of the facility, several minor problems still impact overall continuous operations. Early in the Demonstration Period it was determined that proper clarifier operation provides process feedwater with low alkalinity. While this is ideal for demineralizer feedwater, this low alkalinity water aggressively attacks carbon steel piping; when $\mathrm{pH}$ is controlled between 8.0 to 8.2 , there is low buffering ability. While chemical treatment has reduced corrosion rates significantly, process and potable water piping going to the gasification process still experiences elevated corrosion rates and piping failures due to the corrosive nature of the water. To resolve this problem, additional chemical treatment and metallurgy considerations are being reviewed and implemented, where applicable.

Each of the two demineralizer trains is designed to produce an effluent with a conductance of less than 0.1 microsiemens when operating at a rate of 480 gallons per minute. Packed bed units of this size proved to be challenging for the manufacturer to produce. The design was based on a scaled-up version of a smaller demineralizer. While simply making some components bigger to achieve performance specification seemed realistic, these units have never realized the economic benefits that packed bed units should provide. Throughput and quality limits are achievable, but at a cost that is high by industry standards. Operations personnel continue to investigate ways to reduce total chemical costs during regeneration of these units while also seeking methods to enhance overall performance.

An unexpected event occurred immediately after start-up of the demineralizer trains when Operations personnel were informed that the original equipment manufacturer was going out of business. This created a situation where engineering support and operational assistance were non-existent and made optimization of the process very difficult and time consuming. Additionally problems have been encountered with spare parts availability and any potential design changes to the system, including system expansion if required, will be negatively impacted by the lack of original equipment manufacturer input. 


\subsubsection{Steam Turbine}

The steam turbine, located in PSI's existing main station powerhouse, was originally supplied by Westinghouse and went into commercial operation in 1953 at a nominal rating of $99 \mathrm{MW}$. The turbine was designed for reheat operation with five levels of extraction steam used for feedwater heating. In the reconfigured design, feedwater is heated in both the HRSG and the gasification process, eliminating the need for the extraction steam. Therefore, the steam previously extracted now passes through the steam turbine to generate $105 \mathrm{MW}$ of power. Minor modifications to the original turbine steam path were made to ensure acceptable steam path velocities. All other equipment remains as original. There was no downtime associated with the steam turbine during the Operating Period.

\subsubsection{System Modifications}

There have been no modifications to the reconfigured design of the steam turbine package prior to, or after, the Operating Period.

\subsubsection{Operating Experience}

The steam turbine and its subsystems operated within design specifications during the Operating Period. The total downtime associated with the steam turbine during the Operating Period was 9 hours. In October of 1998, failure of several tubes in the steam ejector condenser delayed startup of the facility for 9 hours. The Tubes were repaired and no further problems have been noted.

\subsubsection{Summary and Conclusions}

The operation of the steam turbine has been uneventful during the Demonstration Period with only minor preventative maintenance performed on the unit. The only event that led to downtime in the four-year operation was due to a warm-up vent valve packing failure, which occurred in January 1996. The vent valve was replaced with an identical valve and the turbine returned to service. Additionally, Operations continued to deal with repeated fouling and leak repair of the steam ejector condenser exchanger tubes due to corrosion and corrosion by-products depositing on the tube walls. Preventative maintenance and appropriately timed flushing of the exchanger have reduced the frequency of fouling and tube replacement. 


\subsection{ENVIRONMENTAL PERFORMANCE}

Project compliance monitoring includes all monitoring that is required by Federal, State and local governmental agencies to satisfy statutes, regulations and terms of leases, permits, grants and other requirements. The permits dictate the monitoring and documentation requirements and reports to regulating agencies. In addition, the Project concluded an Environmental Monitoring Plan (EMP) as required by the Cooperative Agreement. Through the permit and EMP requirement, monitoring of the environmental performance of the Project has been well documented in the reporting requirements of these programs and will be summarized here for the Demonstration Period. The basis for the information contained herein, will be the sampling and analysis program outlined under the EMP and will include information on the non-proprietary process streams and environmental streams of concern. For several of the streams, only years 1997 and 1998 of the Demonstration Period were reported here as the years 1996 and 1999 both had limited operation. Under the requirements of the EMP, Table 6.0A lists the streams monitored under the Cooperative Agreement while Figure 6.0A illustrates their location in the process flow map. 
Table 6.0A: Key to Monitoring Locations

\begin{tabular}{|c|c|c|}
\hline $\begin{array}{c}\text { Location } \\
\text { Designator }\end{array}$ & $\begin{array}{c}\text { Proprietary/ } \\
\text { Non-Proprietary } \\
\text { Status } \\
\end{array}$ & Description of Monitoring Location \\
\hline 1 & NP & Coal Slurry \\
\hline 2 & $\mathrm{P}$ & Raw Syngas \\
\hline 3 & $\mathrm{P}$ & Sour Syngas \\
\hline 4 & $\mathrm{P}$ & Sour Water \\
\hline 5 & $\mathrm{P}$ & Acid Gas \\
\hline 6 & $P$ & Tail Gas \\
\hline 7 & NP & Tail Gas Incinerator Stack Gas \\
\hline 8 & NP & Sweet Syngas \\
\hline 9 & $\mathrm{NP}$ & GT/HRSG Stack Gas \\
\hline 10 & NP & Slag \\
\hline 11 & NP & Sulfur \\
\hline 12 & $\mathrm{NP}$ & Non-Contact Cooling Water (Outfall 001) \\
\hline 13 & $\mathrm{NP}$ & Process Waste Water (Gasification Plant) \\
\hline 14 & NP & $\begin{array}{l}\text { Treatment Pond Discharge to Ash Pond } \\
\text { (Internal Outfall 102) }\end{array}$ \\
\hline 15 & $\mathrm{NP}$ & Ash Pond Effluent (Outfall 002) \\
\hline 16 & NP & Equipment Leak Fugitive Emissions \\
\hline 17 & $\mathrm{NP}$ & Slurry Facility Fugitive Emissions \\
\hline 18 & $\mathrm{NP}$ & Slag Handling Fugitive Emissions \\
\hline 19 & NP & Coal Handling Fugitive Emissions \\
\hline 20 & NP & Slag Transport and Storage Fugitive Emissions \\
\hline
\end{tabular}




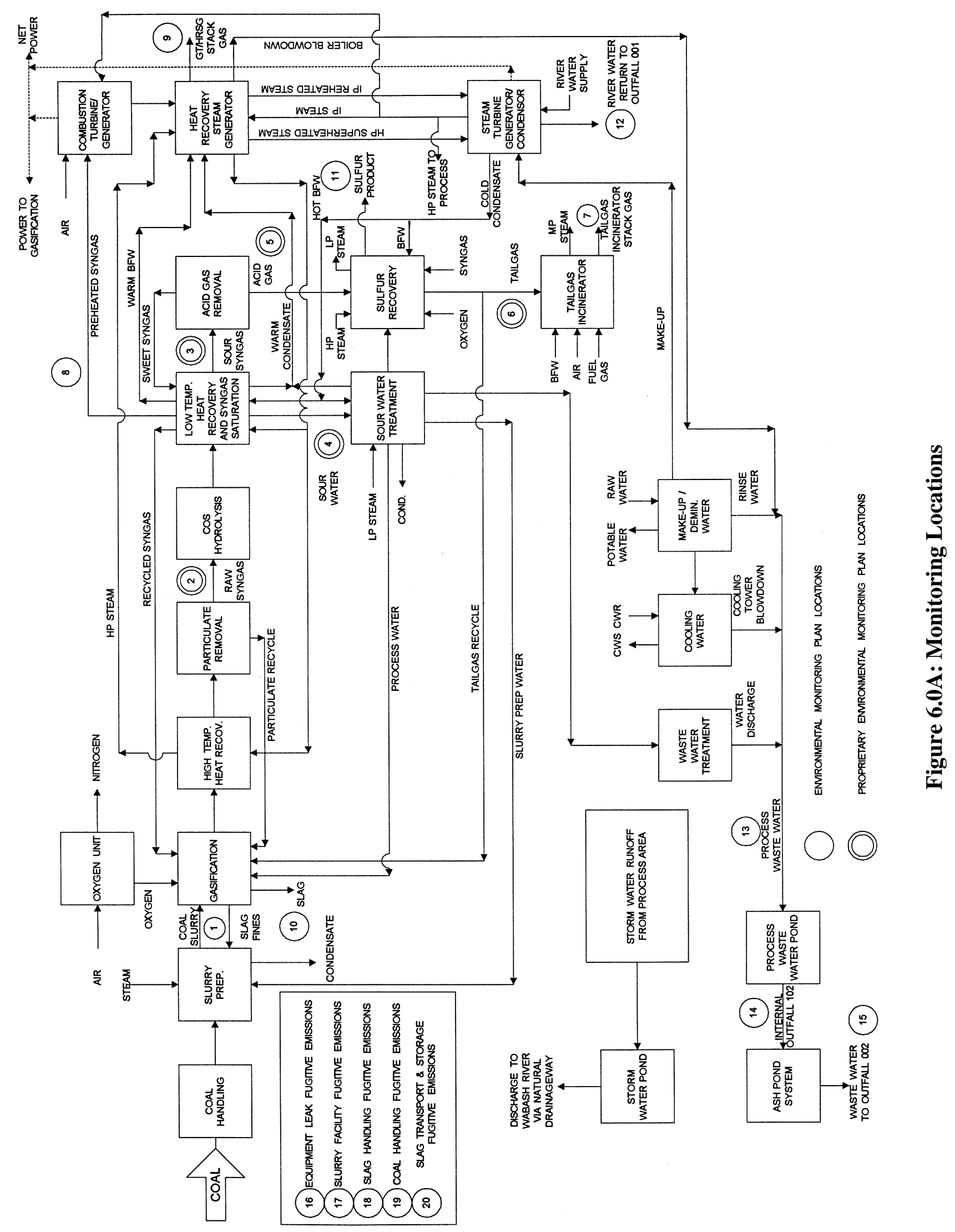

Wabash River Coal Gasification Repowering Project Final Technical Report 


\subsection{Non-Proprietary Streams}

Analytical process information of the non-proprietary streams as designated under the EMP was compiled by on-site laboratory personnel and by independent laboratories to fulfill the requirements under the EMP.

Stream 1: Coal Slurry to the Gasifier

A series of coal slurry samples were analyzed for determination of Group I and Group II Metals analysis at the beginning of each operational campaign on the coal, blunted coal, and petroleum coke feed stocks (approximately 50 samples per year). Table 6.1A illustrates the average values for the years of 1997 and 1998:

Table 6.1A: Coal Slurry Analysis

\begin{tabular}{|c|c|c|}
\hline Units & 1997 Average Analysis & 1998 Average Analysis \\
\hline
\end{tabular}

\begin{tabular}{|l|c|c|c|}
\hline Group I Metals & & & \\
Antimony & $\mathrm{mg} / \mathrm{kg}$ & $<10.0$ & 0.75 \\
Arsenic & $\mathrm{mg} / \mathrm{kg}$ & $<0.0$ & 1.78 \\
Cadmium & $\mathrm{mg} / \mathrm{kg}$ & 4.55 & 0.31 \\
Chromium & $\mathrm{mg} / \mathrm{kg}$ & 1.67 & 5.55 \\
Cobalt & $\mathrm{g} / \mathrm{kg}$ & 12.07 & 0.932 \\
Manganese & $\mathrm{mg} / \mathrm{kg}$ & $<0.080$ & 12.33 \\
Mercury & $\mathrm{mg} / \mathrm{kg}$ & 4.97 & $\mathrm{ND}$ \\
Nickel & $\mathrm{mg} / \mathrm{kg}$ & & 15.99 \\
Selenium & $\mathrm{mg} / \mathrm{kg}$ & & 0.08 \\
& & & \\
\hline Group II Metals & & 323.33 & \\
& & 6.34 & 814 \\
Aluminum & $\mathrm{mg} / \mathrm{kg}$ & 1.18 & 5.82 \\
Barium & $\mathrm{mg} / \mathrm{kg}$ & 99.20 & 1.81 \\
Beryllium & $\mathrm{mg} / \mathrm{kg}$ & 1787 & 106 \\
Boron & $\mathrm{mg} / \mathrm{kg}$ & 3.26 & 1361 \\
Calcium & $\mathrm{mg} / \mathrm{kg}$ & 5827 & 5.9 \\
Copper & $\mathrm{mg} / \mathrm{kg}$ & $<5.0$ & 12233 \\
Iron & $\mathrm{mg} / \mathrm{kg}$ & & 17.3 \\
Lead & $\mathrm{mg} / \mathrm{kg}$ & & \\
& & & \\
\hline
\end{tabular}


Table 6.1A: Coal Slurry Analysis (Continued)

\section{\begin{tabular}{|l|l|l|}
\hline Units & 1997 Average Analysis & 1998 Average Analysis \\
\hline
\end{tabular}}

\begin{tabular}{|l|c|c|c|}
\hline $\begin{array}{l}\text { Group II Metals } \\
\text { (Cont.) }\end{array}$ & & & \\
Magnesium & $\mathrm{mg} / \mathrm{kg}$ & 289 & 227 \\
Molybdenum & $\mathrm{mg} / \mathrm{kg}$ & $<1.0$ & 1.53 \\
Phosphorous & $\mathrm{mg} / \mathrm{LP}$ & 18.67 & 10.52 \\
Potassium & $\mathrm{mg} / \mathrm{kg}$ & 118 & 483 \\
Silicon & $\mathrm{mg} / \mathrm{kg}$ & 152 & 450 \\
Silver & $\mathrm{mg} / \mathrm{kg}$ & $<1.0$ & 0.553 \\
Sodium & $\mathrm{mg} / \mathrm{kg}$ & 394 & 212 \\
Thallium & $\mathrm{mg} / \mathrm{kg}$ & $<20$ & 1.25 \\
Vanadium & $\mathrm{mg} / \mathrm{kg}$ & 9.57 & 9.30 \\
Zinc & $\mathrm{mg} / \mathrm{kg}$ & 26.70 & 49.3 \\
& & & \\
\hline Ultimate Analysis & & & 71.12 \\
& & & 4.95 \\
Carbon & wt $\%$ & 69.0 & 1.41 \\
Hydrogen & wt \% & 4.72 & 8.51 \\
Nitrogen & wt $\%$ & 1.46 & 2.89 \\
Oxygen & wt $\%$ & 12.9 & 11.12 \\
Sulfur & wt $\%$ & 0.29 & \\
Ash & wt \% & 11.56 & \\
& & & \\
\hline
\end{tabular}

\section{Stream 7: Tail Gas Incinerator Stack Gas}

The tail gas incinerator stack operates under the provisions of State and Federal Prevention of

Significant Deterioration (PSD) air permits administered by the Vigo County Air Pollution Control agency. There are separate air permits for gasification plant sources and combined-cycle power plant air emission sources.

Under the guidelines of this permit, pollution standards have been set for various emission points for the facility. Listed in Table 6.1B that follows is an outline of the permit limits for the Tail Gas Incinerator. 
Table 6.1B: Tail Gas Incinerator Permit Limits

\begin{tabular}{||l|c|c|c|}
\hline \multicolumn{1}{|c|}{ Process } & Pollutant & $\mathbf{l b} / \mathbf{h r}$ & tons/yr \\
\hline \hline \multicolumn{4}{|c|}{} \\
\hline Tail Gas Incinerator & Sulfur Dioxide & 527 & 944 \\
\hline Tail Gas Incinerator & Carbon Monoxide & 56 & 221 \\
\hline Tail Gas Incinerator & Sulfuric Acid Mist & 3.79 & 6.8 \\
\hline
\end{tabular}

During the second quarter of 1996, stack testing of the tail gas incinerator was conducted to prove the reliability of the monitoring system. Testing was done during a period of relatively high emissions prior to optimization of the facility's COS hydrolysis unit and AGR/SRU systems and is not indicative of longer term average emissions from this source. Table 6.1C illustrates the results of the test work.

Table 6.1C: Initial Compliance Stack Testing

\begin{tabular}{|l|c|c|l|}
\hline \multicolumn{1}{|c|}{ Process } & Pollutant & lb/hr & \multicolumn{1}{c|}{ Remarks } \\
\hline Tail Gas Incinerator & Sulfur Dioxide & 342.66 & $\begin{array}{l}\text { Value represents an average of 10 } \\
\text { separate 30-minute readings. } \\
\text { Monitor proved relative accuracy } \\
\text { within } 6.89 \mathrm{lb} / \mathrm{hr} \text {. Values varied } \\
\text { from a low of } 145 \mathrm{lb} / \mathrm{hr} \text { to a high } \\
\text { of 487 lb/hr. This unit was then } \\
\text { qualified under 40 CFR parts 60 } \\
\text { and 75 as an acceptable monitor } \\
\text { with no bias. }\end{array}$ \\
\hline Tail Gas Incinerator & Carbon Monoxide & 0.46 & $\begin{array}{l}\text { Well below permitted value and } \\
\text { demonstrates unit in compliance } \\
\text { with permit. CO is not } \\
\text { continuously monitored. }\end{array}$ \\
\hline Tail Gas Incinerator & Sulfuric Acid Mist & 2.69 & $\begin{array}{l}\text { Demonstrates compliance with the } \\
\text { permit. } \mathrm{H}_{2} \mathrm{SO}_{4} \text { is not continuously } \\
\text { monitored. }\end{array}$ \\
\hline
\end{tabular}

Following this initial test work, quarterly "Relative Accuracy" tests were conducted on the stack monitoring equipment to ensure the reliability of the data collected. The tail gas stack is required 
to monitor sulfur dioxide $\left(\mathrm{SO}_{2}\right)$ emissions on a continuous basis, along with flow and temperature monitoring, to ensure compliance with permitted limits.

Based on the results of this stack testing, and additional testing conducted for the EMP, calculated values for carbon monoxide $(\mathrm{CO})$ and sulfuric acid $\left(\mathrm{H}_{2} \mathrm{SO}_{4}\right)$ mist are reported to the administrative agency on an annual basis. From November of 1997 to December 31, 1999, Wabash River continued to operate within the guidelines of both Federal and State regulations and only exceeded emission limits when equipment malfunctions occurred. Specific information regarding these events is covered, in full detail, in the Environmental Monitoring Plan quarterly and annual reports and will not be reproduced here. It is essential to note that none of these emission exceedances resulted in violations of the air permits because each malfunction was properly addressed under the requirements of the regulations.

In both 1997 and 1998, comprehensive stack testing was done to meet the requirements of the EMP. The results of those tests are detailed in Table 6.1D.

Table 6.1D: 1997 and 1998 Stack Testing Results

\begin{tabular}{|c|c|c|c|}
\hline " Constituent & "Units & 1997 Testing & 1998 Testing \\
\hline Antimony & $\mathrm{lb} / \mathrm{hr}$ & $<0.000239$ & $<0.00000667$ \\
\hline Arsenic & $\mathrm{lb} / \mathrm{hr}$ & 0.000358 & 0.000224 \\
\hline Cadmium & $\mathrm{lb} / \mathrm{hr}$ & $<0.000119$ & 0.0000551 \\
\hline Cobalt & $\mathrm{lb} / \mathrm{hr}$ & 0.000222 & 0.00000741 \\
\hline Manganese & $\mathrm{lb} / \mathrm{hr}$ & $<0.0000314$ & 0.000188 \\
\hline Mercury & $\mathrm{lb} / \mathrm{hr}$ & 0.000930 & 0.000161 \\
\hline Nickel & $\mathrm{lb} / \mathrm{hr}$ & 0.0000971 & 0.000137 \\
\hline Selenium & $\mathrm{lb} / \mathrm{hr}$ & 0.0000958 & $<0.00000383$ \\
\hline $\mathrm{PM}_{10}$ & $\mathrm{lb} / \mathrm{hr}$ & 0.28 & 0.57 \\
\hline Sulfuric Acid & $\mathrm{lb} / \mathrm{hr}$ & 1.98 & 0.24 \\
\hline Hydrogen Sulfide & $\mathrm{lb} / \mathrm{hr}$ & $<0.00147$ & $<0.00217$ \\
\hline Benzene & $\mathrm{lb} / \mathrm{hr}$ & $<0.0125$ & $<0.00541$ \\
\hline Toluene & $\mathrm{lb} / \mathrm{hr}$ & $<0.0471$ & $<0.00639$ \\
\hline Ethyl Benzene & $\mathrm{lb} / \mathrm{hr}$ & $<0.00742$ & $<0.00736$ \\
\hline Total Xylenes & $\mathrm{lb} / \mathrm{hr}$ & $<0.004$ & $<0.00541$ \\
\hline Ammonia & $\mathrm{lb} / \mathrm{hr}$ & $<0.081$ & $<0.0031$ \\
\hline Cyanide & $\mathrm{lb} / \mathrm{hr}$ & $<0.003$ & $<0.0000606$ \\
\hline Phenol & $\mathrm{lb} / \mathrm{hr}$ & $<0.011$ & $<0.0002$ \\
\hline
\end{tabular}




\begin{tabular}{|l|c|c|c|}
\hline Hydrogen & $\mathrm{lb} / \mathrm{hr}$ & $<0.413$ & $<0.283$ \\
Methane & $\mathrm{lb} / \mathrm{hr}$ & $<0.367$ & $<0.270$ \\
Carbon Monoxide & $\mathrm{lb} / \mathrm{hr}$ & $<0.030$ & $<0.445$ \\
Sulfur Dioxide & $\mathrm{lb} / \mathrm{hr}$ & 67.4 & 14.64 \\
Nitrogen Oxides & $\mathrm{lb} / \mathrm{hr}$ & 8.82 & 5.33 \\
\hline
\end{tabular}

It should be noted that all values preceded by the < symbol are below the detection limits of the analytical procedure utilized. All analytical procedures utilized for this test work are in compliance with EPA accepted and/or recommended practices for environmental gaseous testing and are either outlined in EPA guidance documents or standard ASTM methodology.

Annual emission rates in tons/year were also provided to Vigo County Air Pollution Control and the Indiana Department of Environmental Management on a yearly basis as totalized from the continuous emissions monitor on the tail gas incinerator. Table 6.1E outlines the tons/year of permitted pollutants reported to these agencies for 1997 and 1998. The years of 1995, 1996 and 1999 were well below the permitted limits for the facility due to reduced operation and are not presented here, but can be found in the EMP reports for those years. Nitrogen oxides, $\mathrm{PM}_{10}$, and volatile organic compounds will be referenced later in this section.

Table 6.1E: Annual Emission Inventory - Tail Gas Incinerator Stack (Tons/Year)

\begin{tabular}{|c|c|c|}
\hline Constituent & 1997 Total Emissions & 1998 Total Emissions \\
\hline Sulfur Dioxide & 139.77 & 152.49 \\
\hline Carbon Monoxide & 0.029 & 0.588 \\
\hline Sulfuric Acid Mist & 3.84 & 0.633 \\
\hline Nitrogen Oxides & 17.13 & 14.07 \\
\hline $\mathrm{PM}_{10}$ & 3.85 & 1.51 \\
\hline Volatile Organics & 0.0019 & 0.0021 \\
\hline
\end{tabular}

\section{Stream 8: Sweet Syngas}

During the Demonstration Period, the quality of the product (sweet) syngas delivered to the combustion turbine was relatively consistent despite differing coal/fuel feeds. Table 6.1F illustrates the average values for the primary constituents in the sweet syngas. Variations in the quantity of sulfur compounds in the syngas are directly related to the operation of the COS 
hydrolysis unit and the AGR/SRU systems. Sections 4.0 and 5.0 provide more insight into the direct cause of these annualized variances as seen in the table.

Table 6.1F: Sweet Syngas Quality

\begin{tabular}{|c|c|c|c|c|}
\hline Constituent & 1996 & 1997 & $\overline{1998}$ & 1999 \\
\hline Hydrogen, vol \% & 33.6 & 33.65 & 33.35 & 32.66 \\
\hline Carbon Dioxide, vol \% & 15.83 & 16.75 & 15.62 & 15.75 \\
\hline Carbon Monoxide, vol \% & 44.44 & 44.45 & 45.54 & 45.52 \\
\hline Methane, vol \% & 1.82 & 1.92 & 2.06 & 1.99 \\
\hline Hydrogen Sulfide, ppmv & 39.39 & 42.48 & 75.24 & 95.98 \\
\hline Carbonyl Sulfide, ppmv & 64.89 & 37.34 & 26.78 & 15.92 \\
\hline
\end{tabular}

The sweet syngas product can also be directed to the process flare. Under the guidelines of the air permit for the flare source, pollution standards have been set and are listed in Table 6.1G below.

Table 6.1G: Flare Permit Limits

\begin{tabular}{|l|c|c|c|}
\hline \hline Process & Pollutant & lb/hr & tons/yr \\
\hline \multicolumn{4}{|l|}{} \\
\hline Flare & Carbon Monoxide & 11,099 & 1,401 \\
\hline
\end{tabular}

Stream 9: Gas Turbine and Heat Recovery Steam Generator

The combustion turbine stack operates under the provisions of State and Federal Prevention of Significant Deterioration (PSD) air permits administered by the Vigo County Air Pollution Control agency. Table $6.1 \mathrm{H}$ illustrates the emission limits in the permit for the combustion turbine stack. 
Table 6.1H: Combustion Turbine Permit Limits

\begin{tabular}{||c|c|c|c|c|}
\hline Process & Pollutant & $\begin{array}{c}\text { Requirement } \\
\text { on Syngas }\end{array}$ & $\begin{array}{c}\text { Requirement } \\
\text { on Oil }\end{array}$ & Comments \\
\hline
\end{tabular}

\begin{tabular}{|c|c|c|c|c|}
\hline Gas Turbine Stack & Nitrogen Oxides & $25 \mathrm{ppmdv}$ & $65 \mathrm{ppmdv}$ & $\begin{array}{l}\text { Corrected to } 15 \% \text { oxygen and dry } \\
\text { conditions. }\end{array}$ \\
\hline Gas Turbine Stack & $\begin{array}{l}\text { Sulfur Content of } \\
\text { Fuel }\end{array}$ & $\leq 360 \mathrm{ppmdv}$ & $\begin{aligned} & \leq 0.05 \% \text { by } \\
& \text { weight }\end{aligned}$ & $\begin{array}{l}\text { Satisfies the requirements of } 40 \\
\text { CFR } 60.333\end{array}$ \\
\hline Gas Turbine Stack & Opacity & $\begin{array}{c}20 \% \\
\text { maximum }\end{array}$ & $\begin{array}{c}60 \% \\
\text { maximum }\end{array}$ & $\begin{array}{l}\text { Fuel oil limit is based on a time } \\
\text { limit of } 10 \text { minutes per } 24 \text { hours } \\
\text { allotted for start-up. }\end{array}$ \\
\hline Gas Turbine Stack & Carbon Monoxide & $15 \mathrm{ppm}$ & $25 \mathrm{ppm}$ & $\begin{array}{l}\text { Values corrected to } 15 \% \text { oxygen } \\
\text { and } 75 \% \text { or greater load. }\end{array}$ \\
\hline Gas Turbine Stack & Sulfuric Acid Mist & $\begin{array}{c}0.01 \\
\text { lb/MMBtu }\end{array}$ & & $\begin{array}{l}\text { Controlled by limiting fuel gas to } \\
\text { less than or equal to } 360 \text { ppmdv } \\
\text { of sulfur and ensuring that } \\
\text { exhaust stack temperature is } \\
\text { maintained at or above } 264^{\circ} \mathrm{F} \text {. }\end{array}$ \\
\hline
\end{tabular}

Included in PSI's operational permit for the power block are limits on their combustion turbine and auxiliary boiler, not included in this report, as part of the overall permit for the main generating station. Compliance testing for these units was conducted in mid-year 1996 and both units met emission requirements as outlined in the operating permit. Some minor difficulties were initially encountered with the data logger system for the emission points, but were rectified early in the Demonstration Period with the installation of a more compatible software program.

Emissions, reported on an annualized basis in the form of an Annual Emission Inventory Report to the Indiana Department of Environmental Management (IDEM), are listed in Table 6.1I on a tons/year basis for the years of 1997 and 1998. These figures represent total emissions from the Power Block to include stack emissions and total fugitive emissions based on EPA publication AP-42 "Compilation of Air Pollutant Emission Factors" calculated methods and from direct emission monitoring equipment. The quantity of total annual stack emissions is directly related to the coal sulfur content, the efficiency of the gasification plant sulfur removal and recovery systems, and the quantity of syngas and fuel oil burned in the combustion turbine during the year. 
Table 6.1I: Power Block Emissions (Tons/Year)

\begin{tabular}{|c|c|c|}
\hline Constituent & 1997 & 1998 \\
\hline Sulfur Dioxide & 666.99 & 872.34 \\
\hline Nitrogen Oxides & 76.87 & 107.96 \\
\hline Carbon Monoxide & 33.67 & 29.68 \\
\hline $\mathrm{PM}_{10}$ & 41.26 & 55.98 \\
\hline Volatile Organics & 8.83 & 3.13 \\
\hline
\end{tabular}

Stream 10: Slag

Vitrified frit, also known as slag, is a by-product of coal gasification and represents the noncombustible portion of the coal leaving the gasifier. Table 6.1J represents the analytical data results for this stream for the operational years of 1997 and 1998. The slag has been determined through laboratory analysis (TCLP (total), which is representative of the total value of all leachable material in the slag) to be non-leachable and is classified as a non-hazardous byproduct, consistent with slag from many different feedstocks (lignite, sub-bituminous coal, bituminous coal, petroleum coke) processed through the E-Gas ${ }^{\mathrm{TM}}$ gasification process during the past three decades.

Table 6.1J: Slag Analysis

\begin{tabular}{|l|c|c|c|}
\hline Constituent & Units & 1997 Average Analysis & 1998 Average Analysis \\
\hline
\end{tabular}

\begin{tabular}{|l|c|c|c|}
\hline $\begin{array}{l}\text { Carbon Content } \\
\text { Moisture Content }\end{array}$ & $\begin{array}{c}\mathrm{wt} \% \\
\mathrm{wt} \%\end{array}$ & 15.67 & 7.91 \\
\hline Group I Metals & & 30.17 & 28.04 \\
& & & \\
Antimony & $\mathrm{mg} / \mathrm{kg}$ & $<10.0$ & 4.8 \\
Arsenic & $\mathrm{mg} / \mathrm{kg}$ & $<10.0$ & 6.39 \\
Cadmium & $\mathrm{mg} / \mathrm{kg}$ & 29.50 & 0.76 \\
Chromium & $\mathrm{mg} / \mathrm{kg}$ & 5.35 & 120 \\
Cobalt & $\mathrm{g} / \mathrm{kg}$ & 33.3 & 1.017 \\
Manganese & $\mathrm{mg} / \mathrm{kg}$ & $<0.08$ & 67 \\
Mercury & $\mathrm{mg} / \mathrm{kg}$ & 22.9 & $<0.01$ \\
Nickel & $\mathrm{mg} / \mathrm{kg}$ & $<10.0$ & 146.7 \\
Selenium & $\mathrm{mg} / \mathrm{kg}$ & & 3.02 \\
\hline
\end{tabular}


Table 6.1J: Slag Analysis (Continued)

\begin{tabular}{|l|c|c|c|}
\hline Constituent & Units & 1997 Average Analysis & 1998 Average Analysis \\
\hline \multicolumn{3}{|c|}{} & \multicolumn{2}{|c|}{} \\
\hline Group II Metals & & & \\
& & 8527 & 49600 \\
Aluminum & $\mathrm{mg} / \mathrm{kg}$ & 37.9 & 80 \\
Barium & $\mathrm{mg} / \mathrm{kg}$ & 2.03 & 10.9 \\
Beryllium & $\mathrm{mg} / \mathrm{kg}$ & 128 & 283 \\
Boron & $\mathrm{mg} / \mathrm{kg}$ & 9253 & 3246 \\
Calcium & $\mathrm{mg} / \mathrm{kg}$ & 12 & 54.1 \\
Copper & $\mathrm{mg} / \mathrm{kg}$ & 17267 & 105333 \\
Iron & $\mathrm{mg} / \mathrm{kg}$ & 8.19 & 97 \\
Lead & $\mathrm{mg} / \mathrm{kg}$ & 1383 & 2783 \\
Magnesium & $\mathrm{mg} / \mathrm{kg}$ & 3.30 & 8.63 \\
Molybdenum & $\mathrm{mg} / \mathrm{kg}$ & $<39$ & 2.0 \\
Phosphorous & $\mathrm{mg} / \mathrm{LP} *$ & 1687 & 7623 \\
Potassium & $\mathrm{mg} / \mathrm{kg}$ & 1207 & 2000 \\
Silicon & $\mathrm{mg} / \mathrm{kg}$ & $<1.0$ & 3.0 \\
Silver & $\mathrm{mg} / \mathrm{kg}$ & 743 & 1037 \\
Sodium & $\mathrm{mg} / \mathrm{kg}$ & $<0.4$ & 16 \\
Thallium & $\mathrm{mg} / \mathrm{kg}$ & 25.10 & 156 \\
Vanadium & $\mathrm{mg} / \mathrm{kg}$ & 32.97 & 213 \\
Zinc & $\mathrm{mg} / \mathrm{kg}$ & & $<0.12 * *$ \\
& & & \\
\hline & & & \\
TCLP (total) & $\mathrm{mg} / \mathrm{l}$ & & \\
\hline
\end{tabular}

*mg/LP=milligrams/Liter as Phosphate

***These values represent the total of all leachates present in the analyzed sample. Barium was the only constituent tested that presented leachable characteristics in the slag samples.

\section{$\underline{\text { Stream 11: Sulfur }}$}

Sulfur quality has remained very consistent throughout the entire Demonstration Period. The purity of the sulfur for the Demonstration Period was consistently above $99.999 \%$ on every quarterly analysis submitted to the purchaser of the by-product.

$\underline{\text { Stream 12: Non-Contact Cooling Water }}$

No analysis was required or conducted for this stream. There were no reported problems associated with this stream from either an environmental or operational standpoint. 
$\underline{\text { Streams } 13 \text { and 14: Process Waste Water (Outfall 102) }}$

Process waste water includes all waste water streams generated or captured during normal operations and equipment purges/wash-downs during maintenance activities. Stream 13 is specific to the internal monitoring of the gasificiation process while stream 14 represents the total waste water streams from the entire Repowering Project. The combined streams include, but are not limited to: cooling tower blowdown; gasification plant process waste water; regeneration waste water from the demineralizer system in the power block; rainwater collected in the process blocks for both gasification and the power block; equipment purges (blowdowns) and water wash-downs during maintenance preparation procedures; and un-recycled condensed water from the process.

Due to the inconsistencies of plant operation immediately after start-up and through 1996, IDEM agreed to suspend Outfall 102 monitoring and reporting requirements until April of 1997. Outfall 102 is the NPDES internal pond that was added to the Wabash River Generating Station water discharge permit for the sole purpose of monitoring the waste water discharge from the Repowering Project. Table $6.1 \mathrm{~K}$ lists the permitted constituents of the process stream along with the set limitations for discharge.

Table 6.1K: Process Waste Water Permit Limits

\begin{tabular}{||c|c|c||}
\hline \hline Parameter & Units & Quality or Concentration \\
\hline
\end{tabular}

\begin{tabular}{|l|c|c|c|}
\cline { 3 - 4 } \multicolumn{2}{c|}{} & Monthly Average & Daily Maximum \\
\hline Flow & $\mathrm{mg} / \mathrm{l}$ & Report & Report \\
\hline Ammonia, (as Nitrogen) & $\mathrm{mg} / \mathrm{l}$ & 27.14 & 54.29 \\
\hline Arsenic & $\mathrm{mg} / \mathrm{l}$ & 0.018 & 0.043 \\
\hline Cadmium & $\mathrm{mg} / \mathrm{l}$ & 0.010 & 0.025 \\
\hline Chromium & $\mathrm{mg} / \mathrm{l}$ & 3.47 & 8.07 \\
\hline Hexavalent Chromium & $\mathrm{mg} / \mathrm{l}$ & 0.014 & 0.032 \\
\hline Copper & $\mathrm{mg} / \mathrm{l}$ & 0.040 & 0.093 \\
\hline Cyanide & $\mathrm{mg} / \mathrm{l}$ & 0.019 & 0.044 \\
\hline Lead & $\mathrm{mg} / \mathrm{l}$ & 0.260 & 0.606 \\
\hline Mercury & $\mathrm{mg} / \mathrm{l}$ & 0.0005 & 0.001 \\
\hline Nickel & $\mathrm{mg} / \mathrm{l}$ & 2.91 & 6.78 \\
\hline Selenium & $\mathrm{mg} / \mathrm{l}$ & 0.017 & 0.040 \\
\hline Zinc & $\mathrm{mg} / \mathrm{l}$ & 0.241 & 0.560 \\
\hline pH & & 6.0 to 9.0 & 6.0 to 9.0 \\
\hline
\end{tabular}


Table 6.1L illustrates the monitoring results for each of the years indicated based on an annual average of monthly averages. The annual average for 1997 represents only the months of April through December. Daily maximum values can be reviewed in the Annual Environmental Monitoring Report for each of the years indicated.

Table 6.1L: Process Waste Water Discharge

\begin{tabular}{||l|c|c|c|c|c|c||}
\hline Parameter/Constituent & Units & $\begin{array}{c}\text { Monthly } \\
\text { Average }\end{array}$ & $\begin{array}{c}\text { Daily } \\
\text { Maximum }\end{array}$ & $\begin{array}{c}1997 \\
\text { Monthly } \\
\text { Average }\end{array}$ & $\begin{array}{c}1998 \\
\text { Monthly } \\
\text { Average }\end{array}$ & $\begin{array}{c}1999 \\
\text { Monthly } \\
\text { Average }\end{array}$ \\
\hline
\end{tabular}

\begin{tabular}{|l|c|c|c|c|c|c|}
\hline Ammonia, (as Nitrogen) & $\mathrm{mg} / \mathrm{l}$ & 27.14 & 54.29 & 3.93 & 6.56 & 8.8 \\
\hline Arsenic & $\mathrm{mg} / \mathrm{l}$ & 0.018 & 0.043 & 0.0077 & 0.0199 & $<0.01$ \\
\hline Cadmium & $\mathrm{mg} / \mathrm{l}$ & 0.010 & 0.025 & $<0.0038$ & $<0.008$ & $<0.01$ \\
\hline Chromium & $\mathrm{mg} / \mathrm{l}$ & 3.47 & 8.07 & $<0.006$ & $<0.0108$ & $<0.0167$ \\
\hline Hexavalent Chromium & $\mathrm{mg} / \mathrm{l}$ & 0.014 & 0.032 & $<0.01$ & $<0.0120$ & $<0.01$ \\
\hline Copper & $\mathrm{mg} / \mathrm{l}$ & 0.040 & 0.093 & $<0.01$ & $<0.0145$ & 0.0185 \\
\hline Cyanide & $\mathrm{mg} / \mathrm{l}$ & 0.019 & 0.044 & 0.107 & 0.2798 & 0.1438 \\
\hline Lead & $\mathrm{mg} / \mathrm{l}$ & 0.260 & 0.606 & $<0.08$ & $<0.08$ & $<0.08$ \\
\hline Mercury & $\mathrm{mg} / \mathrm{l}$ & 0.0005 & 0.001 & $<0.0005$ & $<0.0005$ & $<0.0006$ \\
\hline Nickel & $\mathrm{mg} / \mathrm{l}$ & 2.91 & 6.78 & $<0.02$ & $<0.0236$ & $<0.1140$ \\
\hline Selenium & $\mathrm{mg} / \mathrm{l}$ & 0.017 & 0.040 & 0.0714 & 0.230 & 0.1380 \\
\hline Zinc & $\mathrm{mg} / \mathrm{l}$ & 0.241 & 0.560 & 0.05 & 0.0414 & 0.1363 \\
\hline $\mathrm{pH}$ & & 6.0 to 9.0 & 6.0 to 9.0 & 7.99 & 8.4 & 7.5 \\
\hline
\end{tabular}

Elevated levels of selenium, cyanide and arsenic in the waste water have caused the process waste water to be out of permit compliance. Daily maximum values, though not indicated in the table above, were routinely exceeded for selenium and cyanide, and only occasionally for arsenic. The Project participants have been working closely with IDEM on remediation plans to bring the Project waste water in compliance.

Trace elements from the coal feedstock are volatilized in the gasification process, and later condensed from the syngas during low temperature heat recovery. Further processing of this sour condensate to remove dissolved gases is accomplished by steam-stripping; however, trace elements remain in the sweet processed water stream and must be removed via other means if levels are above the stringent waste water permit limits. 
Removal of certain trace elements, such as selenium, arsenic and cyanide can be effectively accomplished through the use of evaporation systems; however, these systems add cost and complexity to the gasification facility. Continued development of alternate methods to remove trace constituents, such as chemical precipitation, bio-remediation, or reverse osmosis may offer more cost-effective ways to bring these waste water streams into compliance and are currently under investigation. However, laboratory tests have demonstrated that the bio-remediation option will probably require pondage area far beyond the space available at the project site (requires over 50 acres of vegetation). Laboratory tests and field trials of chemical precipitation methods have also proved unsatisfactory, in that the removal efficiency of the system seems to vary in certain plant operating modes, and the maximum removal efficiency achieved to date (about $90 \%$ for selenium) is less than that needed to achieve compliance. The remaining two methodologies, reverse osmosis (with drum dryer) and evaporation are still under study. Field trials on reverse osmosis systems are currently being conducted, and design development of an evaporation system has begun. Installation of either of these systems is expected to resolve all wastewater effluent compliance issues. However, the evaporation system, a more conventional approach, is expected to be significantly more capital intensive (approximately $\$ 5$ million versus $\$ 3.5$ million for the reverse osmosis - dryer system) and is also known to have a significantly higher operating cost. These evaluations are still under way at the time of issue of this report, with determination of the technology to be complete by October 2000. The Project and IDEM have agreed to proceed with a technology selection and system installation schedule to achieve permit compliance by September of 2001.

\section{Stream 15: Ash Pond Effluent (Outfall 002)}

Fly ash and bottom ash from the existing Wabash River Generating Station are conveyed to an ash pond system by high-pressure service water. A channel is maintained by dredging the first pond to facilitate waste water flow to the subsequent ponds and ultimately for discharge to the Wabash River via permitted Outfall 002. Since the ash is managed in the NPDES permitted impoundment system, a solid waste permit is not required for ash management practices. 
Table 6.1M: Ash Pond Effluent (Outfall 002) Permit Limits

\begin{tabular}{|l|l||}
\hline \hline Parameter & Quality or Concentration \\
\hline
\end{tabular}

\begin{tabular}{|l|c|c|}
\cline { 2 - 3 } \multicolumn{1}{c|}{} & Monthly Average & Daily Maximum \\
\cline { 2 - 3 } \multicolumn{1}{c|}{} & Report & Report \\
\hline Flow & $30 \mathrm{mg} / \mathrm{l}$ & $70 \mathrm{mg} / \mathrm{l}$ \\
\hline Oil and Grease & $15 \mathrm{mg} / \mathrm{l}$ & $20 \mathrm{mg} / \mathrm{l}$ \\
\hline Ammonia (as Nitrogen) & Report & Report \\
\hline Arsenic & Report & Report \\
\hline Cadmium & Report & Report \\
\hline Hexavalent Chromium & Report & Report \\
\hline Chromium & Report & Report \\
\hline Copper & $0.04 \mathrm{mg} / 1$ & $0.09 \mathrm{mg} / \mathrm{l}$ \\
\hline Cyanide & Report & Report \\
\hline Iron & Report & $1.0 \mathrm{mg} / \mathrm{l}$ \\
\hline Lead & Report & Report \\
\hline Mercury & Report & Report \\
\hline Nickel & Report & Report \\
\hline Selenium & Report & Report \\
\hline Zinc & Report & Report \\
\hline pH & 6.0 to 9.0 & 6.0 to 9.0 \\
\hline
\end{tabular}

Ash pond discharge has remained within permitted limits for the Demonstration Period. Refer to

Table 6.1M for permitted parameters and limits.

\section{Stream 16: Equipment Leak Fugitive Emissions}

As part of the gasification facility's air permit, equipment leak fugitive emissions are monitored on a continuous basis with the aid of 39 continuous area monitors that measure low levels of carbon monoxide $(\mathrm{CO})$ and hydrogen sulfide $\left(\mathrm{H}_{2} \mathrm{~S}\right)$ throughout the plant. The units have low alarm settings of $30 \mathrm{ppm}$ for $\mathrm{CO}$ and $9 \mathrm{ppm}$ for $\mathrm{H}_{2} \mathrm{~S}$. These units also have high alarm settings of $60 \mathrm{ppm}$ for $\mathrm{CO}$ and $18 \mathrm{ppm}$ for $\mathrm{H}_{2} \mathrm{~S}$. While included in the monitoring program for calculating total $\mathrm{CO}$ air emissions, these units are also utilized to help protect workers in the locations from encountering harmful levels of these toxic air contaminants.

Total CO values are calculated from these readings to provide information to the IDEM on total fugitive emissions from the plant process. As an integral part of the emission reporting process, these levels are reported on an annual basis in tons per year and added to the total emissions inventory. 
Fugitive emissions reported in tons per year to the IDEM for the two years of 1997 and 1998 are indicated in Table $6.1 \mathrm{~N}$ and represent typical values during normal operation for all years of the Demonstration Period. While there are no specific permitted limits for these compounds outlined in the facility's air permit, fugitive emissions must be quantified and reported on an annualized basis to IDEM as part of the Title $\mathrm{V}$ permit reporting process.

Table 6.1N: Fugitive Emission - Tons/Year

\begin{tabular}{|c|c|c|}
\hline Constituent & 1997 & 1998 \\
\hline Benzene & 0.0058 & 0.000017 \\
\hline Carbon Monoxide & 1.0275 & 0.0030 \\
\hline Hydrogen Sulfide & 0.158 & 0.000425 \\
\hline Ammonia & 0.0374 & 0.00011 \\
\hline Total Sulfurs & 0.158 & 0.00058 \\
\hline Volatile Organics & 0.68 & 0.002038 \\
\hline
\end{tabular}

As can be noted, there was a significant reduction of the fugitive emissions reported in 1998 compared to 1997 primarily due to accurate testing that took place at the end of 1997 and the subsequent focused follow-up actions to address the findings. A main contributor to the reduction in reportable emissions was the implementation of improved operational and maintenance procedures directed at initiating immediate repairs to any leaking valves and equipment.

Stream 17 through 20: Fugitive Emissions for the Coal, Slag, Slurry and Transport

These sites focus on fugitive dust emissions from the facility for both industrial hygiene concerns and pollution from particulates. Independent testing of these process areas reveals that, as would be expected from a wet slurry process, fugitive dust emissions are of little concern in this process. Particulate concentrations of 39 to 99 microgram per cubic meter are common in most processing and handling areas. The highest concentration of particulate, as one would expect, is upstream of the beginning of the wet slurry process in the rod mill coal feed hopper building and has been measured with a level of 224 micrograms per cubic meter. $\mathrm{PM}_{10}$ concentrations ranged from 22.9 to 165 micrograms per cubic meter in all areas sampled. Both total particulate and 
$\mathrm{PM}_{10}$ concentrations were well below the American Conference for Governmental Industrial Hygiene (ACGIH) threshold limit value (TLV) for coal dust, which is 2,000 micrograms per cubic meter over an 8-hour period. Triplicate visible emission tests have also been completed for each area by a certified smoke reader who indicated that there were no visible emissions detected during any of the tests. Visible emission limits have been set in our Operating Air Permit for the facility to be maintained at or below $20 \%$ opacity. As indicated by these tests the plant was well within limits of its permit.

\subsection{Conclusions}

\subsubsection{Process Waste and Waste Water}

As can be seen by the information presented in this section, the components that have contributed to the environmental performance issues of this facility stemmed from volatile components in the coal feedstock. Sulfur, arsenic, selenium and cyanide, among others, either fully or partially partition into the gas phase. Arsenic, selenium and cyanide, typically end up in the condensed vapor stream and preferentially leave the process via the process waste water stream. At the end of the Demonstration Period, the participants had a plan well underway to bring the waste water into permit compliance for these constituents.

Also, due to the presence of arsenic in some of the deposits in the process, additional industrial hygiene programs were developed to ensure worker safety while doing maintenance in localized areas of the process.

Ensuring procedures for safe, cost effective, and environmentally sound options for the recycle, treatment, or disposal of all excavation/demolition materials and process waste was a top priority during the development of the waste handling program. Of particular importance was ensuring that each waste stream, whether hazardous or non-hazardous, was managed according to all State and Federal regulations. The programs established at Wabash River have been recognized by the State of Indiana government officials as models for other companies against which to benchmark. Additionally, Wabash River operated a comprehensive recycling program throughout the Demonstration Period and is continuing that effort today. For its efforts, the 
Wabash River Coal Gasification Plant was named the 1998 recipient of the state of Indiana Governor's Award for Excellence in Recycling. Over 358 tons of materials were recycled and eliminated from being land filled during the course of the Demonstration Period.

\subsubsection{Air Emissions}

The Wabash River Coal Gasification Repowering Project was designed to exceed the requirements of the 1990 Clean Air Act Amendments for 2000 while at the same time offering an alternative means to generate power from mid-to-high sulfur-containing coals. Based on the emissions reported to the IDEM, the Project has met or exceeded every expectation outlined in the pre-construction literature. Table 6.2.2A represents total emissions, in pounds emitted per MMBtu of dry coal feed to the gasifier, based on all sources monitored or calculated at the Wabash River Coal Gasification Repowering Project during the years of 1997 and 1998. It should be noted that sulfur dioxide emissions from the Wabash River site have demonstrated nearly an order of magnitude reduction from the 1990 Clean Air Act Amendment year 2000 target of $1.2 \mathrm{lb} / \mathrm{MMBtu}$ of feed.

Table 6.2.2A: Component Emissions in Pounds per MMBtu of Dry Coal Feed

\begin{tabular}{|l|c|}
\hline 1997 & 1998 \\
\hline
\end{tabular}

\begin{tabular}{|l|c|c|}
\hline Sulfur Dioxide & 0.13 & 0.13 \\
\hline Nitrogen Oxides & 0.024 & 0.021 \\
\hline Carbon Monoxide & 0.056 & 0.033 \\
\hline Volatile Organics & 0.002 & 0.0021 \\
\hline $\mathrm{PM}_{10}$ & 0.012 & 0.011 \\
\hline
\end{tabular}




\subsection{ECONOMICS}

\subsection{Actual Installed Costs for Wabash River}

The initial budgeted cost for the construction of the Wabash River facility was $\$ 248$ million for the syngas facility (Destec scope) and approximately $\$ 122$ million for the new power block and modifications to the existing Wabash River Generating Station (PSI Energy scope). The power block budget also included the initial infrastructure work for the site, including leveling the hill where the Project was sited, remediation of the abandoned mineshaft on the site, all roads, and all underground drainage and fire-protection lines.

Both Destec and PSI acted as general contractors for their individual scopes of work. Detailed design engineering and procurement was subcontracted (Dow Engineering for the syngas facility and Sargent \& Lundy for the power block). In the field, Destec and PSI each acted as construction manager, hiring local and national contractors to perform specific areas of the work (excavation, foundation, structural steel, piping, electrical and instrumentation, refractory, etc.). Additionally, Destec subcontracted the air separation unit as a turnkey contract from Liquid Air Engineering Corp. (Air Liquide).

Table 7.1A provides the total costs for the power block and for the syngas facility. The syngas facility is additionally broken down functionally. These costs are equivalent to what is commonly referred to as the EPC (engineering-procurement-construction) cost. This cost includes conceptual, process and detailed engineering, environmental permitting, equipment procurement, project management, construction management, construction and start-up, and the costs of hiring and training Operations personnel up to the commercial operations date of November 17, 1995. The cost as shown excludes fuel supply and owner's costs such as interest during construction, financing fees and license fees. There were no significant interconnection costs for water or power since the IGCC facility was built at the site of an existing power station. 
Table 7.1A: Project Costs

\begin{tabular}{|c|c|c|}
\hline Cost Area & Budget * & Actual * \\
\hline \multicolumn{3}{|l|}{ SYNGAS FACILITY } \\
\hline Engineering \& Project Management & 29.6 & 27.3 \\
\hline Equipment Procurement & 98.3 & 84.5 \\
\hline Construction & 55.5 & 106.1 \\
\hline Construction Management & 7.9 & 8.1 \\
\hline ASU & 36.9 & 32.8 \\
\hline $\begin{array}{l}\text { Pre-Operations Management } \\
\text { Prement }\end{array}$ & 19.8 & 21.7 \\
\hline POWER BLOCK & 121.8 & 136.2 \\
\hline Total & 369.8 & 416.6 \\
\hline
\end{tabular}

*\$MM, 1994 Average

These values do not include any offset for the DOE CCT Program contributions to the Project capital cost, but reflect actual expenditures. On an EPC basis, including start-up, the installed cost of the overall IGCC facility was about $\$ 1,590 / \mathrm{kw}$ (1994\$). Allowing for new equipment that would have been required if this had been a greenfield project instead of repowering, the installed cost figure on this Demonstration Project was \$1,700/kw (1994\$).

It should be noted that one area that contributed to the Project cost, but that is somewhat hidden, is the cost of sulfur removal and recovery beyond the normal requirements. As discussed elsewhere, the Wabash River facility is the cleanest coal-fired power plant of any technology in the world. It was designed to operate at one sixth of the $\mathrm{SO}_{\mathrm{X}}$ emissions allowed under the Clean Air Act Amendment rules for the year 2000, and normally runs at one half to one fifth of the design point. These low emissions have been achieved on coal and pet coke supplies with up to $5.5 \%$ sulfur content. This design philosophy for the Project, included in the budget numbers, added approximately $\$ 100 / \mathrm{kw}$ to the installed cost.

As shown in Table 7.1A, nearly all cost areas within the syngas facility were completed under budget or virtually at budget, with the exception of the construction cost and the pre-operations management cost of the syngas facility. Overruns in the power block budget were in the same areas. The construction cost was nearly double the budgeted amount, due to several factors, many of which were beyond the control of the Project participants. 
- Weather delays at the outset of the Project: The initial dirt work and site forming on the Project, originally expected to take five months, took nine months due to extreme and constant rainfall through the spring, summer and fall of 1993. This was the year of the 500-year flood of the Mississippi River, as a sign of the extreme rainfall. The constant rain took its toll on the progress of the dirt work and initial job activities. Even into November of 1993, Indiana recorded the wettest November since 1888. The late start of civil work on the Project was further compounded by a severely cold winter, frequented by both snow and ice storms that shutdown the Project, in addition to daily temperatures that often did not rise above zero degrees Fahrenheit. (The lowest recorded temperature at the jobsite during this period was minus 28 degrees Fahrenheit, for instance, with a wind chill of about 50 below zero.) Both the rainfall and the cold winter were far from the norm for central Indiana.

- Equipment shipment problems: In an effort to save both time and money, several equipment systems were shipped as modularized pieces of equipment, where possible within the prevailing union craft rules. These modules were generally designed to be as large as possible, up to 200 tons and 20 feet wide, based on initial traffic studies. After the design phase of this equipment, while it was being fabricated, three states in the traffic pattern changed their superload laws. This resulted in extended permitting times, change of routes and even changes to barge freight in some cases. Delays of up to four months were experienced with the equipment in some plant areas. There were also delays on a variety of other items, including alloy piping which was ordered well in advance of the start the civil construction, but nonetheless impacted the Project schedule after being delayed.

- Mechanical Contracting: Both Destec and PSI experienced contractual, schedule and budget problems with their respective mechanical contractors. Destec's problems were severe, complicated by an initial piping estimate that was insufficient. When Destec sought to accelerate construction to regain a portion of the Project schedule lost due to the weather and equipment delays, labor shortages in the summer and fall of 1994 compounded the problem. At one point, Destec was forced to change mechanical contractors, losing about a month of schedule, which was subsequently regained by 
construction overtime. The overtime costs contributed significantly to the construction cost overrun.

- Start-up: During start-up, there were significant problems with some of the equipment related to the novel technology employed on the Project, in particular the dry char filtration system (as discussed elsewhere in this report). These problems led to a prolonged start-up period, during which the fixed costs for both the site contractors and Destec's own Operations personnel accrued to the construction budget, as did the costs for equipment modifications, dry char filter replacement, and other non-warranty equipment related costs. These costs are estimated at $\$ 15$ million, or approximately $6 \%$ of the gasification facility cost (excluding the ASU and power block).

Having noted the major areas of cost overruns on the Wabash River Project design and construction, it is only fair to note that it was also by far the least expensive of the first generation coal gasification combined cycle plants that were built in the 1992 to 2000 timeframe. The other coal IGCC's, two in the U.S. and two in Europe, all first generation at this scale, have been reported to have cost $\$ 2,000 / \mathrm{kw}$ and over.

An additional \$14 million was spent in the first two years of operation to improve plant availability, especially with respect to the operation of certain components of the novel technology incorporated into the facility. The primary areas that this improvement program focused on were the addition of a chloride scrubber, a change in the geometry of the syngas piping exiting the second stage of the gasifier and numerous changes in the dry char filtration system. 


\subsection{Forecast Costs for Year 2000 Installation}

The Wabash River Coal Gasification Repowering Project was constructed in the 1993 to 1995 timeframe, at an equivalent EPC cost of about $\$ 417$ million in 1994 dollars $(\$ 1,590 / \mathrm{kw})$, as discussed in detail in the preceding section.

As part of another study being conducted with Nexant LLC (a Bechtel technology and consulting company), the Wabash River facility costs were examined to determine the cost of the same facility being built today in the same location. All cost components were escalated, reflecting differential rates of escalation for different commodities. However, adjustments were made to remove the costs of construction acceleration that caused some of the construction budget overruns above. The result of this evaluation, which is the estimated cost of an identical plant with no benefit from what was actually learned at Wabash River, was a greenfield project with an estimated cost of about $\$ 390$ million (2000\$) or about $\$ 1,444 / \mathrm{kw}$.

A more realistic value for a current generation plant, that does incorporate lessons learned and improvements to the technology, would be $\$ 1,250-\$ 1,300 / \mathrm{kw}$ (2000\$) with a heat rate of approximately 8,250 Btu/kwh (HHV) for a greenfield coal gasification facility (inclusive of costs for the new steam turbine and other equipment that were available at the Wabash River Station). A new, stand-alone greenfield IGCC to produce power, but no other products, and utilizing petroleum coke as fuel would have an approximate installed EPC cost of $\$ 1,100-\$ 1,200 / \mathrm{kw}$ (2000\$), based on reduced equipment requirements with petroleum coke feeds. An approximate breakdown of these costs is shown in the Table 7.2A.

Table 7.2A: Costs of Near Term IGCC Projects, $\$ / \mathrm{kW}$

\begin{tabular}{|l|c|c|}
\hline \multicolumn{1}{|c|}{ Cost Area } & Coal * & Petcoke * \\
\hline \hline \multicolumn{2}{|c|}{ * } \\
\hline SYNGAS FACILITY & 720 & 607 \\
\hline AIR SEPARATION UNIT (ASU) & 148 & 137 \\
\hline POWER BLOCK & 407 & 406 \\
\hline Total & $\mathbf{1 , 2 7 5}$ & $\mathbf{1 , 1 5 0}$ \\
\hline
\end{tabular}

$\$ / \mathrm{kW}(2000 \$)$ 


\subsection{Operational Costs}

\subsubsection{Fuel Cost}

The Wabash River Coal Gasification Repowering Project operates at a nominal heat rate of $8,910 \mathrm{Btu} / \mathrm{kWh}$. Fuel consumption for the nominal $262 \mathrm{MWe}$ facility is, therefore, 2,334 MMBtu/hr. The Project can run on medium to high sulfur Midwestern bituminous coals, which typically cost in the range of $\$ 1.00$ - $\$ 1.25$ per MMBtu delivered to the West Terre Haute plant site (\$22 - \$27 per ton). At an annual availability of 75\%, total fuel cost while running on this coal feedstock would be in the range of $\$ 15.3$ - $\$ 19.2$ million.

\subsubsection{Non-Fuel Operations and Maintenance Costs}

When constructed, the Wabash River syngas facility was over 800 miles from the nearest Destec-operated facility. The only other syngas facility in operation by Destec was in the Louisiana Division of Dow Chemical (Louisiana Gasification Technology, Inc., or LGTI); all other Destec operated plants were conventional natural gas-fired cogen power plants. The LGTI plant benefited from the substantial infrastructure and support base of the Dow complex for labor and support services. At Wabash River, much of this support base needed to be established, requiring additional staffing and infrastructure to set up this stand-alone location for Destec.

Using 1999 budgeted costs as a basis, the non-fuel operating and maintenance (O\&M) cost for the syngas facility (excluding the Power Block) was $6.8 \%$ of installed capital based on a $75 \%$ operating rate. Included in this figure are all operating labor and benefits, technical and administrative support labor from on-site staff as well as technical and managerial support from the corporate office.

Also included in this cost figure is administrative cost (including insurance), routine and major maintenance, chemicals, waste disposal, operating services and supplies, and a sizable budget for plant betterments (about 5\% of the total O\&M cost). Projected O\&M cost for a mature greenfield IGCC facility (including the Power Block) is 5.2\% of installed capital. Additional operating cost definition has been provided to DOE in Appendix C. (Appendix C, the operational cost information, is classified as "Protected Clean Coal Technology Data" under the Wabash 
River Cooperative Agreement and is not included in the public issue of the Final Report at this time.)

\subsection{Economic Analysis}

\subsubsection{Historical Perspective}

The Wabash River Coal Gasification Repowering Project was originally approved by the Indiana Utility Regulatory Commission in 1993 based on the results of a financial model considering projected avoided costs for other types of generation and projected load growth in what was then a totally regulated electrical utility environment. In a model for the entire PSI-owned electrical grid, these avoided costs were calculated considering factors such as performance and incremental operation costs at other power generation facilities, costs of new facilities to meet expected load growth, fuel and maintenance costs at the syngas facility and repowering project, and revenues from slag and sulfur sales from the gasification facility. Other factors, such as the avoided cost of retrofitting flue gas desulfurization scrubbers to the Wabash River station for compliance with the Clean Air Act, were considered as well. All factors were viewed in the perspective of the impact to the entire grid of electric generation in the state of Indiana.

\subsubsection{Evaluation of Future Power Generation Projects}

Prospective new plants are evaluated in a much different way, of course. Most markets are fully or partially deregulated, and power is marketed across the state or across the country to meet the requirements of peak demands. In the current situation, utilities are not proposing to build new generation that would be rate based, because this structure has or will soon disappear under deregulation. Even in states that have not yet deregulated, federal or state mandates for such a structural change are expected in the next five years - and utilities would risk that any new generation would become a stranded asset before the capital costs were retired via electricity rate-based capital cost recovery. A greenfield, base load IGCC facility, owned and operated by an independent power producer rather than a regulated electric utility, must be evaluated against a market that is increasingly dominated by new natural gas-fired peaking plants and older, fully depreciated, coal-fired utility plants that have been restructured as wholesale generators. Most 
new generation capacity additions must stand alone on their own merits in a market place without guaranteed long-term power purchase agreements.

The following economic analysis was made utilizing the projected year 2000 capital and operating costs discussed previously to determine the potential for coal and pet coke based IGCC plants in the current environment. The IGCC model developed by Nexant LLC for the DOE was used to evaluate the rate of return for IGCC facilities utilizing today's fuel and power prices with conventional project financing methods. Expansion of the IGCC into coproduction plants, capable of producing revenue streams other than electric power, were not evaluated. No advancements in the IGCC technology, as are expected from the advanced gas turbine programs already in place, were included in this analysis.

Inputs to the economic model:

- Fuel cost: Coal \$20/ton with $1.0 \%$ annual escalation

Coke $\$ 5 /$ ton with $0 \%$ annual escalation

- Power: \$35/MWh with $3.0 \%$ annual escalation

- Discount Rate: $\quad 10 \%$

- Financing: $\quad 70 \%$ Debt, $30 \%$ Equity; $70 \%$ Senior Debt at $10 \%$ interest on 15 year term with $2 \%$ financing fee, $30 \%$ Subordinated Debt at $10 \%$ interest on 15 year term with $3 \%$ financing fee, no debt reserve fund

- Additional Capital Costs (\% of EPC costs): Owner's Contingency 5\%, Development Fee, Owner's Costs and Licenses 4\%, Start-up 1\%

- Construction Depreciation 7 years, Financing Depreciation 12 years

- Initial Working Capital: 3\% of first year revenue

- Three year construction period, excluding start-up. Start-up ramping considered for revenues

- Plant Economic Life: 20 years from January 1, 2002 Start-up

- Slag \$1/ton, Sulfur \$25/ton, Escalation of Slag and Sulfur 3\%

- Coal Heating Value 11,400 Btu/lb HHV (25,080 Btu/kg), 3\% Sulfur, 11\% ash

- Petcoke Heating Value 14,800 Btu/lb (32,560 Btu/kg), 6\% Sulfur, 0.5\% ash

- Escalation of O\&M costs $2 \%$

- Income Tax Rate $40 \%$ 
Net generation, heat rate, capital and operating costs differ for the coal and petroleum coke cases reviewed, as noted in Table 7.4A.

The heat rate values utilized in the analysis reflect results from coal and petroleum coke operation at the Wabash River plant. Operation in near-future plants with Global Energy's advanced gasifier design and/or advanced gas turbine models is expected to be at a heat rate of 8,000 - 8,300 Btu/kWh (HHV).

Likewise, the availabilities used reflect that achieved with the Wabash River design on coal and projected for long-term operation on petroleum coke, but are not indicative of future plants incorporating planned improvements. Plant availabilities in the 90-95\% range can be achieved by installation of multiple smaller units, with some incremental increase to the capital and operating costs.

Lower capital and operating costs and a higher availability are used for the base case for petroleum coke operation. Operation on 100\% petroleum coke at Wabash River in 1997 and 1999 has indicated that certain pieces of equipment can be reduced in size or eliminated in a plant designed for petroleum coke, as opposed to coal. Operating costs and availability both benefit from petroleum coke operation as well, due primarily to the improved consistency of the feed (as opposed to blended coal or alternating coal supply trains from different mines, as experienced at Wabash River). 
Table 7.4A: Results of Economic Analysis for Wabash River Style IGCC Single Train

\begin{tabular}{|l|c|c|}
\cline { 2 - 3 } \multicolumn{1}{c|}{} & Coal & Petroleum Coke \\
\cline { 2 - 3 } \multicolumn{1}{c|}{} & \multicolumn{2}{c|}{} \\
\hline Plant Net Generation, MWe & 270 & 271 \\
\hline Plant Heat Rate, Btu/kWh (HHV) & 1,910 & 8,790 \\
\hline Plant EPC Capital Cost, \$/kw & 5.2 & 1,150 \\
\hline Plant Operating Cost, \% of capital & $75 \%$ & 4.5 \\
\hline Annual Availability & $(59)$ & $80 \%$ \\
\hline NPV 10, Millions \$ & $5 \%$ & $17 \%$ \\
\hline Internal Rate of Return, at \$35/MWh for power & \multicolumn{2}{|c|}{} \\
\hline \multicolumn{3}{|c|}{ Required Power Pricing in first year } \\
\hline Sensitivity Analysis Cases, 12\% IRR & 42 & 30 \\
\hline \multicolumn{1}{|c|}{ Base Case } & 38 & 27 \\
\hline $10 \%$ reduction in capital & 41 & 30 \\
\hline $10 \%$ reduction in O\&M & 38 & 28 \\
\hline $10 \%$ increase in availability & 34 & 24 \\
\hline $\begin{array}{l}10 \% \text { reduction in capital, O\&M } \\
10 \% \text { increase in availability }\end{array}$ & 39 & NA \\
\hline Minemouth (\$10/ton fuel) & \multicolumn{2}{c|}{} \\
\hline
\end{tabular}

As evidenced in Table 7.4A, the strongest drivers of overall plant economics are fuel type and capital cost. The economic analyses of project returns with coal as a feedstock reach a credible economic condition of $12 \%$ IRR at power pricing of $\$ 34$ - \$40/MWh, depending on how capital, operating and maintenance costs are set and the availability that is assumed. Plant design and operation based on petroleum coke is economically stronger, due not only to the lower fuel cost, but also the incrementally improved capital and operating costs for a plant designed for petroleum coke initially. 
References:

"IGCC Economic and Capital Budgeting Evaluation Model", prepared by Nexant LLC for the U.S. DOE under Contract No. DE-AMOI-98FE64778, May 2000

"Improved Performance of the Destec Gasifier", Dr. David L. Breton, 1999 Gasification Technologies Conference, San Francisco, California, Oct. 18-20, 1999

"Commercial Operation of the Wabash River Gasification Project", Phil Amick, AIChE Spring Meeting 2000, Atlanta, Georgia, March 9, 2000

"Gasification Plant Cost and Performance Optimization", Nexant LLC and Global Energy Inc., DOE Cooperative Agreement No: DE-AC26-98FT40342 (expected to be published 1Q2001)

"IGCC Power Plants - EPRI Design \& Cost Studies", Neville Holt, Electric Power Research Institute, 1998 Gasification Technologies Conference, San Francisco, California, October, 1998 


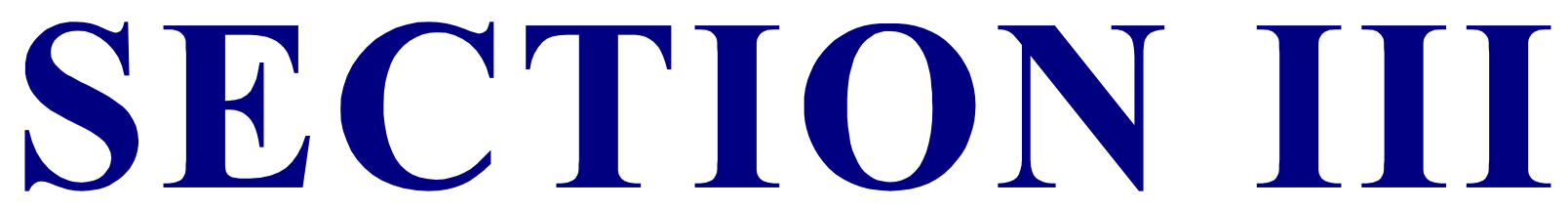

Commercialization

and

Recommendations 


\subsection{COMMERCIALIZATION POTENTIAL AND PLANS}

The 1999 World Gasification Survey is a database of all the gasification projects in the world, on all fuels (natural gas, coal, petcoke, biomass) and producing all products (power, hydrogen, heat and chemicals). The output of all of these facilities was presented in equivalent megawatts of power generation. The total of all these projects, dating back to 1952 and including those projected to start-up by 2004 , is 30,325 equivalent megawatts. Figure $8.0 \mathrm{~A}$ shows the cumulative increase in the installed gasification capacity over this period, and indicates a significant increase in activity in just the past decade.

Particularly of note is that the majority of the recent increase in installed gasification capacity is in solid fuel gasification (coal and petroleum coke). Overall, 16,505 MW (equivalent) of the $30,325 \mathrm{MW}$ total equivalent capacity is coal or petroleum coke based (approximately $54 \%$ of the total). Of the $16,505 \mathrm{MW}$ of solid fueled capacity, nearly half (43\%) is starting up in the tenyear period ending in 2004.

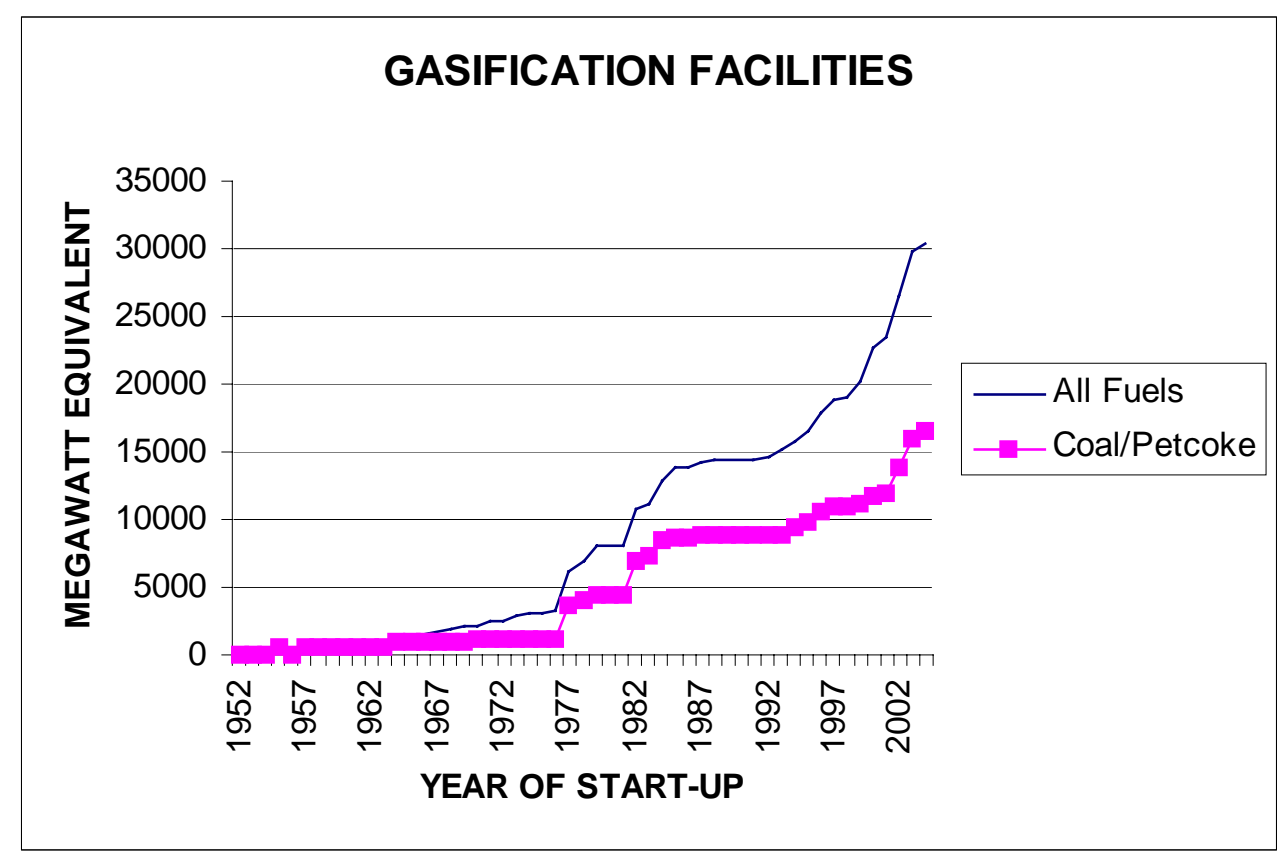

Figure 8.0A: World Gasification Facility Capacity (from data in the 1999 World Gasification Survey) 
The impetus for this growth includes the costs of environmental compliance, the drive to improve efficiencies in refinery settings, the availability of low cost alternative feedstocks and the need to utilize indigenous coals in markets without access to natural gas. The maturation of gasification technologies in large-scale facilities, following completion of several demonstration projects, has made this technology a popular and viable alternative (technology-wise) to the historically conventional combustion technologies.

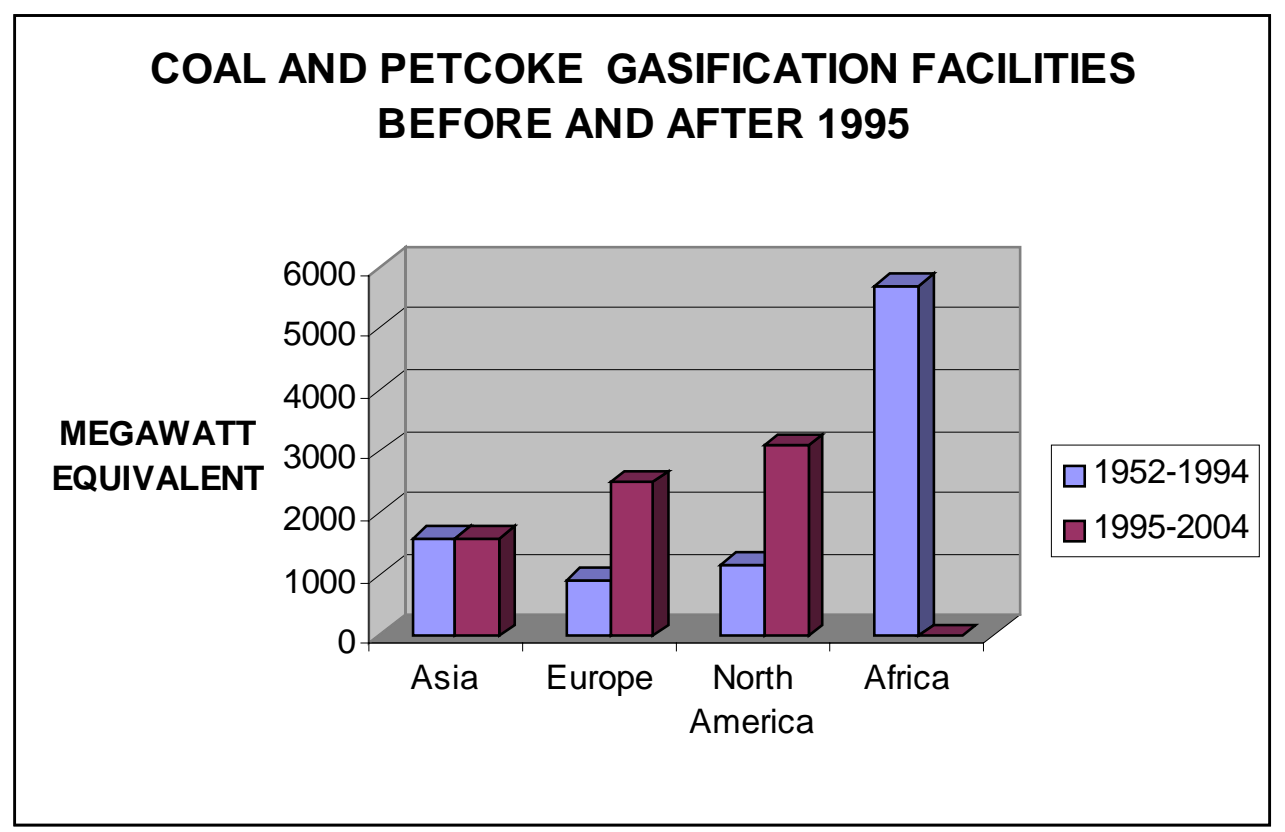

Figure 8.0B: Solid Fueled Gasification Facilities Starting Up Before and After 1995 (from data in the 1999 World Gasification Survey)

Figure $8.0 \mathrm{~B}$ examines the solid fueled projects geographically and chronologically. Interestingly, the break point chronologically is 1995, the year that Wabash River started commercial operation. This figure also captures the last ten years of data from the survey, 19952004, to illustrate the substantive growth. Excluding South Africa, where gasification has been driven by an abundance of coal and lack of almost all other fuels, the solid fueled gasification capability is nearly tripling in the last decade of the survey period. The area with the greatest forecast growth, both capacity and percentage wise, is North America, namely the United States. 
According to still other industry sources, there are over 1,600 MW of gasification-for-power projects in operation and another 2,700 MW that have started construction or been financed for start-up by the year 2001. Historically, and certainly before the widespread use of combustion turbines, gasification-for-power was much less common than the chemical and fuel gas production applications. This represents better than a tenfold increase over the gasification-forpower market as it existed ten years ago. General Electric (GE) reported in a recent Gasification Technology Council meeting and at the Sixth Annual Clean Coal Conference that there are about 5,000 MW of gasification projects for power generation that have proceeded to the point of placing orders for combustion turbines. Many of these projects include co-production facilities. GE states also that it is in discussions with various refiners, developers and other parties about projects totaling another 50,000 MW (This includes unannounced projects and projects starting up after the 2004 end date in the World Gasification Survey).

Reviewing this market information, it is clear that market trends support the creation of additional opportunities for solid fuel gasification technologies. Trends of rising energy prices and tightening environmental controls are most evident in Europe and North America, and the growth in environmentally superior gasification facilities in these areas is a result of those trends. The single strongest market in either of these areas is the United States. Indications are that many of these domestic projects will be refinery based, utilizing petroleum coke and other low cost refinery by-products to produce power, steam and hydrogen for the refinery and additional power or chemicals for export.

Global Energy has prepared the E-Gas ${ }^{\mathrm{TM}}$ Technology for these applications through a petroleum coke operational program at the Wabash River facility, now in its second phase. In the first phase of the program, two trials of full load operation (about 2000 tons per day of pet coke with no coal blending) were completed. All environmental and operational parameters were proven in these trials. The second phase of the program is the long-term operation of the facility on petroleum coke, commencing in August 2000. 
The E-Gas ${ }^{\mathrm{TM}}$ Technology is also being readied for co-production applications through other study and co-operative evaluation programs, some of which are taking place under other DOE programs. Extensive investigations are also being made into optimizing plant performance and improving the operating life of certain components of the plant.

Global Energy expects that the E-Gas ${ }^{\mathrm{TM}}$ Technology, as demonstrated at the Wabash River facility on both coal and petroleum coke feedstocks, will be utilized in a significant portion of new solid fuel based gasification facilities. It should be particularly suited to those refinery based applications utilizing petroleum coke in areas that have been declared as non-compliance areas for one or more air emissions, because of the superior environmental performance of the EGas $^{\mathrm{TM}}$ Technology.

Somewhat further in the future, as the price of other forms of energy, particularly natural gas, increase domestically and as existing conventional coal-fired power-generating stations strive to meet future environmental regulations, it is also expected that a repowering market will develop in the United States. This market may include both repowering of the coal plants of the 1960's and 70's and repowering of the natural gas-fired combined cycle plants of the 1990's and present day. The E-Gas ${ }^{\mathrm{TM}}$ Technology is expected to be well positioned to recreate the Wabash River repowering scenario with improved technology in either of those applications.

\section{$\underline{\text { References: }}$}

Luncheon Keynote speech, Doug Todd, General Electric, Sixth Annual Clean Coal Technology Conference

1999 World Gasification Survey, SFA Pacific Inc., published by the Gasification Technologies Council (www.gasification.org) 


\subsection{CONCLUSIONS AND RECOMMENDATIONS}

\subsection{Success of the Demonstration Project}

The Wabash River Coal Gasification Repowering Project began as a Joint Venture between PSI Energy and Destec in the summer of 1990. At that time, there was relatively little experience with gasification for power generation (Texaco's Cool Water Plant and LGTI), and none of this experience had been aligned with what was then a regulated utility generation and distribution system. The primary goal of the Wabash River Project was thus a formidable one: commercial operation on the utility grid, matching the utility reliability and availability requirements for baseload operation. The associated technology goals to achieve this were daunting as well:

- Demonstrate Bituminous Coal Operation

- Prove the Repowering of a 40 year old Utility Plant

- Demonstrate Advance Combustion Turbine Application for Syngas

- Demonstrate Superior Environmental Performance

- Prove Particulate Removal System/Reliability

- Establish Availability on the Utility Electrical Grid

Each of the following sections summarizes the challenge, the lessons learned and the outcome in these areas. All are discussed in more detail elsewhere in the report.

\section{$\underline{\text { Bituminous Coal Operation }}$}

Operation at LGTI had been primarily on sub-bituminous coals. The sizing of the sulfur system and constraints on the air permit did not allow demonstration testing at LGTI with the high sulfur bituminous coals envisioned for Wabash River. Operation on bituminous coal would mean changes in the gasifier design, the slag removal system design, operation of the gasifier systems, and unknown impacts in ash deposition control and heat recovery. The high sulfur content of the coal would result in COS levels in the syngas that would have to be removed to meet the stringent emission standards set for the Project. Catalysts for COS conversion had been tested in the laboratory and certain other limited applications, but had never been tested with syngas or at the scale needed at Wabash River. 
Through four years of operation, several differences were noted in comparison with subbituminous coal operation, particularly in requirements for gas path design and first stage gasifier operation as well as differences in gasifier subsystems. None of these differences are now an impediment to operation and plant run-times have been extended beyond the records set at LGTI.

Ash deposition in the hot gas path, which had never really been solved at LGTI, has been eliminated as a cause of unplanned outages. Initial problems with slag quality have been overcome and this by-product is now being successfully placed in construction applications. The COS catalyst, after some initial problems, is now achieving desired conversion levels and evidencing a substantially longer life than originally expected. Operation of the acid gas removal and sulfur recovery systems has been demonstrated with up to $5.5 \%$ sulfur-bearing feedstocks.

\section{Repowering of a 40-Year Old Utility Plant as an IGCC}

Even repowering of older steam turbine plants with natural gas-fired gas turbines was fairly rare in the 1990's. Integration with the gasification plant, and the high level of integration on the steam system with the gasification high temperature heat recovery unit, the combustion turbine HRSG and the reheat steam turbine had never been attempted.

Operation of the steam turbine with steam from the gasification and gas turbine plants and the integration of the combustion turbine and gasification boilers has been successful. The Project operates well below its design heat rate. Fuel swaps occur in a matter of minutes. P procedures for starting up and shutting down the combined cycle and swapping to syngas have become routine.

\section{Syngas Application with an Advanced Combustion Turbine}

Wabash River utilized one of the first ten General Electric F class machines produced. It was the first GE Frame 7FA to operate on syngas as well. With its $192 \mathrm{MW}$ rating on syngas, the Wabash River combustion turbine was the largest combustion turbine in North America when it was installed. The 7FA turbine has been measured as running comparatively smoother and cooler on syngas than it does on fuel oil operation. The predicted $192 \mathrm{MW}$ output has been 
achieved with syngas at a heat rate significantly better than the design guarantee. Emission levels have been met as well, and the plant has operated at as low as one-fortieth of the Clean Air Act Year 2000 standard for sulfur dioxide emissions.

\section{Environmental Performance}

Despite its planned design to use up to 5.9\% sulfur coal, Wabash River also set out to be one of the cleanest coal-fired power plants in the world. A sulfur dioxide emission level was targeted that was less than one-fifth the emissions allowable under the year 2000 standards of the Clean Air Act. The plant has met all of its emission criteria for $\mathrm{SO}_{\mathrm{x}}, \mathrm{NO}_{\mathrm{x}}, \mathrm{CO}$ and particulate emissions, and it has done this while operating with both coal and high sulfur petroleum coke. The Project is the cleanest coal-fired power plant in the world.

\section{$\underline{\text { Particulate Removal System }}$}

In order to meet the efficiency goals set for the plant, a $20 \%$ improvement on the heat rate of the existing unit, the plant would utilize dry barrier filtration to remove char and particulates from the raw syngas stream, rather than a wet quench operation as had been utilized at the LGTI facility. The dry char barrier filtration installation would be only the third in the world at this scale, and with a much higher dust loading and finer char than the other systems.

In the first year of operation, the particulate removal system was the chief cause of facility downtime. Today, it has been virtually eliminated as a cause of unplanned outages and the campaign life of the elements has been extended to a level comparable with the other runlimiting factors.

\section{Availability}

In order to function within the utility grid system, incremental increases to an annual availability factor of $75 \%$ were planned for the syngas facility. This level of operating availability was a significant increase from the operating record of any single train, solid-fueled gasification facility in the early 1990's. 
Despite severe initial problems with some aspects of the novel technology, the syngas facility achieved an average availability of approximately $70 \%$ over the last two years of the Demonstration Period. It achieved as high as $77 \%$ availability over one nine-month period, and should be able to achieve this level of performance on an annualized basis in the future

The Project proved successful in meeting the challenges of each of these areas of technical advancement (superior environmental performance, particulate removal system application, and commercial availability levels) as demonstrated in four years of operation as part of the Clean Coal Technology Program and documented in this report. This success was not quick and easy, but rather came as a result of a dedicated, persistent effort to meet the challenges posed by these lofty objectives. In the end, all of the goals of the Project were met.

Significant challenges were met and overcome in many other areas outside of the primary demonstration objectives, including technical, commercial and organizational challenges. The Project has also demonstrated success in some areas that were not planned at the outset operation on petroleum coke, for instance, and operation on a blend and combination of coals that sometimes changes daily. The Project operates today as part of the utility power generation system, competing with Cinergy's alternative market options for on-peak and off-peak power. Competitive market-based pricing allows the syngas facility to run at base-load in Cinergy's system. 


\subsection{Commercialization Barriers and Areas of Recommended Research}

The Wabash River Project has successfully met the challenges set forth for it under the Clean Coal Technology Program. As a result of the experience at Wabash River and other projects like it, in the year 2000 gasification has become established as a viable technology for power generation. It has not historically been as widely accepted as being economically competitive in these applications, however. Gasification remains somewhat of a niche application, currently seeing utilization where feedstock costs are well below the baseline price of coal or where products more valuable than electricity can be produced. Tremendous progress has been made in solid fuel gasification technology applications since 1991 when the Wabash River Project was selected for inclusion in the Clean Coal Technology Program. This is largely due to the initiative of and incentives through the United States Department of Energy in their partnership arrangements with industrial technology developers. However, major inroads to commercialization of gasification and a significant share of the U.S. electric power generation market are dependent on additional progress in several related areas.

Based on the experiences at the Wabash River Coal Gasification Repowering Project, five areas are suggested for continued research and development to promote gasification technologies.

- Availability Improvement

- Capital Cost Reduction

- Operating Cost Reduction

- Fuel Flexibility

- Product Flexibility

The first three principal areas can be viewed as barriers to widespread market penetration of solid fuel gasification technologies. These areas are the availability, capital cost and non-fuel operating cost of the IGCC facility. The other two bulleted items are "opportunity" areas, namely fuel flexibility and product flexibility, or coproduction, where additional progress will aid the economics of future projects. Obviously, these barriers and concepts have been discussed elsewhere in this report and in the industry in general, and are the basis of many of NETL's current programs, but warrant review here in the context of the Wabash River experience. 


\section{Availability}

An availability target of over $85 \%$ may be needed to successfully compete in the power generation industry against older technology baseload facilities. The refinery industry demands availabilities of "95\% plus" for the products it gets from gasification facilities. Meeting these higher availabilities can be achieved with the current technology, although multiple trains at an increased capital cost would currently be required. Exploration into more cost-effective redundancy within the plant and low-cost back-up systems of conventional technologies needs to continue. Global Energy and Nexant LLC are exploring these areas as part of the Gasification Performance and Optimization Study, DOE Contract No. DE-AC26-98FT40342. Also needed are advances in the current campaign and run-limiting process units and equipment in the gasification facility. In addition to Global Energy's internal development of advanced burners and mechanisms and operating disciplines to reduce ash deposition and boiler fouling, Global Energy has been studying materials and designs for better candle filter operation. Wabash River is operating a slipstream unit of char filtration toward this end (DOE Cooperative Agreement No. DE-FC26-97FT34158).

\section{$\underline{\text { Capital Cost }}$}

An integrated gasification combined cycle will always cost more than a natural gas-fired combined cycle plant; the increase in output is not expected to overcome the cost difference between the gasification plant required for IGCC and the mere pipeline construction cost for the natural gas plants. Nonetheless, substantial inroads are being made on reducing capital cost, both by integration of new technologies and through the optimization process of studies like the one mentioned previously.

Capital costs are expected to decrease, as well, due to increases in the capacity and decreases in the cost of the combustion turbines that are the prime movers in IGCC facilities. The advent of even more advanced gas turbines will improve economics both on the capital cost (to $\$ 1000 / \mathrm{kW}$ ) and efficiency parameters (45-50\% HHV).

Further work is needed to develop the H class turbines for syngas applications. 


\section{Operating Costs}

The Wabash River syngas facility reduced its operating costs by over $25 \%$ in its first three years of operation while simultaneously increasing run-times and availability. Efforts continue to further reduce operating and maintenance costs, including programs for operator cross-training, materials improvements in critical high cost areas such as refractory and char filtration, and general continuous improvement in O\&M practices. Reduction of non-fuel operating and maintenance costs below $5 \%$ of total installed cost is achievable for the next generation of solidfueled gasification facilities.

\section{Fuel Flexibility}

Fuel flexibility may be the area of the greatest opportunity for solid fuel gasification. Operation with low cost feedstocks such as petroleum coke greatly enhances project economics. Incorporation of other fuels, especially those opportunity fuels with tipping fees (negative cost feedstocks), can turn the fuel component of the cost of power into a revenue stream. Global Energy is pursuing identification and characterization of these feedstocks and is planning future testing at Wabash River as well as incorporating them into the design basis of other projects. There are particular opportunities at Wabash River to utilize the second stage of the gasifier for operation of these opportunity fuels, especially biomass feedstocks that may not be available in great quantities in the local area.

\section{Product Flexibility}

As well as reducing the costs of the inputs to the plant (fuel and operating costs), there are opportunities to increase the revenue streams for the plant products. Global Energy is studying coproduction economics for Wabash River and future plants as part of NETL's Early Entrance Coproduction Plant program (in Cooperative Agreement DE-FC26-99FT40659). Other opportunities have been identified to improve the value of the slag by-product. The already extremely pure sulfur by-product is a bulk commodity with pricing determined by market availability. 
Further research aimed at reducing the costs of sulfur removal equipment to achieve the high syngas purities needed for utilization in hydrogen production and gas-to-liquid process units will be needed. 


\subsection{Outlook}

All of the aforementioned areas, in essence, are economic barriers and not "technology" barriers. The novel technologies developed at Wabash River are advanced enough to allow the Project to operate commercially. Reducing the cost of operation is part of the economic improvement needed. The primary barriers are economics and competition with new gas-fired peaking plants and cogens, and in the off-peak hours, with existing baseload facilities.

Market penetration for gasification technologies is obviously picking up speed, especially for solid fuel applications and particularly in the United States (as discussed in Section 8.0). Gasification-produced megawatts will increase tenfold from 1992 to 2002, based on plants already in operation or construction. The current opportunities are not primarily in power generation, however. They are in co-production facilities, especially those able to use opportunity fuels. Looking at low-cost feedstocks and high-value products stretches both ends of the economic equation. These facilities seem to be primarily in the refining sector, and it is expected that most of the next generation of solid fuel gasification plants will be inside the fences of refineries, as opposed to the entire first generation of greenfield and repowering applications for power generation facilities.

The power market, especially for repowering of older plants as demonstrated at Wabash River, still exists, but may not be significant in the near term. Eventually, increasing fuel costs, the aging of the coal-fired fleet, and increasingly stringent environmental regulation will create opportunities in the generation system.

The reality of a market for power generated from gasification facilities is coming into focus however, and the beginnings of this market are here with us now. The demonstration plants are operating on utility grids in the U.S. and in other countries. The need and interest in coproduction plants for refining and chemical industry complexes is increasing steadily. It appears that the current reality has caught up with the Department of Energy's vision of the future as it was fifteen years ago when the Clean Coal Technology Program was initiated. The "Vision 21" Program, looking ahead ten to fifteen years from now, certainly holds the same promise for 
additional increases in the utilization of gasification technologies to meet market demands for environmentally superior ways to generate power and produce other products.

Wabash River Coal Gasification Repowering Project Final Technical Report 


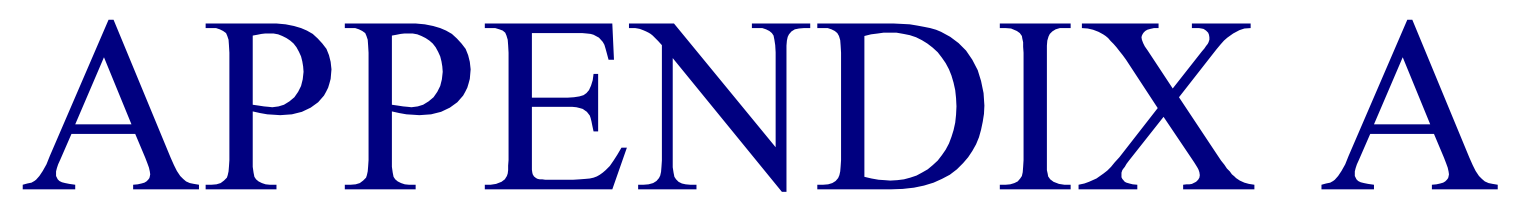

Glossary of

Acronyms,

Abbreviations and

Symbols 


\section{APPENDIX A}

\section{Glossary of Acronyms, Abbreviations and Symbols}

$\begin{array}{lll}{ }^{\circ} \mathrm{C} & - & \text { degrees Celsius } \\ { }^{\circ} \mathrm{F} & - & \text { degrees Fahrenheit } \\ \$ & - & \text { dollars (U.S.) } \\ \text { \$MM } & - & \text { millions of dollars (U.S.) } \\ \text { \$/kw } & - & \text { dollars per kilowatt } \\ \text { \$/ton } & - & \text { dollars per ton } \\ \text { \$/MMBtu } & - & \text { dollars per million British thermal unit } \\ \% & - & \text { percent } \\ \text { AC } & - & \text { alternating current } \\ \text { acfm } & - & \text { actual cubic feet per minute } \\ \text { ACGIH } & - & \text { American Conference for Governmental Industrial Hygiene } \\ \text { AGR } & - & \text { acid gas removal } \\ \text { AIChE } & - & \text { American Institute of Chemical Engineers } \\ \text { AP-42 } & - & \text { EPA publication "Compilation of Air Pollutant Emission Factors" } \\ \text { API } & - & \text { American Petroleum Institute } \\ \text { Ar } & - & \text { argon, elemental } \\ \text { As } & - & \text { arsenic, elemental } \\ \text { ASU } & - & \text { air separation unit } \\ \text { atm } & - & \text { atmosphere(s) } \\ \text { avg. } & - & \text { average } \\ \text { ASTM } & - & \text { American Society for Testing and Materials } \\ \text { bbl } & - & \text { barrels } \\ \text { bbl/d } & - & \text { barrels per day } \\ \text { BFW } & - & \text { boiler feed water } \\ \text { Btu } & - & \text { British thermal unit(s) } \\ \text { Btu/kWh } & - & \text { British thermal unit(s) per killowatt-hour } \\ \text { C } & - & \text { carbon, elemental } \\ \text { CA } & - & \text { cooperative agreement } \\ \text { CAA } & - & \text { Clean Air Act } \\ \text { CAAA } & - & \text { Clean Air Act Amendments of 1990 } \\ \text { CCT } & - & \text { clean coal technology } \\ \text { CCT IV } & - & \text { fourth CCT program solicitation } \\ \text { CCT Program } & - & \text { Clean Coal Technology Demonstration Program } \\ \text { CEM } & - & \text { continuous emission monitoring } \\ \text { CFD } & - & \text { computational flow dynamics } \\ \text { CFR } & - & \text { Code of Federal Regulations } \\ & & \end{array}$




\begin{tabular}{|c|c|c|}
\hline $\mathrm{CH}_{4}$ & - & methane \\
\hline $\mathrm{CO}$ & - & carbon monoxide \\
\hline $\mathrm{CO}_{2}$ & - & carbon dioxide \\
\hline Corp. & - & corporation \\
\hline $\operatorname{COS}$ & - & carbonyl sulfide \\
\hline CSS & - & chloride scrubbing system \\
\hline CT & - & combustion turbine \\
\hline CWR & - & cooling water return \\
\hline CWS & - & cooling water supply \\
\hline $\mathrm{d}$ & - & day(s) \\
\hline $\mathrm{dB}$ & - & decibel(s) \\
\hline DBB & - & double block and bleed \\
\hline DCS & - & distributed control system \\
\hline DCSS & - & dry char slipstream system \\
\hline DOE & - & Department of Energy \\
\hline DP & - & differential pressure \\
\hline dscf & - & dry standard cubic feet \\
\hline dscfm & - & dry standard cubic feet per minute \\
\hline EIA & - & Energy Information Administration \\
\hline $\mathrm{E}-\mathrm{Gas}^{\mathrm{TM}}$ & - & current name of the gasification technology at the WRCGRP \\
\hline EPA & - & Environmental Protection Agency \\
\hline EPC & - & engineer(ing)-procure(ment)-construct(ion) \\
\hline EMP & - & environmental monitoring plan \\
\hline EPRI & - & Electric Power Research Institute \\
\hline FAA & - & Federal Aviation Authority \\
\hline FCC & - & Federal Communications Commission \\
\hline $\mathrm{ft}, \mathrm{ft}^{2}, \mathrm{ft}^{3}$ & - & foot (feet), square feet, cubic feet \\
\hline gal & - & gallon(s) \\
\hline $\mathrm{g}$ & - & $\operatorname{gram}(\mathrm{s})$ \\
\hline gr & - & grain(s) \\
\hline $\mathrm{gr} / \mathrm{dscf}$ & - & grain(s) per dry standard cubic foot \\
\hline GE & - & General Electric \\
\hline GSA & - & Gasification Services Agreement \\
\hline GT & - & gas turbine \\
\hline GTC & - & Gasification Technologies Council \\
\hline $\mathrm{H}$ & - & hydrogen, elemental \\
\hline $\mathrm{H}_{2} \mathrm{O}$ & - & water \\
\hline $\mathrm{H}_{2} \mathrm{~S}$ & - & hydrogen sulfide \\
\hline $\mathrm{H}_{2} \mathrm{SO}_{4}$ & - & sulfuric acid \\
\hline HHV & - & high heating value \\
\hline
\end{tabular}




$\begin{array}{lll}\text { HP } & - & \text { high pressure } \\ \text { hr } & - & \text { hour(s) } \\ \text { HRSG } & - & \text { heat recovery steam generator } \\ \text { HSS } & - & \text { heat stable salts } \\ \text { HTHRU } & - & \text { high temperature heat recovery unit } \\ \text { IDEM } & - & \text { Indiana Department of Environmental Management } \\ \text { IGCC } & - & \text { integrated gasification combined-cycle } \\ \text { IPP } & - & \text { independent power producer } \\ \text { IRR } & - & \text { internal rate of return } \\ \text { ISEP } & - & \text { ion separation unit } \\ \text { IURC } & - & \text { Indiana Utility Regulatory Commission } \\ \text { JV } & - & \text { joint venture } \\ \text { in, in } & 2 \text { in } & \\ \text { kg } & - & \text { inch(es), square inches, cubic inches } \\ \text { kW } & - & \text { kilogram(s) } \\ \text { kWh } & - & \text { kilowatt(s) } \\ \text { l } & - & \text { kilowatt-hour(s) } \\ \text { lb or lbs } & - & \text { liter } \\ \text { lb/hr } & - & \text { pound or pounds } \\ \text { lb/MMBtu } & - & \text { pound(s) per hour } \\ \text { LGTI } & - & \text { pound(s) per million British thermal units of heat input } \\ \text { LIN } & - & \text { Louisiana Gasification Technology, Inc. } \\ \text { LLC } & - & \text { liquid nitrogen } \\ \text { LOX } & - & \text { limited liability corporation } \\ \text { LP } & - & \text { liquid oxygen } \\ \text { Ltd. } & - & \text { low pressure } \\ \text { LTHRU } & - & \text { limited } \\ \text { MCC } & - & \text { low temperature heat recovery unit } \\ \text { MDEA } & - & \text { motor control center } \\ \text { mg } & - & \text { metyldiethanolamine } \\ \text { min } & - & \text { milligram } \\ \text { Mlb } & - & \text { minutes(s) } \\ \text { MMBtu } & - & \text { thousand pound(s) } \\ \text { MMSCF } & - & \text { million British thermal units } \\ \text { mo } & - & \text { millions of standard cubic feet } \\ \text { MP } & - & \text { month(s) } \\ \text { MSW } & - & \text { medium pressure } \\ \text { MW } & - & \text { municipal solid waste } \\ \text { MWe } & - & \text { megawatt(s) } \\ \text { MWh } & - & \text { megawatt(s)-electric } \\ & - & \text { megawatt-hour(s) } \\ & & \end{array}$




\begin{tabular}{|c|c|}
\hline $\mathrm{N}_{2}$ & - nitrogen, gas \\
\hline ND & - $\quad$ non-detectable \\
\hline NEPA & - National Environmental Policy Act \\
\hline NETL & - National Energy Technology Laboratory \\
\hline $\mathrm{NH}_{3}$ & - $\quad$ ammonia \\
\hline $\mathrm{NiO}$ & - nickel oxide \\
\hline No. & - number \\
\hline $\mathrm{NO}, \mathrm{NO}_{2}, \mathrm{NOx}$ & - $\quad$ nitric oxide, nitrogen dioxide, nitrogen oxides \\
\hline NP & - $\quad$ non-proprietary \\
\hline NPDES & - National Pollutant Discharge Elimination System \\
\hline $\mathrm{NPV}_{10}$ & - net present value at $10 \%$ discount rate \\
\hline NSPS & - new source performance standards \\
\hline $\mathrm{O} \& \mathrm{M}$ & - operating and maintenance \\
\hline OEM & - original equipment manufacturer \\
\hline $\mathrm{O}_{2}$ & - $\quad$ oxygen, gas \\
\hline $\mathrm{P}$ & - $\quad$ proprietary \\
\hline P\&ID’s & - piping and instrument drawings \\
\hline $\mathrm{pH}$ & - the negative logarithm of the effective hydrogen ion concentration \\
\hline PLC & programmable logic controller \\
\hline $\mathrm{PM}_{10}$ & - particulate matter less than 10 microns in diameter \\
\hline PM & - preventative maintenance \\
\hline PMP & - $\quad$ project management plan \\
\hline PON & - $\quad$ program opportunity notice \\
\hline ppm & - $\quad$ part(s) per million (mass) \\
\hline ppmdv & - $\quad$ part(s) per million by volume, dry basis \\
\hline ppmv & - $\quad$ part(s) per million by volume \\
\hline PSD & - $\quad$ prevention of significant deterioration \\
\hline psia & - $\quad$ pound(s) per square inch absolute \\
\hline psig & - $\quad$ pound(s) per square inch gauge \\
\hline PT & - potential transformer (electrical) \\
\hline RDF & - refuse derived fuel \\
\hline rpm & - revolutions per minute \\
\hline RTD & - resistance temperature device \\
\hline $\mathrm{S}$ & - $\quad$ sulfur, elemental \\
\hline $\operatorname{scf}$ & - standard cubic feet at $60^{\circ} \mathrm{F}$ and 1 atmosphere \\
\hline scfm & - standard cubic feet per minute at $60^{\circ} \mathrm{F}$ and 1 atmosphere \\
\hline $\mathrm{SO}_{2}$ & - $\quad$ sulfur dioxide \\
\hline $\mathrm{SO}_{3}$ & - $\quad$ sulfur trioxide \\
\hline $\mathrm{SO}_{\mathrm{x}}$ & - combined sulfur dioxide and sulfur trioxide \\
\hline SRU & - $\quad$ sulfur recovery unit \\
\hline
\end{tabular}




$\begin{array}{lll}\text { TCLP } & - & \text { toxicity characteristics leaching procedure } \\ \text { TLV } & - & \text { threshold limit value } \\ \text { U.S. } & - & \text { United States (of America) } \\ \text { USA } & - & \text { United States of America } \\ \mathrm{V}_{2} \mathrm{O}_{5} & - & \text { vanadium pentoxide } \\ \text { VOC } & - & \text { volatile organic compounds } \\ \text { vol } & - & \text { volume } \\ \text { WRCGRP } & - & \text { Wabash River Coal Gasification Repowering Project } \\ \text { WREL } & - & \text { Wabash River Energy Ltd. } \\ \text { wt } & - & \text { weight } \\ \text { Y2K } & - & \text { the year } 2000 \\ \text { yr } & - & \text { year(s) } \\ \text { ZLD } & - & \text { zero liquid discharge }\end{array}$




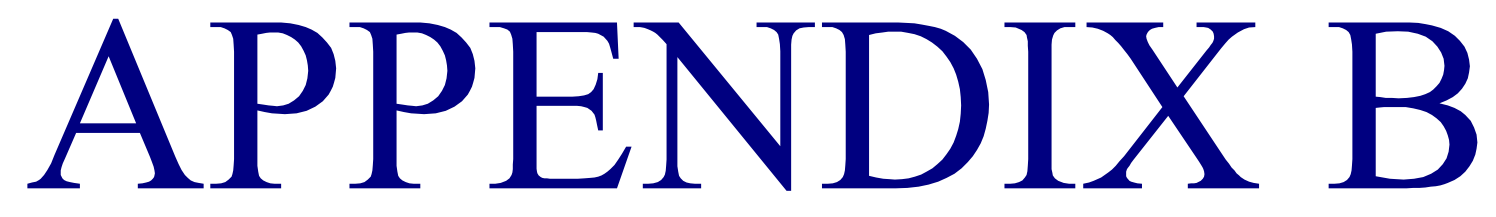

Monthly Plant

Production Data 


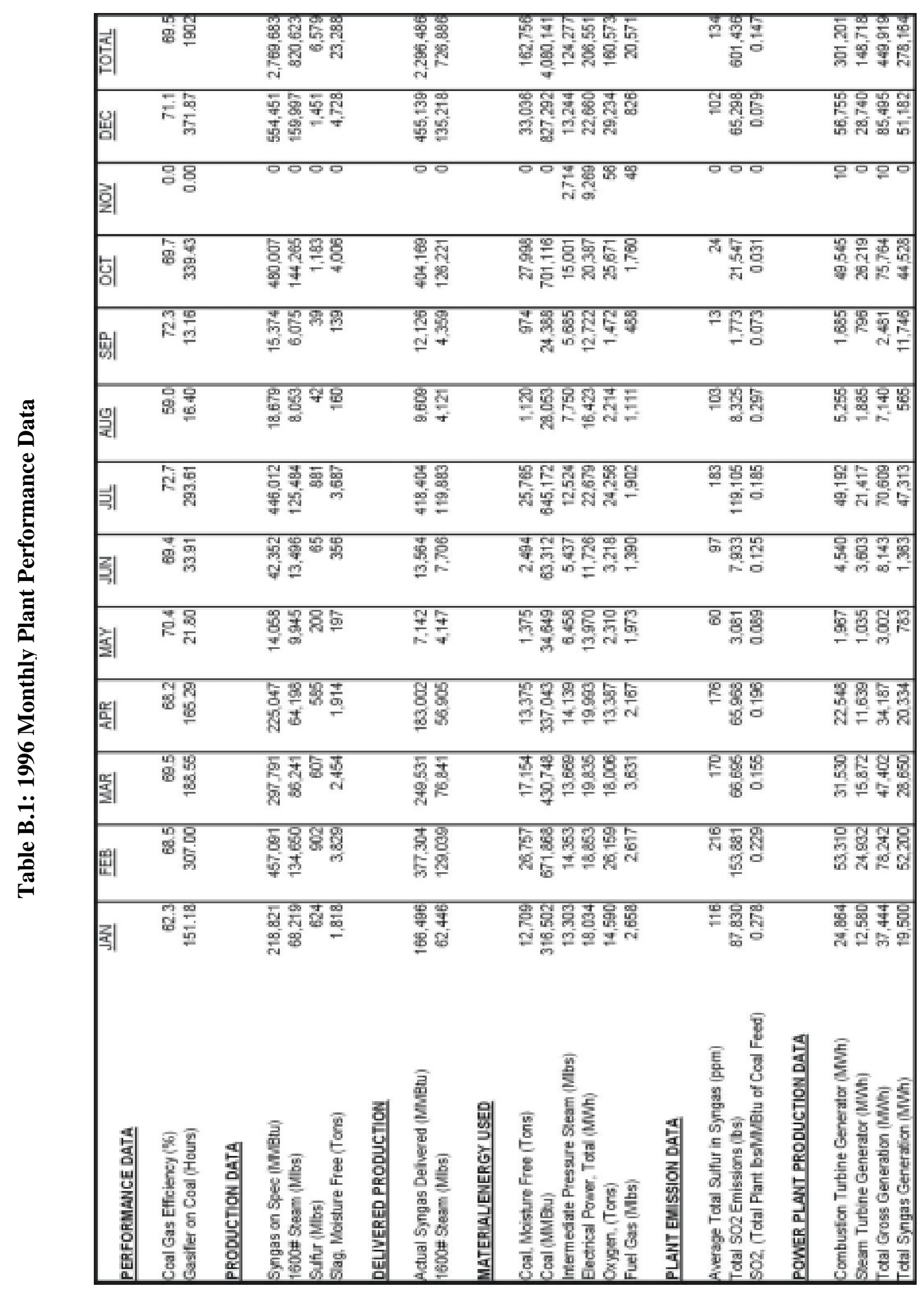

Wabash River Coal Gasification Repowering Project Final Technical Report 


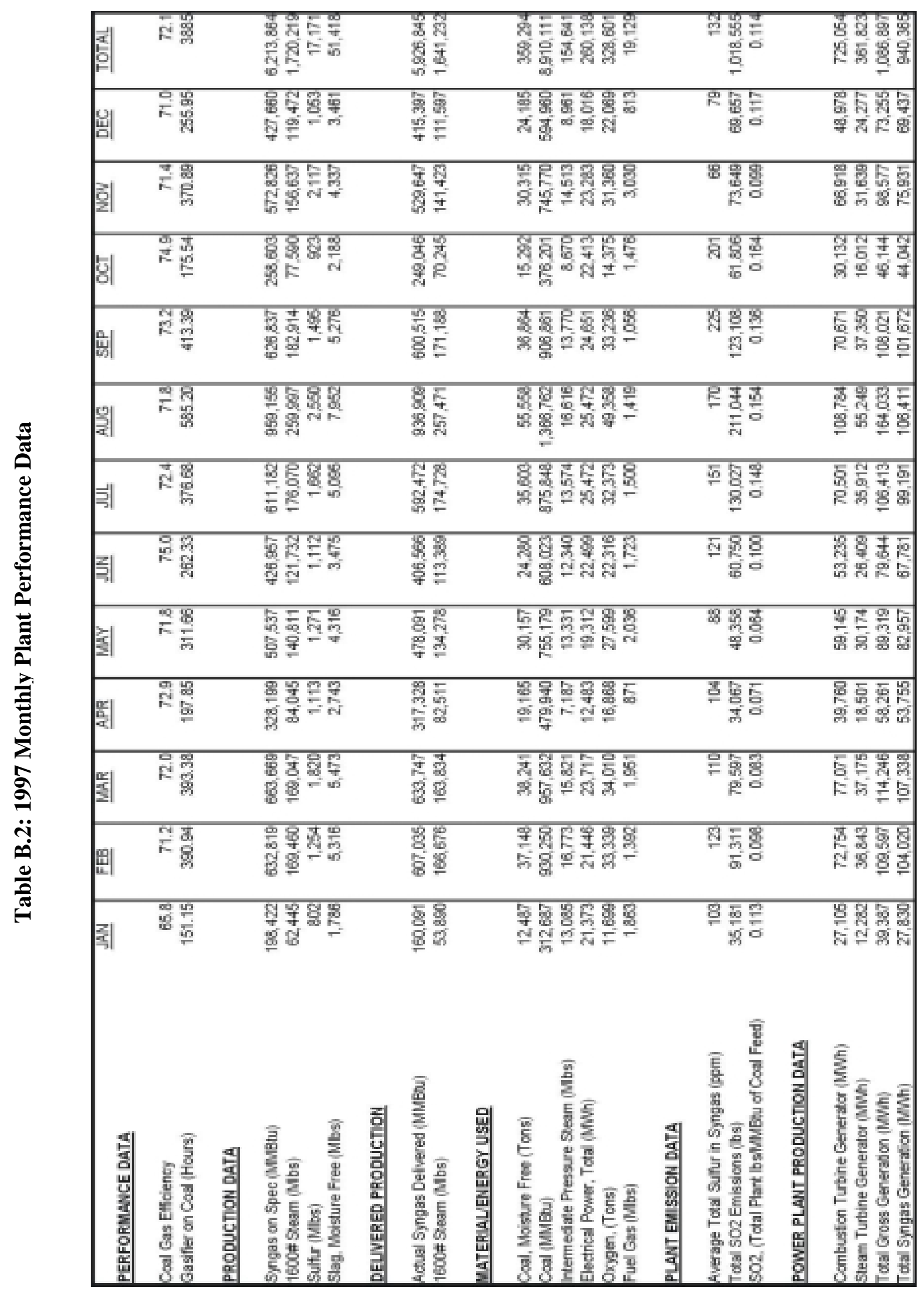

Wabash River Coal Gasification Repowering Project Final Technical Report 


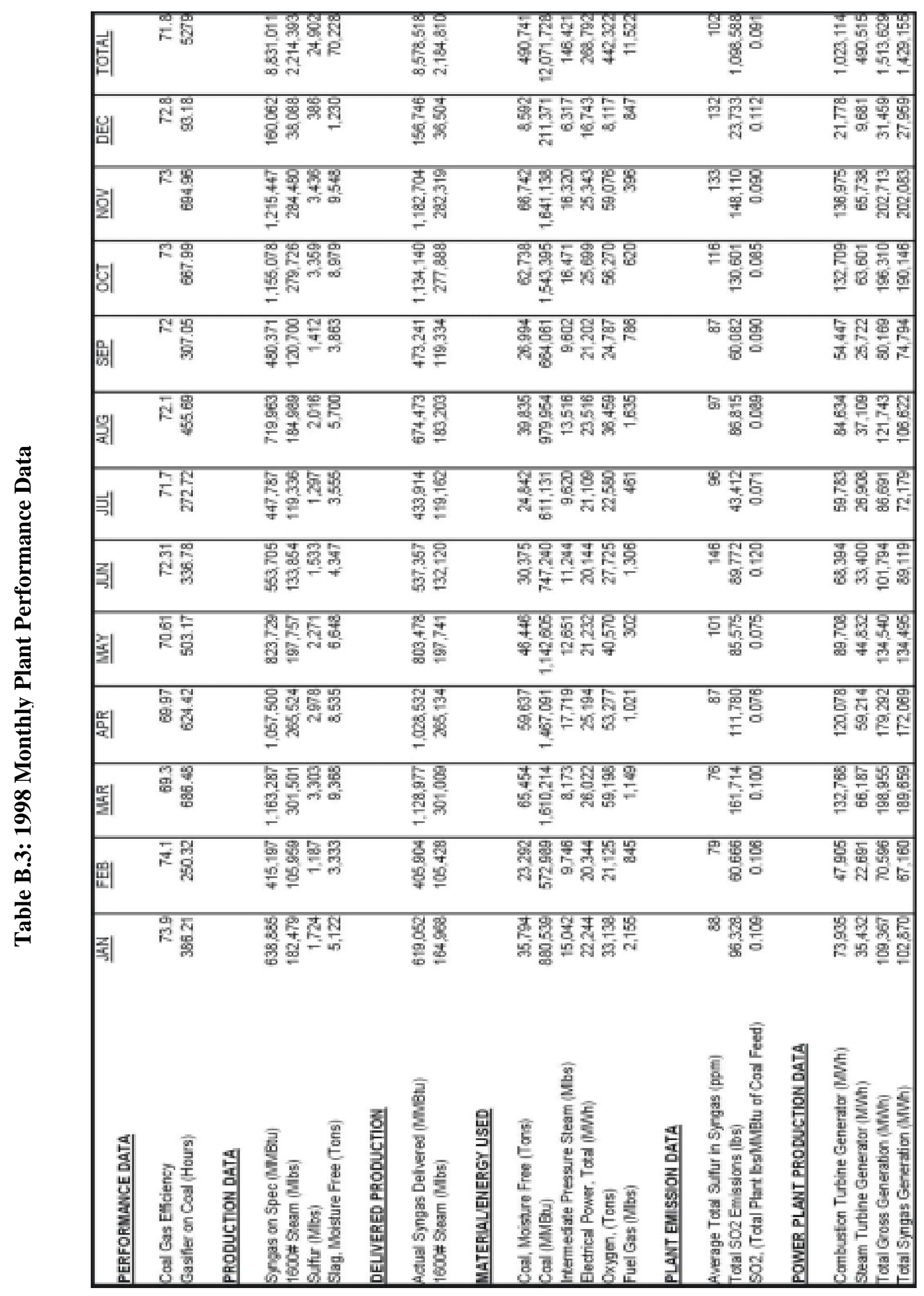

Wabash River Coal Gasification Repowering Project Final Technical Report 


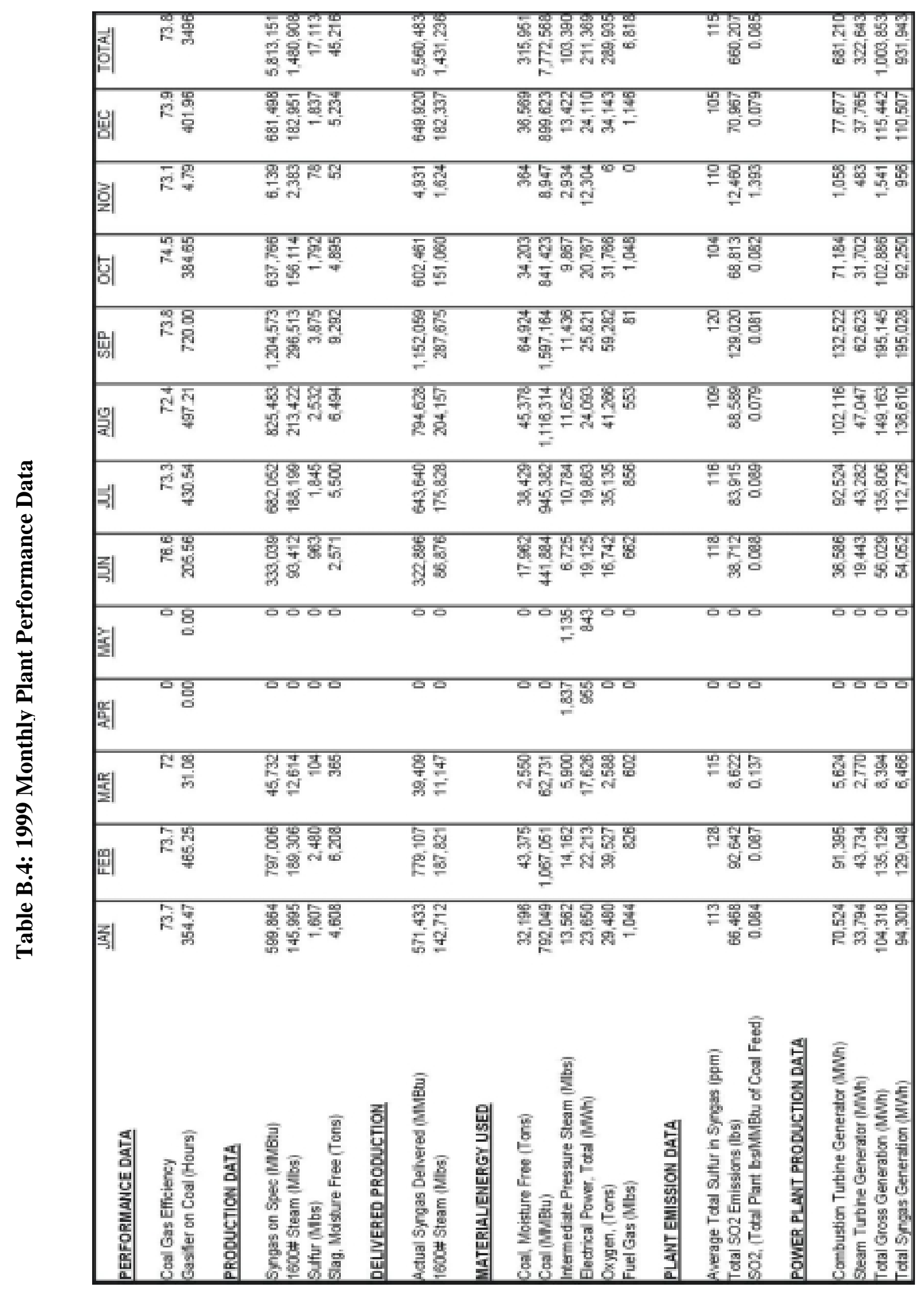

Wabash River Coal Gasification Repowering Project Final Technical Report 